\title{
Gudrun Ziegler
}

\section{Moskau und Petersburg in der russischen Literatur (ca. 1700-1850)}

\section{Zur Gestaltung eines literarischen Stoffes}

Verlag Otto Sagner München · Berlin · Washington D.C.

Digitalisiert im Rahmen der Kooperation mit dem DFG-Projekt „Digi20“

der Bayerischen Staatsbibliothek, München. OCR-Bearbeitung und Erstellung des eBooks durch den Verlag Otto Sagner:

http://verlag.kubon-sagner.de

( $)$ bei Verlag Otto Sagner. Eine Verwertung oder Weitergabe der Texte und Abbildungen, insbesondere durch Vervielfältigung, ist ohne vorherige schriftliche Genehmigung des Verlages unzulässig. 


\title{
SLAVISTISCHE BEITRÄGE
}

\author{
BEGRÜNDET VON ALOIS SCHMAUS \\ HERAUSGEGEBEN VON JOHANNES HOLTHUSEN UND JOSEF SCHRENK \\ REDAKTION: PETER REHDER
}

Band 80

\author{
Bayerische \\ Staatsbibliothek \\ Münctien
}


GUDRUN ZIEGLER

\author{
MOSKAU UND PETERSBURG \\ IN DER RUSSISCHEN LITERATUR \\ (Ca 1700-1850) \\ ZUR GESTALTUNG \\ EINES LITERARISCHEN STOFFES
}

VERLAG OTTO SAGNER - MÜNCHEN

1974 
00047412

Slavist. Beiträge

ISBN 3876900921

Copyright by Verlag Otto Sagner, München 1974

Abteilung der Firma Kubon und Sagner, München 8 München 19, Ysenburgstraße $7^{I}$

Gudrun Ziegler - 9783954793303

Downloaded from PubFactory at 01/10/2019 06:03:37AM
via free access 
MEINEN ELTERN 
I $\mathbf{n} \mathbf{h}$ a $\mathbf{l} t$

I. Einleitung. Thema und Methode 1

II. Die panegyrische Dichtung des 23 XVIII . Jahrhunderts

III. Moskau und Petersburg in der russi-

schen Literatur der 2. Halfte des

18. Jahrhunderts

IV. Die dichterische Gestaltung der

beiden russischen Metropolen im

1. Viertel des 19. Jahrhunderts

V. Stadtsicht und stadterleben bei

108

A.S. Puskin

VI. Die dreibiger Jahre des 19. Jahr-

hunderts. Moskau und Petersburg im

Werk der zeitgenossen Puskins und

Gogol's

VII. Die erzählte Stadt im Werk N.V. Gogol's

VIII. Uberblick uber die vierziger Jahre

IX. Zusammenfassender Uberblick

Literaturverzeichnis 
I. E $1 \mathrm{n} l$ e 1 t $\mathrm{u}$ n $\mathrm{g}$. Thema und Methode.

Die Stadt ist dem Menschen, der tăglich in ihr lebt, als Ganzes nicht mehr bewust, wie es auch die Technik nicht mehr ist, mit der er tăglich ungeht. Die Problematik der stadt ist die Problematik des modernen Menschen: Sie lossen wollen, verlangt, geistig - seelisch das zu bewältigen, $z u g e s t a l t e n$, was die weit vorausgeeilte Ratio materiell entstehen lieB, bedeutet $B$ e $w$ u $t m a c h$ e $n$ des $G$ e $u$ B$t e n(1)$.

In diesen zeilen spricht $J$. Pahl nicht nur die Kohärenz sozialer Lebensformen mit der historischen Entwicklung an, sondern er weist am Modell stadt darauf hin, das in dieser Verbindung die Moglichkeit schopferischen Erkennens keimhaft enthalten ist (2). Konkret heibt das in unserer Fragestellung nach der stadt in der Literatur: nur das wissen un das Wesen der stadt und eine individuelle Auseinandersetzung mit den erkannten Inhalten und zusammenhängen kann einer sinnvollen Anwendung der Erfahrung dienen. Dieser ProzeB ist allgemein für den in seine Umwelt integrierten Menschen zu jeder zeit von grundsätzlicher Bedeutung. denn er zeigt als Ergebnis individuelles Realitätsverständnis und Bewăltigung der Wirklichkeit.

Die primăre und unmittelbare Einstellung des Menschen zur Wirklichkeit ist nicht die eines abstrakten, erkennenden Subjektes, eines erwágenden Kopfes, der sich zur Wirklichkeit spekulativ verhalt, sondern die eines gegenständlich

(1) Pahl, Jürgen: Die Stadt im Aufbruch der perspektivischen Welt, Berlin 1953; S.7.

(2) Pahl meint in seiner Arbeit den zusamenhang zwischen architektonischer und sozialer Gestalt. Es handelt sich hier um den Vorgang, der mit Rezeptionsasthetik umschrieben wird. Als solcher ist er auch auf die Literatur übertragbar. 
und praktisch handelnden Wesens, eines historischen Individuums, das seine praktische Tätigkeit der Natur und dem Menschen gegenüber, die Verwirklichung seiner Absichten und Interessen, in einem bestimnten Komplex geselischaftlicher Beziehungen betreibt (1).

Dieser "Komplex gesellschaftlicher Beziehungen", der eine der Grundsituationen des Menschen anspricht, bedeutet für dessen Wirklichkeitsverständnis: einmal unmittelbar - praktische Anschauung der Umgebung, stăndige Konfrontation mit Erscheinungen, die sich an der Oberflăche wesentlicher Prozesse abspielen und - vor allem - eine stăndige Projektion dieser Phănomene in das Bewubtsein des Menschen (2). Am Grad der BewuBtwerdung einzelner Elemente dieses Spannungsfeldes kann der Stand menschlicher Erkenntnis 'sichtbar' werden. Elne der vielfältigen Möglichkeiten der Dichtung besteht darin, menschliches Verhalten und individuelles Wirklichkeitsverstăndnis zu reproduzieren. Der zugang zu diesen zusammenhägen wird durch die Wahl von 'Themen' begünstigt, die sich einer "poetischen Konsistenzbildung" widersetzen (3).

Eine Untersuchung zur stadt in der Dichtung, wobel der Begriff stadt noch erläutert werden soll, muB von obigen Uberlegungen ausgehen (4).

(1) Kosik, K.: Die Dialektik des Konkreten, Frankfurt/M. 1967; S.7.

(2) Kosik, K.: Dialektik ...; S.9.

(3) Jauss, H.R.: Das Ende einer Kunstperiode ... in: Literaturgeschichte als Provokation, Frankfurt/M. 1970: S.132.

(4) Vorgänge dichterischer Rezeption, literarischer Geschmacksbildung und auch Stoff- und Motivubernahme werden hierbel gleichfalls als Reproduktionen sinnlicher und seelischer Vorgänge, d.h. Auseinandersetzung mit der Realitat, verstanden. 
Hinweise auf die Berücksichtigung eines Themas in der Forschungsliteratur dienen einer ersten Bestandsaufnahme und konnen die aktuelle Untersuchung nicht unwesentlich beeinflussen. Karl Riha konstatiert am Beginn seiner Arbeit "Die Beschreibung der 'groBen Stadt'" einen offensichtlichen Mangel an solchen germanist1schen Arbeiten, die sich mit "Form und Funktion moderner zivilisationsphänomene" in der Literatur befassen (1). In seinem Forschungsbericht kann er jedoch auf einen anregenden Fundus zumindest spezieller Untersuchungen zurückgreifen. Das Fehlen einer ăhnlichen Ausgangsposition für die russische Literatur veranlast bei einem vergleichbaren Thema, auch indirekte Hinweise dankbar aufzunehmen. Für das methodische vorgehen vorliegender Arbeit gab die genannte Untersuchung Rihas zahlreiche Anregungen, obwohl sich bereits bei der sichtung des tatsăchlich in der russischen Literatur vorhandenen Quellenmaterials ein anderes Ordnungs- und Darstellungsprinzip andeutete (2).

Einen großen Raum nehmen in der erwăhnten germanistischen Darstellung die sogenannten auBerliterarischen Texte ein wie: topographische Beschreibungen, Reiseliteratur und journalistische Beitrăge. In ihnen sieht der Autor die Grunamodelle für spătere "künstlerische Beschreibungen" und "beschreibende Erzăhlformen". Riha konzentriert sich auf ausgewăhlte Prosa zwischen 1750 und 1850. Die Beschrănkung auf reine Erzahlformen vereinfacht die Durchfuhrung seines Programms,

(1) Riha, K.: Die Beschreibung der 'groben stadt', Bad Homburg 1970; S.7.

(2) Ein Grund dafür liegt 2.B. In der für die russische Literatur eigenen Gattungsentwicklung. 
das Eindringen des Stadtstoffes und einzelner stadtmotive in die $P r \circ s$ a $g$ t $t u n g$ e $n$ verfolgen. Auf diese Weise kann Riha zwar einzelne "Etappen" auf dem Weg zum GroBstadtroman aufweisen, erweckt aber in seiner Darstellung mehr den Eindruck einer stofflichen Revolution als den eines evolutionăren Eindringens (1).

Auch V. Klotz konzentriert sich in seiner umfassenden Untersuchung "Die erzählte Stadt. Ein Sujet als Herausforderung von Lesage bis Dobblin" auf die reine Prosaform, auf den Roman. Er untersucht ein "gutes Dutzend Romane aus drei Jahrhunderten und fünf Nationalliteraturen" (2). Seine ziele sind in der Einleitung klar formuliert: 1. Aufdeckung der Relation Dichtung - Stadt im historisch-veränderlichen ProzeB; 2. Erkundung von Möglichkeiten und Leistungen der Romanform für den Vorwurf stadt; 3 . Uberprüfen der Hypothese, daB zwischen "einem auBerpoetischen Gegenstand und einer poetischen Gattung" eine Affinitat besteht (3).

(1) Der Autor nimmt hier eine Einteilung nach

a) Kunstformen der stadtbeschreibung und nach

b) Erzählformen der Großstadtbeschreibung vor. Beispiele zu: a) Stifter,A.: Wien und die wiener; zu: b) Nicolai, F.: Sebaldus Nothanker; Tieck, L.: William Lovell; Hoffmann, E.Th.: Des Vetters Eckfenster: Grillparzer, F.: Der arme Spielmann und Keller, G.: Der grüne Heinrich.

(2) Klotz, V.: Die erzählte stadt. Ein sujet als Herausforderung des Romans von Lesage bis Döblin, München 1969; S.9.

(3) Klotz, V.: Die erzahlte Stadt; S.11. Berücksichtigt werden Romane von Lesage, Defoe, Wieland, Hugo, Sue, Dickens, Raabe, Zola, Belyj, Dos Passos und Döblin. Die Eintellung ist nicht nur chronologisch, sondern auch wertend. 
Seine vor allem deskriptiven Analysen haben in dem von ihm ausgewăhlten Kanon ein fur uns wesentliches Ergebnis erbracht, das bel klotz allerdings in der stofffulle verschwimmt.

Zunăchst sind es immer nur Teilbereiche des stadtkomplexes, $g$ e $i s$ s $A n s i c h t e n$, b e s o nde r e E r l e b n 1 s qu a l i $t$ ar$t$ e $n$ /von mir gesperrt, G.z./, die für die einzelnen Autoren im Vordergrund stehen. Von diesen systemprägenden Tellbereichen dringen sie dann nach epischer strategie, jeder anders und verschieden tief, weiter, um mehr oder minder umfassend das Ganze des Gegenstandes durch das Ganze des Romans zu erschlieben (1).

Da vor allem auf die enge Beziehung zwischen Form und Stoff hingearbeitet wurde, die ja tatsächlich und nicht nur für das Thema stadt gilt, erlangen die Fragen nach der Gattung eine Autonomie, welche z.B. oben angedeutete Erlebnisqualităten und deren Ursache uberspielt. Darüber hinaus ist bel einer von vornherein auf den Roman fixierten Untersuchung, die zwar eine Fulle von Gestaltungsmöglichkeiten aufdeckt, eine Analyse auBerpoetischer Einflüse an den Rand gedrăngt (2). In einem Exkurs, der die Vorgeschichte der "erzăhlten" stadt darstellt, erfahrt der Leser etwas von Stadttopol, Mythen und christlichen Symbolen. Die Möglichkeit, daB diese fest umrissenen vorstellungen und auch Sprachschablonen uber die Barockliteratur hinaus wirksam werden, ist vom Autor zu wenig beachtet worden (3).

(1) Klotz, V.: Die erzăhlte Stadt; S. 438/439.

(2) Hier wăren zu nennen: literarische Rezeption, gesellschaftliche Notwendigkeit, Stellenwert des Werkes innerhalb des Gesamtwerkes und der zeit.

(3) Dies kann 2.T. durch die Auswahl der Werke begründet werden. 
Die Arbeiten von Riha und Klotz haben bereits verdeutlicht, das ein derart komplexes Thema, wie die stadt in der Literatur, unbedingt der Beschränkung bedarf. Die meisten Untersuchungen aus dem Bereich der deutschen und französischen Literatur sind deshalb Einzelproblemen gewidmet, wobei das zeitliche Interesse eindeutig dem 19. Jahrhundert und dem Beginn des 20. Jahrhunderts gilt (1).

In ihrer "Stoff- und Motivgeschichte" hat E. Frenzel auf folgendes hingewiesen:

Städe wie Rom, Paris und Venedig entfalten als Motive eine Fülle von Spannungselementen, die ihnen die Geschichte und das, was menschliche Empfindung und menschliches Denken mit dieser Geschichte verbanden, verlieh (2).

Die Vorliebe der Dichter für bestimmte städte ist ein Phănomen, das in seiner Evidenz eine Analyse geradezu heraus forderte.

Vor allem Paris, $W$. Benjamin nannte es die "Hauptstadt des 19. Jahrhunderts", diente nicht nur den französischen Dichtern als ständige Anregung (3).

(1) Mit dem 20. Jahrhundert drinọt das Bild der FroBstadt wieder verstärkt in die Lyrik ein, wobei besonders französische und deutsche Expressionisten ganze zyklen der Stadt widmen. Stellvertretend für die russische 'stadtlyrik' des beginnenden 20. Jahrhunderts seien hier genannt: A. Achmatova, Z. Gippius, A. Blok, O. Mandel'stam. Schon allein dieser Vorgang nimmt der Verbindung Roman - Stadt den Anspruch von AusschlieBlichkeit.

(2) Frenzel, E.: Stoff- und Motivgeschichte, Berlin 1966; S. 23.

(3) Benjamin, W.: Paris - die Hauptstadt des 19. Jahrhunderts, in: Schriften I, Frankfurt/M. 1955;

S. $406-422$. 
Stellvertretend für zahlreiche Untersuchungen zum Thema Paris in der Dichtung soll hier Robert Minders Aufsatz "Paris in der französischen Literatur (1760 - 1960)" genannt werden (1). Minder versteht Paris nicht nur als unerschöpfiche Quelle für die Literatur; sein eigenes Verstăndnis ist eine Mischung aus Mythos und Historie. So ist auch seine Feststellung $z u$ verstehen:

Die radikal moderne Erfassung der Großstadt als "anonymer Korallenstock für das Lebewesen Mensch" kam nicht aus einer $g$ e $s h i c h t s u b$ e $r-$ l a g e r t e $n, u r a l t e n$ siedlung/von mir gesperrt, G.z./ wie Paris, sondern aus Städten ohne groBe Tradition, in denen die Pioniere sich der zukunft um so mehr ungehemmter offnen konnten: dem New York von Dos Passos und dem Berlin Alfred Döblins (2).

Ein Uberblick über die Arbeiten, die sich mit dem Thema Stadt in der deutschen und franzorsischen Literatur auseinandersetzen, läßt heute ein zumindest quantitătsmäBig gesteigertes Interesse an unserer Fraoestellung erkennen. Für die russische Literatur gibt es, um es vorweg $\mathrm{zu}$ sagen, keine vergleichbaren Untersuchungen. Eine umfassende Arbeit zum Thema Moskau oder Petersburg in der russischen Literatur fehlt uberhaupt. Bei dem für diese Arbeit vorliegenden Material wird uberdies deutlich, daB besonders für die neueren sovetischen Darstellungen eine vollig andere Ausgangsposition und Fragestellung, als für die genannten westlichen Arbeiten, bestimmend war. AuBerdem kann in den meisten Fällen kaum von einer untersuchung oder Analyse etwa nach dem Beispiel Rihas

(1) Minder, R.: Paris in der französischen Literatur $(1760-1960)$, in: Dichter in der Gesellschaft, Darmstadt $0 . J^{\text {. : S }}$ S. $287-340$.

(2) Minder, R.: Paris ...; S. 333 . 
gesprochen werden, denn nicht selten beschränkt sich die 'Stellungnahme' zum Thema lediglich auf registrierende AuBerungen.

zur vordergründigen Beschreibung von Moskau und Petersburg in der Literatur liegen zwei Sammelbănde vor, die in der Art eines literarischen Baedekers die rein biographische Beziehung einzelner Dichter zu Moskau oder Petersburg in abgeschlossenen skizzen chronologisch aneinanderreihen.

Der 1968 in 2. Auflage erschienene Band "Liter. pamjat. mesta Leningrada" /Literarische Gedenkstatten Leningrads/ beabsichtigt folgendes:

Avtory predlagaemych oxerkov delajut popytku poznakomit' sovetskogo Citatelja so mnogimi pamjatnymi literaturnymi mestami Leningrada, pokazyvajut rol' 1 znatenie goroda $v$ zizni 1 tvorłestve togo 111 inogo pisatelja, poéta (1).

/Die Autoren der vorliegenden Skizzen unternehmen den Versuch, den sovetischen Leser mit vielen literarischen Gedenkstäten Leningrads bekannt zu machen, sie zeigen die Rolle und die Bedeutung der stadt im Leben und Werk dieses oder jenes Dichters und Schriftstellers./

Das Schwergewicht der Darstellung liegt eindeutig bei Puskin, Gogol', Nekrasov und Dostoevskij, wăhrend z.B. die Vertreter des 18. Jahrhunderts trotz ihrer nachweislich engen Beziehungen zu Petersburg in nur einem Kapitel zusammengefast werden. Grundprinzipien der einzelnen, von verschiedenen Autoren bearbeiteten $\mathrm{Ab}-$ schnitte sind: 1. Nennung biographischer Daten, die sich aus den Aufenthalten der bekanntesten Dichter in Petersburg ergeben, mit genauer Bezeichnung der Woh-

(1) Literaturnye pamjatnye mesta Leningrada, L. $1968 ;$ S. 15 . 
nungen; 2. Wiedergabe reprösentativer Stellen aus ihren Werken und Briefen, mit Andeutungen des zeitgeschichtlichen Hintergrundes. Eine Synthese der Teilaspekte findet nicht statt; die Interpretation erschopft sich in der Deskription auffallender Text- und Wirklichkeitsnahe.

Als kurz vor AbschluB der hier vorliegenden Arbeit das Buch "Russkie pisateli v Moskve" erschien, konnte man eine dem obigen Werk adăquate Darstellung erwarten. Die Herausgeber, ein Autorenkollektiv, beabsichtigen, dem "Leser einen Fuhrer durch das literarische Moskau anzubieten" und Moskau als einzigartiges, vor allem historisches Kulturzentrum darzustellen (1). Die Einzelportrăts beginnen mit Trediakovskij und enden mit Esenin. Der Unterschied zu "Literaturnye pamjatnye mesta Leningrada" besteht nun darin, daB hier vor allem Skizzen uber die gesellschaftiche Tätigkeit der Dichter eine Darstellung ihres Moskaubildes verdrăngen. Es ist schon darauf hingewiesen worden, daB ein Uberblick uber die "Forschungsliteratur" mehr als eine Bestandsaufnahme sein kann. In unserem Fall muB festgestellt werden, daB sich die bisherige Forschung eindeutig auf Petersburg bzw. Leningrad konzentrierte (2). Ergănzend $z u$ den allgemeinen, ubberblickartigen Untersuchungen muB noch die kulturpolitische Betrachtung von Ettore Lo Gatto "Il mito di Pietroburgo" genannt

(1) Russkie pisatel1 v Moskve, M. 1973; S. 4. Das Rivalitätsdenken zwischen Moskau und Petersburg, das mit der Erhebung Petersburgs zur russischen Hauptstadt aufkam, ist noch heute - und vor allem im genannten Buch - zu spüren.

(2) Moskau war die Stadt der literarischen Salons und der literarischen Gesellschaften. Die Dichter, vor allem zu Beginn des 19. Jahrhunderts, hielten sich gern in Moskau auf, lebten aber die meiste zeit in der Hauptstadt, wo sie dann auch eine 'Stellung' innehatten. 
werden, deren Untertitel "Storia, leggenda, poesia" lautet (1). Lo Gatto knüpt an zwei in den zwanziger Jahren erschienene Schriften von N.P. Anciferov an: "Dusa Peterburga" (1922) und "Byl 1 mif Peterburga" (1924). Der bei Anciferov bereits im Titel suggerierte Mythos bezieht sich auf die Gestalt Peters des Groben als Erbauer der neuen stadt. Lo Gatto hingegen sieht sowohl die Leistung des stadtgründers als auch die Rolle der stadt selbst in erster Linie in der Erfullung einer Ideologischen Aufgabe; deshalb entspricht sein Mythos von Petersburg der Idee Peters vom 'Fenster nach Europa', das RuBland dem Westen offnen sollte. An der Verwirklichung dieser Idee miBt Lo Gatto die Evolution der Stadt Petersburg, ihrer Gesellschaft und auch ihres Bildes in der Literatur, wobel die wachsende Urbanisierung vom Autor in erster Linie an einer raumlich-ästhetischen Verănderung dargestellt wird.

Der Wert der hier genannten Untersuchungen liegt vor allem in der zusammenstellung des umfangreichen nuellenmaterials und somit in ihrer zunăchst informatorischen Bedeutung. Lo Gatto hat darüber hinaus auf den Zusammenhang der literarischen Rezeption der stadt mit ihrer realen ideologischen Bedeutung hingewiesen. Joh. Holthusen macht in einer als Vortrag konzipierten Skizze auf "Petersburg als literarischen Mythos" aufmerksam (2). Obwohl er sich aus organisatorischen Grüden auf Anregungen beschrănken muB, wird ein repräsentativer AbriB des sich in der russischen Literatur ver-

(1) Lo Gatto, E.: Il mito di Pietroburgo, Milano 1960.

(2) Holthusen, Joh.: Petersburg als literarischer Mythos, in: RuBland in Vers und Prosa. Vortrăge zur russischen Literatur des 19. und 20.Jahrhunderts, München 1973; S. $9-34$. 
ändernden Petersburgbildes vermittelt. Dieser ProzeB wirkt in der Darstellung vor allem deshalb besonders instruktiv, weil Holthusen auch ausgewählte Oden des 18. Jahrhunderts berulcksichtigt. Darüber hinaus werden verschiedene Motive angesprochen, die sich im Zusammenhang mit Petersburg in der Literatur gebildet haben (1).

Neben den wenigen allgemeinen Uberblicken zum genannten Thema liegen noch einige Einzeluntersuchungen vor, die sich mit den Beziehungen verschiedener Dichter $z u$ den beiden Hauptstadten beschätigen. Mit dem eingangs erwahnten Band "Literaturnye pamjatnye mesta Leningrada" ist eine Reihe $z u$ vergleichen, die in abgeschlossenen Darstellungen 2.B. "Gogol'v Peterburge", "Krylov v Peterburge" und "Dostoevskij v Peterburge" beschreibt (2).

Für den Anspruch der einzelnen Bändchen kann stellvertretend folgende Passage aus "Dostoevskij v Peterburge" stehen:

On nazyvaet $i$ charakterizuet takze ulicy, plošadi, mosty, zdanija, traktiry tech vremen, upominaemye $v$ romanach Dostoevskogo, pomogaet Citatelju prosledit' dvizenie ego geroev po Peterburgu, pomogaet emu glubze 1 konkretnee omyslit' obraz Peterburga, vstajußcij so stranic proizvedenij pisatelja (3).

/Er /d.1. der Autor/ nennt und charakterisiert auch die Straßen, Plätze, Brücken, Gebăude, Gasthăuser

(1) Zu diesen Motiven, die heute schon zum topischen Bestand der Petersburgdichtung geworden sind, gehoren u.a.: Petersburger Klima, Rivalität Moskau - Petersburg, das năchtliche Petersburg, die Beamtenstadt.

(2) M.J. Gillel'son, V.A. Manujlov, A.N. Stepanov: Gogol' v Peterburge, L. 1963.

A.Gordin: Krylov v Peterburge, L. 1969.

E. Saruchanjan: Dostoevskij v Peterburge, L. 1970. 
jener zeit, die in den Romanen Dostoevskijs erwăhnt werden, hilft dem Leser dem Gang seiner Helden durch Petersburg zu folgen, hilft ihm das Bild Petersburgs, wie es sich auf den Seiten der Werke des Schriftstellers zeigt, tiefer und konkreter zu verstehen./

Zu diesen Darstellungen, die vor allem eine Uberprüfung topographischer und biographischer Tatsachen anstreben, seien als Ergänzung genannt: Aškin, N.S.: Moskva v żizni 1 tvor ̌estve A.S. Puškina, M. 1949; Ivanova, T.A.: Moskva v żin1 1 tvorČestve M.Ju. Lermontova, 1827-1832, M. 1950 und der Aufsatz von Anciferov, N.P.: Moskva 1 Peterburg v Zizni i tvorXestve Gogolja, M. 1954 (1). Auch diese Darstellung hat vornehmlich Informationswert; eine Analyse des individuellen Petersburg- oder Moskauverständnisses fehlt in den sovetischen Darstellungen fast ganz. Eine Ausnahme bildet Gukovskijs "Realizm Gogolja". Der Autor versucht hier aufgrund seiner literaturtheoretischen Fragestellung, die 'licnost' Peterburga' im Werk Gogol's zu beschreiben. Gukovskij versteht Petersburg nicht nur als topographische Realitat, vor deren Hintergrund die "Petersburger Erzählungen" handeln, sondern:

Peterburg u Gogolja - èto konkretnyj 1 real'nyj obraz sovokupnosti ljudskich mass, svjazannych, skovannych konkretnym ukladom zizni (2).

/Petersburg bel Gogol' - das ist das konkrete und reale Bild der Gesamtheit jener menschlichen Massen, die an die tatsächlichen Lebensbedingungen gebunden und gekettet sind./

(1) Der Aufsatz uber Gogol' ist erschienen in: Gogol'v skole, Sbornik statej, M. 1954.

(2) Gukovskij, G.A.: Realizm Gogolja, M.-L. 1959; S. 250 . 
Gukovskij sieht in der Vorliebe Gogol's für die 'niederen Beamten' den Ansatz zu einem kritischen Realismus. Auf die Untersuchung Gukovskijs wird bel der Besprechung des Gogolschen Werkes noch einzugehen sein. In diesem zusammenhang soll darauf hingewiesen werden, daB das Interesse der Literaturwissenschaftler, die in irgendeiner Weise das Thema Stadt und Dichter berücksichtigt haben, eindeutig bei Gogol' und Petersburg liegt (1).

Unter der Kapiteluberschrift "The City As Madhouse" behandelt V. Erlich in seiner Monographie "Gogol" die "Petersburger Erzählungen" dieses Dichters (2). Obwohl Erlich die Bedeutung der genannten sovetischen Untersuchung zum Realismus bel Gogol' ausdrücklich betont, verkurzt er deren Ergebnis ganz erheblich, wenn er die stadt als "madhouse" in direkte Verbindung zu bekannten romantischen Motiven bringt wie: Doppelgänger, Automaten, Wahnsinnige. Mit Hinweisen auf die franzorsische "Stadtliteratur" und auch auf russische Ansätze elnes neuen 'Stadtverständnisses' hatte aber bereits Gukovskij Gogol' in einen Rahmen gestellt, der uber die romantische Tradition hinausgreift.

D. Fanger nimmt in "Dostoevsky and Romantic Realism" das Problem einer literaturgeschichtlichen Standortbestimmung der Werke Gogol's und Dostoevskijs auf. Indem er hier die belden russischen Dichter in Relation

(1) zu nennen sind hier auch die beiden Aufsätze von $J$. Holthusen, auf die später eingegangen wird: Holthusen, Joh.: Gogol' und die Grobstadt. In: RuBland in Vers und Prosa, München 1973; S. 35-37. Holthusen, Joh.: Zum Motivbestand der "Petersburger Erzăhlungen". In: WS1; IV,2, 1959; S.148-168.

(2) Erlich, V.: Gogol; New Haven-London 1969. 
zu Dickens und Balzac setzt, nennt er auch ihr gemeinsames Thema: die "grobe moderne Stadt - Paris, London, Petersburg" (1). Der im Titel der Arbeit angesprochene Antagonismus "romantischer Realismus" wird im Komplex der Grobstadt aufgelost.

Die hier kurz umrissenen Materialien zum Thema Petersburg und Moskau in der russischen Literatur haben verschiedene Aspekte des stoffes und seiner Darstellungsmöglichkeiten aufgedeckt. Ein vollständiger Uberblick, der hier bewubt nicht angestrebt wurde,könnte folgende methodische Grundtendenzen der vorhandener. Untersuchungen bestätigen:

1. Darstellung biographisch-topographischer Tatsachen und eine Einbeziehung sozio-bkonomischer Fakten in die Biographie des Autors, wobei die Uberprufuna ihrer authentischen Wiedergabe im Werk des Dichters einziger Anspruch der Untersuchung ist.

2. Fragen nach Motivkomplexen und literarischer Tradition des stadtbildes.

3. Darstellung individueller Wirklichkeitserfassung (=Wirklichkeitserkenntnis) und ihre poetische Umsetzung.

Bereits eine enzyklopädische Vergegenwärtigung des in verschiedenen Nationalliteraturen gezeigten Interesses an der stadt bestätigt die Vermutung, daB obengenannte Möglichkeiten lediglich Ansătze sein können (2)

(1) Fanger, D.: Dostoevsky and Romantic Realism. A study of Dostoevsky in relation to Balzac, Dickens and Gogol, Chicago-London 1967.

(2) Reiches Material bieten hier die Untersuchungen von Klotz und Riha. Zum Interesse an bestimmten GroBstäten, mit deren Gestalt sich die verschiedensten Vorstellungen verknüpfen, sind als Ergănzung die "anonymen Städte" hinzuzufügen, deren Bedeutung vor allem im symbolhaften liegt, z.B. die stadt als GefăB der Seele. Zu berücksichtigen wăre ebenso

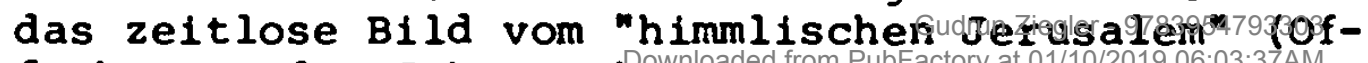
fenbarung des Johannes). 
E. Frenzel sprach von einer "Fülle von Spannungselementen", die sich mit der literarischen Darstellung und Vorstellung bestimmter GroBstadte bildeten (1). Sie deutet damit einen vorgang lediglich an, den darzustellen das ziel dieser Arbeit sein soll: die Aufdeckung der Relation zwischen der historisch sich verändernden stadt und ihrem jeweils in der Dichtung dargestellten Verständnis. DaB sich hier mehrere Prozesse überlagern, soll kurz angedeutet werden:

1. Das Verständnis des Dichters von Moskau und Petersburg orientiert sich an einer Idealvorstellung von diesen Städten.

2. Der Autor sieht die Stadt als historisches Ergebnis und stellt in möglichst objektivierter Form zeitgenössische Tendenzen dar (2).

3. An seinem Werk ablesbar erweist sich die stadt als Erlebnishintergrund des Autors. Das bedeutet:

a. eine Bewältigung individueller psychischer vorgänge innerhalb oder durch die dichterische Darstellung. Zugrunde liegt die 'Auseinandersetzung' Individuum - Stadt (=umwelt).

b. den AbschluB eines Erkenntnisprozesses und Einsicht in die Historizität der Umielt.

Die Trennung der hier nebeneinandergestellten Vorgänge ist methodisch nicht möglich. Ihre Identifizierung ist von verschiedenen Faktoren abhängig, von denen andeutungsweise nur die literarischen GesetzmäBigkeiten genannt seien. Diese lassen sich wiederum in der chronologischen Abfolge oft als "zeitgemäB" aufdecken (man den-

(1) Frenzel, E.: Stoff- und Motivgeschichte, S. 23.

(2) Als Beispiel wäre hier das organisch gewachsene, historische Moskau zu nennen; Petersburg hingegen ist als Ergebnis eines Verwaltungsaktes unorganisch, künstlich. 
ke hier an die Vorliebe verschiedener Epochen fur bestimmte literarische stoffe), aber schon der damit verbundene Vorgang literarischer Rezeption verweist auf Tendenzen, die z.B. mit einer immanenten Werkbetrachtung allein nicht darzustellen sind. Es ist in dieser Arbeit nicht allein mit einer Deskription der Details getan, an denen sich die Veränderbarkeit des literarischen stadtbildes ablesen läBt. Gefragt wird nach den realen Voraussetzungen, die einen Wandel in den Moskau- und Petersburgdarstellungen der russischen Literatur zwischen 1700 und 1850 bewirken. Folgende Hypothesen sollen daruber hinaus uberpruft werden:

1. In der Veränderung des Stadtbildes in der Dichtung spiegelt sich ein realer historischer ProzeB,

2. die individuelle Darstellung der stadt in verschiedenen Werken ist Ausdruck fur den Erkenntnisgrad des Autors von seiner Umwelt.

Mit dem hier gestellten Thema verbindet sich notwendigerweise ein Stadtbegriff, der zunächst durch aktuelle Problemstellungen vorgeprägt ist. Es ist unerlablich, diesen Standort wenigstens einzugrenzen. Das Ergebnis wird nicht eine komplexe Gesamtschau der stadt schlechthin sein, denn es kann sich in diesem Rahmen nur um Andeutungen handeln. Diese sind eine Bilanz verschiedener Untersuchungen zur modernen Stadtplanung, die als Gesamtheit jedoch eine Herausforderung an das literarische Moskau und Petersburg darstellen.

A.W. Schlegel hat im Jahre 1801 geschrieben:

.... nur mit dem, was in einer einzigen Stunde in einer einzigen stadt vorgeht, wenn man alles wissen könnte, könnte ein Mensch leicht sein ganzes Leben hinbringen, es zu erlernen und seinem Gedăchtnis einzuprägen (1).

(1) Schlegel, A.W.: Die Kunstlehre, Stutegragt-978537335. 16. 
Bereits damals verband sich also in der Vorstellung Schlegels der Begriff stadt mit einer Fille von Einzelaktionen.

N. Schmidt-Relenberg bezeichnet 1968 die Stadt als ein System, das "eine bestimmte struktur aufweist, zu dessen Erhaltung bzw. Entwicklung bestimmte Funktionen notig sind (1)."

Die stadt wirkt vor allem als soziales System, das in einen begrenzten geographischen Rahmen eingefügt ist.

Menschen schaffen sich in den städten einen Lebensraum, aber auch ein Ausdrucksfeld mit Tausenden von Facetten, doch rückläufig schafft diese stadtgestalt am sozialen Charakter der Bewohner mit (2).

Es besteht, wie Mitscherlich angedeutet hat, eine ewige Wechselbeziehung zwischen Stadt und Individuum, zwischen dem Gesch bpf und seinen Schøpfern. So werden z.B. menschliche Aktionen durch răumliche Notwendigkeiten ausgelkst und wirken auf die zurück, von denen eine Verănderuno durchgeführt wird. Mit anderen Worten: "Der Mensch wird so, wie die stadt ihn macht, und umgekehrt (3)." Nicht nur aufgrund dieser Vorgänge ist die stadt kein statisches Gebilde, sondern ein "Geschehen, das gerade in seiner Dynamik seine Daseinsberechtigung findet (4)." Diese Bewegung setzt sich aus unzahligen Einzelaktivităten, Interaktionen zusammen. In ihnen lebt die stadt; doch an allem ist der Mensch beteiligt, auf ihn wirkt alles zurück.

(1) Schmidt-Relenberg, N.: Soziologie und städtebau, Stuttgart 1968 ; S. 92 .

(2) Mitscherlich, A.: Die Unwirtlichkeit der Stădte, Frankfurt/M. 1969; S. 9 .

(3) Mitscherlich, A.: Unwirtlichkeit; S. 16.

(4) Hammel, P.: Unsere Zukunft: die Stadtom Z Eranks954793303 furt $/$ M. 1972; S. 57 . 
Die Stadt war zu allen zeiten der Ort, wo individuelle und offentliche Interessen aufeinandertrafen und sich gegenseitig bedingten. Die stadt war und ist vor allem auch der ort, wo Menschenmengen Vereinsamung bedeuten können.

Trotz vielfacher Negativwirkung der stadt auf ihre Bewohner, sei es als Gruppe oder als Individuum, besteht eine intensive Bindung des Menschen an die stadt, an seine stadt (1).

Der Mensch baut und liebt stadte, weil er in der urbanen Form ein Idealbild seiner Ideale konstruiert. Der gemeinsame Nenner aller stădte von Ninive bis New York ist ein kollektiver Gotzendienst, der um Macht uber Natur, Schicksal, Wissen und Reichtum betet (2).

Die stadt wirkt auf der einen Seite als Psychotyp, als "ein Stück der Selbstvergewisserung" sich darstellend für den, der der "stadt mit verdankt, was er ist (3)." Der Weg zum Mythos stadt ist hiermit bereitet. Auf der anderen seite bedeuten die groBen städte auch ein Angriff auf die Existenz des Menschen. Sie können denjenigen vernichten, der das system stadt nicht erkennt und anerkennt (4).

Die Einsicht in die struktur und Funktionszusammenhänge der Großstadt ist ein Ergebnis der im 19. Jahrhundert allgemein einsetzenden 'Verstädterung'. Heute spricht man bereits von einer urbanen Gesellschaft.

(1) Negativwirkung meint hier z.B.: bedrückende soziale Verhältnisse, Uniformiertheit der Gesellschaft durch intensive Gruppenbildung, Vereinsamung usw.

(2) Sibyl Moholy Nagy, zitiert nach: Mitscherlich, A.: Thesen zur Stadt der Zukunft, Frankfurt/M. 1971; S. VII.

(3) Mitscherlich, A.: Thesen ...; S. 12.

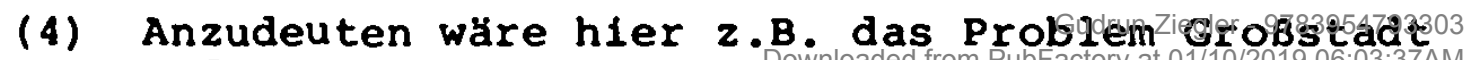
und Neurose. 
Unabhängig von dieser allgemeinen Entwicklung hatten sich bereits in der 2. Halfte des 18. Jahrhunderts Paris und London $2 u$ solchen Metropolen entwickelt, die in ihrem Sozialgefüge und ihrer Dynamik durchaus mit heutigen Großstădten vergleichbar sind. Beide Städte liefern schon fruh das Material zu dichterischen Darstellungen und konnten demzufolge in der Mitte des 19. Jahrhunderts auf eine gewisse 'literarische Tradition' zurückblicken.

Die Parisromane des 19. Jahrhunderts faszinieren vor allem durch eine Mischung von Fiktion und realem Hintergrund. Die Wirkung der Romane von Sue, Hugo und Balzac liegt darin, das sie die stadt als Ganzes, als vielschichtiges Gebilde darzustellen versuchen (1). Sie gelten heute als die ersten Grosstadtromane, die, als Ergebnis einer notwendigen Entwicklung, von verschiedenen Grundhaltungen des Menschen zur realen Stadt geprägt sind.

Auf zwel Phänomene, die wegen ihrer Allgemeingültigkeit beachtenswert sind, soll hier hingewiesen werden.

Man könnte sagen, um die Mitte des 18. Jahrhunderts steige am Horizont die Natur als Abbild und Begriff, als Sehnsucht und Hoffnung empor und wende sich gegen die Stadt... Ein Jahrhundert später jedoch hat die Stadt die Natur entthront. Die Re-Präsentation der Natur ist nur durch und für die urbane Wirklichkeit, die als solche Gestalt angenommen hat, möglich. Die Natur ist nur noch Bedauern, Wehmut, Schmuck der Jahreszeiten (2).

(1) Man denke hier an: Dickens: A Journal of the Plague Year (1722); Mercier: Le Tableau de Paris (1781). Die Vielschichtigkeit der Stadt ist auch in solchen Vergleichen angedeutet wie: Stadt als Meer, -als Buch, - als Bühne.

(2) Lefèbvre, H.: Die Revolution der Städte, München 1972; S. 117. 
Dieses Wechselspiel von Natur und stadt ergibt sich zunächst aus der rein natürlichen Lage jeder stadt. Mit der Entstehung der Städte als Konzentrationen im geographischen Raum, bildete sich auch immer ein Umland, das sich notwendigerweise von der stadt abhob. Verfolgt man die Entwicklung natürlich gewachsener Städte, so besteht ihre Bedeutung zunächst in der Wahrnehmung einer Marktfunktion. Als Märkte waren sie zwar einerseits direkt vom Umland abhängig, übernahmen aber andererseits firr die ländliche Umgebung neben der okonomischen auch ideologische Funktion. Die stadt wurde vorübergehend zum Inbegriff menschlicher Freiheit, der vor allem auf der Vorstellung einer verhältnismäßig 'freien' Sozialordnung innerhalb des städtischen Verbandes basiert (1).

Gleichzeitig erweckt die daraus resultierende Veränderbarkeit und Unberechenbarkeit städtischer Gesellschaft Angst und Unsicherheit. Die Stadt wird zum "Schreckbild" (2). Die großen Städte ziehen die Menschen an und stoßen sie gleichzeitig ab. Aus diesem Spannungsfeld lassen sich die verschiedenen individuellen Grundhaltungen zur stadt erklären.

Eine Arbeit, in der die literarische Rezeption Moskaus und Petersburgs in der russischen Dichtung untersucht werden soll, muB notwendigerweise auf die Begriffe Stoff und Motiv zurückgreifen. Eine Klärung dieser Termini bzw. eine Entscheidung uber ihre Anwendung ist bei

(1) Ein beliebtes Motiv in der Dichtung ist die Reise in die Stadt, oft in die Metropole, um sich zu 'bilden'. Für Petersburg wurde das Motiv "pereezd v Peterburg" wesentlicher Bestandteil jener Darstellungen, die neben der 'Erzählung' auch die Beschreibung der Hauptstadt beabsichtigten.

(2) nach: Sengle,F.: Wunschbild Land und Schreckbild Stadt. In: Studium Generale, Jg. 16, H. 10, 1963; S. 619-631. 
einer chronologischen Darstellung nicht zu umgehen. Die Rolle, die diese mit Inhalt gefullten Begriffe in einer am Stofflichen orientierten Untersuchung spielen, konnte man als aktiv und passiv bezeichnen. Als reine ordnungsbegriffe dienen sie einmal der organisation des Darzustellenden. Voraussetzung hierfür ist die eindeutige zuordnung ihrer Inhalte. Die Passivitat liegt dabei in ihrer Konstanz als Begriff. Ihre Aktivitat tritt dann zutage, wenn sich innerhalb eines ausgewăhlten zeitraumes Verănderungen ihrer Inhalte oder Ihres Kontextes nachweisen lassen. Es ist festzuhalten, daB die Literaturwissenschaft bislang keine eindeutige Definition jener Elemente geben konnte, die von ihr als wesentliche Bausteine der Dichtung uberhaupt angesehen werden. Stellenweise wollte man die Problematik dadurch lobsen, das etwa die beiden $z u$ klärenden Begriffe in direkte Relation gesetzt wurden. Dabei kann 2.B. die Feststellung, daB Motive Bestandteile eines stoffes seien, nur dann weiterfuhren, wenn die Funktionen von stoff und Motiv geklärt, also definiert sind.

Auf die Schwierigkeit, den stoff aus der Verschmelzung von Gehalt und Form zu losen, hat E. Frenzel hingewiesen (1). Damit ist gleichzeitig angedeutet, das der Stoff weder mit dem Gehalt (=Aussage) noch mit der Form (=Gestaltungsprinzip) $z u$ identifizieren ist. Der Stoff muB also so beschaffen sein, daB er trotz dichterischer Gestaltung erkennbar bleibt und das er die vom Dichter beabsichtigte Aussage erfullt. Man könnte dieses offensichtlich formbare Element auch vereinfachend mit Material ubersetzen, wobei die Antwort nach der Herkunftsfrage im Erlebnisbereich des Autors $2 u$ suchen ist.

(1) Frenzel, E.: Stoff- und Motivgeschichte; S. 25. 
In der vorliegenden Arbeit fallt die Entscheldung dahingehend, Moskau und Petersburg von vornherein als Stoffkomplexe zu bezelchnen. Die Darstellung wird aber zeigen, daB sich das Bewubtsein der Autoren, in beiden Stadten relchlichen literarischen stoff vorliegen zu haben, erst bilden muste.

E1n welteres Merkmal des Stoffes liegt in selner Morphologie. Man hat die Einzelelemente, aus denen er sich zusammensetzt, als Motive bezelchnet. Im Gegensatz zum Stoff sind sie zwar relativ konstant, konnen aber sowohl in der Aneinanderreihung (=Motivkomplex) als auch im Kontext verschieden wirken. Es 1st durchaus moglich, das lange bevor ein literar1scher stoff als solcher erkannt wird, ein $1 \mathrm{hm}$ zugehoriges Detall als Motiv in der Dichtung Eingang findet. Es wird gezeigt werden, daB sich mit Moskau und Petersburg in der russischen Literatur elne Fulle von Vorstellungen verknlipfen, die als literar1sche Motive nicht nur zeitlich unbegrenzt sind, sondern auch uber die einzelnen Gattungen hinaus wirken.

Es liegt an der Komplexitat des Themas, daB sowohl die Behandlung einzelner Autoren als auch die Berücksichtigung der verschiedenen Gattungen oft fragmentar $1 \mathrm{sch}$ bleiben muB. Eine erschbpfende Behandlung der Fragestellung hatte nicht nur, wie es in der vorliegenden Arbelt geschieht, die sogenannte "schone Literatur", sondern auch die 'journallstischen Genre' zu berucksichtigen. Auch muB, um den uberblickartigen Charakter der Darstellung zu wahren, oft auf elne vertiefende Darstellung der "Kulturphllosophie" einzelner Autoren verzichtet werden. Trotz dieser sehr wesentlichen Einschrankungen wurde an der Art der Untersuchung festgehalten. Dies geschah vor allem aus dem Grund, um die Entwicklung vom Einzelmotiv, von der Beschreibung hin zum komplexen Stoff aufzeigen zu konnen, um das Material zu bereiten, das Dostoevskij, der eigentliche 'Dichter der Grobstadt', vorfindet. 
II. Die panegyrische Dichtung des XVIII. Jahrhunderts

2u Beginn des 18. Jahrhunderts hatte Peter der GroBe mit rigoroser Gewalt in RuBland den einschne1denden Trennungsstrich 2 wischen der mittelalterlichreligiobsen, von der europäischen Gesamtentwicklung abgeschlossenen Altmoskauer Lebensweise und einer allem Neuen und Fortschrittlichen aufgeschlossenen modernen Welthaltung gezogen (1).

\section{Preslavnyj grad, čto Petr nas osnoval...(2)}

Mit der Gründung Petershurgs im Jahre 1703 schuf Peter I. nicht nur einen militäischen Vorposten im Norden des russischen Relches, sondern er legte auch den Grundstein zu einer stadt, die kaum entstanden bereits zum Mythos wurde. Die Lage dieser neuen Stadt in einer unwirtlichen Landschaft, die Schnelligkelt ihres Wachstums, eine für russische Verhaltnisse villig ungewohnte architektonische Gestaltung, kurz die Verwirklichung elner außergeworhnlichen Idee - dies alles mußte eine Herausforderung sein. Sie war an d 1 e Vorstellungen eines politischen und geistigen zentrums gerichtet, die sich aus den mit Kiev und Moskau verhundenen Erfahrungen entwickelt hatten. Die Verlegung der Residenz im Jahre 1712 nach Petersburg war nicht nur ein politischer Akt, sondern auch die Voraussetzung dafü, daß sich die neue lietropole als kulturelles Zentrum des Landes aushilden konnte. Die von Peter $I$. vorgegebenen Tendenzen wurden in der

(1) Graßhoff, H.: Zur Menschenbildproblematik der russischen Aufklärung; In: $2 S 1, X V, 6,1970 ; S .822$.

(2) Trediakovskij, V.K.: Pochvala Ižerskoj zemle...; Izbrannye prolzvedenija, M.-L. 1963; S. 180. 
bewuBten Frrderung geistiger Aktivitäten von seinen Nachfolgern aufgenommen (1).

Für die spătere kulturpolitische Entwicklung der Hauptstadt waren vor allem zwei Institutionen von entscheidender Bedeutung, und zwar die "Peterburgskaja tipografija" /Petersburger Druckerei/ und die Akademie der Wissenschaften. Iit der Einrichtung der Petersburger Druckere1, bereits 1711 von Peter I. veranlaßt, bewies der $\mathrm{Zar}, \mathrm{da \beta}$ er die presse als Kommunikationsmittel kannte und sie als einflußnehmendes und steuerndes Medium verstand. Das Erscheinen der ersten russischen Ze1tung "Vedomosti" /Nachrichten/ 1711 in Petersburg begründete den Ruf der neuen :1etropole als zentrum des russischen Journalismus. Dies traf vor allem für die 2. Halfte des 18. Jahrhunderts $2 u$. I1t einer Ustav hatte Peter I. 1724 die Errichtung einer "nkadenie der Wissenschaften und seltsamen Künste" /nkademija nauk 1 kur'eznych chudožestv/ konziplert. Diese blieb zwar noch lange nach threr Eroffnung 1725 vornehmlich ein wirkungsfeld ausländscher professoren, doch gehen vor allem seit Trediakovskij von ihr entscheidende Impulse für die Gestaltung der russischen sprache und des Schriftums aus (2).

RuBland war zu Beginn des 18. Jahrhunderts in einzigartiger Weise ourch die Aktivitäten Peters I. geprăgt und befand sich vor allem auf kulturellem Gebiet in einem zustand permanenter Rezeption.

(1) Mit Peter I. beginnt sich das geistige Leben der ausschließlichen EinfluBnahme durch die Kirche zu entziehen. Moskau blieb als kirchliches zentrum weiterhin bestehen und war als solches die inoff1zielle Hauptstadt des Landes.

(2) Die erste Ausnahme unter den vorwiegend aus Frankreich und Deutschland berufenen Wissenschaftlern bildete Trediakovskij, der 1745 zum Professor für lateinische und russische Eloquenz ernannt wurde. 
Man sollte in diesem zusammenhang beachten, das die Ubernahme anerkannter ze1tphănomene und Ideen als bewuBter bzw. unbewubter Vorgang gesehen werden kann. Fur den hier angesprochenen zeitraum ergibt sich daruber hinaus die Problematik von auBen gesteuerter Rezeptionsvorgănge (1). In der Iiteratur splelt die aktive und passive Rezeption elne wesentliche Rolle, wenn nicht sogar die wesentlichste iberhaupt. Sie bestimmt unter anderem den Proze $B$ der stoffindung und daraus resultierend den der stoffgestaltung durch den Autor (2). Dieser Vorgang ist nur in den seltensten Fällen unmittelbar. GemäB seiner Abhängigkelt vom GeschlchtsprozeB erweist er sich als zeltlich langrăumiger evolutionärer Vorgang, der von den verschiedensten Faktoren bestimmt wird (3). Fur die hier gestelite Thematik ergibt sich die einnalige situation, den zeitlichen Ausqangspunkt einer dichterischen Rezeption präise bestimmen zu konnen, denn die stadt Petersburg findet gleichzeitig mit ihrer Grúndung Eingang in die Literatur.

Um Moskau, das vor 1712 Hauptstadt des russischen Re1ches war, hatte sich bis $z u$ diesem zeltpunkt vornehmlich in der Volksliteratur ein fester Formelbestand ausgebildet. Als Beispiele wären hier zu nennen: kamennaja

(1) Man kann eine bewubte Ubernahme als aktive, elne unbewuite Ubernahme als passive Rezeption bezelchnen.- Elne Steuerung durch Peter I. lag vor allem In der Ubernahme und We1tergabe westlichen 'Ge1stesgutes'.

(2) In diesem Sinne wird hier literarische Rezeption verstanden. Gemeint ist nicht die Rezeption des bereits Dargestellten durch ein Lesepublikum.

(3) Hier zelgt sich, daB der Autor zwar spontan reproduzleren kann, aber in nicht nachzuvolizlehender Weise reziplert. Fragen der literarischen Tradition spielen hier ebenso eine Rolle, wie das Selbstverständnis des Autors. 
Moskva; belo-kamennaja Moskva; ... poechal1 ko matułke k kamennoj Moskve; slavnaja Moskva (1). DaB die Gestaltung des spateren literarischen Moskaublldes nicht unwesentlich durch die Rolle Petersburgs beeinflubt wird, soll in der weiteren Untersuchung deut$11 \mathrm{ch}$ werden.

Die russische Literatur des 18. Jahrhunderts ist entscheidend von Fragen der Form und der thr adaquaten Sprache bestimmt. Als zunachst vorwiegend panegyr1sche Dichtung zeigt sie sich heute in besonderer Abhăngigkelt von der Gunst des Hofes.

Als der Ukrainer $F$ e f a n $P$ r o k o p o v 1 c (1681-1736) 1716 von Peter $I$. In die neue Hauptstadt berufen wurde, engagierte sich der Herrscher in $1 \mathrm{hm}$ elnen rückhaltlosen Bewunderer.

$V$ ego "pochval'nych 1 pozdravitel'nych" "slovach 1 rečach" gromko 1 tor ̌̌estvenno zazvucala ta tema Petra, stroitelja Peterburga, geroja Poltavskoj pobedy, ... (2)

In selnen "Lob- und Gluckwunschreden und Predigten" erklang laut und trlumphal das elne Thema Peter, des Erbauers von Petersburg, Held des Sieges von Poltava,..../

Seinen ersten Auftritt als Hofprediger hatte Feofan Prokopovic im oktober 1716, am 2. Geburtstag des Carevit Petr Petrovic (3). Das in der Dreifaltigkeitskathe-

(1) Diese Formeln sind auch auf andere Stadte, wie Klev und Novgorod ubertragbar. Nur "matuska Moskva" ist typisch.

(2) Blagoj, D.D.: Istorija russkoj literatury XVIII $\nabla .$, 4. peresm. 12d. M. 1960; S. 74 .

(3) Petr Petrovix, der 2. Sohn Peters I. wurde am 29.0ktober 1715 geboren; Prokopovit wurde Anfang oktober 1716 nach Petersbura berufen. 
drale /Trolckif sobor/ gehaltene "Slovo pochval'noe - den' roždestva blagorodnejłego gosudarja carev1ða 1 velikogo knjazja Petra Petrovica" ist nicht nur dem aktuellen AnlaB gewidmet, sondern es ist auch der erste Versuch einer literarischen 'Beschreibung' der neuen llauptstadt. Prokopovil benutzt in seiner Predigt die Regeln der besonders aus der antiken Rhetorik bekannten Staats- und Lobrede (1). Dies bedeutet unter anderem auch, daB das gegenwartig zu Lobende als historlsche Notwendigkeit dargestellt wird. Im vorliegenden Fall dient der Geburtstag des Carevic als AnlaB, um auf die Erfordernis der Nachfolgeregelung noch zu Lebze1ten eines Herrschers, hier Peter I., hinzuweisen. Denn nur in einem geeigneten Nachfolger kann die "Iloffnung auf Fortführung unserer Glückseligke1t" /Podaet nadeřdu prodolženija nałego blaženstva/ gewährleistet $\operatorname{sein}(2)$.

Die genannte "Glückseligkeit" hat RuBland von Gott in der Gestalt Peters I. erhalten. Mit dieser Uberhohung beginnt Prokopovic einen Lobpreis auf seinen Gornner. den zaren. Dessen Gröe zeigt sich in den Taten; sichtbarer Ausdruck dafür ist die neue stadt.

A ty, novyj 1 novocarstvujuscij grade Petrov, ne vysokaja 11 slava es 1 fundatora tvoego? Ideže ni pomysl komu byl zitel'stva Celoveceskogo, dostojnee vskore ustroisja mesto prestolu carskomu (3).

/Und du, neue und neuherrschende stadt Peters, hist du nicht erhabener Ruhm deines Grüders? Wo niemandes Gedanke an menschlichen Aufenthalt war, war ein wirdiger Platz, um in Kilrze den $\mathrm{zarenthron} z \mathrm{u}$ errichten./

(1) Feste Regeln für verschiedene Panegyrici gab es seit der römischen Antike. Es ist zu vermuten, daß der Aufenthalt Prokopovics in Rom, ihn mit den "klassischen Regeln" der Rhetorik vertraut machte.

(2) F. Prokopovit: Socinenija, M.-I. 1961; S. 43.

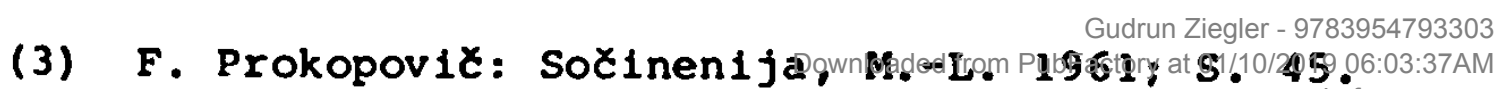


Durch den Gegensatz "ni pomysl komu byl zitel'stva Celoveceskogo" und "dostojnee ... mesto prestolu carskomu" wird zwar die Bedeutung der stadtgründung hervorgehoben, die Aussage ist jedoch dem Grundtenor der panegyrischen Rede untergeordnet. Nicht die stadt ist zu loben, sondern der Herrscher, der mit diesem Werk identifiziert wird.

Kto by ot strannych zde prised 1 o samoj 1stine ne uvedav, kto by, glagolju, uzrev takovoe grada velicestvo 1 velelepie, ne pomyslil, jako sie ot dvuch 111 trech sot let uže ziždetsja (1)?

/Wer von den Fremden hierher kommen würde und uber die fiahrheit nicht unterrichtet worden ist, wilrde der nicht glauben, so sage $1 \mathrm{ch}$, nachdem er solche Majestat und Herrlichkeit der Stadt gesehea hat, das diese schon seit zwelhundert oder dre1hundert Jahren existiert?/

Auch wenn Prokopovit hier die Stadt hereits als Ergehnis eines ivachstumsprozesses markiert, um dadurch ihre rroßartiçkeit hervorzuheben, spricht er doch auch in diesem zusammenhang den $z$ aren als schonfer und Erhaue: Petershurgs an.

Lñst man aus diesem. Redetell des "slovo pochval'noe" die riemente, die in direkter Relation zum rrundungsvorgang und zur 'Vorgeschichte' der stadt stehen, dans entspricht "Ideže ni pomysl komu byl žitel'stva..." /Wo niemals der Gedanke an menschlichen Aufenthalt wa:/ den tatsächlichen Ereignissen. Berücksichtigt man abe: sowohl den inlaß dieses "Slovo" als auch die Gattungstradition, dann tritt auch dieser llinweis auf die geographische Lage und die 'historischen' Ereignisse hinter den Forderungen der nanegyrischen Dichtung zurück.

(1) F. Prokopovic: Socinenija; S. 45. 
Die aufgebotenen nualitäten sagen nichts uber die individuelle Gestalt Petersburgs aus. Der stellenwert dieses "Städtelobes" wird aus dem Textzusammenhang deutlich: als Teil eines unfassenden "lierrscherlobes" dient es dazu, die Grobe Peters I. vor allem an seinem 'sichtbaren Werk' hervorzuheben. Damit ist die Funktion Petersburgs innerhalb des "Slovo" erfullt (1).

Prokopovit beschließt seinen panegyrikós auf die neue liauptstadt in einer Gleichsetzung der Trias: Petersburg - Peter I. - RuBland.

In Abwandlung eines Ausspruchs des rörischen Kaisers Augustus, er habe ein Rom aus ziegeln übernomnen und ein riarmornes Rom hinterlassen (2), heiBt es bel Prokopovic:

(1) E.R.Curtius hat in seiner Untersuchung "Europalische Literatur und lateinisches Mittelalter" auf die besentlichen Bestandteile des Herrscherlobes hingewiesen. Deminach sind zu berucksichtigen: ruhniende Hervorhebung der Vorfahren, der Jugendtaten und des Mannesalters. Als Vorschriften für das Städ telob haben sich seit der romischen Antike herauskristallisiert: Beschreibung der Lage der stadt, lilnweise auf den Gründer, Aufzăhlung besonderer Vorzluge und Sehenswürdigkeiten.

E.R.Curtius: Europäische Literatur und lateinisches Mittelalter, 6. Aufl. Bern 1967; S. $166 \mathrm{f}$. Wie Klotz dargestellt hat, gelten noch diese Regeln, wenn auch in erweiterter Form, in der Literatur des 17. Jahrhunderts. V. Klotz: Die erzählte Stadt, München 1969;

Exkurs: Vorgeschichte der erzahlten Stadt; S. 444462 .

(2) Sueton schreibt hierzu:

Urbem neque pro maiestate imperil ornatam et inundationibus incendisque obnoxiam excoluit adeo, ut iure sit glorlam marmoream se relinquere, quam latericiam accepisset.

Sueton: De vita caesarum, Stuttgart 1958;

liber II, S. $62(28-31)$.

In sehr freier Ubersetzung:

Rom, das weder der GrBBe noch der liurde des Re1ches entsprechend ausgebaut war und of mungen und Brände heimgesucht wurde, verschbnte er in solchem Maße, daB er sich ruhmen konnte, an stelle einer Stadt aus Backsteinen, die er ubernommen hat, eine aus Marmor zu hinter lassen Gudrun Ziegler-9783954793303 
Ispovesti vo 1stinnu podobaet: drevjanuju on obrete Rossiju, a sotvor1 zlatuju: ...(1)

/Es geziemt sich wahrhaft zu bekennen: er hat ein holzernes RuBland vorgefunden, aber ein goldenes geschaffen: ..../

Selbst $1 \mathrm{~m}$ Vergleich mit dem ant1ken Rom erfahrt das Werk Peters I. eine Uberhohung, denn: Augustus muBte sein "marmornes Rom" selbst loben, Petersburg als Ausdruck des goldenen RuBland ehrt den Herrscher allein durch seine Existenz (2).

Das Bild des idealen Herrschers und Stadtgründers Peter I. verlor während des 18. Jahrhunderts nichts von seiner Anzlehungskraft. ilt der Ehrung seiner Person ist fast lmmer eine Verherrllchung seines greifbaren Werkes, d.h. Petersburg, verbunden.

Fünf Jahre nach dem Tod Peters $I$. begann A.D. $K$ a $n t e-$ m 1 r (1708-1744) sein unvollendet gebliebenes "geroiCeskij poèm" "Petrida". Der hauptsächlich als Satiriker und Ubersetzer französ1scher Werke bekannt gewordene Autor versuchte in dieser Dichtung eine wurdigung der Persönl1chkeit und Tätigkeit des großen Herrschers. Das Poem beginnt mit einer Totenklage auf den zaren. Indem Kantemir die Taten des verstorbenen Herrschers besingt, wird der Verlust, den RuBland durch seinen Tod erlitten hat, manifest.

(1) Prokopovit: Socinenija; S. 45.

(2) Die "laudes Romae" waren in der lateinischen Dichtung sehr bellebt. Der Begriff vom "goldenen Zeitalter" ist elne latelnische Prăgung. In ihr spiegelt sich das Augusteische Rom. (Aeneis, VI, 792ff.) Vergl. F. Schlegel, Gespräch uber die Poes1e, 1800: "... keine Nation wollte fernerhin ohne thr goldenes Zeltalter bleiben."

In: Athenaeum II, Reinbek 1969; S. 162. 
Der Sieg des 2 aren uber die Schweden hatte die Gründung der neuen Stadt ermoglicht. Kantemir beschreibt dieses Ereignis, um gleichzeltig auf die notwendige Funktion Petersburgs als militărischen Vorposten hinzuweisen. Dieser Aufgabe scheint die Neugründung gerecht zu werden, denn sle begann "durch ihren Anblick zu erschrekken" $/ \ldots$, tto ustrałat1 prežde vidom sej zacal, .../ In 21 Verszeilen folgt die erste langere poetische Beschreibung Petersburgs in der russischen Literatur (2). Kantemir beginnt mit einer Darstellung der naturlichen Lage der Stadt, auf die er im vorangegangenen Text bereits hingewiesen hatte, als er von der Eroberung "Ingermanlands" sprach (3). In den versen 185-188 prăzisiert nun der Dichter:
Texet mez gradom reka bystrymi strujami,
$\mathrm{V}$ prostranno trexislennymi vpadaja ustami
More, ego ze vody brega podmyvajut
Severnych carstv, Balticko drevni, nazyvajut (4).
li1t elligen liassern fliebt der Flus zwischen
der Stadt, in dreifacher Mündung sich in das weite lieer ergießend, dessen iasser die Ufer der nörd- lichen Reiche umspult, das Baltische nennen es die Alten./

An diesen Zeilen ist bemerkenswert, daß Kantemir die Lage der stadt an Fluß und nicht, wie es in der Folgezeit ublich wird, die unwegsame, sumpfige Umgebung hervorhebt. Dies heibt, daB er den traditionellen iegeln des "Lobes" folgt, die eine ausfuhrliche Beschreibung nicht vorsehen.

(1) "Petrica". In: Kantemir, A.: Sobranie stichotvorenij, L. 1956 ; S. $245 ;$ V. $182-183$.

(2) Literaturnye pamjatnye mesta Leningrada, L.1968; S. 20 .

(3) Petrida. In: Sobr. stichotv. S. 245.

(4) Petrida. In: Sobr. st1choty. S. 24 fudrun Ziegler - 9783954793303 
Nad bregi rek1 vschodjat iskusstvom preslavnym domy tak, tto chot' nov grad, nitem chuždši davnym, ... (1)

/An den Ufern des Flusses erheben sich Hăuser so uberaus kunstvoll, daB die stadt, obgleich sie neu ist, in nichts schlechter ist als eine alte, ...l

Von Kantemir wird zwar die für Petersburg typische enge Verbindung von Stadt und FluB betont und in "nad bregi reki vschodjat ... domy ..." das Neva-Panorama angedeutet, doch bleibt dieser Eindruck im Allgemeingultigen befangen. Darüber hinaus wird aber bestätigt, daß die neue Stadt als Gesamtheit neben älteren Stadten durchaus bestehen kann. Wie schon bei prokopovic dient ein solcher Vergleich dazu, die Qualităt Petersburgs hervorzuheben. Kantemir weist darauf hin, daB der Anblick der Stadt das Auge zwar erfreut, daB eine weitere Bedeutung der Stadt aber auch in ihrer Wehrhaftigkeit zu suchen sei (2).

Sestibočnaja krepost', v vode vodruženna, ne boltsia usil'stva Marsa voruženna, ... (3)

/Die sechseckige Festung, im wasser errichtet, fürchtet nicht die Stärke des bewehrten Mars, ...l

$\mathrm{Zu}$ den bisher schematisch angedeuteten Realien der Stadt fügt Kantemir das Bild vom "tatigen Petersburg", das heibt vor allem vom Schiffsbau, den der 2 ar selbst mit "elgenen Händen" und "scharfem Verstand" leitete (4).

(1) Petrida; Sobr. stichotv.; S. 245-246; V. 189-190.

(2) Petriaa; Sobr. Stichotv.; S. 246; V. 191-192.

(3) Petrida; Sobr. stichotv.; S. 246; V. 194-195.

(4) Petrida; Sobr. Stichotv.; S. 246; V. 196. 
Von der Admiralitat als dem zentrum des Schiffshaus ausgehend, erstrecken sich zahlreiche neue Gebaude (1):

Ottol' vverch $v$ prjamu Certu, vel'moz nepresecny prostranny zrjatsja dvory; ... (2)

Non dort entlang, in gerader Linie, erblickt man ununterbrochen die weitlăufigen H*fe der wurdenträger; ..../

Kantemir vermittelt auch hier den Eindruck von Hăuserzellen, der schon durch den llinwels auf die die Neva săumenden llăuser entstanden war (3). Er abstrahiert den Elndruck einer ausgedehnten stadtanlage zu einer von einem Fixpunkt ausgehenden Linie.

Der Bau Petersburgs, der schon 1703 berann, ging zunăchst ohne ausg̣earbeitete Entwürfe für die Anlage der Bebauung der Stadt vor sich. Trotzden stelite es sich heraus, daB die dabel unmittelbar ari Ort geschaffenen Grundlagen für den späteren Bebauungsplan ausgezelchnet waren. Die erste HaBnahme bestand in der Festlegung der standorte für die liauptbauwerke der Stadt: die Peter-PaulsFestung und die Werft der Admiralitat. Damit war das topographische Bild des Zentrums schon im voraus festgelegt. Die Wahl flel auf die Neva-Gabelung, und damit war der Ausgangspunkt der stadt gegeben (4).

So beschreibt Bunin rückblickend die ursprüngliche Stadtanlage. Als Kantemir 1730 sein Poem begann, konnte er als wesentliche Bauwerke die Festung und die Admiralitat hervorheben. $D a B$ er diese Bauten nennt, entspricht

(1) Kantemir bezeichnet diesen Teil der stadt mit "obonpol", d.h. jenseits. Die stadt lag ursprünglich auf Vas.Ostrov; die Admiralitat lag deswegen jenseits.

(2) Sobr. st1chotv.; S. 246; V. 201-202.

(3) vergl. Vers 189

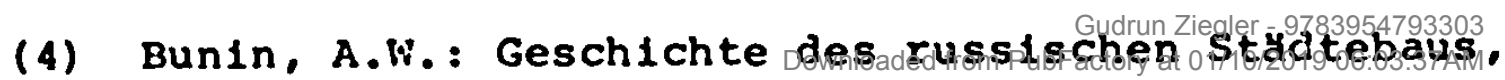
Berlin 1961; S. 108 . 
auf der einen Seite den Tatsachen, auf der anderen aber dienen sle, auf ihre bloBe Funktion 'reduziert' der Vervollständigung des Bildes vom $z$ aren als Stadtgrunder und als Baumeister.

Abschließend greift Kantemir noch einmal das Motiv Flub-Stadt auf. Dort, wo sich die Neva krümt und in zwei Arme teilt - "tut Petr obitaet" /hier wohnt Peter/ (1). Sein llaus ist armlich im Vergleich zu den Hofen der Wurdenträger und Kantemir fragt, ob nicht einem groBen Geist auch äußere pracht gebühre (2). Im folgenden wird die Persönlichkeit Peters I., die in dieser 'beschreibenden' Passage den ideoloqischen IIintergrund bildete, wieder direkt angesprochen. Das Petersburg-Bild Kantemirs unterscheidet sich der Intention nach kaum von den zeilen Prokopovics. Bei beiden Dichtern dient die stadt dazu, als Werk des Herrschers dessen Größe zu betonen. Darüber hinaus liefert aber bereits Kantemir toponranhische Einzelheiten. Der Eindruck eines räumlichen Petershurgs wird durch die Häufung verschiedener Rauriwrter, wie ohonpol, prostranno, ottol' vverch, vermittelt. Trotzdem erscheint cias Gesamtbild der Stadt unverbindlich und trägt, durch die festgelegte lolle innerhalh des poems unterstitzt, den Charakter einer idealen Stadt, die von einem idealen llerrscher gegründet vurde. Nichts stört die Klarheit dieses Stadtbildes, der vollkommenen Einhelt von ivatur und lenschenwerk.

(1) ...; gde Ze skoroternyj

Vtorlěj $v$ grade strui Neva iskrivaet, Deljasja $v$ dva ramena, tut Petr obltaet: ... (v. 202-204).

(2) Ne prostranno żllše, dovol'no i pokoju Cto vnešna pyšnost' tomu, kto velik dušoju? (V. 205-206). 
Fast gleichzeitig mit Kantemirs "Petrida" (1730) entstanden Verse, die ausschlleblich an elne stadt gerichtet waren. 1728 schrieb V.K. T r e d 1 a k o vs k 1 f (1703-1769) wăhrend elnes lăngeren Aufenthaltes In Paris die "Stich1 pochval'nye Parlzu". Dieses Gedicht soll deshalb hier berücksichtigt werden, well es elnmal Aufschlusse über den Erlebnis- und Ausdrucksberelch des Dichters geben kann, zum anderen etwaige Differenzen zwischen der Darstellung heimatilcher und auslandischer städte aufzudecken er laubt. Trediakovskij beginnt sein Lobgedicht auf die franzosische Hauptstadt mit einem enthusiastischen Ausruf:

Krasnoe mestol Dragoj bereg Senskij! (1)

/Herrlicher Platz! Teures Ufer der Selne!/

In dieser 1. Verszelle liest man berelts die Grundhaltung des ganzen Gedichtes. Geschildert wird im folgenden nämlich nicht die Metropole, die Paris als grobste stadt des europăischen Kontinents um 1730 berelts war, sondern ein "locus amoenus". Einziger realer Hinwels auf die Hauptstadt könnte "bereg Senskij" sein (2). Die reale stadt Paris ist in den Versen Trediakovskijs vollig zugunsten eines an Ufer der Selne lokalisierten Arkadien verdrăngt: "Tebja ne luł̌e polja Elisejski:... (3)" /Die elysischen Gefilde sind nicht schoner als du.../

(1) Trediakovskij, V.K.: Izbrannye proizvedenija, M. - L. $1963 ;$ S. 76 .

(2) Trediakovskij, Izbr. prolzved.; S. 76. "bereg Senskif" ist als Ortsangabe zwar so indifferent, das hiermit ebenso elne landliche Umgebung gemeint sein kbnnte, doch liegt hier eher eine Glelchsetzung von stadt und Flus vor (vergl. Petersburg-Neva).

(3) Izbr. prolzved.; S. 76. 
Blagoj faBt den Inhalt dieser "Stichi pochval nye" zus ammen :

V Pariže 1 solnce svetit luše, Cen gde-libo,1 dol'se cvetut 1 blagouchajut cvety $(. .$.$) ; po$ parizskim ulicam razgulivajut pojustie nimfy, 1 sam Apolion $s$ muzami imeet tam svoe prebyvante (1).

In Paris scheint auch die Sonne heller als irgendwo, und die Blumen blühen und duften länger (...); durch die Pariser Straßen flanieren singende Nymphen und selbst Apollo hält sich dort mit den Musen auf./

Das Gedicht Trediakovskij steht unter starkem Einfluß zeitgenossischer französischer anakreontischer Lyrik unc Pastoraldichtung (2). Selbst die letzten zeilen, die ein Bekenntnis des Dichters an diese Stadt sind, die er selbst erlebt hat, vermitteln in ihrer Formelhaftigkeit nur den Eindruck unreflektierter Begeisterung.

Krasnoe iresto! Dragoj bereg Senskij!

Kto tja ne ljubit? razve byl duch zverski!

$\lambda$ ja ne rogu nikogda zabyti,

Poka ineju zdes' na zemli byt1 (3).

/Herrlicher Platz! Teures Ufer der Selne!

wer liebt dich nicht? vielleicht ein wilder Geist!

ther ich kann es niemals vergessen,

solange ich auf der Erde verweile./

Denl Lobpreis auf Paris folgte zwanzig Jahre später eine 'russische Variante'. Trediakovskijs "Pochvala IŽerskoj

(1) Blagoj, D.D.: Istorija russkoj literatury XVIII veka, H. 1960; S. 126.

(2) Trediakovskij ubersetzte gleichzeitig Paul Tallements "Voyage á l'Isle d'Amour" ins Russische.

(3) Izbr. proizved.; S. 77. 
zemle 1 carstvujustemu gradu Sankpeterburgu" wurde anlabllch der 50. Jahrfeler der russischen Hauptstadt geschrieben.

Es 1st ein Lobgedicht auf die von Peter begründete Hauptstadt, die wie eln Splegelbild das weise Schaffen Peters darstellt, dessen zu kurzes Leben der Dichter beklagt (1).

Trediakovskif beginnt die "Pochvala" auf Ižerskaja zemlja, das Land an der Neva, und auf Petersburg ahn11 ch wie das Paris-Gedicht.

Prijatnyj bereg! Ljubeznaja strana! Gde svoj Neva potok stremit k pucine (2).

/Angenehmes Ufer! Liebenswildiges Land! Wo der Nevastrom seinen Lauf zur Meerestiefe nimmt. /

Auch hier steht am $\Lambda$ nfang elne aus der Rhetorlk bekannte 'exclamat10' (3), die den Versen den Anschein dichterischen Engagenents verleiht. Thre Redeutung erschrpft sich hingegen in einer traditionellen Trope. Nachdem in der zwelten zelle "ljubeznaja strana" durch die Nennung der Neva prăzislert wurde, weist Trediakovsk1f auf den ungeheuren Gegensatz hin, den die neue Hauptstadt und die fruheren topographischen Gegebenhe1ten bilden. Er henutzt hier die Formel - gde nrežde ... tam nyne -, die auch bel spateren Dichtungen zum festen

(1) Brinkmann, H.: Peter I. In der russischen Literatur, phil. Diss. Gießen 1963; S. 56.

(2) Trediakovskif, V.K.: Izbrannye prolzvedenie, M.-L. 1963; S. 179 .

(3) Siehe: Lausberg, H.: Flemente der literarischen Rhetor1k, Munchen 1967; S. 131. 
Bestandtell jener Schilderungen wird, die sich mit der Grüdung der stadt befassen (1).

Nach elner raumlich stilisierten Charakteristik von "Ižerskaja zemlja" und Hinwelsen auf die historische Bedeutung dieses Landstriches, stellt der Dichter die Verbindung zu Peter I., dem Grunder der stadt her.

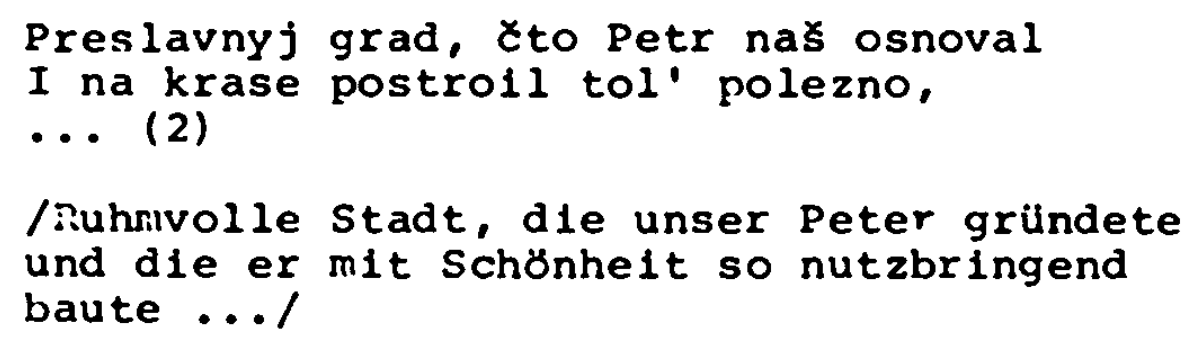

/ Suhrivolle stadt, die unser Peter gründete und die er mit Schönheit so nutzbringend baute ...l

Obwohl Petersburg erst funfilg Jahre besteht, kann sich die Stadt nach den Worten Trediakorskijs mit den westlichen lietropolen messen. Er nennt die Städe: London, Venedig, Rom, Paris und Mmsterdam (3). Bislang waren cilese großen Städte loffnung und ziel vieler Reisender. Bis jetzt lohnte es sich, sich an sie zu erinnern. Hunderbar hebt sich von ihnen das neue Petersburg ab:

ilo vam uzret', potomk1, v grade sem, Iz vsech tech stran sletajustichsja gusto, Smotrjascich vse, divjascichsja o vsem, Glasjastich: "Se raj stal, gde bylo pusto!"

/ Aber ihr Nachkommen werdet es noch erleben, ¿aB man aus allen Ländern dicht gedrängt in diese stadt herbeielit,

(1) Der unvorstellbare Gegensatz zwischen Natur und Stadt war ein Grund dafür, daB Petersburg zum Mythos wurde.

(2) Trediakovsk1j, Izbr. proizved.; S. 180.

(3) Der Dichter kannte diese Stadte aus eigener Erfahrung. Von 1726-1730 weilte er u.a. In Holland und Frankreich.

(4) Trediakovskij, Izbr. proizved.; S. 181. 
um alles anzusehen und sich uber alles zu wundern, und man wird sagen: "Hier 1st ein Paradies entstanden, wo Ode warl"/

Trediakovskif bezelchnet Petersburg als Paradies auf Erden, als ort der Schonhe1t und Unvergängl1chke1t. Das Gedicht kl1ngt mit elnem gebethaften SchluB aus:
ol bože, tvoj predel da sotvorit'. Da o Petre Rossil vsej v otradu, Svetilo dnja vpred' ravnogo ne zrit, Iz vsech gradov, vezde Petrovu gradu (1).
/O Gott, dein RatschluB mogge es fugen, daB, zur Freude des ganzen RuBland uber Peter, die Leuchte des Tages kunftig uberall unter allen städten kelne sleht, die der stadt Peters glelch wăre./

Indem in diesen zellen die stadt aus dem bisherigen engen geograph1schen und histor 1 schen Rahmen herausgelost wird, erfăhrt sie elne Uberhohung Ins Transzendente. Die Vorstellung vom "himmlischen Jerusalem" und der "ewigen Metropole" klingt hier an (2). Obwohl Tredlakovskif durch die Vermischung von Herrscher- und stadtelob formal der Tradition panegyrischer Dlchtungen treu geblieben war, sprechen zwel Grunde fur ein verăndertes "Petersburgbild". Elnmal stellt der Dichter die neue stadt Petersburg bewust den alten europä1schen Metropolen gegenüber und betont dadurch 1hre Elnzigartigke1t, zum anderen hebt er sie durch den Ge-

(1) Tredlakovskij, Izbr. prolzved.; S. 181.

(2) Das B1ld des himmilschen Jerusalem, aus der Offenbarung des Johannes. Kap. 21,10 klang auch schon in Ilarions Lobpre1s auf $\mathrm{K} 1 \mathrm{ev}$ an. In der I1teratur ist damit nicht nur der S1tz Gottes, sondern die Idealstadt schlechthin gemeint. 
danken an eln neues, küntiges zentrum von elnem zeitlich festgelegten Bedeutungshintergrund ab. Mit anderen Worten: Trediakovskif sieht Petersburg nicht mehr ausschl1eBl1ch als Werk Peters I., sondern fur thn ist sie eine stadt mit zukunft. Trotz allem bedeutet dieses Bild bel Trediakovskif noch nicht die Entdeckung eines individuelien Erlebnisfeldes in der stadt. Noch ist es nusdruck fur elne politische Anschauung, die allerdings zuge beginnenden Kosmopolitentums trăgt (1).

Der vielseltigste russische Dichter des 18.Jahrhunderts war ohne Zweifel M.V. L o m o n o s o v (1711-1765). Er wird vielfach als der eigentliche Dichter Peters I. bezelchnet, denn:

... es 1st wohl auch unter den Dichtern der zeit Elisabeths, oder auch besser des ganzen 18. und 19. Jahrhunderts, nlemand so sehr vom Geiste der petrinischen Reformen erfillt gewesen wie Lomonosov, und keiner hat das Band der Vergangenhelt stărker mit der Gegenwart verknupft als er (2).

In seinen panegyrischen Oden oder in seinem Poem "Petr Velikij" ist der Herrscher fur ihn "Stroitel', plavatel', $v$ poljach, v morjach geroj."/Baumelster, Seemann, Held auf den Feldern und auf den Meeren/ (3).

(1) Dieser Elndruck wird durch die Vorsteliung Trediakovskijs bewirkt, das Petersburg auch luber die Grenzen RuBlands hinaus zu wirken beginnt.

(2) Brinkmann, H.: Peter I. In der russischen Iiteratur, phil.Diss. GieBen 1963; S. 57 .

(3) Blagoj, D.D.: Istorija russkoj literatury XVIII veka, 4. Aufl. is. 1960; s. 160. 
Auch noch bel Lomonosov ist jede Darstellung der russischen Hauptstadt mit der Person des Gründers verbunden. Petersburg ist fur den Dichter eine akzeptable Grobe, die sich in seiner Dichtung als Mischung von Petrinischem Mythos und topographisch-geographischen Realien darstellt. Es wurde schon darauf hingewiesen, daß die panegyrischen Oden Trediakovskijs und Kantemirs eng mit den Regeln cier antiken Rhetorik verbuncien sind. In seinem "kratkoe rukovodstvo v krasnorečlju" (1748) stellt Lomonosov einige Normen auf, die bel der Beschre1bung lebloser Dinge (vesti) zu beachten sind.

Er nennt Folgendes: Beschreibung der Iage, Beschreibung des Ganzen und der Telle, sowie Beschreibung der Beschaffenhelt (1). Beispielhafte Textstellen wahlt Lomonosov aus den vichtungen Lucians, Ciceros und anderer antiker Autoren.

In $\$ 302$ dieser "Rhetorik" stellt der Verfasser fest:

Tak 1storik1, naprimer, kogda im o kakom gorode tol'ko umpomjanut' nužno, opisyvajut ego veličinu, znatnye Casty 1 tto drugoe, primezanija dostojnoe, libo upominajut o sluxivsichsja $v$ nem kakich znatnych dejstvijach, skazyvajut o lch sozdateljach 111 drugoe ¿to, tomu podobnoe (2).

/So beschreiben zum Beispiel Historiker, wenn uber eine stadt irgendetwas zu berichten 1st, ihre GroBe, bekannte Teile und anderes Benerkenswertes; oder sie erinnern sich an bekannte Vorkommisse, die sich in thr ereignet haben, sie erzahlen von ihren Gründern oder ahnlichem./

Diese 'Regeln' ergaben sich ebenfalls aus der Lekture römischer Klassiker.

(1) Lomonosov, M.V.: Polnoe sobranie sozinenij, $t$. VII, M. L. 1952; S. 348 (§ 288).

(2) Lomonosov, Polnoe sobr. soc., t. VII; s. 360 (\$ 302). 
In seiner Odendichtung ist Lomonosov überwiegend Panegyriker. Seine Verehrung für Peter I. uberträgt er verbal auch auf dessen Nachfolgerinnen, auf die Glanz der Petrinischen Taten fälit. Auch für Lomonosov gilt die Gründung Petersburgs noch als die bedeutendste Tat des groBen Herrschers. Wie sich schon bei Kantemir und Trediakovskij andeutete ist die stadt fur den Dichter hereits Ergebnis und die Leistung Peters muB nicht erst bewiesen werden. Folglich kann sich Lomonosov in seinen Oden verschiedenen Details zurenden.

Stellvertretend für die recht zahlreichen stadthilder seien hier nur einige genannt.

Wenn der Dichter in "Oda na pribytie eja velicestva... Elisavety Petrovny 12 loskvy $v$ Sanktpeterhurg 1742 goda po koronaci1"(1) schreiht: "Rreqa "levy rukam1 plescut" /Die Ufer der ileva klatschen mit den lländen/, dann steht hier "brega :Jevy" einral synonym für die newe llauptstadt. Gleichzeitia ibertrăt der Dichter aber ein biblisches Fild auf eine zeitọenrssische 'Erscheinung', aemeint ist das juhelnde und feiernde petershurg (2). Iomonosov "Ijubil izohrazat' Peterhurg $v$ dn l toržestv, korga ulicy perepoljujalis' narodom 1 temnoj noc'ju zaZigalis' jarkie fejerverk1 (3).". /Er liebte es, Petershurg̣ an Festtagen darzustellen, wenn die strapen bevkikert waren und in der dunklen Nacht helle Feuerwerke abgebrannt wurden./ Diese Feststellung des sovetischen Kommentators erweckt den Anschein, als zeichne Lomonosov ein annähernd realistisches Bild einer aktiven stadt. Gerade diese Bilder aber, das Motiv von "likovanie Peterburga" findet sich auch in anderen Oden, sind eng riit den Psalmendichtungen verhunden.

(1) Lomonosov, PSS, t. VIII; s. 82-102.

(2) Lorionosov, PSS, t. VIII; S. 82, V. 9. vergl. hierzu auch Isalm 96: "Die liasserströme frohlocken..." 
Die Stadt Petersburg lebt mit der Neva und wird zumindest in der stadtanlage von ihr beherrscht. Pereits Kantemir hatte in einer einfachen Formel auf das fur diese Stadt typische 'Panorama' an der Neva hingewiesen (1). Auch Lomonosov greift dieses Motiv auf:

V stenach vnezapno ukreplena

I zdanijami okružena

Somnennaja Neva rekla:

... (2)

/Durch Mauern unerwartet befestigt und von häusern umgeben sprach die zweifelnde lieva: ...l

oder:

V stenach Petrovych protekaet Polna vesel'ja tem lieva, Vencem, porfiroju blistaet, pokryta lavrami glava (3).

IIn Peters Mauern fliebt voller Froblichkelt dort die Neva, glanzt mit Krone und Purpur das mit Lorbeer bekränzte Haupt./

Die neue russische llauptstatd bleibt als Gesamthelt auch in den Oden Lomonosovs vage und schemenhaft. Tonograph1sche lennungen sinù der einzige Realitätshezug, während der vermittelte Eindruck eher einer Idealstadt entsprechen würde.

(1) vergl. Kantemir "Petrida". Die Neva ist bei den Dichtern des 18. Jahrhunderts der 'idyllische' Strom, wăhrend zu Beginn des 19. Jahrhunderts der FluB als Bedrohung erfaBt wird (Uberschwemmungen).

(2) "Oda na den" voš̌estvija ... Elisavety Petrovny 1747 goda". In: PSS, t.VIII, S. 200 .

(3) PSS, t. VIII, S. 224

'Oda na den' vošsestvija... 1748 groda zogler-9783954793303 
Neben diesen wenig ergiebigen Passagen liefert Lomonosov die erste lăngere 'Prosa'-Beschrelbung Petersburgs. Sein "Slovo blagodarstvennoe eja Imperatorskomu vel1Cestvu na osvjaక̌cenle Akademil Chudožestv, Imenem eja govorennoe" (1764) ist vor allem im Vergleich mit späteren Darstellungen bemerkenswert (1).

Nach elner Art Zelebritatenkatalog der verschiedensten Kunste und nach Hinweisen auf die Notwendigkeit und Bedeutung einer Akademie weist Lomonosov auf die ideale Einfugung des neuen Gebaudes in seine naturliche Umgebung hin.

Nakonec, rassuždaja mesto sego učreždenıja, vozmožnoll predstavit' drugoe pristojnee 1 udobnee sego velikago 1 prekrasnago goroda vo vsem Rossijskom gosudarstve. Vopervych, primečaja sostojanie sego mesta, nachodim, čto pol'zuemsja velikim dobrochotstvom natury ...(2)

/Schlieblich, wenn man den Platz dieser Institution beurteilt, dann kann man sich kaum einen schicklicheren und geeigneteren im ganzen Russischen Relch, als diesen der großen und herrlichen Stadt vorstellen. Erstens, die Beschaffenheit dieses Platzes betrachtend, finden wir, daß er sich des großen Wohlwollens der Natur bedient ..../

Die naturlichen Bedingungen der Stadt, "rovnaja 1 niskaja zemlja"/ebenes und niedriges Land/, schildert Lomonosov als von solcher Art, daB "chotja net zdes' natural'nych vozvyłenij, no zdanija ogromnyja vmesto 1 ch voschodjat (3)." /obwohl es hler keine natürlichen Erhebungen gibt, treten die gewaltigen Gebaude an ihre stelle./

(1) Lomonosov, PSS, t. VIII; $s .807-816$.

(2) Lomonosov, PSS, t. VIII; s. 811.

(3) Lomonosov, PSS, t. VIII; S. 812. 
Lomonosov hebt hier die Grobenverhaltnisse in der neuen Stadt hervor. Die Lage Petersburgs im flachen Land läbt die Dimensionen der Paläste noch pragnanter hervortreten. Fur die Ausweltung der stadt in den Raum sprechen die bebauten FluBufer.

Rasprostertyja rjadom po glavnym beregam nevskim 1 men' 31 ch protokov gosudarstvennyja 1 obyvatel'skija palaty ... (1)

/Indem sich an den hauptufern der Neva und der kleineren Verbindungskanăle Staats- und zivilgebăude erstrecken ..../

Die hier noch fehlende Raumtiefe, die durch eine flächige Aneinanderreihung einzelner objekte ersetzt wurde, wird wenig spater durch eine Art Turmblick vermittelt. Lomonosov wahlt zwei Bilder, die elnen der firklichkelt adăquaten Elndruck beinhalten. Er nennt hier die Hauser der Stadt, die auf dem Wasser zu schwimmen scheinen und deren Anordnung mit einer militärischen Formation zu vergleichen 1st. In diesen beiden Metaphern 1st perspektivisches Sehen abstrahiert.

Vzojdet kto na vysokoe zdanie, uvidit, krugom osmatrivaja, jakoby plavajustija na vodach domy 1 tokmo razdelennyja prjamymi linejam1, kak by polk1, postavlennyja urjadnymi strojami (2).

/Wer auf ein hohes Gebaude steigt, der sleht, wenn er ringsum blickt, gleichsam die Hauser auf dem wasser schwimmen und nur geteilt durch gerade Linien, wie Regimenter in Reih und Glied./

Lomonosov begnligt sich zwar bel seiner Schau uber die Stadt mit Andeutungen, benutzt aber bereits eine mogliche Art der Stadtbeschrelbung, die im 19. Jahrhundert sehr bellebt wurde: das Erfassen einer stadt durch den Bllck von oben. 
Noch 1841 schreibt 2.B. J.G. Kohl in seinem "Petersburg in Blldern und Skizzen":

6 3. Da die Stadt sich nirgends vor dem Auge erhebt, so ist es in Petersburg mehr als Irgendwo notig und mehr als Irgendwo hier lohnend, das der Beschauer sich uber sie erhebe, um eine Aussicht zu gewinnen und des mächtigen Bildes Herr zu werden (1).

Mit der Nennung der Kirchen findet Lomonosov auch erstmals die Möglichkeit, das neue "Petropol'" mit der alten Hauptstadt Moskau zu vergleichen. Er steht damit gleichsam am Anfang der s1ch noch entwickelnden literarischen Thematik: der Rivalitat zwischen den beiden stadten Moskau und Petersburg.

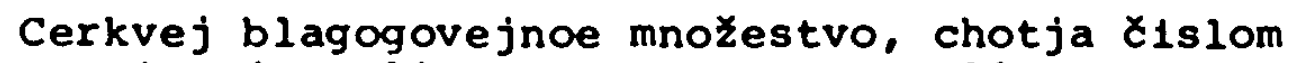
starinnoj stolice ustupaet Petropol', no krasotoju prevoschod1t. Ona drevnostiju blagorodnee, sej novost1ju కtastlivee, Cudnee skorym vozrascentem, osnovatelem preslavnee (2).

IIn der Menge ehrwürdiger K1rchen ist Petersburg zwar zahlenmäBlg der alten Hauptstadt unterlegen, aber mit deren Schonhe1t wird Moskau ubertroffen. Jenes (i.e. Moskau) ist ehrwurdiger durch das Alter, dieses (1.e. Petersburg) ist in seiner Neuheit glucklicher, wunderbarer durch schnelles Wachstum, ruhmvoller durch seinen Grunder./

Bei Lomonosov klingt die vor allem im 19. Jahrhundert thematislerte Elfersucht zwischen der alten und der neuen Hauptstadt erst an. In der Gegenuberstellung "blagorodnee" und "novostiju stastlivee" liegt aber

(1) Kohl, J.G.: Petersburg in Bildern und Skizzen, Dresden-Le1pz1g 1841 ; S. 3 .

(2) Lomonosov, PSS, t. VIII; s. 813. Mit Lomonosov und Sumarokov wurde es ublich, fur Petersburg das grobere "Petropol" zu gebrauchen. Vergl. metropolis, das bel den Griechen "Mutterstadt" Hauptstadt bedeutete. 
bereits eine Charakteristik der belden stădte: das "russischere", ehrwürdigere Moskau und das in seiner architektonischen Neuhe1t glänzende Petersburg. Daruber hinaus ist die stadt fur Lomonosov nicht mehr nur ein 'corpus', sondern sle 1st berelts Hintergrund fur 'Leben':

Ożivlenie sego prekrasnago mesta ot množestva raznych obyvatelej 1 gostej .... (1)

/Dieser herrliche Platz wird von zahlrelchen Bewohnern und Gasten belebt ..../

Die das stădische Leben charakterisierenden Elemente stehen enumerativ nebeneinander und zeigen dadurch die Mannigfaltigkeit des Ganzen.

Kupecestvo, pristan', uC1l1sCa, suchoputnoe vojsko, flot, sudebnyja mesta, posol'stva ... (2)

/Raufmannschaft, Anlegestelle, Lehranstalten, Landstreitkraft, Flotte, Gerlchtsort, Gesandtschaften .../

Lomonosov streift damit glelchzeltig die Bedeutung Petersburgs als llandels- und Reglerunngszentrum. Ir velteren Interessenfeld der stadt - aber wiederum nur punktuell angedeutet - stehen die "Lustorte" (Carskoe Selo) und die 'Beschäftigungen' der MüBlggănger.

Po vstuplen11 vesny vyezdy v uveselitel'nye domy, prichod korablej s dovol'stvifami, letanie po okrytym vodam sudami ... (3)

/Nach Anbruch des Frülings /erfreuen/ Ausfahrten zu den Lusthăusern, die Ankunft der Dampfer mit Versorgungsgutern, das Dahinellen der Barken über das offene wasser ..../

(1) Lomonosov, PSS, t. VIII; $S .813$.

(2) Lomonosov, PSS, t. VIII; $S .813$.

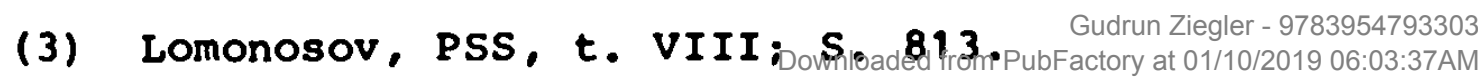


Der Expansion des topographischen Rahmens Uber die Stadtgrenzen hinaus - Carskoe Selo, Peterhof - glbt Lomonosov in der Einbezlehung jahreszeitlich bedingter Ereignisse elne zeitliche Parallele:

... no ne bez prijatel'nost1 sut' dva obyknovennyja v godu pozorista: skrytye 1 otverstie rek, obtekajusčlch 1 napajußżch grad sej, mnogich zritelej naberegi privlekajut (1).

/... und voller Freude sind geworhnlich zwe1 Schauspiele im Jahr, die viele Zuschauer an das Ufer locken: das Bedecken/Zufrieren/ und offnen der Flusse, die diese stadt durchflieben und sie bewässern./

In Lomonosovs "Slovo blagodarstvenno" liegt die erste ausführliche Beschrelbung Petersburgs vor. Rückbllckend läBt sich erkennen, daB das Neue nicht nur in einer detallilerten Schllderung liegt. Zwar ist die Bindung an traditionelle panegyrische Dichtung noch vorhander, doch wird der bisher bekannte abstrakte und nur als Summe uberlieferter Topol und Metaphern bestehende "GroBstadtbegriff" partiell erweltert. So bedeutet z.B. die Elnführung des dynamischen Elements (Ablauf der Jahreszelten, Erwahnung der Bevolkerung und der Gäste, Vergnügungen ....) den Ansatz zu elnem neuen Stadtbild, cas sich von der reinen Optik lobst und individuelle Formen annimmt.

Innerhalb der Beschrelbung Petersburgs hatte Lomonoscv die ehemalige Hauptstadt Moskau als "blagorodnaja" bezelchnet; $1754 \mathrm{schrleb}$ er in seiner "Oda na rozdenle ... Pavla Petrovica sentj. 20, 1754 goda" :

Moskva, stoja v sredine vsech, Glavu, velikimi stenami Venčannu, vavodit $k$ vysote, Kak kedr mez nizkimi drevami Prečudna v drevnej krasote (2). 
/Moskau, in der Mitte von allen stehend, mit hohen Mauern von Ruppein gekront, strebt empor, wie eine zeder unter niedrigen Bămen, luberaus wunderbar in alter schonhe1t./

Moskau, Mittelpunkt der russischen stadte, überragt diese mit hohen Mauern und Kuppeln wie eine zeder. Diese Attribute lassen sich im Topos "kamennaja Moskva" wle er aus den verschledenen Volksdichtungen bekannt wurde, zusammenfassen. In "prexudna $v$ drevnej krasote" / Uberaus wunderbar In alter schonhelt/ ist berelts jene zeltliche Distanz Intendiert, welche die alte Hauptstadt als Ergebnis eines historischen Prozesses sieht (1). Moskau bildet auch den historischen Hintergrund $f$ ur Lomonosovs unvollendet gebliebenes Poem "Petr Velikij" (1760/61).

V poeme "Petr Velikij" povestvujetsja o vnutrennich 1 vnesnich sobytijach russkoj istoril: Pervoe 12 nich vosstanie strel'cov ... (2)

/Im Poem "Peter der Grobe" werden Innere und ăuBere Erelgnisse der russischen Geschichte ber1chtet: das erste 1st der Strelizen Aufstand ..../

Die Ereignisse im Jahre 1697 und 1698 in Moskau geben dem Dichter kelnen AnlaB, die stadt in den Vordergund zu rücken. Dies entspricht den 'Regeln' des Genres (3). Stadttore, der Kreml, Häuser und StraBen werden zwar genannt, aber nicht plastisch geformt. Ihre Bedeutung liegt elnmal darin, die dargesteliten Ereignisse durch einen realen Hintergrund glaubhaft $2 u$ machen. Zum anderen sollen auch solche formelhaften Wendungen wie: "Trănen- und Blutströme

(1) Vor allem in der Literatur des 19. Jahrhunderts wird Moskau dann zum Handlungshintergrund, wenn historische Erelgnisse erzahlt werden.

(2) Sokolov, A.N.: Ocerk1 po 1stor11 russkoj poèmy XVIII 1 pervoj poloviny XIX veka, M. 1955; S. 112 .

(3) Sujetbestimmend ist fur das Poem (allgemein) der

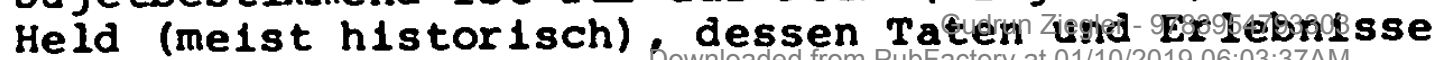
dargestelit werden sol len. via free access 
ergossen sich vom Kreml aus durch die Stadt" / ... 1 slez 1 krovi tok po gradu 12 Kremlja razsypalsja (1)/ einer Intensivierung der Vorgänge dienen.

In den Odendichtungen, die formal nach antiken Vorbildern gestaltet waren und bel denen sich Stoff und sprache der Gattung völlig unterordneten, konnte eln Thema wie die stadt nur als 'Bild' elne Rolle spielen (2). Dieses 1st als Summe figuraler Aufzahlungen selbst noch nicht stoffgestaltend. An der Verwendung bereits konventionalisierter Sprachbilder läBt sich die Abhängigkeit der Dichter von der literarischen Tradition ablesen (3). Daruber hinaus spricht der jewellige 'Einsatz' Moskaus und Petersburgs, vorwiegend in panegyrischen Dichtungen, für eine enge Bindung der Autoren an das Herrscherhaus.

Auch A.P. S u m a $r \circ k \circ v$ (1717-1777) steht wie seine Vorgänger und Zeitgenossen noch ganz im Bann der Persönlichke1t Peters I. Diesem Herrscher und den an seinem Ruhm partizipierenden Nachfolgern widmet er zahlreiche Oden und "nadpisi".

Selne "Oda goracianskaja", die anläßlich der Geburt Petr Fedorovits (1754) geschrieben wurde, vermittelt die schon aus anderen Dichtungen bekannte synonyme Behandlung von Neva und Petersburg (4).

(1) Lomonosov, PSS, t. VIII; $s .519$.

(2) Bild 1st hier im Sinne der aus der Malerel bekannten Vedute gebraucht, d.h.: eindringliche Zusammenordnung der unverwechselbaren Merkmale einer stadt.

Es geht hierbel nicht um topographische Authentizitat, sondern um Markierung und Uberhohung des Typischen.

(3) "Konventionalisierte Sprachbilder" meinen hier Metaphern und auch Topol, dle aus früheren Dichtungen bereits bekannt sind.

(4) z.B. Trediakovskijs "Pochvala Ižerskoj zemle ..." 
Sumarokov beginnt:

Skazl svoe vesel'e, Neva, ty mne, tto stalosja za stastie sef strane (1)?

/Nenne du mir Neva delne Freude, was fur ein Gluck ist in dieses Land gekommen?/

In den folgenden Strophen besingt der Dichter die Taten des Herrscherhauses, wobel vor allem Peter I. als vorbild11ch dargestellt wird. In Strophe 10 erbittet er Wachstum fur das, was peter I. In der neuen stadt begonnen hat.

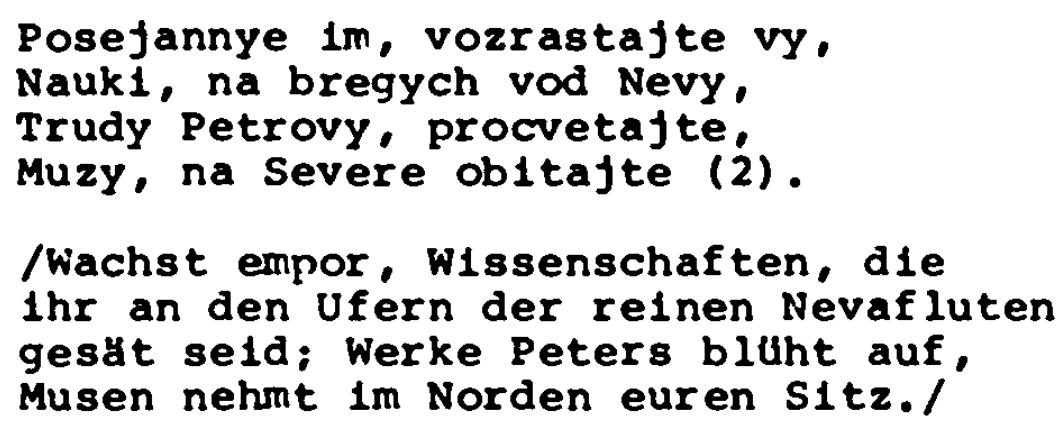

Diese zellen können stellvertretend fur das Petersburgb1ld Sumarokovs stehen. In lelcht abgewandelter Form findet man ahnliche Passagen auch in seinen spateren Dichtungen ( 3 ).

Eine enge persbnliche Bindung hatte Sumarokov zu Moskau. Wesentlich hăufiger als seine zeltgenossen berücksichtigt er die alte Hauptstadt in seinen Werken. Zusammenfassend sel hier gesagt: Moskau 1st fur den Autor vor allem "pervoprestol'nyj grad"/d.h. die alte Hauptstadt/, die Geburtsstadt Peters / k kotorem mudryj Petr rožden/ und der

(1) Sumarokov, A.P.: Izbrannye prolzveden1ja, L. 1957; S. 100 .

(2) Sumarokov, Izbr. proizved.; S. 101.

(3) Dies gilt vor allem fur die Oden auf Elisabeth II. 
Ort der zarenkrönungen/gde rosskie odnes' monarch1 vzlagajut na glavu venec,...(1)/.

In "Oda Grigor'ju Aleksandrovicu Potemkinu 1774 goda" ubertraggt Sumarokov den als "likovanie Peterburga" bekannten Topos auf Moskau (2).

Uzrit Moskva Ekaterinu,

Strui moskovskich rek viygrajut,

Voskl1knut radostno brega,

Put1 usteleljutsja cvetami,

Ogni toržestvenny zažgutsja

I plesk proniknet oblaka (3).

Moskau erblickt Katharina, die Wellen der Moskauer Flüsse hüpfen vor Freude, freudig rufen die Ufer einander $z u$, die Wege werden mit Blumen bedeckt, festliche Feuer werden entzundet und das Belfallklatschen errelcht die Wolken./

Hier zeigt sich die Abstraktion der einzelnen Bildelemente besonders deutlich. S1e sind aus dem Kontext lobsbar und fügen sich nahtlos zu einem neuen Bild zusammen (4).

Trotz Konventionalitat in seinen Odendichtungen ist Sumarokov vor allem in seinen satiren originell. Die Satire bietet ihrer Bestimmung nach eine Verzerrung und Umkehrung der wirklichke1t. Für die stadtliteratur offnet sich hier ein weites Feld den Darstellungen, die

(1) Vergl. "Oda Grigor'ju A. Potemkinu" (1774) und "Pis'mo ko knjazju Aleksandru M1chajlovicu Golicynu" (ca. 177o).

(2) Vergl. Lomonosovs "Ode auf die Ankunft Elisabeth Petrovnas aus Moskau in Petersburg, 1742".

(3) Sumarokov, Izbr. proizved.; S. 81.

(4) Es handelt sich auch hier um biblische Topol. 
vor allem gesellschaftliche Erschelnungen skizzieren und karrikieren wollen.

Eine Beschreibung dessen, was man im russischen wort "byt" zusammenfassen kann, oder als Milleu und Lokalkolorlt bezelchnet, bietet sich in der Satire geradezu an. Bel Sumarokov, und auch noch bel Novikov und krylov, handelt es sich hier allerdings nicht um eine simultanschau sozlaler zustande, wie die sovetische Forschung gern behauptet. Es sind vielmehr Detalls, belachenswerte Modeerscheinungen, die in den fruhen Satiren einen verzerrten 'Elndruck' städtischer Gesellschaft anzudeuten beginnen. Die belden groben Städte, Moskau "als das grobte Dorf Im Zarenrelch" und "Piter" lieferten hierzu uber Jahrzehnte literarischen Gesprăchsstoff (1).

Das vor allem im 19. Jahrhundert bellebte Motiv einer Gegenuberstellung des Moskauer- und Petersburger Theaterpublikums findet sich schon bel Sumarokov (2). In dem Dialog "pilt 1 drug ego", der zwischen 1770 und 1774 entstand, vermittelt der Dichter folgende Charakteristik: das Publikum von Petersburg zeigt Geschmack und ist dem Neuen aufgeschlossen, wahrend das Interesse der Moskauer am und 1hr Verhalten im Theater "abscheul1ch" /gnusnyj/ 1st. Uber diesen Kontrast, dem eln verallgeme1nerndes Denken zugrunde llegt, reflektiert noch Gogol' in seinen "Peterburgskie zap1sk1, 1836". Sumarokov schreibt zu diesem Thema:

V Petropole on I /dramy/ vsemu narodu vkusny, A zdes' 1 gorodu 1 mne podobno gnusny: Tam s"edutsja dija nich vnimati 1 molcat'.

(1) "Moskau das grobte Dorf", slehe: Hingley, R.: Von Puschkin bis Tolstoj, eine Literatursoz1ologie, München 1967; S. 166 und Benjamin, W.: Stadteb1lder, Frankfurt/M. $1963 ;$ S. 24 .

"Piter". wie die Hauptstadt vertraulich genannt wurde, ist die Abkürzung der holländ1schen Form: P1 terburch.

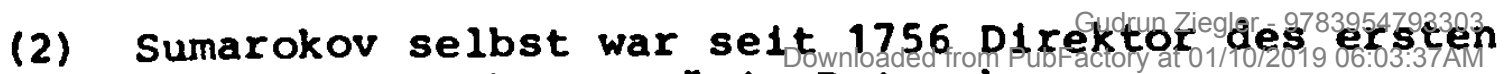


A zdes' orech1 gryzt', sumet1 1 kricat', Blagopristojnost1 ne dopuskaja $v$ modu, ... (1)

In Petropol schmecken sie /a1e Dramen/ dem ganzen Volk, Aber hier sind sle sowohl der Stadt als auch mir widerwartig:
Dort versammelt man sich aufmerksam und schwelgend,

Aber hier knackt man Nüsse, lärmt und schreit, Wohlanständigkeit ist noch nicht in Mode, ...l

Mit den beiden städten wird hier pauschal eln unterschiedich sich verhaltendes Publikum ldentifiziert, wobel die Reaktionen der zuschauer auf einfachste gegensatzliche AuBerungen reduzlert sind. Sumarokov deutet in dieser Passage des Dialogs eine der Moglichkeiten an, die das 'Wesen' der Stadt erfassen. Das bedeutet h1er: uber den Ansatz elnes Genrebildes wird typisches Verhalten der Moskauer oder der Petersburger Bewohner in einer speziellen Situation hervorgehoben (2).

Die Vlelseitigkeit Sumarokovs zelgt sich in einem "tcpographischen Rätsel", das 1774 als "Pis'mo ko prijatelju v Moskvu" geschrieben wurde (3). In verschlüsselter Form wird hier die nachste Umgebung des Dichters in Petersburg dargestellt. Es helBt zum Beispiel:

$S$ zaborom o zabor,

$V$ kotorom Żtel'stvo imeet senator,

(1) Sumarokov, Izbr. proizved.; S. 186-187.

(2) Bereits vor Sumarokov hatte V.I. Lukin in seiner "Brief an El'Caninov" uber die Eroffnung des "Allgemelnen Volkstheaters" in Petersburg berichtet und eine Typengalerle des Publikums vorgefuhrt. Vergl. hierzu: Gesemann, W.: Die Entdeckung der unteren Volkssch1chten durch die russ1sche I1teratur, Wiesbaden 1972; S. 74.

(3) Sumarokov, Izbr. pro1zved.; S. 304-305. 
Nauk1 koemu, chudožestva ljubezny;

On vedaet, oni dlfa obstestva polezny.

-...

On sdelal u sebja $v$ Petropole Parnas (1).

/ aun an Zaun mit einem Senator,

der die Wissenschaften und künste liebt;

er weib, dab sle für die Gesellschaft nütz-

$11 \mathrm{ch}$ sind.



Sumarokov spricht hier eine typische zelterscheinung an. Bere1ts in der 2. Halfte des 18. Jahrhunderts waren die literarischen Salons in Petersburg zum Treffpunkt der ge1st1g aufgeschlossenen 'Gesellschaft' geworden. Daruber hinaus hatten diese krelse noch eine andere wesentliche Aufgabe ubernommen: sie bildeten elnmal das notwendige 'Gegengewicht' zum llof, zum anderen waren sie 'Räume' gegen Langeweile und :Melancholie (2). Diese Funktionen sind aus sumarokovs zeilen noch nicht abzulesen. Für inn ist lediglich von Bedeutung, daB Petersburg $2 u$ einer Stadt der Musen werde. Diesen Wunsch außert er mehrfach direkt in seinen Dichtungen, z.B.:

Zelaj, ¿tob na bregach sich muzy obltali, Kotorych vod strui Petrom preslavny stali. Oktavij Tibr voznes, 1 Sejnu - Ludovik (3).

/ iulnsche, das die Musen an den Ufern heimisch werden, deren wasserfluten durch Peter beruhrit wurden, Oktavius hat den Tiber erhbht, die Seine aber Ludwig./

(1) Sumarokov, Izbr. proizved.; S. 305.

(2) Vergl. hierzu die ausfürliche Darstellung: Lepenies, $W_{\text {.: }}$ Melancholie und Gesellschaft, Frankfurt/:1. 1972 .

(3) Sumarokov, Izbr. protzved.; S. 130. 
Grobe Bedeutung erlangte Sumarokov vor allem als Dramaturg und als Autor verschiedener Tragodien. Diese sind streng nach den Regeln des Klass1z1smus aufgebaut, das helbt sie berulcksichtigen konsequent die Elnhelt von Ort, zeit und Handlung. Die russische klassizistische Tragodie zeigt eine besondere Vorliebe für historische Themen, v.a. Stoffe aus der elgenen Geschichte (1). In diesem zusammenhang bietet sich Moskau als die ehemalige Hauptstadt für den Handlungshintergrund an. Die Rolle, die eine Stadt Innerhalb elnes Dramas spielen kann, ist sehr begrenzt. Einmal kann sie als Raumausschnitt, etwa Platze, Hauselngănge, Hofe mittels Kulissen optisch zugăngl1ch machen. Zum anderen kann z.B. Moskau in 'verbaler Form' durch die handelnden Personen reproduziert werden und somit Reflexionen und persornliches Engagement der Helden ausdrücken.

In Sumarokovs "Dmitrij Samozvanec" (1771), dessen Handlung Im Kreml spielt, wird die stadt Moskau von Ksenija und Georgif unmittelbar angesprochen. Die Ausdruckskraft des Gesagten liegt 1r: Metaphorischen und vor allem in der zum symbol gewordenen stadt.

o ty pecal'nyj Kreml', stal nyne ty svidetel'. Cto dnes' nizverženna s prestola dobrodetel'. Tomjascajas' Moskva v unynil drożit. Blaženstvo $v$ goresti iz sten eja bežlt. Dni svetly kažutsja gustoj temjane noక̌l, Prekrasny vkrug Moskvy pokryty mrakom roši (2).

/O du traur1ger Kreml, du wurdest heute Zeuge, dab heute die Tugend vom Thron gesturzt wurde. Indem Moskau vor Mutlosigke1t zitterte, ellt die Gluckseligkeit vor Kummer aus seinen Mauern. Die lichten Tage scheinen wie dichte dunkle Nacht, die herrlichen Haine un Moskau sind mit Dunkelheit bedeckt./

(1) Die Tragodien der deutschen und franzosischen Klassik bevorzugen antike stoffe.

(2) Sumarokov, Izbr. proizved.; S. 438. 
Wenn Rsenija in Gedanken abschlednehmend verschiedene Platze der Erinnerung besucht, dann gestalten slch auch diese nicht zu elner konkreten Form.

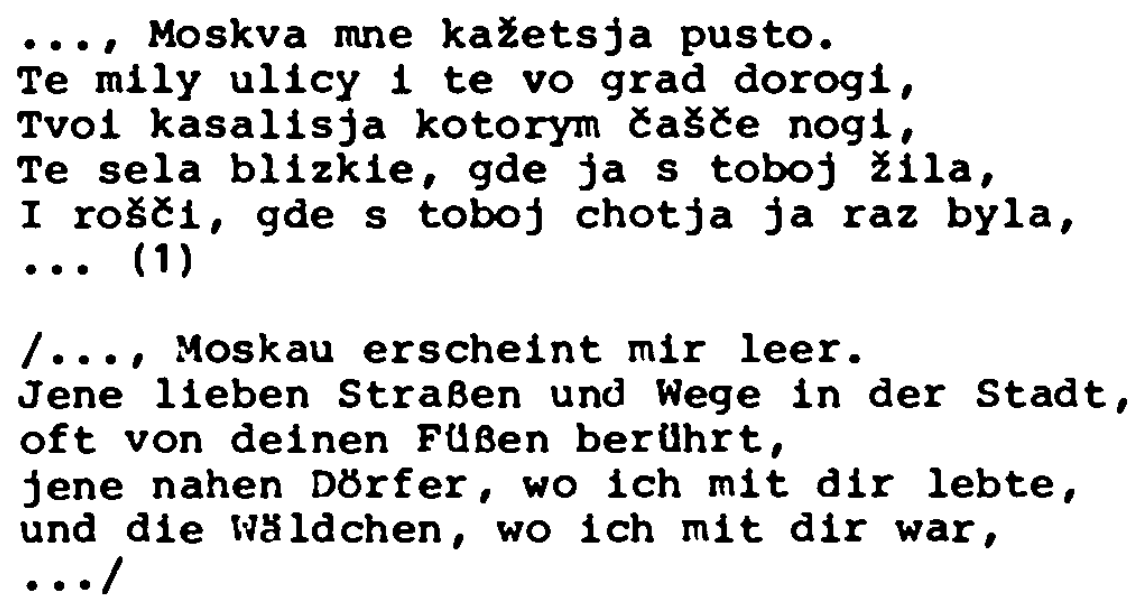

Fur Ksenija bleibt die stadt am Rande, wăhrend sich mit der dorflich-ländlichen Umgebung Moskaus persinnliche Empfindungen verbinden.

Georgif spricht in seinem Monolog von der Auswirkung tyrannischen lierrschertums auf das Volk. Hierbei wird Moskau mit dem 'unterdrückten' russischen Staat gleichgesetzt. In Fragen an die zukunft zeichnet er nicht nur ein visionăres Idealbild, sondern stellt indirekt die fur inn gegenwärtigen zustănde dar.

Uvižu l', solnce, ja tebja nad zdešnym gradom Narodu sčastlivu svetjašce $v$ vysote, LuCi puskajuše vo prežnej krasote?

Voplešcut li opjat', Igraja, zdešnij vody?

İbavitsja 1 ' sej grad besstudija 1 sramov,

I vozblistajut 11 verchi zlatye chramov (2)?

/ iverde ich dich, o Sonne, wieder uber dieser Stadt sehen, dem glücklichen Volk in der Hơhe glänzend, Strahlen aussendend in fruherer Schornheit? Ob wieder die hiesigen Wasser spielend plätschern werden? ... Ob in dieser Stadt, befreit von Schmach und Schande, wieder erglänzen werden die goldenen Kirchen?

(1) Sumarokov, Izbr. proizved.: S. 449. 
Auch wenn hier eine personliche Antellnahme am Schicksal der Stadt und ihrer Bewohner vorzuliegen scheint, bleiben die Reflexionen Georgijs in Denkschablonen verhaftet (1). Vor allem wird dies in seinem, den Monolog beschlleBenden Traumbild deutlich:

Vozn1k1 zdes' pokoj, vozlikovstvuj ljubov'

I budi stastlivych serdec uveselen'em!

$\Lambda$ ty Moskva, a ty bud' rajskim nam selen'em!

/Es herrsche hier Ruhe, die Liebe frohlocke und wecke die glücklichen Herzen mit Vergnügen! Und du Moskau, sei du uns paradiesische Wohnung!/

Damit hat Sumarokov die dramatischen Mrglichkeiten einer Elnbeziehung des Handlungshintergrundes in die Vorgänge ausgeschöpft. Sprachlich wird er gleichsam auf ein Minimum herabgesetzt und in einer fast volligen Reduktion auf den Begriff neuen Reflexionen freigegeben. Im Werk Sumarokovs haben sich bereits die formalen Möglichkeiten angedeutet, die in zukunft, d.h. im ausgehenden 18. Jahrhundert und vor allem im 19. Zahrhundert, die literarische Rezeption der stadt bestimmen. Abgesehen von den panegyrischen Oden, die mit Deržavin zu ihrer letzten großen Form gelangen, ist es zunächst die Satire mit ihren Möglichkeiten gesel:schaftlicher Karlkatur, die sich des "Stadtstoffes" ledient.

(1) Auch Sumarokov verwendet hier die schon bekanntex Topo1: Jubelnde Flüsse; Paradies auf Erden; Im Glanz der Sonne erstrahlende Stadt.

(2) Sumarokov, Izbr. prolzved.; S. 454. 
III. Moskau und Petersburg in der russischen Literatur der 2. Half te des 18 . Jahrhunderts

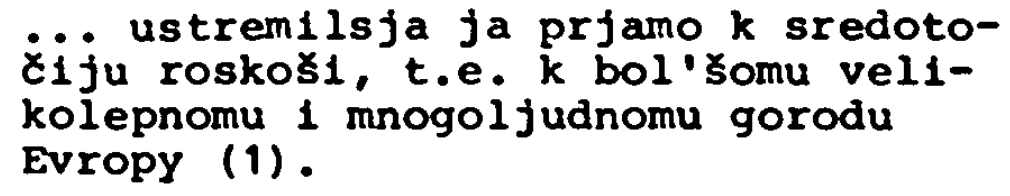

Kak chorosa Moskva belokamennaja!

Die Epoche Katharinas II. (1762-1796) gilt als repräsentativ für den "aufgeklärten Absolutismus" (3). Als die Herrscherin 1782 Peter I. das berümt gewordene Denkmal setzen lieB, wollte sie sich vor allem als wahrerin und "prodolzatel'nica"/Fortsetzerin/ der Petrinischen Ideen gesehen wissen. Unter Ihrer Herrschaft wurden in elnem zeltraum "von gut zwanzig Jahren uber zwelhundert Städte" gegründet,

well sie sich hatte Uherzeugen lassen, $d a B$ RuBland ein Burgertum brauche, das bis dahin noch nicht bestand, und vor allem, weil sie die Verwaltungskontrolle über ihr weitverzweigtes Land stärken wollte (4).

So entstanden die meisten russischen Städte auf den Verwaltungswege. Tatsächlich hatte sich etwa hundert Jahre nach thren :1aßnahmen ein Bürgertum gebildet, das sich aber in vielen Dingen von der westlichen Bourgeoisie unterschied.

(1) Krylov, I.A.: Potta duchov. In: Polnoe sobr. sot., t. II, SPb. 1904; S. 364 .

(2) Karamzin, N.M.: Natal'ja, bojarskaja dox'. In: Izbr. sot., t. II, M.-L. 1964; S. 627 .

(3) Stช̌k1, G.: Russische Geschichte, Stuttgart 1962; S. 399 .

(4) Hingley, R.: Von Puschkin bis Tolstoj, München 1967; S. 174 . 
Die architektonische Umgestaltung Moskaus und der Ausbau der neuen Hauptstadt wurde unter Katharina neu organisiert.

Razvitie architektury Peterburga $v$ epochu klassicizma slo pod rukovodstvom centralizovannych organizacif, kotorye zanimalis' rassmotreniem proektov planirovki 1 zastrojki goroda. $v$ vtoroj polovine XVIII veka eto by la "Komissija o kamennom stroenie Sankt-Peterburga 1 Moskvy" (1).

/Die Entwicklung der Architektur Petersburgs wurde in der Epoche des Klassizismus unter der Leitung zentraler Organisationen durchgefuhrt, die sich mit der Prufung von Planungs- und Bauprojekten der stadt befasten. In der 2. Halfte des 18. Jahrhunderts ubernahm dies die "Komission zum Steinbau SanktPetersburgs und Moskaus"./

Das Interesse Katharinas an "1hren" Stadten fand auch in einem Erlas von 1763 seinen Ausdruck, der die "Anfertigung von Spezialplänen sämtlicher städte, threr Bebauung und Straben, fur jedes Gouvernement gesondert" betraf (2).

(1) Architekturnyj putevoditel' po Leningradu, L. 1971; S. 12 .

(2) Bunin, A.W.: Geschichte des russischen stădebaus b1s zum 19. Jahrhundert, Berlin 1961; S. 97.

Selt dieser Verordnung Katharinas, vereinzelt auch schon fruher, erschienen zahlrelche Stadtfuhrer und Beschre1bungen der HauptstraBen mit ihren Poststationen. Ein gesteigertes Interesse an solchen Materialien hatte die gegen Ende des 18. Jahrhunderts populare Reiseliteratur. Stellvertretend fur die topographisch-statistischen Beschreibungen, die in der Arbeit nicht naher berucksichtigt werden kơnnen, selen hler genannt:

1753 Plan stol1Cnago goroda Sanktpeterburga s 1zobraženiem znatnejక1ch onago prospektov. SPb.

1762 Op1san1e dorog1 ot Sanktpeterburga do Moskvy. SPb.

1778 Rosp1s' moskovsk1ch cerkvejl sobornych, monastyrsk1ch, ružnych ... vnutr 1 vne carstvujužego grada sostojastich. M.

1779 Bogdanov, A.I.: IstorlCeskoe, geograf1Ceskoe 1 topograflceskoe opisanle Sanktpeterburga, ot naxala zavedenija ego. SPb. 
1769 wurde der neue Bebauungsplan Petersburgs, 1775 das Projekt der Ungestaltung Moskaus vorgelegt. Aus dem Jahre 1780 stammt die "Urkunde uber die Rechte und Privileglen der Städte des Russischen Relches". Vor allem der Adel und die Kaufmannschaft wurden hierdurch zur stadtischen Selbstverwaltung zugelassen. Dieser Versuch "auch die stätische Bevolkerung als geschlossenen stand zu konstituleren, entbehrte der sozialen Voraussetzungen (1)."

Mit der răumlichen Ausdehnung und Umgestaltung der belden russischen Großstädte war notwendigerweise auch eine Veränderung der gesellschaftlichen Struktur verbunden. Es fehlte aber den städten noch an politischem Selbstbehauptungswillen. Hinzu kommt das Fehlen dessen, was die moderne stadtforschung als "Duophänomen offentlichkelt - Privatheit" (2) bezelchnet, aus deren Begegnungen und Gegensäzen heraus die stadt lebt. Im Petersburg des 18. Jahrhunderts splelte sich diese Kommunikation zumindest bel entscheidenden Fragen - wie Blldung und Verwaltung - auf hochster Ebene ab, und alles, was zum Beispiel fur die Blldung geschah, stand Im "Zelchen des Staatsnutzens" und war vorwlegend Privileg des Adels (3). Die Reglerungszelt Katharinas war von den Ideen der Aufklärung bestimmt. Das helBt vor allem Forderung der Wissenschaften und der Literatur, Orientierung an und Ubernahme von westlichen Vorbildern Im Sinne Peters I. Als folgerlchtige Entwicklung bildete sich, je nach dem Stand menschlicher "Aufgeklarthelt", elne gezlelte Krit1k. An thr spiegelt sich die Elnsichtnahme in politische und gesellschaft 11 che Unzulănglichke1ten.

(1) St8k1, G.: Russ1sche Gesch1chte; S. 407.

(2) Hamme 1, P.: Unsere Zukunft die Stadt; S. 88.

(3) Stbkl, G.: Russ1sche Gesch1chte; S. 427. 
Literarische Moglichke1ten fur krit1sche Auberungen waren vor allem: Satire (in Vers und Prosa), Kombdien und die sehr einflubrelchen satirisch-kritischen Journale, die sich in der zwelten Hälfe des 18. Jahrhunderts rasch vermehrten (1).

In Sumarokovs satirischen Eplsteln klang schon eine ze1tkritik an, in den Zeitschriften Novikovs "Truten" und "Z1vop1sec" und der "Potta duchov" Krylovs fand sie in der prosa eine neue Darstellungsform. Die sovetische Forschung sleht in den Journalen Novikovs und Krylovs Belspiele für den "prosvetitel'skij realizm."

V prosvet1tel'skom reallzme peremenilos' samoe znaCenle satıriCeskoe lzobraženija dejstvitel'nosti. Iz "Žanrovogo" burlesknogo "komizma" satıra stanovitsja polnopravnym, daže veduscim vidom 1skusstva ... Tak, v pervuju ocered' dlja prosvet1tel'skogo realizma charakterno pojavlenie prozy, prozaiceskich žanrov: žurnal'nogo fel'etona, satiričeskich oðerkov, putešestvij, nravoopisatel'nych romanov vospi$\tan 1 j a(2)$.

/Im "aufklärerischen Realismus" ändert sich die elçentliche satirische Bedeutung der Wirklichkeitsdarstellung. Aus der "genrehaften" burlesken "Komik" entwickelte sich die Satire als vollberechtigte, ja sogar führende Gattung der kunst... So ist in erster Linle fur den aufklärer1schen Realismus das Erscheinen der Prosa, der Prosa-Genres charakterist1sch: das Prosa-Feuilieton, die satirischen Skizzen, Re1sen, sitten-beschreibende Romane und Erziehungsromane./

Die Bezelchnung "aufklärerischer Real1smus" erscheint fur den Fall durchaus gerechtfertigt, der den Begriff "Realismus" von unseren heutigen Vorstellungen lost. Dies muB vor allem belm satirischen Genre beachtet wercen,

(1) Den realen Dingen hatten sich, gemäB der Dreitellurg des literarischen Stils, vor allem die Kombdie und Satire zu widmen.

(2) Razvit1e real1zma v russkoj literature M. 1970; S. 70 . 
denn es handelt sich hier nicht un eine wirklichkeitsnahe, sondern verzerrte Darstellung. Die in der Satire Intendierte Kritik kann auf diesem Wege zur Befreiung des Dichters und des Publikums von gesellschaftlichen und politischen zwängen fuhren. El ne neue Bezelchnung. wie "emanzipatorischer Realismus" ware demnach dann angebracht, wenn das $21 e l$ des Autors (Abs1cht) und seine Wirkung erkannt sind.

Eine der bedeutendsten Personlichkeiten des fruhen russ1schen Journalismus war N.J. N O V 1 K O v. Als er 1769 seine satirische zeltschrift "Truten" herausgab, antwortete er damit unmittelbar auf eine Aktion Katharinas. Diese hatte mit der "Vsjakaja vsjacina" selbst die Redaktion elnes Journals übernormen und auch elgene Aufsătze veroffentlicht. Dem ausgesprochen politischen Charakter ihres Journals begegnete Novikov mit "Truten'". In fingierten Leserzuschriften, sprachlichen Imitationen der zu verspottenden Krelse und Parodien auf bestimmte gesellschaftliche Auswilchse, zelchnet Novikov ein karikaturistisches Bild seiner zeitgenossen in der Grobstadt und auf dem Land (1).

I vse Že, kogda $v$ ego Zurnal'nych l1stkach 1 det re`' - petimetrach 1 ఈxegolichach, o pridvornych tinach. vsjakogo roda prevoschoditel'stvach, o Xinovnikach... netrudno ponjat', ¿to rec' 1det imenno o Peterburge o byte 1 nravach dvorjanskogo peterburgskogo obscestua (2).

(1) Nach Stender-Petersen war die in manchen Epistein nachgeahmte einfache, den St11 des Landadels dokumentierende Sprache so täuschend, daB sie von einigen Lesern fur echt gehalten wurde. Stender-Petersen, A.: Geschichte der russischen Literatur, Bd. 1, München 1957; S. 426.

(2) Literaturnye pamjatnye mesta Leningrada, L. 1968; S. 42 . 
/Trotz allem, wenn in selnen Journalbeltragen die Rede von Modedamen, Hofrängen, jede Art von Exzellenzen, Beamten 1st .... dann 1st es nicht schwer zu begreifen, daB gerade von Petersburg gesprochen wird, vom Milieu und den sitten der adilgen Petersburger Gesellschaft./

Beisplelhaft selen hier zitiert: Nachrichten luber die Abrelse von Taschensplelern und Intriganten nach Moskau (1): der Brief elner jungen Dame an den Herausgeber, in dem sie thre Entwlcklung zur "modnaja scegolicha" - dank der Hilfe einer Franzosin - schildert und um Rat in Liebesfragen bittet (2).

Das Journal "Zivopisec", se1t 1772 nach der Elnstellung des "Truten" von Novikov herausgegeben, arbeltete ebenfalls mit den Mitteln der Satire und Karikatur. In der Aufmerksamke1t, die vor allem dem elnfaltigen, am Alten hängenden Gutsbesitzertum galt, 1st sekundar auch die stadtkultur angesprochen. Als exemplarisch fur diese Aussage können die "P1s'ma k Falaleju" gelten, In denen ein Gutsbesitzer seinen in Petersburg lebenden Sohn zu uberreden versucht, den staatsdienst aufzugeben, auf das vaterl1che Gut zurückzukehren und sich zu verheiraten.

Prlezžaj, drug moj Falalejuska, priezzaj boga radi poskoree ... TY sam vidis', tto tebe doma zit' budet vesele peterburgskogo ... (3)

/Komm, meln Freund Falalejuska, komm, um Gottes willen bald ... Du wirst selbst sehen, daB du zu Hause frohlicher leben wirst als in Petersburg .../

Das gleichze1tig geăuBerte Interesse dieses Vertreters des Landadels an dem Geschehen in der Hauptstadt er-

(1) N.I. Novikov 1 ego sovremenn1k1, M. $1961 ;$ S: 45.

(2) N.I. Nov1kov 1 ego sovremenn1k1, M. 1961; S. 70.

(3) Russkaja proza XVIII veka, M. 197duar S. 12789954793303 
schbpft $81 \mathrm{ch}$ in nalven Fragen, wie etwa:

Otp1s1. Falalejułka, cto u vas v P1tere delaetsja, skazyvajut, cto velikie zate1: kolokol'nju strojat 1 chotjat sdelat' vyłe Ivana Velikogo ....(1)

/Schrelbe, Falalej, was man bel euch in Piter macht, erzahlt, dab man neue Einfalle hat: ob man elnen Glockenturm baut, der grober als der Ivan Velikif sein wird ...?

Novikov vermittelt kein optisch greifbares stadtbild. mit straffen Konturen und Sehenswirdigkeiten als topographischen Fixpunkten. Das in selnen Journalen dargestellte Modell der stadt $18 t$ satirisch 'verzerrt' und grelft somit liber elne răumliche Begrenzung hinaus. Gesch1ldert werden gesellschaftliche Extreme und Kuriositaten, adliger und burgerlicher Eskapismus (2) . Der 11terarischen Uberformung zeltgen 68 sischer Verhaltensweisen liegt zumindest auf der Selte des Dichters die Einsicht zugrunde, dab das Individuum nicht nur leicht beeinflubbar ist, sondern auch in seinem Nachahmungstrieb gern die 'Vorb1lder' kritiklos uberstelgert. Novikov stellt die Tatsachen dar, ohne nach den Ursachen zu fragen. In der Satire fand er eine wirksame Waffe der Aufklärung gegen die extrem "aufgekläre" Gesellschaft. Dab in den satirischen Werken, und das nicht nur bel Novikov, die Konstellation Stadt - Land zum Ausdruck kommt, spricht fur eine reale Entwicklung. Nicht nur die stadte sind ein fruchtbarer Boden fur alle Neuerungen und Verănderungen, sondern auch der Landadel versucht hier nachahmend Schritt zu halten (3).

(1) Russkaja proza XVIII veka, M. 1971; S. 115.

(2) Als 'Formen' der Exzentrizitat bilden sich in der 2. Half te des 18. Jahrhunderts: Dandy und Flaneur; zu Beginn des 19. Jahrhunderts: die Boheme.

(3) Es b1ldet $81 \mathrm{ch}$ in der Literatur das Motiv "pereezd v Peterburg", das die Ankunft b1ldurigshighgriger Landadliger in der Hauptstadt meint. 
Novikovs Journale, sowle die 1789 erschienene "Potta duchov" Krylovs, legten den Grund

fur elne Haltung, die zu den wesentlichen Kennzelchen der russischen Literatur gehort und deren Hauptmerkmal die stete Bereitschaft 1st, die russische Wirklichkeit kritisch zu Uberwachen, ihre Werte und Institutionen anzuzweifeln, ihre Fassaden und Kulissen zu durchschauen (1).

Ähnlich wie in "Truten" und "Zivopisec" gewinnt das Bild Petersburgs in einer Karikatur seiner Gesellschaft an Gestalt. Hinter dem 'exot1schen' Kolorit der "Poxta duchov" (1789), das I.A. K r y 1 o v durch die wahl mythologischer Figuren gestaltet, verbirat sich folgender Plan:

S odnoj storony, $v$ pis'mach gnomov zora 1 Buristcna opisany $v$ satiriceski-oblilitel'nom aspekte sovremennye nravy stolicy, razvrascennost' 1 licemerie vyş̌ego obక̌̌estva, soclal'naja nespravedlivost' 1 urodstvo vsego stroja (2).

/Auf der einen seite werden in den Briefen der Gnome zora und Buriston in satirisch-entlarvender Art die zeitgenossischen sitten der Hauptstact beschrieben, Ausschwelfungen und Heuchele1 der hoheren Gesellschaft, die soziale Ungerechtigkeit und Misgestalt dieser Ordnung./

Obwohl die "Pocta duchov" monatilch in einzelnen Bancchen erschienen, blieb die Einheitlichkeit des Sujets gewahrt. Zum Inhalt ist hier andeutungswelse zu sager:

(1) Braun, M.: Der Kampf un die Wirklichkeit in der russischen I1teratur, Gottingen 1958; S. 19.

(2) Razvitie realizma v russkoj literature, $t . I$, M. $1972 ; S .75-76$. 
Die Guttin Proserpina, die Frau Plutons, Herrscherin des Totenreiches, will nach einem Aufenthalt auf der Erde den Hades wieder beleben. Einer der Hadesgeister, Zora, wird auf die Erde gesch1ckt, um Schnelder, Friseure und Handler mit Galanteriewaren in den Hades zu bringen. Gleichzeltig wurde der Gnon Buriston auserwăhlt, auf der Erde nach neuen unbestechlichen Richtern fur die Totenwelt zu suchen. Die Korrespondentenberichte dieser be1den Geister beschreiben Ihre Erlebnisse auf der Erde, vor allem in der russischen Hauptstadt.

In elnem Brief zoras helBt es:

... ustremilsja ja prjamo k sredotodiju roskori. t.e. $k$ bol'somu velikolepnomu 1 mnogoljudnomu gorodu Evropy (1).

/Ich begab mich geradewegs zum Mittelpunkt der Pracht, das heist zur prachtvollsten und volkrelchsten Stadt Europas./

Obwohl der Name Petersburg nicht genannt wird, verrat slch die stadt durch thre verschiedenen, von den zeltgenossen als typisch erkannten Phănomene. Zora halt sich in Gasthăusern auf, macht die Bekanntschaft mit Schneidern und Haarkünstlern, begegnet Kartensplelern und MüBIggăngern. Modeneuheiten werden ebenso geschildert, wie "aktuelle" Ilebesaffaren. Theaterauffuhrungen und das Angebot in Buchladen. An vielen Stellen wird deutlich. daB das von Krylov beabsichtigte fiktive satirische Erzuhlen von einer typisierenden, zeitnahen Schilderung durchbrochen wird. Der Dichter selbst 1st zu sehr städer, als daß er die szenen, die seinen unmittelbaren Lebensberelch betreffen, als unbetelligter AuBenselter schildern konnte.

wahrend bel Novikov in der Darstellung des AuBergew chen die satire vorherrscht, fugen sich die bel Krylov

(1) Krylov, I.A.: PSS, t.II, SPb. 1904; S. 364. 
geschilderten Detalls zu elner Gesamtschau städtischen Lebens, zu elnem Petersburger 'sittenspiegel' bzw. einer Moralsatire.

Ein Jahr nach Krylovs "Potta duchov" erschien R a d 1 s c e v s "PuteSestvie 12 Peterburga v Moskvu". Die Interpretationsversuche dieses Werkes reichen von der Bewertung als "erste russische sentimentale Reise" bis hin zum politischen Pamphlet und zur zornigen Predigt (1). In unserem Zusammenhang liegt die Bedeutung Radiscevs in dem, was er nicht sagt. Petersburg und Moskau sind Ausgang und Ende einer Relse, deren Verlauf, d.h. die Reiseroute ebenso nebensächlich war wie die beiden Endpunkte. Der Leser erfahrt nichts von der Hauptstadt - weder Rückblick noch Panorama. Die stadt ist als raumliches Gebilde uninteressant und der Vorgang der Ausfahrt läBt sich in dem " $v$ neskol'ko minut ja byl uze za gorodom (2) N/In wenigen Minuten war ich schon aus der Stadt/ auf ein M1nimum komprimieren. Mit der Ankunft in Sofija liegt die Hauptstadt hereits 22 Werst hinter dem Reisenden und auch von der Ankunft in Moskau wird der Leser nur durch die Zeilen unterrichtet: " ... Vot uže Vsesvjatskoe! ... Moskva! Moskva! (3)"/Da ist schon Vsesvjatskoe! ... Moskau! Moskau !/

Im Vorwort hatte Radišev die Intention des "Putesestvie" angesprochen:

Ja vzgljanul okrest menja - dusa moja stradan1jami Celovecestva ujazvienna stala. Obratil vzory moi vo vnutrennost' moju - 1 uzrel, Cto bedstvija Celoveka proischodjat ot Celoveka, 1 Často ot togo tol'ko, tto on vilraet neprjamo na okruzastie ego predmety (4).

(1) Razvitie realizma v russkoj literature, t.I, :1. 1972; S. $85 \mathrm{f}$.

(2) Rad1కðev, A.N.: Putesestvie 12 Peterburga v Moskvu, L. 1969 ; S. 20.

(3) Radišev, Puteకestvie

(4) Radí̌tev, Puteక̌stvie ...; S. 19. via free access 
/Ich schaute auf meine Ungebung - meine seele wurde durch das Leid der Menschhelt verwundet. Ich wandte melnen Blick in mein Inneres und $s$ ah, daB das Elend des Menschen durch den Menschen kommt, und dies oft nur aus dem Grunde, weil er nicht genau auf die thn umgebenden Dinge achtet./

Das ethnographische, historische und geographische Materlal wird durch lyrische Abschweifungen und vor allem durch solche Passagen unterbrochen, die das Gedankengut der zelt wiedergeben. Elne der Rousseauschen Ideen: daB mit dem Fortschreiten der Kultur eln Verfall der sitten elnhergehe, wird von Radistev aufgenommen und auf die russischen zustände ubertragen. Dabel stellt er zwar soziale Ungleichheiten fest, hinterfragt aber nicht die natürlichen Blndungen der Individuen. Auch wenn Radišev nicht in extenso von den beiden großen russischen stadten spricht, kann aus seiner Grundhaltung und aus den in seiner "Reise" berücksichtigten Themen sein Engagement gegenüber der stadtkultur aufgedeckt werden. Dabel kann man nicht elnfach schließen, daß in dem Interesse an der ländlichen Bevölkerung elne Abkehr von der GroBstadt nach dem Motto "zurück zur Natur" enthalten 1st. Wesentlich 1st wohl die Intention, $d a \beta$ a $u$ h die ländiche Idylle vom Verfall bedroht sein könnte, der von den "Bchausungen der Tiger" ausgeht.

Ne v"edu nikoli $v$ sie zilisce tigrov. Edinoe ich veselie - gryzt' drug druga; otrada 1ch - tomit' slabogo do izdychanija 1 rabolepstvovat' vlasti (1).

/Niemals werde $1 \mathrm{ch}$ in ciese Behausungen der Tiger einkehren. Ihre einzige Freude ist, elnander zu qualien, ihre Erquickung, den Schwachen bis zum Tode zu plagen und der Macht knechtisch ergeben zu sein./

Wie Rousseau entschled er sich für die landliche Lebensweise. Dadurch weist Radistev auf die Fragwürdgkeit der zivili- 
sation hin, die in der stadtkultur einen Hohepunkt gefunden hat. Inwlewelt eigene Erfahrungen in sein Verhaltnis zur stadt eingegangen sind oder lediglich eine Rezeption fremden Gedankenguts stattfand, ist nicht $2 u$ klären. Insgesamt wird die literarische Darstellung auf eine gedankliche Schablone reduziert (1).

Neben den Journalen und Radiševs 'revolutionărer' Reise, in denen die Kritik der Aufgeklărten an der Aufklärung selbst zum Ausdruck kommt, steht am ausgehenden 18. Jahrhundert die Lyrik G.R. D e $r$ a $v i n s$ (1743-1816). Er schrieb zwar noch ganz im sinne der klassizistischen Panegyriker, loste sich jedoch formal und sprachlich von den strengen Aufbauprinzipien der Oden.

$V$ poèzil Deržavina pered Citatelem razvertyvaetsja real'nyj vestnyj mir vo vsej ego Cuvstvennoj nagljadnost1, osjazatel'nosti, oscutimosti, v obil11 krasok, zuukov, tonov, prelivov (2).

In der Poesie Derzavins wird vor dem Leser die reale Dinowelt in all ihrer sinnlichen Anschaulichkeit, Greifbarkeit, Fühlbarkeit im Reichtum der Farben, Klänge, Tơne, Nuancen ausgebreitet./

Die Thenen, die Derzavin in seiner Lyrik behandelt, sind so vielgestaltig, daB man Blagojs Behauptung "Deržavin risuet iskljucitel'no jarkie kartiny byta époch1" (3) /Verzavin zelchnet ausnahrslos lebhafte Bilder des hesens seiner zeit/ zustiımen kann. Es ist ein liebenswürdiges Fild der Ze1t, dargestellt in Felertagen und Festlichkeiten, begrüßenswerten Nachbarn, ländllchen Vergnligungen u.a.m.

(1) Die im gleichen lierk geschilderte Situation der Leibeigenen gab der $\mathrm{zar}$ in den Anlaß, Radiocev zum Tode $z u$ verurteilen bzw. später zu 10 Jahren Verbannung zu begnadigen.

(2) "kartiny byta" würde dem aus der Malerei bekannten Genrebild entsprechen.

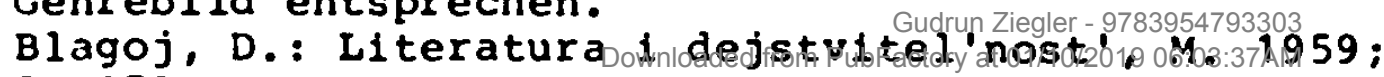
S. 173 . 
In "Videnie Murzy" (1783/84) schildert Deržavin das nächtliche Petersburg. Am Anfang des Gedichtes steht ein "mondbeschienenes Interieur".

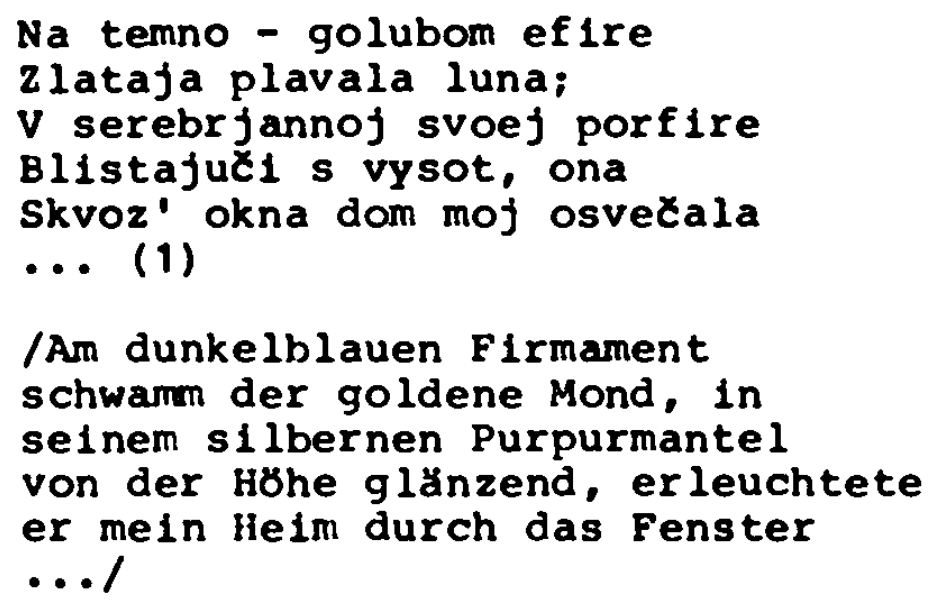

/Am dunkelblauen Firmament schwarm der goldene Mond, in seinem silbernen Purpurmantel von der Hohe glänzend, erleuchtete er mein lieim durch das Fenster ...l

Dem Interieur als ort der Innerlichkeit wird - verbunden durch ein răumliches "vokrug" - die AuBenwelt entgegengesetzt.

Vokrug vse oblast' notivala, Petropol' s bašnjami dremal, Neva iz urny Cut' mel'kala, Cut' Bel't $v$ bregach svolch sverkal;

... (2)

/Der ganze Umkreis schlief, Petropol mit den Türmen trăunte, die Neva blinkte kaum aus ihrer 'Urne' hervor, der belt glänzte ein wenis an seinen Ufern; ...l

Mit sparsamsten Mitteln gibt Deržavin einen intensiven Eindruck von der "mondbeleuchteten" hauptstadt wieder. Neva und Belt sind hier nicht nur realitätsverbundene georgraphische Fakten, sondern sie sind Elemente des Bildes, das Petropol inmitten der nordlichen Landschaft darstellt (3).

(1) Deržavin, G.R.: Stichotvorenija, L. 1957; S. 109.

(2) Deržavin, G.R.: Stichotvorenija, L. 1957; S. 109.

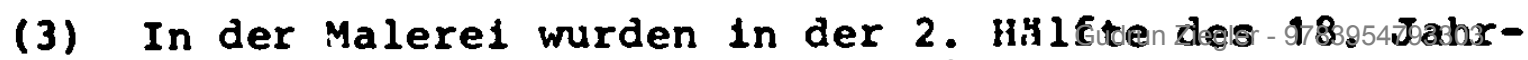

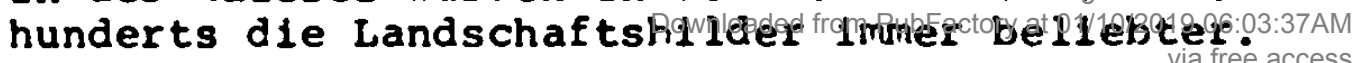


In dem im Jahre 1810 geschriebenen Gedicht "Sestie po Volchovu rossijskoj Amfitry" heibt es:

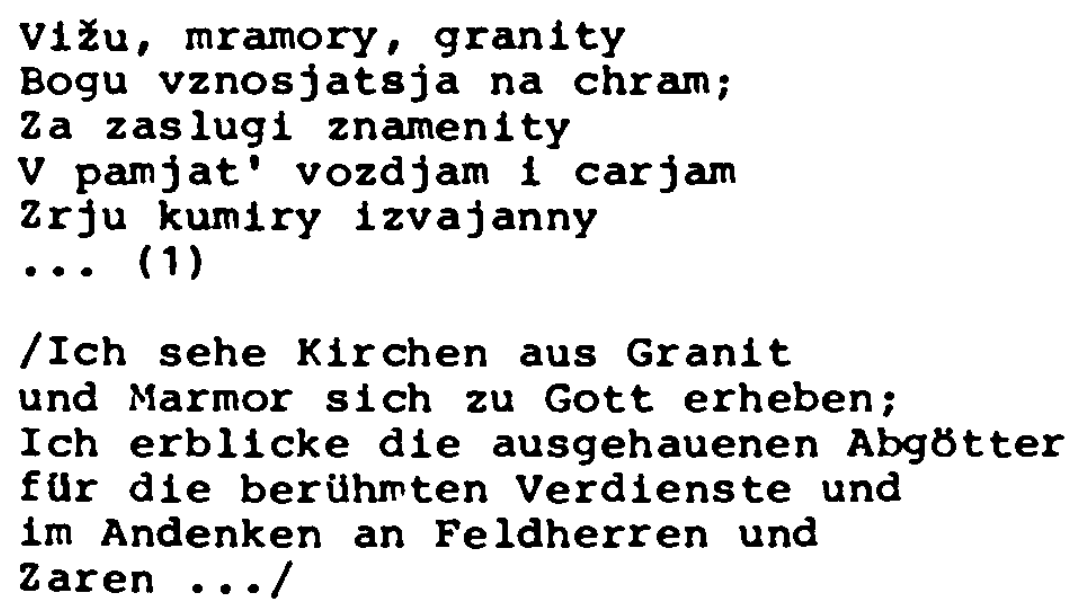

/Ich sehe Kirchen aus Granit und Marmor sich zu Gott erheben; Ich erblicke die ausgehauenen Abgotter fur die berühmten verdienste und im Andenken an Feldherren und zaren .... I

Deržavin beschreibt hier im Blick auf die Stadt - vom FluB her - ein Panorama, das nicht mit detalllierter Schilderung beelndruckt, sondern durch Akzentsetzung verschiedene typische Merkmale hervortreten labt: Türme, Kirchen, der in Stein gefaBte FluB, der den wald zuruckdrăngt (2). Die Hauptstadt RuBlands mit ihren monumentalen Formen, die vor allem noch Lomonosov und Sumarokov beeindruckten, ist bel Derzavin nur noch sekundăr das steingewordene Symbol für Peter I. An die Stelle einer abgeschlossenen 'Festung' tritt die Stadt in der Landschaft. Carskoe Selo und verschiedenen Gärten widmet Deržavin zahlreiche 'Spaziergänge' in Gedichtform. In der Beschreibung der ldyllischen Petersburger Ungebung liegt indirekt eine Verklärung der Stadt und persönliches Empfinden. Diese Vorstellungen von Petersburg sind geprägt von einer uberaus positiven Einstellung des Dichters zur Hauptstadt und ihrer landschaftlichen Umgebung. Kinnliches, d.h. die Gleichsetzung der großen stadt mit einem 'locus amoenus' war zwar auch schon

(1) Deržavin, G.R.: Soð̌inenija, t. III, SPb. 1864; S. 39 .

(2) Diese Anordnung ist charakteristisch fur die aus der Malerei bekannten Veduten. 
bei Trediakovskij nachzuweisen. Derzavin bedeutet jedoch eine wesentliche 'Weiterentwicklung'. Durch die Mischung von "hohem" und "nlederem" stil erhalten selne Bilder eine Lebendigkeit, die in den starren durch aneinandergereihte Topol 'gestalteten' klassizistischen Oden vollig fehlte. Auf diese Welse kann sich in den Bildern Derzavins der Gegensatz und das Nebenelnander von Subjekt und objekt auflosen.

Mit dem Erscheinen der sentimentalen Erzählungen Karamzins tritt die Erzählung als eigene Gattung in das Gattungssystem der russischen Literatur ein (1).

Von den Erzăhlungen N.M. $K$ a $r$ a m z 1 n $s$ (1766-1826) hatte vor allem "Bednaja L1za" die grobte liirkung auf das zeitgencssische Lesepublikum. Durch die Verbffentlichung der Erzăhlung 1791 im "lyoskovskij zurnal" konnten breite Kreise, wenn auch uberwiecend adlige, angesprochen werden. Das von Karamzin gestaltete Zusamsiensniel von Form, Inhalt, Sprache und 'psychologischer llandlungsführung' mußte diese Erzahlung als Novität anbleten, auch wenn ein rein privates Interesse an der 'sentinentalen Geschichte' sicher zunachst im Vordergrund stand.

Das Landmächen Liza wird von einem reichen adilgen Städter verführt. Er verspricht thr zunächst die Ehe, versucht dann aber sich ihr mit der nusrede zu entziehen, er trete in die $\lambda$ rmee ein. Inzwischen heiratet er (Erast) aus finanzielien Gründen elne relchc Erbin seines Standes. Bel einer zufälilgen Begegnung mit Liza in Moskau will er das Madchen mit Geld abfinden. Vor Schmach ertränkt sich Liza.

(1) Stadtke, K.: Die Entwicklung der russischen Erzahlung (1800-1825), Berlin 1971; S. 29. 
Karamzin beginnt seine Erzählung mit einer Beschreibung des Moskauer Panoramas. Vom Simonov Kloster aus bietet sich dem Dichter die stadt wie folgt dar:

Stoja na sej gore, vidis na pravoj storone potti vsju Moskvu, siju užasnuju gromadu domov 1 cerkvej, kotoraja predstavljaetsja glazam $v$ obraze velicestvennogo $a m$ f $i$ e a $t r$ a: velikolepnaja kartina, osoblivo kogda svetit na nee solnce, kogda vecernie luci ego pylajut na bescislennych krestach, k nebu voznosjastichsja! (1)

/Auf diesem Hügel stehend sieht man auf der rechten Selte fast ganz Moskau, diese schreckliche Masse von Häusern und Kirchen, die sich dem Auge in der Form eines majestatischen $A m p h i t h$ e $t e r s$ darbietet: ein groBartiges Bild, besonders wenn es von der Sonne beschienen wird, wenn ihre abendilchen Strahlen die unzählig̣en Kreuze entflammen lassen, die in den Himmel rag̣en./

Die Landschaft, in die Moskau eingebettet ist, weitet sich vor dem Betrachter wie ein Amphitheater, dessen angedeutete Weitläufigkeit durch seine architektonisch strenge Form begrenzt wird. Die $\mathrm{z}$ ahl der vergoldeten Kuppeln und Kreuze könnte in der Wiederholung des "besčislennyj" diese räumliche Einengung ebenso aufheben, wie "k nebu", würde nicht Karamzin gleichsam durch verschiedene Schnitte das Bild in Segmente zerlegen. Man gewinnt den Eindruck, der Dichter versuche seine Idealvorstellung eines Landschaftsgemäldes mit mehreren Fluchtpunkten in der Dichtung zu verwirklichen. Zunächst wird das "großartige" Bild vertikal geteilt: die Hăuser Moskaus und Kirchen bilden eine Fluchtlinie. Als darüber

(1) Karamzin, N.M.: Izbrannye socinenija, t.I, M. -L. 1964 ; S. 605 .

Puškin verwendet ein ähnliches Bild Im "Evgenij Onegin", Kapitel VII, Str. $36 / 37$. 
hinaus ragend werden die Kuppeln und Kreuze genannt. Der untere Teil des Bildes, der Vordergrund, wird durch folgende Einzelelemente "charakterisiert":

\begin{abstract}
Vnizu rasstilajutsja turnye, gusto-zelenye cvetustie luga, 1 za nimi, po Zeltym peskam, tecet svetlaja reka, volnuemaja legkimi vesiami rybac'ich lodok .... (1)

/Unten breiten sich fruchtbare, dunkelgrüne bluhende wiesen aus, und jenselts von ihnen fliest uber gelben Sand der helle Flus, bewegt von den leichten Rudern der Fischerboote ...l
\end{abstract}

Karamzin schildert seine Ideallandschaft vor den Toren iloskaus, in der auch "dubovaja roša" /Eichenhain/ und "molodye pastuchi" /junge schafer/ nicht fehlen (2). Diese Idylle wird durch topographische Nennungen unterbrochen, gleichsam als sollten die normalen 'Dimensionen' wieder hergestellt werden.

Podalee, $v$ gustoj zeleni drevnich vjazov, blistaet zlatoglavyj Danilov monastyr': esce dalee, pott 1 na kraju gorizonta, sinejutsja Vorob'evy gory ... ina levoj storone vidny obsirnye, chlebor: pokrytye polja, ... 1 vdali selo kolomenskoe s vysokim dvorconi svoim (3).

In der Ferne glänzt im dunklen Grün alter Ulmen das goldbedachte Danilov-Kloster; noch weiter, fast am Rand des llorizonts, schimriern blau cilc Sperlingsberge... nuf der linken Selte sind weite mit lieizen bedeckte Felder sichtbar....

(1) Karamzin, Izbr. proizved.. I.; S. 605.

(2) Karamzin war mit der westlichen Idyllendichtung vertraut. In der Moskauer Pension des deutschen Professors Schaden wurde er mit den Dichtunģen Gellerts bekannt und ubersetzte selbst nach Verlassen der Pension Verse Gessners ins Russische.

(3) Karamzin, Izbr. proizved.,I.;S. 606. 
und in der Ferne das Dorf Kolomenskoe mit seinem erhabenen Palast./

Durch die Elnbezlehung des Horizontes und durch die Raumworter "dalee", "podalee", "na gorizontu" wird Raumtiefe vermittelt und der Eindruck von der Stadt in der Landschaft verstărkt (1).

Die Stadt Moskau, vor deren Hintergrund die Erzahlung teilweise spielt, wird durch die Wahl des Panoramablicks, d.h. durch eine răumliche Distanz des Betrachters, zum Objekt. Karamzin hat diese 'Komposition' bewußt an den Anfang seiner Erzăhlung gestellt, denn sie bedeutet gleichsam die bildliche Vorwegnahme des nachfolgenden Konfliktes: Stadt-Land. Das Panorama Moskaus 1st auf die unverwechselbaren Merkmale der Stadt beschränkt: Hăuser, Kirchen, goldene kuppeln und unzăhlige Kreuze, wobel die toporgraphische Realität in diesem zusammenhang nicht betont werden muß. Karamzin steht hier ganz in der Tradition des "literarischen Rokoko" und der europalischen Idyllendichtung. Das für die Idylle bestimmende Ineinander von Nalvitat und Bewristsein spiegelt sich deutlich in Karamzins Bildern (2).

iitt der am. Beginn von "Bednaja Liza" geschilderten Landschaft ist eine Reflexion des Dichters uber die Schsnheit und Vergänglichkeit in Natur und Geschichte verbunden.

Vse sie obnovljaet $v$ moej pamjati istoriju našego otexestva - pexal'nuju istoriju tech vremen, kogda

(1) In der europäischen Malerel des ausgehenden 18.Jahrhunderts war die "Stadt in der Landschaft" ein sehr bellebtes Thema. Wie in der Beschreibung Karamzins werden dabei oft staffagefiguren in den Blldvordergrund gestellt.

(2) Die Ansicht Moskaus ist mit verschiedenen Stadtpanoramen aus Karamzins "Reisebrlefen" zu vergleichen, wie etwa: die Landschaft bei Dresden und MeiBen. 
svirepnye tatary 1 litovcy ognem 1 mexom opustorali okrestnost 1 rossijskoj stolicy 1 kogda nes Moskva, kak bezastitnaja vdovica, ot odnogo boga ozidala pomoži svoich bedstvijach (1).

/All dies erneuert in meinem Gedachtnis die Geschichte unseres Vaterlandes - die traurige Geschichte jener zeit, als die grimmigen Tataren und Litauer mit Feuer und Schwert die Umgebung der russischen Hauptstadt verwisteten und als das ungluckliche Moskau, wie eine schutzlose Witwe, von Gott Hilfe in ihrer Not erhoffte./

Dem dramatischen Geschehen liegt ein sozialer Konflikt zugrunde, der sich motivisch in die "Stadt-Landproblematik" einordnen labt. Hierbei zeigt sich der Vorbildcharakter Rousseaus. In seiner "Nouvelle Helo1se" (1761) war der standesunterschied zwischen saint Preux und Julie einer Ehe hinderlich. Karamzin thematisiert diesen Konflikt zwar auch, doch geht er noch einen Schritt weiter, Inder er den sozialen Unterschied mit der Idee Rousseaus vom Schaden der zivilisation verbindet. Erast ist der Vertreter seines zivilisierten Jahrhunderts, und es ist symptomatisch fur das Eewußtsein Karamzins, daB er die zivilisation mit der stadt, hier mit Moskau, gleichsetzt (2).

Der soziale Konflikt wird von der Vorstellung in den Hintergrund gedrăngt, daB alles Böse mit einem Verlust der sitten (Stadtkultur) einhergeht. Am Inde des aufge-

(1) Karamzin, Izbr. proizved.; S. 606 . Das Bild "iloskva - vdova" verwendet Puskin auch in "Mednyj vsadnik". Es ist anzunehmen, daB diese Redewendung entstand, nachdem die Residenz nach Petersburg verlegt wurde, wobei Moskau ohne den unittelbaren Schutz des zaren blieb.

(2) Saint preux und JuJie leben beide in ländlicher Umgebung, sind von den sitten der stadt unverdorben. Daruber hinaus stehen sie intellektuell auf gleicher stufe, so daB ihr 'Konflikt' tatsăchlich nur auf der sozialen Ungleichheit beruht. 
klärten 18. Jahrhunderts zeigt sich jedoch, daB das "Zurück zur Natur" Rousseaus mehr ist, als eine Variante des arkadischen Ideals (1). Karamzin deutet die Problematik erst an, die sich aus der Spannung zwischen Natur und Kultur ergab; erst im 19. Jahrhundert und seiner Dichtung wurde dieses Dilema bewuBt herausgestellt und $z u$ bewäligen versucht.

Seit es die Idylle gibt (seit der Antike), fallt auch der stacit ein gewisses Rollenspiel zu, das nicht unbecingt antithetisch sein ruß. Auch wenn Karamzin in seinen Dichtungen kontrastive Elesiente bevorzugt und seelischen Empfindungen in der Natur direkte Entsprechungen gibt (2), bleibt : loskau im hintergrund. Der Sysbolsielialt der Stadt als Ausgangspunkt des Bösen ist erst in der 'Lösung' des Konfliktes erkennbar. Liza und Erast sind in ihrem Sentiment so gleichartig, dab sie kaum als typisches Landmädchen bzw. als typischer städter eingestuft werden können. Ihr Denken ist zunächst ganz auf die Idy1le hin ausgerichtet. Vor diesem Vorstellungs- und Erlebnisinterọrund kommt es schließlich zum Konflikt, als Erast sich freiwlilig aus dieser Gefühlswelt löst (3). Iiza kann diesen Schritt nicht vollziehen, da sie in ihrer Naivität nur aus sich heraus, aus ihrem Gefühl lebt.

(1) Es zeigt sich hier das "Unbehagen in der Kultur". Von Rousseau wurde daraus die These entwickelt, "daB der Kulturmensch eine Degenerationserscheinung und die ganze historische Kultur ein Verrat an der ursprünglichen Bestimnung der Menschheit set."

Hauser, A.: Sozialgeschichte der kunst und Literatur, München 1967; S. 589 .

(2) Karamzin untermalt unter anderem folgende Ereignisse: dem Erwachen der Liebe entspricht ein Erwachen der Natur im Frühling, wăhrend nach der verführung ein Gewitter hereinbricht.

(3) Erasts Flucht hat vollig reale Gründe: wegen hoher Schulden ist eine reiche Erbin firdithn vortedibafter. 
Sie bewegt sich z.B. In der stadt so, als existiere diese nicht fur sie, wahrend ihr Aufenthalt in der Natur mit einem ganzen Katalog Idyllischer Topol und Metaphern beschrieben wird. Die 'katastrophale' Begegnung Lizas mit Erast, nachdem er sle verlassen hatte, findet in Moskau statt. Hier wird besonders deutlich, daB die stadt als 'Erlebnishintergrund' nicht in Frage kommt. Sie ist als Raum lediglich Rahmen und Staffage. Was am Beginn der Erzählung von Karamzin als ideales Ineinander - Stadt in der Natur - beschrieben wurde, erwelst sich am SchluB für Liza als unvorstelibares Nebeneinander. Obwohl Liza freiw1llig aus dem Leben scheldet, ist inr Tod nicht als Protest gegen die $\mathrm{z}$ vilisation, gegen die stadt, die ihren Erast genommen hat, zu sehen. Ihre Reaktion entspricht zwangslaufig threr Vorstellungswelt, ohne $d a \beta$ sle die Ursachen für die Zerstorung der Idylle begriffe.

Ebenfalls im "Moskovskij Zurnal" erschien 1792 Karamzins historische Erzăhlung "Natal'ja, bojarskaja doč".

Die Erzăhlung ist in einen Rahmen eingefügt, in dem die Erzahlprinzipien durch den Dichter ironisch hervorgehoben werden.

Natal'ja ist die Tochter des Bojaren Matvej, der als wichtiaster Berater des zaren elne bedeutende politische Machtstellung innehat. Nach einer Beschrelbung des Tagesablaufes der Heldin wirc berichtet, daB mit Einbruch des Frülings eine "unbestimmte Sehnsucht" in ihr erwacht. Natal'ja trifft bel einem Kirchgang Aleksej, in den sie sich verliebt. Nach heimlicher Flucht und Trauung sucht das Paar ein Versteck im Wald. Aleksejs Lebensgeschichte wird aufgedeckt und weist ihn als Sohn eines zu Unrecht verurteilten "Aufruhrers" aus. Natal'ja und Aleksej leben in bukolischer Einfachheit und Freude, bis ein Rrieg mit Litauen entbrennt. Nachdem Natal'ja sich als Mann verkleidet hat, zieht sie zusammen mit Aleksej in die Schlacht, 
um auf diese Weise beim $z$ aren Vergebung $z u$ erlangen. Der $z$ ar erhalt den Bericht uber den Sieg der Russen, den diese dem Eingreifen zweier unbekannter Ritter $z u$ verdanken haben. Die beiden Helden erscheinen, werden begnadigt und erhalten Vergebung vom Vater Natal'jas.

Wahrend die Fabel ganz dem Muster der sentimentalen Erzahlung gleicht, liegen ort und zeit des Geschehens in der Vergangenheit, "kogda russkie byl1 russkimi ...(1)" /als die Russen noch Russen waren/. Konkreter Bezugspunkt ist das "historische" Moskau und seine Umgebung. $\mathrm{Zu}$ diesen beiden zeitebenen (d.h. zeitgenઠssisches sujet im historischen Kleid) tritt als drittes Element der reflektierende Erzahler. Mit Hilfe der Ironie verbindet Karamzin diese verschiedenen Bereiche. Er gestaltet eine Erzăhlung, in der historische und sentimentale Elemente mit ironisch realen Beglaubigungen wechseln. In der Einleitung nimmt der Dichter stellung zu seinem Plan, indem er z.B. seine GroBeltern als Gewăhrspersonen für die Glaubwürdigkeit seiner Erzăhlung anfuhrt.

Kto iz nas ne ljubil tech vremen, kogda russkie by 11 russkimi, korda on $1 v$ sobstvennoe svoe plat'e narjalis', chodili svojeju pochodkoju,... ro krajnej mere ja ljublju sil vremena; .... (2)

/Wer von uns liebt nicht die zeiten, als die Russen noch Russen waren, als sie sich noch mit eigenen Kleidern schmückten, als sie noch ihren eigenen Tritt gingen, .... Venigstens ich liebe diese zeit;..../

Karamzin erwähnt in seiner Einleitung das Bild der erzăhlenden Großmutter: "i počti vsjakij vecer skazyvala

(1) Karamzin, Izbr.proizved., I;S. 622.

(2) Karamzin, Izbr.proizved.; I;S. 622. Der Erzahlanfang und der stil erinnern an die 'Novellen' Wielands. 
skazki carice N.N." /und fast jeden Abend erzahlte sie der Zarin N.N. Marchen/. Karamzin wăhlte fur den Beginn dieser Erzahlung den formelhaften Beginn, wie er aus der Volksdichtung bekannt ist:

$V$ prestol'nom grade slavnogo russkogo carstva, $\checkmark$ Moskve belokamennoj. $Z 11$ bojarin Matvej Andreev ... (1)

/In der Thronstadt des ruhmvollen russischen Reiches, Im weibsteinigen Moskau, lebte der Bojar Matvej Andreev ..../

lliermit beginnt die spielerische Handhabung wirklichkeitsbezogener und "phantastischer" Elemente. Die reale Ortsangabe - Moskva - am Beginn der Erzăhlung ist hier lediglich topographisches Zeichen. li1t dem nuftreten der Heldin rükt "belokamennaja Moskva" von dieser Funktion ab. In die Schilderung des Tagesablaufes Natal'jas ist eine Beschreibung Mloskaus eingefügt, die aus zwe 1 jahreszeltlich diverglerenden Bildern besteht. Der in "Bednaja Liza" vorgegebene Blick hin zur Stadt, ist hier zu einem Blick uber die stadt Moskau geworden (Turmblick). Der Hinweis auf einen zeitlichen und das Xußere des Raumes verandernden. Ablauf bedeutet im zusanmenhang mit der Heldin eine Charakteristik ihrer Persinnlichkeit. vile schon in "Bednaja LIza" das Panorama Moskaus durch das Rund eines fiktiven Amphitheaters begrenzt wurde, gelangt hier der Elick durch ein "rundes" Fenster wie durch eine camera obscura nach auBen. Damit ist der Rahmen und die Begrenzthelt des Bildausschnittes gleichsam in einer Idealen geometrischen Form angedeutet. Von den gestalterischen Moglichkelten, die der Turm- bzw. Fensterblick für eine stadtschllderung geben, ist bel Ka-

(1) Karamzin, Izbr.soc., I; S. 623. 
ramzin nur zaghaft Gebrauch gemacht. Was sich hier vor Natal'ja ausbreltet, lst zunachst elne mit sparsamsten Mitteln formelhaft stilisierte Landschaft:

... /Natal'ja/ podchodila k kruglomu oknu vysokogo svoego terema, ... vzgljanut' na zlatoglavuju Moskvu, s kotoroj lucezarnyj den' snimal tumannyj pokrov nox 1 .... - vzgljanut' na moskovskie okrestnosti, na mracnuju, gustuju, neobozrimuju Mar'inu rołcu, kotoraja, kak sizyj, kudrjavyj dym, terjalas' ot glaz $v$ neizmerimom otdalenil ...(1)

/... Natal'ja/ ging zum runden Fenster ihres hohen Turmes, ... un auf das goldbedachte Moskau zu schauen, von dem der glanzende Tag die dunkle Decke der Nacht abhob ... um auf die Moskauer Umgebung zu blicken, auf das dunkle, dichte, unubersehbare Marlenwaldchen, das sich, wle graublauer, flockiger Rauch, dem Auge in unendilcher Ferne verlor ....

Es heiBt zwar, daB Natal'ja auf Moskau mit seinen goldenen Kuppein blickt, ihre Aufmerksamkeit gilt jedoch mehr der Umgebung der stadt. Auch hier finden sich wieder topographische Anhaltspunkte - Mar'ina roša, der FluB Moskva, diesmal jedoch innerhalb elner distanzierten Idylle. Hervorgehoben wird nicht so sehr die prächtigke1t der Landschaft (nur in Natal'jas Gedanken wird sie als solche eingeordnet), sondern der dichte, dunkle ilarlen-Hain, wilde Tiere und Bauern, die zwar singen und arbeiten, aber "kotorye po sie vremja ni v Cem ne peremenilis"" (2)/die sich in dieser zeit in nichts verandert haben/. Mit dem gedankl1chen Ausruf Natal'jas "Kak chorosa Moskva belokamennaja! Kak chorošl ee okruznosti!" (3) /Wie schon ist das weiBsteinige Moskau! Wie schön seine Umgebung!/ schließt die erste Beschrelbung iloskaus innerhalb dieser Erzahlung. Mit dem Hinweis,

(1) Karanzin, Izbr.soc., t. I; S. 627.

(2) Karamzin, Izbr.soC., t. I; S. 627.

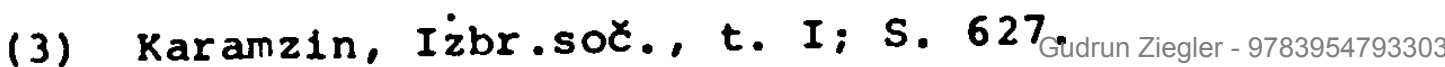


daB die Heldin jeden Tag den Mittagsgottesdienst besucht, hat der Autor die Moglichke1t, auf die abwechslungsrelchen stădtischen Vergnügungen $s$ e 1 n $r$ zeit zu verweisen (byt).

V starinu ne bylo ni klobov, ni maskeradov, kuda nyne ezdjat sebja kazat' 1 drugich smotret'; 1tak, gde ze, kak ne $v$ cerkvi, mogla togda ljubopytnaja devurka pogljadet' na ljudej? (1)

In alten zelten gab es keine Klubs, keine Maskeraden, wohin man heute geht um sich. zu zeigen und andere zu sehen;also, wo denn - wenn nicht in der Kirche - konnte damals ein neugleriges iadchen die Leute betrachten? /

Zusammen mit dem Blick auf die Stadt, am Beginn der Erzahlung fügt sich diese Passage andeutungsweise zu einer "Gesamtheit' Stadt. Durch das "po gorodu" und den Hinweis auf menschliche Aktionen list sie sich hier von der reinen Staffage. In der Replik auf Aleksejs Geschichte wird dieser Gedanke zunächst vordergründig bestätigt.

Ja uvidel blestjasxie glavy cerkvej, narodnoe mnoZestvo, ogromnye domy, vse Cudesa vel1kogo grada, 1 radostnye slezy sverknull $v$ glazach molch. zlatye dnl mladencestva ... provedennye mnoju v russkoj stolice, predstavilis' moim mysljam kak veseloe snovidenie (2).

/Ich erblickte die glänzenden Kuppeln der Kirchen, die Volksmenge, riesige Hăuser, alle liunder der groben stadt und Tränen der Freude glänzten in meinen Augen. Die goldenen Tage der Jugend ... die $1 \mathrm{ch}$ in der Hauptstadt verbracht habe, entstanden in meinen Gedanken als frohlicher Traum./

Aus dem Bericht Aleksejs, der nicht nur den historischen Rahmen, sondern auch die Geschichte der Begegnung mit

(1) Karamzin, Izbr. soc., t. I.; s. 628.

(2) Karamzin, Izbr. soc., t. I.; S. 647. 
Natal'ja aus seiner sicht wiedergibt, kristallisiert sich ein individuell reflektiertes Moskau. Fur den Helden hat die stadt, mit der sein Schicksal verknüpft 1st, eine weltaus grobere Bedeutung als fur Natal'ja. Ihr "kak choroła Moskva belokamennaja!" ist volkstimliche Formel; Aleksejs "zlatye dni mladencestva ... provedennye $v$ russkoj stollce" /goldene Tage der Jugend ... die $1 \mathrm{ch}$ in der russischen Hauptstadt verbrachte/ gehort der schon erwăhnten sentimentalen Ebene an.

Das historische Moskau ist in seiner ăußeren Ersche1nung auf typische Bilder reduziert. In der Verbindung der Stadt mit der Geschichte eines Menschen (Aleksej) zeigt sich ein neuer Aspekt der Verwendung diese Stoffes.

Die Hervorhebung lloskaus lediglich als Handlungshintergrund und als eine sich situationsmäßig wandelnde Grobe wird am Ende der Erzăhlung noch einmal aufgenommen. Dem jahreszeitlich veränderbaren lloskau am Beginn steht die Stadt im. 'Ausnahmezustand' gegenüber.

Vozvratimsja v Moskvu - tam nacalas' nał istorija, tam dolżno ej konCit'sja. Uvv! Kakaja pustota $v$ stolice rossijskoj! vse ticho, vse pexal'no. isa ulicach ne vidno nikoqo, krome slabych starcev 1 żenstin, kotorye s unylimy licami ldut $v$ cerkov, molit' boga, ...(1)

/Kehren wir nach Moskau zurück - dort hat unsere Geschichte ang̣efangen, dort soll sie auch enden. 0 weh! Welche Leere in der russischen Hauptstadt! Alles ist still, alles traurig. Auf den StraBen ist niemand zu sehen, auBer schwachen Greisen und Frauen, die mit verzagten Gesichtern in die Kirche gehen, um zu Gott zu heten,..../

Die angedeutete stille in der stadt will die Trauer über die politischen Ereignisse wiederspiegeln. Es ist

(1) Karamzin, Izbr.sot.; t. I, s. 656-657. 
die auf einfache Elndrücke reduzierte Umschreibung eines Notstandes.

Obwohl sich Karamzin in "Natal'ja" mit der Wahl des Raum-Sujets als sentimentaler Erzähler präsentiert (am deutlichsten in den Naturszenen), geht er in der Verarbeitung des stoffes uber ein bisher ubliches szenisches Aneinanderreihen hinaus. Mit Hilfe der ironischen Distanz, ausgedruckt in Reflexionen des Erzăhlers, bewaltigt er nicht nur die verschiedenen zeitebenen, sondern lenkt auch die Aufmerksamkeit des Lesers durch seine 'verfremdenden' Einwände vom reinen stoff ab.

Auch wenn Karamzin in den belden genannten Erzählungen noch keine eigene Stadt-Sprache entwickelt hat und Formeln aus der Folklore mit 1dyllischen Wendungen vermischt, wird die stadt Moskau unterschiedlich eingesetzt:

1. In "Bednaja Liza" als Kulisse und Raum ohne Tiefe; das Geschehen spielt in einer ländlichen Umgebung $v \circ r$ den Toren der Stadt. Die in der Natur sich wiederspiegelnden seelischen Erregungen werden $n i c h t$ auf die Stadt ubertragen. Diese ist im Sinne Rousseaus $s$ y $\mathrm{m}$ b o 1 für die zivilisation und wirkt als solches zerstörend.

2. Historische Ereignisse um die Stadt Moskau sind der zeitliche llintergrund von Karamzins "Natal'ja, hojarskaja doc'". Der damit vorgegebene Rahmen wird im Verlauf der Erzählung aus verschiedener sicht gestaltet. zunächst steht er im zusammenhang mit einer 'Charakterislerung' der Heldin, deren Tages- und Lebenslauf vor dem Hintergrund der Stadt dargestellt wird. Eine Verflechtung der beiden Bereiche (aber keine Kommunikation) findet in der formelhaften Bewunderung der Heldin für "belokamennaja Moskva" statt. Die andere Schau Moskaus 
In dieser Erzăhlung ist mit dem Leben des Helden verbunden. Zwischen stadt und Individuum besteht eine zumindest e $1 \mathrm{n} s$ e $1 \mathrm{t} 1 \mathrm{~g}$ e $R$ e 1 a $t 10 \mathrm{n}$, denr. die politischen Vorgănge um die russische Hauptstadt bestimmen die Aktionen Aleksejs.

Karamzin stelit in selnen Erzăhlungen die alte russische Hauptstadt als I d y 1 l e dar. Dies entspricht der Konzeption des "empfindsamen Erzăhlers", der, "wenn er zur Feder greift, ein Portrat seiner seele und seines Herzens" zeichnet (1).

(1) Städtke, K.: Die Entwicklung der russischen Erzählung (1800-1825), Berlin 1971; S. 36. 
IV. Die dichterische Gestaltung der beiden russischen Metropolen Im 1. Viertel des 19. Jahrhunderts

Moskva est' vyveska 111 zivaja kartina nasego otecestva (1).

Karamzins "Reisebriefe" hatten den russischen Leser m1t einem Genre vertraut gemacht, das $1 \mathrm{~m}$ Westen bereits ein weites Publikum gefunden hatte und dessen Gestaltung eng mit der Entstehung des Journalismus zusarmenhangt.

\footnotetext{
Nachrlchten über die groben stadte der ze1t, Kolportagen, Aufrisse, Analysen werden zu allgemeinen, in Europa beliebten Lekturestoffen, hauptsăchlich im Rahmen jener Journal- und Reiseliteratur, deren Anwachsen eines der Hauptcharakteristika des 19. Jahrhunderts 1st (2).
}

Bereits Novikov hatte in seinen Journalen in didaktischer whsicht seine stadtische Umgebung blobgestelit. In der "Potta duchov" benutzte Krylov eine Form, die be 1 Novikov bereits erfolgreich erprobt war: den Brief. Dieses Genre, das in der L1teraturwissenschaft u.a. als "družeskoe pis'mo" oder als "epistoljarnaja obrabotka putesestvij" bezelchnet wird, bietet die Moglichkeit des freien Uberganges von Thema zu Thema, von Sehenswürdigke1t zu Sehenswirdigkeit (3). Darüber hinaus dominiert im Briefgenre die Personlichkeit des Schreibers

(1) Batjuskov, K.is.: Progulka po Moskve. In: Sotinenija, M.-L. 1934; S. 298.

(2) Riha, K.: Die Beschrelbung der 'großen Stadt'; S. 33 .

(3) Roboli, T.: L1teratura "Putesestvij". In:

Russkaja proza, The Hague 1963; S. 44.

$\mathrm{Zu}$ unterscheiden sind fiktive und authen$t$ ische Reisebriefe, nach den Mustern von L.Sternes "Sentimental Journey" und Dypatys "Lettres sur l'Italie" Gudrun'Ziegler-9783954793303 
(ličnost'); sie verrät sich nicht nur durch direkte Reflexion, sondern auch in der wahl des Materials.

Karamzin war

der erste russische Reisende, der sich vor allem die Aufgabe stellte, den Leser mit der europäischen kultur bekannt zu machen und nicht nur durch Beschreibung amüsanter Sehenswiirdigkeiten zu unterhalten (1).

Seine Jchilderungen der europäischen Metropolen Paris unà London, die in ausgehenden 18. Jahrhuncert bereits Vieltstälte waren, geben abcr kaum ein wirklichkeitsnahes Bild des Wesens dieser städte wiedier. In Deutschland war zu dieser zeit das Interesse und vor allem der direkte Kontakt $z u$ diesen beiden städen so groB, daB es zur Grïndung eines eigenen Korrespondentenblattes $\mathrm{kam}$. Is sollte nichts anderes, als alle Neuigkeiten aus diesen städten unter "das Volk zu bringen" (2). Nicht selten waren solche Berichte aus reiner Sensationslust yescirrieben. Die Korrespondenten wetteiferten in der Darstellung von Kuriositäten und erfreuten das Publil:um mit "exotischen cindrucken".

In Iußlanc fand dieses 'ienre' nur zögernc Verbreitung. Die spärlichen iontakte nit dem liesten waren sicher nur ein Grund ciafür, daß sich das zweifellos vorhandene Interesse an den europäischen GroBstädten nur in den Berichten Einzelner spiergelte. lit dern Eeginn des 19. Jahrhunderts und vor allem mit der Besinnung auf die eigene :ation (Romantik) werden Reiseberichte üher verschieciene Teile des russischen Reiches sehr nonulär (3).

(1) Ciževskij, D.: Russische Literaturgeschichte des 19. Jahrhunderts; I. Die Romantik; :iunchen 1964;S. 23.

(2) vergl. hierzu: :iha, Die Beschreibung der 'groben stadt': S. 33 ff.

(3) Zu nennen sind hier vor allem Berichte über SüdruBlanci und den asiatischen Tell des Relches. Be-

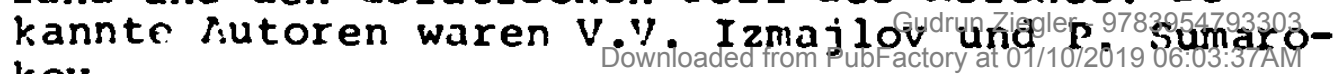
kov. 
Die sovetische Literaturwissenschaft sieht in diesen "Reisen" hauptsächlich eine Nachahmung Karamzins und betrachtet sle vor allem unter dem Gesichtspunkt, wie weit ihre "nravoopisatel'nost" fur das in den vierziger Jahren sich bildende Genre der "oterki" von Bedeutung 1st.

Als eine der ersten Skizzen dieser Art wird K.N. B a tj u $\leq k \circ v s$ (1787-1855) "Progulka po Moskve" aus dem Jahre 1811 angesehen.
"Progulka" myslilas' Batjuskovym kak bytopisatel'- noe proizvedenie, imejustee formu druzeskogo pis'- ma ... Obrastenie Batjuskova zanru progulok otraza- lo narastanie realisticeskich tendencif $v$ ego pro- ze (1).
/"Der Spazlergang" 1st von Batjuskov als milleu- beschrelbendes Werk gedacht worden, es hat die Form eines Briefes an einen Freund ... Die Hinwen- dung Batjuskovs zum Genre des Spazlerganges re- flektlert das Anwachsen der realistischen Tenden- zen in selner Prosa.l

Der Plan Batjuskovs war, eine "kurze Beschrelbung Moskaus, seiner Bewohner, seiner Poeten, seines Parnaß." Er führt zwel Grüde an, die $1 \mathrm{hm}$ diesen plan als sehr schwlerig erscheinen lassen: einmal muste sich ein Bericht uber Moskau mit der Historle dieser Stadt auseinandersetzen, zum anderen ware ein ausfuhrlicher Bericht mit korperlichen Strapazen verbunden, denen sich der Autor nicht unterziehen mochte (2). Mit solchen einle1tenden Bemerkungen sichert sich Batjuškov jeder kritik gegenuber ab, die $1 \mathrm{hm}$ eventuell Unvollständigkelt vorwerfen konnte. Seln Bericht uber Moskau wirkt ungeordnet, aber intultiv und spontan. Der letztere Eindruck wird vor allem durch die sogenannte "domasnost'" des

(1) Fridman, N.V.: "Progulka po Moskve" K.N.Batjuskova. In: IANSSSR, otd.11t.1 jaz.,1962, XXI,6; S. 511.

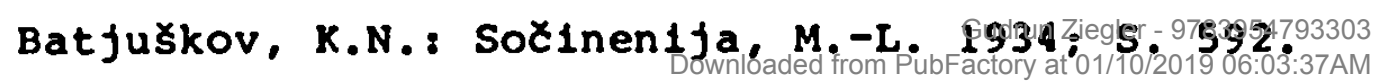


Stoffes hervorgerufen (1). Räumlicher Ausgangspunkt für Batjuskovs "Progulka" solle der historische Kern der Stadt, der Kreml sein. Auf dem 'Weg dorthin' hat der Schreiber des Berichtes MuBe, das alte und das neue Moskau an verschiedenen Dingen $z u$ beobachten und schriftlich zu fixieren. Als besonders kontrastreich werden die Architektur und das Kußere, die Kleidung der Moskauer bevollkerung herausgearbeitet.

Iloskva est' vyveska 111 žlvaja kartina nasego otecestva. Posmotri: zdes', protiv zuhcatych basen drevnego Kitai goroda, stoit prelestnyj dom samoj novejకej Ital'janskoj architektury .... (2)

/:ioskau ist das Aushängeschild oder das lebende B1ld unseres Vaterlandes. Schau: hier, gegenüber den gezackten Türmen des alten Kitaigorod, steht ein herrliches Gebäude in neuester italienischer nrchitektur./

Der Gestalt "v alinnomm kaftane, s okladistoj borodoju" /im langen Kaftan mit Vollbart/ wird ein Pendant " $v$ modnom frake" /im modischen Frack/ beigegeben.

Die schilderung cies kreml erschripft sich in bekannten Gemelnplätzen.

... my uviaim velicestvennye zdanija, s blestjašimi kupolami, s vysokimi bašnjami, 1 vse éto obneseno tverdoju stenoju. Zdes' vse dyšt drevnostiju... (3)

/... wir sehen großartige Gebäude, mit glänzenden Kuppeln, mit hohen Türmen, und alles 1st von einer festen Mauer umgeben. Alles atmet hier Alter ....

Nachdem auf die Ruhe des geschlossenen Kreml-Bereiches hingewiesen wurde, gewăhrt der Lrzähler seinem Leser einen Blick auf das Panorama Moskaus:

(1) Stepanov, N.: Družeskoe pis'mo nacala XIX v. In: Russkaja proza, The Haque 1963; S. 84.

Batjuకkov, K. . .: So丈.; S. 292. Gudrun Ziegler -9783954793303

(3) Ratjuškov, K.ił.: Soč.; S. 29: 
"Choxes' 11 videt' edinstvennuju kartinu? (1)" /Mbchtest du ein einzigartiges Bild sehen?/ Die Vorliebe Batjuskovs für kontraste ist sicher ein Grund dafur. daB er diesen Panoramablick auf den Abend verlegt. Bereits Karamzin hatte in "IJatal'ja" Moskau und seine Ungebung aus der Vogelschau geschlldert. Er war dabei jedoch im allgemein Bildhaften verblieben. Das von ihm vermittelte Bild entsprach im Aufbau den Panoramabildern der zeit, d.h. die Anordnung der stilisierten topographischen Realien wurde nach ästhetischen und effektvollen Gesichtspunkten vorgenormen. Bel Batjußkov sind die topographischen Fixpunkte so gewăhlt und im Raum verteilt, daß sie als reales Dokument gesehen werden können. Gleichzeitig wird der Findruck eines sich tatsächlich ereignenden Rund- und liberblicks iber linskau erweckt. Genannt werden "Kamennyj most; Golycinskaja bol'nica. Dom orlovoj" (2). Diese Art, einen stadtausschnitt darzustellen, ist sehr gut geeignet, mittels :iomentaufnahmen einen möglichst vielgestaltigen Findruck der stadt zu vermitteln.

... zdcs' predstavljaetsja vzoram kartina, dostojnaja velicajŁej $v$ mire stolicy, postroennoj velicajక̌m narođom prijatnejšm meste (3).

/... hier bietet sich dem Blick ein Lild dar, das der ehrwürdigsten llauptstadt in der lielt würdig ist, erbaut von. ehrwirdigsten Volk am lieblichsten Platz./

Diese Superlative werden durch einen polemischen uinweis auf die "linzigkeit und Enge" deutscher Stäte noch betont. Nach der raumlichen Beschreibung wird die stadt als "Spielraum" dargestellt. Der Dichter bezieht einen Beobachtungsposten auf dem Kuzneckij most, "gde vse $v$

(1) Batjuskov, Soð.: S. 298 .

(2) Batjuskov, Soð.: S. 298/299.

(3) Batjuskov, Soč.; S. 299. 
dviženii, vse spešt" (1) /wo alles in Bewegung ist, alles eilt./ Die hier angedeutete Dynanik, die auf eine gelebte und erlebte stadt hinweist, entfaltet sich in einzelnen szenen. Batjußkov beschreibt einige "lavki" /Läden/ und deren kunden, die in seinen Augen eine für ioskau typische Frscheinung darstellen, und registriert gleichzeitig die iodetorheiten der iloskauer, d.h. ihr Nachäffen englischer und franzisischer vorbllder.

Kakoe stečenie naroda, kakoe raznoobrazie! Eto soveršennyj bazar vostočnyj l (2)

/lielcher ilenschenandrang, welche Vielfalt! Es ist canz wie ein orientalischer Bazar!/

Der Vergleich iloskaus mit einem Bazar entspricht dem bekannten fild von der stadt als der lelt im Kleinen; der "T'versłoj bul'var" wird zur schaubühne:

Vot guljan'e, kotoroe ja posescal vsjakoj den' 1 pozti vsegda s novym udovol'stviem (3).

/Das ist eine Promenade, die ich jeden Tag gern besuchte und fast inmer mit neuer. Vergnügen./

Die große Straße, der Eoulevard, wird zum locus comnunis, zu einer Tynenschau cier lloskauer Eevollkerung. Batjuškov nennt einige Vertreter, beschreibt ihr XuBeres und versucht sogar durch biographische Details das Persönlichkeitsbild abzurunden. Dadurch geht er über die reine Beschreibung hinaus: er macht sie für das erzählerische Elenent durchlässig.

Trotz der dargesteliten Vielfalt ist die stakt noch nicht die lïrmende und komplexe Masse späterer Eeschrei-

(1) Latjuskkov, Sot.; S. 300.

(2) Iatjưkkov, Sot.; S. 301.

(3) Eatjuškov, Soł.; S. 302. 
bungen, denn bel Batjuxkov fehlt jede Kommunikation zwischen "Handelnden" und "Handlungsraum". Er versucht zwar das Typlsche an der Moskauer Bevblkerung hervorzuheben, doch zeigt slch in der vor allem auf Kontrasten basierenden Beschrelbung eine bestimmte Haltung. Elnmal bedeutet sie eine satirische Absicht, zum anderen (damit verbunden) elne pădagog1sch-moralische (1m sinne der Aufklärung) Unterwe1sung.

Ja dumaju, čto ni odin gorod ne imeet ni že malejšego schodstva s Moskvoju. Ona javljaet redkle protivupoložnosti $v$ stroenijach 1 nravach žitelej. Zdes' roskoš' 1 niščeta, 1 obille 1 krajnjaja bednost', nabožnost' 1 neverle, postojanstvo dedovsk1ch vremen 1 vetrennost' neimovernaja, kak vraždebnye stich11 v večnom nesoglasil, 1 sostavljajut sie čudnoe, bezobraznoe, ispolinskoe c e 10 e, kotoroe my znaem pod obščim Imenem: Mos k v a (1).

/Ich denke, das keine stadt auch nur geringe Xihnlichkelt mit Moskau hat, sie zelgt seltene Gegensatze in der zusammensetzung und im Wesen der Bewohner. Hier gibt es Luxus und Armut, UberfluB und auberste Not, Frommigkeit und Unglauben, Beständigkelt der altvaterlichen zeiten und unglaublichen Leichtsinn, als feindliche Elemente in ewiger Uneinigke1t, und daraus setzt sich dieses wunderbare, hăßliche, riesenhafte $G$ a $n z e$ zusammen, das wir unter dem allgemeinen Namen kennen: $M \circ s k$ a $u . /$

In Batjuskovs "Progulka" wird Moskau, das "wunderbare und häbliche Ganze" auch in seiner sozialen Gegensatzlichkelt erfaBt. Die Feststellung, daB in dieser stadt arm und relch nebeneinander wohnen, bedeutet aber allein noch keine sozialkritische Elnstellung des Autors. Batjuskkov vervollständigt hlermit vielmehr seine letztlich als 'Moralsatire' angelegte Skizze Moskaus. Er steht damit in der Tradition der Aufklarung, wȟhrend seine beschreibenden und auch genrehaften Passagen auf eine neuere Entwicklung weisen. Darin lost er sich vom 'pada- 
gogischen' Grundtenor der Satiren Novikovs und Krylovs (1). Batjuskov ist trotz der 'negativen' Bilder bemüh, die stadt von ihrer angenehmen seite zu zeigen, wobei sich das persönliche Engagement Batjuškovs vor jede mogliche objektive Darstellung schiebt. Moskau ist für ihn die unvergleichliche stadt, vor deren Originalität selbst die Weltstadt London zurückweichen muB. $\mathrm{zu}$ den von Batjuskov vermittelten Imnressionen gehrrt auch ein Motiv, das in diesem zusammenhang nur angedeutet wird, und zwar: der Blick in die lläuser der stadt, der Blick in die zimmer. Die "Stadt im Inneren", die später bei Dostoevskij als wesentliches Element der Großstadt eine Rolle spielt, dient bei Batjuškov zur Vervollständiqung? seiner bisher geschilderten Typenschau. Das Haus ist "als vilnkel der ivelt" (2) noch nicht in seiner nsychologischen Ledeutung erfaBt.

reereits Krylov hatte in seiner "potta duchov" vom Theaterleben gesprochen und somit den reschmack der zeit charakterisiert. Nuch Batjuxkov weist auf verschiedene Theaterauffuhrungen hin, wohei er die Petersburger szene rit der Moskauer verglelcht, aber letzten Fndes zu der Ergejnis kommt, daB das Theater in heiden stricten schlecht sel, weil es keine ruten Akteure çebe. Soine kritik am zeitrencssischen Theater erschïpft sich weitgehend darin, daß er die spleenigen Einfälle der protaqonisten aufzahlt. liit einer abschließenden Szenenwechsel 'begibt' sich der Dichter vor die Tore der Stadt, un: die Flanierenden $\mathrm{zu}$ beobachten. Nuch hier nimsit er die Gelecienheit zur

(1) Groken FinfluB auf die regen Ende des 18. Jahrhunderts in Furona sich verbreitenden 'Sittenbilder' hatte I,a Bruyères "Les Charactères ou Les "loeurs de ce siècle" (1688).-Die russischen"bytopisanija" cies frihen 19. Jahrhunderts werden vielfach mit ten Genrehildern des lolländers D. Teniers (16101690) und den "Moral nictures" l. llorarths (16971764) veralichen.

(2) Dachelard, G.: Doetik des Paumes, München 1960; S. 36 . 
Gestaltung wahr (verạl. Kuzneckij most), wobei er die einzelnen Spaziergänger mittels anekdotischer Bemerkungen charakterisiert. Der ironische Grundtenor wird abschließend noch einmal deutlich, wenn der Autor die Vergangenheit der stadt 'beschworrt'.

Ėto gul'bišcě imeet velikoe schodstvo s Poljani Elisejskimi. Zdes' my vidim teni velikich ljudej. kotorye otygrav važnve roli $v$ svete, zanrosto progulivajutsja v Mostre. Mnogie iz nich perežili svoju slavu. Eheu, fugaces! ... (1)

/Dieser Vergnügunạsort hat aroße Xihnlichkeit mit der Elysium. Hier sehen wir die Schatten der groBen Leute, die, nachdem sie ihre wichtine Rolic in der Welt ausgesnielt haben, einfach curch Moskau wandeln. Viele von ihnen haben ihren Ruhm uberlcbt. Eheu fugacrs! .../

Batjuskovs Moskaubild ist eine ironische Ecschreibun: der :loskauer und ihrer Verhaltensweisen. In dieser Typenschau, vor szenenhaft wechselndem Hinterarund, weist er auf die resellschaftliche "Polymorphie" hin. In der kontrastierenden Schilderung einzelner Individuen steht er den Moralsatiren iovikovs und Krylovs nahe. Seine Perzeption des städtischen laumes und dessen verbale Realisierunc bedeuten aber nicht nur einen Schritt zur "nravoopisatel'naja povest"" sondern einc Lhisung vom bishericen literarischen stadtbild. Dazu haben wesentlich beicetraçen: erstens die soc̣enannte "domašnost"." die iller eine reing̣efühlsmäßiae Bincuna hinausqeht, zweitens die Intention des Werkes, d.h. die Absicht einer "Beschreibuna" (opisanie).

1814 schrieb Batjuškov eine zweite Skizze, deren Titel "Progulka v Akaderiju Chucozestv" hereits auf Petcrsbura hinweist. Auch hier wăhlte Batjułkov dic Form des Briefes.

(1) Eatjuškov, K.:..: Soč.; S. 309. 
Elnleitend erwahnt der Schrelber, das er mit diesem Bericht fruhere "Spazlergange" durch Petersburg fortsetzen w111 (1). Der Dichter beginnt den Brief an seinen Freund mit Erinnerungen an die gemeinsam in Moskau verbrachte ze1t. Er bedauert zutlefst, daB durch den groben Brand (1812) die "prelestnye vidy" gelitten haben, mit denen sich der Autor verbunden fuhlt. Selne Empfindung: "Sčastlivoe, nevozvratnoe vremjal" (2)/gluckliche, unwiederbringbare zeit/. Dem historischen Moskau (vor dem Feldzug Napoleons) stellt Batjuškov die "novost" "Pe- . tersburgs gegenuber.

Vsjakaja novost' 12 stolicy prijatna pustynniku, kotoryj 1 na starosti let esce plamenno ljubit otečestvo, .... (3)

/Jede Neuheit aus der Hauptstadt ist dem Einsledler angenehm, der auch im hohen Alter sein Vaterland noch flammend liebt./

Ein Stimmungsbild bildet den Ubergang zu einer 'panegyrischen Reminiszenz' an Peter I. und seine Stadtgrundung. Der Monarch wird von Batjuškov nicht nur als "Seefahrer und Bauherr" gesehen, sondern vor allem als Wegbereiter fur eln aufgeklärtes RuBland, das in der neuen Stadt Gestalt angenommen hat. Enthusiastisch helBt es:

Velikolepnye zdanija, pozlašennye utrennim solncem, jarko otražal1s' v ¿̇stom zerkale Nevy, 1 my oba edinoglasno voskliknuli: "Kakof gorod! kakaja rekal" - "Edinstvennyj gorod!" ...." skol'ko prednetor dlja kist1 Chudožnika! (4).

(1) Nach D.D. Blagof handelt es sich hier um ein Vorhaben des Dichters, das nicht zur Ausfuhrung kam.

(2) Batjǔskov, N.K.: Soč.: S. 320.

(3) Batjuškov, N.K.: Soč.; S. 321.

(4) Batjuškov, N.K.: Soč.; S. 323. 
/Die herrlichen Gebaude, von der Morcensonne vergoldet, wurden scharf im reinen Spiegel der Neva reflektiert und wir riefen beide einstimmig aus: "Welche Stadt! Was für ein FluB!" - "Eine einzigartige Stadt!" ... "Wieviel Dinge für den Pinsel des Künstlers!" / (1)

Batjuškov deutet hier an, daB sich Petershurg zu einem Zentrum der Kunst entwickelt hat (2). Tatsachlich war mit der Gründung der Akademie der Künste durch Katharina II. die neue Hauptstadt $z$ u einem "Musensitz" geworden, was bereits Sumarokov in seinen Versen herbeigesehnt hatte. Das in den Zeilen "skol'ko predmetov dlja kisti chudožnika" /wieviel Dinae für den Pinsel des Künstlers/ intendierte: Petershurq als Gegenstand der Malerei, entspricht realen 'Ergebnissen'. Mit dem ausgehenden 18. Jahrhundert wurde die hauptstadt zunächst in Veduten abgebildet, zu denen dann um 1820 die Genrebilder traten (3). In einem fingierten Gespräch, das dem Brief eingefügt wurde, beschreibt ein funger Maler die llarmonie und Schbnheit Petersburgs (4). Die Einzigartiqkeit der llauptstadt wird im Verqleich mit "vetchif Pariž"/hinfälliqes Paris/ und "zakončennyj London." /vercualm.tes London/ hervorgehoben. Der Künstler beschreiht verschiedene Stadtausschnitte, ceren Auswahl für einen aktuellen Findruck spricht (5).

(1) Batjuškov, N.K.: Soč.; S. 323.

(2) Der Künstler spielt im. Werk Gogol's eine wesentliche Rolle. Gogol' stellt allerdines fest, daB die Künstler in Petersburg eine "unnatürliche" Erscheinung sind. Indem Gogol' Petersburg mit Rom vergleicht, deutet er an, daß die russische Hauntstadt selbst keine kïnstlerischen nnregungen gehen kann, da sie selbst ein "Bild" ist. (vergl."Nevskij prospekt")

(3) Als Veduten-und Genremaler sind vor allem zu nennen: A. Alekseev, S.Ščedrin, Venecianov.

(4) Auf ein ästhetisches Ideal weist die Passage "mit den linckelmann in der fiand".

(5) 2u Berinn des 19. Jahrhunderts wurde in petershurg

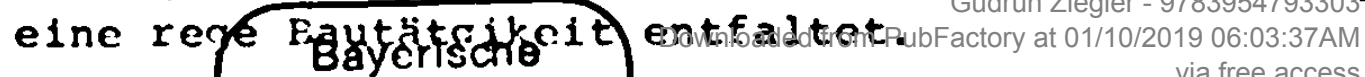


Betrachtet wird der arch1tektonisch gestaltete Vasil'evskif ostrov mit der Borse, deren Bau 1816 abgeschlossen wurde. Dem jungen kunstler erscheint das neue Petersburg bewundernswert, wăhrend der Schrelber des Briefes auf die sich ständig verăndernde stadt hinwe1st, mit der sich seiner Melnung nach auch die Menschen andern. Trotz allem 1st Petersburg Ausdruck fur die kulturelle Entwicklung RuBlands. Während Batjuskovs Moskauer "Spazlergang"versuchte, den Perspektivenrelchtum der alten Stadt in elner Art Gesamtschau aller stadtischen Elemente darzustellen, 1st der Gang zur Akademie der kunste ein kulturgeschicht11 ches Exempel. Der Moskauer Typengalerie wird hier, abgesehen vom Schreiber und vom künstler, nur e 1 n vertreter städischer Lebensart gegenubergestellt: Starozilov (1). Er 1st das Abbild des reichen Mubiggăngers, der routinemäbig alles Fremde nachafft und uber die kunst veraltete Ansichten vertritt (2).

zusammenfassend kann die Beurtellung Cejtlins ubernomen werden, der Batjuskov wie folgt einordnet:

Avtor "Progulk1 po Moskve" uze ne moralist 1 ešce ne fizlolog, on tol'ko nabljudatel' nravov, ne zabotjastijsja o pridanil svoim kartinam kakogoto obobstajustego smysla (3).

/Der Autor des "Spazierganges durch Moskau" 1st nicht mehr Moralist und noch kein Physlologe, er ist nur ein Beobachter der Sitten, der sich nicht um die Mitgift einer allgemeingultigen Idee in seinem Bild sorgt./

(1) Starozilov, d.h. im Ubertragenen sinne der nach dem Alten lebende und dem Alten verhaftete; wortlich: der Alteingesessene.

(2) Im zusammenhang 1st Starožllov nicht so sehr Repräsentant der Hauptstadt, sondern er hat mehr die Rolle eines "dramatisierenden Elementes" ubernommen.

(3) Cejtlin, A.G.: Stanovlenie realizma ....; M. 1965; S. 8. - 1817 erschien in "Russkif vestnik" anonym "Ešče zamečatel'nyj den' moej progulki v Moskven". 
Ergănzend zu den "Progulk1" Batjuškovs soll hier die Skizze "Moskva" aud F.N. G 1 in $\mathrm{k}$ a s "Pis'ma russkogo oficera" (1815) nur genannt werden, da deren Intention mit den eben besprochenen Werken ubereinstimmt. Auch bei Glinka wird für Moskau vor allem die widersprüchlichkelt (alt und neu) konstatiert, was der nutor wie Batjuškov an architektonischen Eindrücken und an den Bewohnern der ehemaligen llauptstadt zeiṛt (1).

Indem K.F. $R$ y 1 e e $v$ (1795-1826) in seiner skizze "Provincial v Peterburge" den erzăhlerischen Elementen gegenüber der reinen Beschreihung Priorität einrăumt, lost er sich von der bisherigen Praxis, die stadt weniçstens andeutungsweise als Ganzes darzustejlen. Bereits in seinen "Briefen aus Paris" (1815) hatte Ryleev stădtisches Leben vor zeitpolitischem Hintergrund geschildert. Sein Urteil uber die franzosische Hauptstadt ist für ein allgemeines stadtverständnis von Interesse.

Nakonec, ja ostavljaju Pariž, siju šumnuju stolicu zabav 1 veselost1, sie obitališce razvrata 1 norokov: - ja ostavljaju sej Lavirinf, $v$ koem tysjači Minotavrov, oblečennych $v$ primančivuju odeždu sladostrastija 1 nelsčerpaemych naslaždenıj, ežeminutno ožldajut žertv, dlja utolenija žaždy svoej: ... (2)

/Schlieflich verlasse ich paris, diese lärmende llauptstadt des Vergnugens und der Frohlichkeit, liohnung der sittenverderbnis und des Lasters:ich verlasse dieses Labyrinth, in dem tausend M1notauren in verfuhrerischer Kleiduna der wollust und des unerschopflichen Genusses angetan sind, die jede Minute ein Opfer erwarten zur Befriedigung threr Gier: ..../

(1) Gilnka, F.N.: Pis'ma russkogo of icera (otryvk1). In: Russkie oterki, t.I, M.. 1956; S. 66-88.

(2) Ryleev, K.F.: PSS, M.-L. 1934 (repr. The Hague 1967): S. 382 . 
Selne Abneigung gegen die Grobstadt, hier gegen das labyrinthische Par1s, das durch Merclers "Tableaux de Par18" (1781 ff.) fur ganz "Europa lebendig gemacht" worden war, Ubertrăgt Ryleev in gemäigter Form auf das zu seiner zelt noch wenlger verdorbene Petersburg (1). In seinem 1821 veroffentlichten "Provincial v Peterburge" verarbeltet Ryleev ein aus dem Gegensatz Stadt-Land erwachsenes Motiv zu einer Humoreske, in der er sehr wirklichkeltsnah folgendes sujet gestaltet:

Ein junges Paar aus der Provinz kommt nach Petersburg, um slch "uberall aufzuhalten und alles anzusehen". Am ersten Tag nach der Ankunft wollte man die Kazarer-Kathedrale besuchen, um fur ein "gluckl1ches Gelingen der Reise" zu beten. Man bricht zwar auf, errelcht die Kathedrale jedoch nie, denn der Weg dorthin, uber den Nevskij-Prospekt, ist mit franzobischen Laden gesaumt ...

Die Handlung spielt zwlschen Kazanskij sobor, Nevskij prospekt und Pollcejsk1j most; die dargestellte zelt entspricht etwa einem Tagesablauf. Ryleev beschreibt die Faszination, die von den Modeladen ausgeht und von all dem, was mit dem wort Paris verbunden 1st:

U menja teper' očen mnogo novostej 12 Parı̌̌a. Iz Parı̌̌a? Ach, pokažite, požalujstal (2)

/Ich habe jetzt viele Neuhelten aus Par1s.Aus Paris? Ach, zelgen sie sie mir bittel\%.

Solche Dialoge und Szenen wiederholen sich in verschiedenen Lyden. Glelchzeltig stellt Ryleev sehr realistisch dar, daB sich mit der wachsenden Begeisterung der fungen Frau der Geldheutel des Mannes immer mehr leert.

(1) Vergl. hierzu Minder, R.: Par1s in der franzbs1schen Literatur. In: Dichter in der Geselischaft, Darmstadt 0.J.; S. 294 .

(2) Ryleev, PSS; S. 300. 
Das Resümee des resignierenden Themannes:

Pervyj vyezd stoil mine tysjači semidesjati pjati rublej. Cto, esli vtoroj, i tretij stol'ko ze budut stoit? Echat' vmeste s ženoju - beda! (1)

/Die erste nusfahrt hat mich 1075 Rubel gekostet. was ist, wenn die zweite oder gar die aritte ebensoviel kosten? Wer zusammen mit seiner Frau ousfährt, der ist ein armer Mann!/

Diese nur knapn vier Seiten urfassende Studie gehrit zur Genre der "nravoonisatel'nve očerki". Das $2 i e l$ Rỵleevs ist nicht eine vorderg̣rilndige, tynische Reschreiluung der russischen Hauptstadt und ihrer rodischen "Attraktionen', sondern eine ellgereine skizzierung tvpischer Verhaltensweisen. Dicse Idee wird in der Darstellung dadurch besonciers effektvoll, dap der hutor den städischen saum auf ein Mininuri rerluzicrt, reit unc Ereignisse aber inaximal ausweitet. Rivleev verarheitet zwei bekannte sotive, die wercen ihrer Aktualităt auch von anderen Dicitern aufgenomen wurden (2). Finrial ironisiert cr das Bemühen der Damen aus der Provinz, niodisch auf der Laufenden zu sein, zum ancieren ciemonstriert er, daß der Geschmack seiner zcit von der franzrisischen : fode diktiert wird. Is entspricht cen realen keobachtungen, daf sich die russische iaurtstacit fiir alle Neuerungen offen zeint und das sic in cer Provinz dankbare itachahrier hesitzt.

In A.S. G $\mathrm{r} i \mathrm{~b}$ o e $\mathrm{d} \circ \mathrm{v} \mathrm{s}(1795-1829)$ "Sore ot uria" (ur 1822-24 entstanden, 1831 Urauffihrung) wirc cas von Ryleev als Humoreske ciargestellte zeitrhänorien zur Satire.

(1) Ryleev, K.F.: PSS; S. 302.

(2) Zu nennen ist vor aller: krylovs kombilie "'indnaja lavka" (1806) und das vielfach und verschiecien gestaltete i:otiv: nereezd v reterburadun Ziegler -9783954793303 
Es gehört zum Charakteristikum der Komödien, das in Ihnen

... otražaetsja smexnoe 1 nesoobraznoe v žizn1. osmelvaetsja kakoe-l1bo nezdorovoe obščestvennoe 111 bytovoe javlenıe, smešnye črty človečeskogo charaktera (1).

1... das Lacherliche und die Ungereimtheit im Leben sich wledersplegelt, irgendelne krankhafte gesellschaftliche Erscheinung oder allgemein verbreitete Sitten, lacherliche zuge des menschlichen Charakters verspottet werden./

In diesem sinne aubert sich auch A.S. Puškin uber Griboedovs "Gore ot uma", als er Im Januar 1825 an A.A. Bestužev schrieb:

Cel' ego /d.1.Griboedov/ charaktery 1 rezkaja kartina nravov (2).

/Sein ziel sind Charaktere und ein scharfes sittenbild./

Es sind typische Charaktere, die Griboedov in "Gore ot uma" agleren labt, typisch fur das "alte Moskau", das sich in thnen und durch sie darstelit.

Nach dreijahrigem Aufenthalt im Ausland kehrt Cackif nach Moskau zuruck. Er provoziert die Kreise, in denen er früher erzogen wurde, durch selne Reden. Selne Jugendfreundin Sofija, die er zu helraten gedenkt, hatte sich von ihm abgewandt und zieht das Leben mit elnem langweiligen Menschen niederen Standes vor. Man erklart Cackij wegen seiner Ideen für verrulckt. Dieser erkennt, daB er nicht länger in Moskau verwellen kann. Er ergreift die Flucht.

Die stadt wird immer dann direkt von den Akteuren angesprochen, wenn bestimmte individuelle Verhaltensweisen

(1) Timofeev, L.I.:Kratkif slovar' literaturoved. terminov, M. 1963 ; S. 68 . 
"entschuldigt" werden sollen, $d . h . m i t$ anderen worten: Griboedov gibt den Anschein, als seien die von thm dargestellten Typen durch die Stadt geprägt. Es wăre zu fragen, ob auch die entgegengesetzte Wirksamkelt, d.h. der EinfluB des Menschen auf die stadt dargestellt wird. Beschreibungen des städtischen Raumes sind selten und dienen als Reflexionen der Helden ihrer Charakteristik. Dies gilt besonders fur Famusov, dessen Verhältnis zu Moskau durch die Tradition geprägt ist und der aus diesem Grund alle modischen leuerungen, die in das zeitgenössische - konservative Moskau eindringen, als verwerf $11 \mathrm{ch}$ abtut. Famusov lebt in der stadt und durch sle, wohel er deren Veränderungen wahrnimmt, aber doch selbst im Alten verhaftet bleiht. Er ist Ausdruck eines abgeschlossenen stagnierenden $s \quad t \quad d \quad t z u t a n d e s$, in den er vollig integriert ist. Famusov ist der 'TYP' des Moskauers vor 1812 .

Griboedov stelit die alte russische Hauntstadt als widerspruchliches Gehilde dar. Dominierend ist das alte Gesellschaftssystem mit seinen Vertretern Famusov, Skalozub, Molčalin u.a. Aus ihren Gesprächen und Reflexionen wirc jedoch deutlich, daB es auRerhall ihrer lielt auch noch etwas 'Neueres' gibt. Was anfanrs nur konstatiert wird und auf verschiedenen Beohachtungen heruht, ist in Cackij personifiziert. Dieser hricht in das geschlossene System der :ioskauer ein; als intipode Famusovs ist er Reaktion auf die Moskauer Geselischaft. Cackij erkennt die Stagnation der stadt und ihr Verhaftetsein in der Vergangenhe1t.

Doma novy, no predrassudki stary. Poradujtes', ne istrebjat Ni gody ich, ni modv, ni požary.

(1) Griboedov, A.S.: Solinenija, t. I, H. 1971; S. 92. Griboedov spielt hier auf den grofen Erand in Moskau wăhrend des Napoleonischen Feldzuçes an. 
/Die Hauser sind neu, doch die Vorurtelle alt. Freut euch, weder Jahre, noch Moden, noch Brände können sie vernichten./

Bevor Cack1j selbst ein Opfer des 'alten Systems' wird. entzieht er sich dieser 'Gefahr' durch Flucht.

Von 12 Moskvyl sjuda ja bol'še ne ezdok. Begu, ne ogljanus', pojdu iskat' po svetu, Gde oskorblennomu est' cuvstvu ugolok!

Karetu mne, karetu! (1)

/HInaus aus Moskaul Hierher werde $1 \mathrm{ch}$ kein Reisender mehr sein. Ich eile, schaue nicht zuruck, $1 \mathrm{ch}$ werde durch die Helt gehen, um zu suchen, wo fur ein gekranktes Gefuhl ein Eckchen lst! Meinen Wagen, den Wagen!/

Obwohl Moskau Hintergrund der Handlung ist und thr "byt" durch die verschledenen Typen repräsentiert wird, scheint Griboedov zumindest die Gallomanie als symptomatisch für die gesamte stădische Gesellschaft anzusehen. In fruheren Handschriften ist im Monolog Cackifs uber den Franzosen aus Bordeaux nur von Moskau die Redes. In der endgultigen Fassung (Bulgarinskij spisok) stehen lloskau und Petersburg glelchrangig nebeneinander (2).

Griboedov selbst ist zwar Moskauer, aber hat eine d1stanzierte Haltung $2 u$ dieser stadt. 1818 schrieb er an Beg1 Čev:

V 'Moskve vse ne po mne. Prazdnost', roskoš', ne soprjažennye ni malejšim Cuvstvom $k$ čemu nibud' chorošemu. Prežde tam ljubill muzyku, nynče ona $v$ prenebrežen11; ... (3)

(1) Griboedov, A.S.: Sox.,t. I.: S. 163 (IV,14).

(2) siehe: III. Akt, 22. Aufzug.

(3) Griboedov, A.S.: SoX., t. II; S. 187. Brief an Begitev, vom 16.9.1818. 
/In Moskau ist alles nicht nach meinem Sinn. MUBiggang, Luxus, die nicht mit dem geringsten Gefuhl fur irgendetwas Schones verbunden sind. Einst liebte man dort die Musik, heute verschmaht man sie: ..../

Auch Cackijs Resiumee aus seinen Eindrucken lautet ăhnlich: "Net! nedovolen ja Moskvoj." (1) /Nein, 1ch bin mit Moskau nicht zufrieden./

Schon den zeitgenossen Griboedovs war klar, daß in "Gore ot uma" ein sehr einseitiges Bild des damaligen ioskau gezelchnet wurde. Besonders P.A. Vjazemskij çriff immer wieder das Thema "Griboedovskaja" hzw. "Tamusovskaja Moskva" auf und wandte sich gec̣en eine Identifizierung der stadt mit dem Kreis um Famusov (2). In der Kritik an der iloskauer Gesellschaft hatte Griboedov sein elgenes Unbehagen an der kulturellen Fntwicklung zum Ausdruck gebracht. In der Skizze "zaqorodnaja poezdka" (1826) wird diese Finstellung des Dichters relativiert.

Na vysoty! Na vysoty! Podalee ot šuma, pyl1, ot dušnogo odnoobrazija našich ploščadej 1 ulic. Kuda-nibud' qde vozduch reže, otkuda grudy zdanij $v$ nejasnoj dali slilis' by $v$ odnu tocku, ves' by gorod predstavil iz sebja centr otmenno melkoj. ničtožnoj dejatel'nost1, kipjaščlj ruravejnik. No kuda ze voznestis' tak vysoko, tak svohocino 12 Peterburga? - v Pargolovo (3).

/Fuf die Höhen! nuf die Hohen! Weiter weg vom Lărm, Stauh, von der bedrückenden Einfrrmigkeit unserer Platze und straßen. Irgend wohin, wo die luft frischer ist, von wo die Husermenge in unklarer Ferne in einem Punkt verschwimmt, als ware die. ganze stadt Zentrum einer auBerordentlich unwichtigen, nichtigen Tătigkeit, ein siedender Ameisenhaufen. Aber wo kann man sich so hoch erheben, so frel von Petershurg sein? - in Pargolovo./

(1) Grịboedov, A.S.: SoC., t. I.: S. 139 (III,29).

(2) siehe hierzu: Wytrzens, G.: P.A. Vjazemskij. bien 1961; S. $220 \mathrm{ff}$.

(3) Griboedov, A.S.: Sot., t. II.: S. 80. 
Stadtmudigke1t spricht aus diesen zellen. Wle Cackif fluchtet der Erzahler aus der groben stadt, aus der anonymen Hausermasse, mit dem einen Wunsch, sich dorthin zu begeben, wo man frel ist von Petersburg. Grlboedov beschrelbt die Ausfahrt aus der stadt, wie sich mit Vergroberung der Entfernung die normalen Dimenslonen des Stadtpanoramas verringern, bis die Stadt in einem Punkt komprimiert 1st. Bel der Fahrt liber Land werden "mesta kartinnye" registriert. Diese entsprechen bel Griboedov nicht mehr der 1dealen Landschaft - wie man sie bel Karamzin noch kennt -, sondern werden als weite Panoramen geschildert. Begegnungen mit Vertretern verschiedener Volksgruppen geben Gelegenhelt zu Reflexionen uber Volkslieder und Brauchtum. Die Ruckkehr in die Stadt wird in wenigen zellen skizziert:

Vozvrat111s' opjat' v Pargolovo; ottuda v gorod. Prežnuju dorogoju, prežnee unyne. K tomu že surovost' klimatal Pri spuske s odnogo prigorka my razom pogruz111s' v pogrebnoj, viažnyj vozduch;... I čem bliže $k$ Peterburgu, tem chuže po storonam predatelskaja trava; .... (1)

/Wir kehrten wieder nach Pargolovo zuruck; von dort in die Stadt. Auf dem fruheren Weg, die alte Verzagtheit. Dazu die Rauheit des Klimas!

Belm Herabfahren vom llugel sinkt man mit einem Mal in die feuchte Kellerluft; .... Und je naher Petersburg ist, um so hagerer das verräterische Gras an der Seite; ..../

Griboedovs "Zagorodnaja poezdka" kann nicht auf die Opposition Stadt - Land, räumliche Gedrangthe1t gegenuber Weltlaufigke1t beschrankt werden. In der Aufmerksamke1t, mit welcher der Autor sich auberdem in dieser kurzen 'Erzahlung' ethnographischen und kulturpoliti-

(1) Griboedov, A.S.: SoC., t. II.; S. 82. 
schen Fragen widmet, deutet er an, dab etwa im Sinne Herders das Volk bzw. die elnzelnen Volksstämme innerhalb einer Nation an der kulturelien Entwicklung telihaben (1).

Fur Griboedov sind Moskau und Petersburg in den beiden erwähnten Werken als architektonisch gestaltete Răume unwesentlich. Sowohl in "Gore ot uma" als auch in "Zagorodnaja poezdka" sind beide städte symbol. In der Kombdie steht Moskau für die russischen Gesellschaftskreise, die man entweder als Konservative oder als Ignoranten bezeichnen kann. In der "Skizze" entspricht die "Flucht" aus der stadt einer Hinwendung zum Ideal des "Menschen in der Natur".

(1) Ruffallend ist auch die Nahe zu Schillers

"Spazlergang" (1795), In dem die 'Natur' als Voraussetzung für die Kulturleistungen darg̣estellt wird. 
V. Stadtsicht und Stadterleben bel A.S. Puskin

Ljublju tebja, Petra tvoren'e (1).

Die direkte Beziehung der Dichter zu den realen stadten nachzuweisen, 1st nicht die Aufgabe dieser Arbe1t, zumal die zusamenstellung eines "literarischen Baedekers" hier nur untermalend sein konnte. Es ist aber ohne Problematislerung einleuchtend, daB sich eine intime Kenntnis von Moskau und Petersburg auch in den dichterischen Bearbeltungen auBert. Hierbel werden belde stadte in der Regel wie folgt eingeordnet: das kalte, neue und weltmănnische Petersburg steht dem "gewachsenen", altmodischen und auch skurrilen Moskau gegenuber. Eine Entscheldung fur oder gegen die eine oder andere stadt ist auch in diesem zusamenhang nur von sekundarer Bedeutung, denn es handelt sich bel diesen Urtellen bereits in den zwanziger Jahren des 19. Jahrhunderts oft um einen top1schen llerkmalsbestand. Ein verändertes BewuBtsein gegenuber der Stadt (allgemein) bewirkt, daB verstärkt erlebnishafte Elemente in die Beschreibung eindringen. Die subjektive Stadtsicht, das persinliche stadterlebnis beginnt sich von den uberlieferten klischees abzusetzen. Man kann sagen, daB diese Tendenzen, die bereits bel Batjuskov und Ryleev ansatzwelse vorhanden waren, Im Werk Puskins deutlich sichtbar werden. Durch die Tatsache, daB Moskau und Petersburg bel Puskin stofflichen Antell an den verschiedensten Genres haben, labt sich ein moglichst "umfassendes" Stadtbild gewinnen. Die beiden groBen Städe, zu denen der Dichter selbst eine intensive Bezlehung hatte, durchziehen seine Dichtung wie ein roter Faden. In den frühen Gedichten, die formal wie

(1) Puskin, A.S.: Mednyj vsadnik. In: PSS, t. IV, M. 1957 ; S. 381 . 
stofflich dem Klassizismus sehr nahe stehen, waren Ioskau und Petersburg verschledentlich als Motive verarbeitet worden (1). Diese sind in ihrer Auswahl und Darstellung $m i t$ den Bildern in Deržavins Lyrik vergleichbar. In dem 1819 entstandenen Gedicht "Derevnja" nimmt Puškin die Grundidee des Poems "Cygany" vorweg: das Problem menschlicher Freihelt und schopferischen Seins inmitten der Natur. Elne Absage an die Stadtkultur ist damit notwendigerweise verbunden.

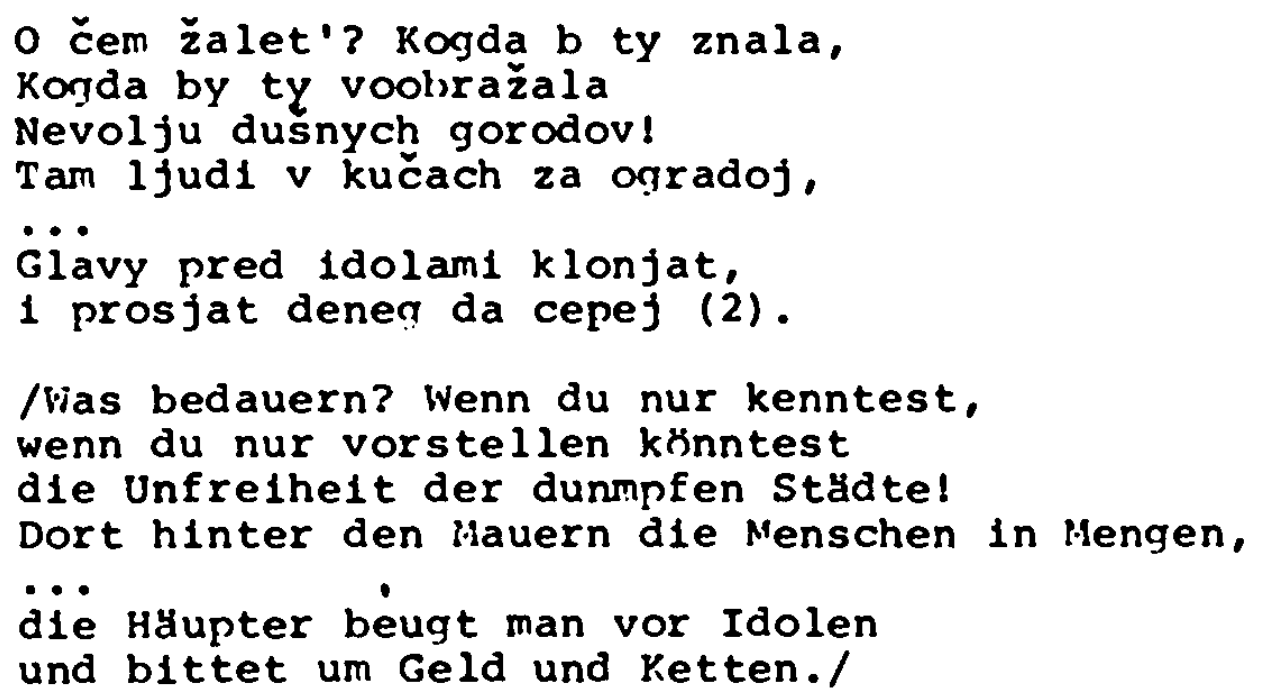

Alekos Absage an die stadt ist aus der suche nach einer nebulosen Freiheit zu verstehen, die er bel dem ungebun-

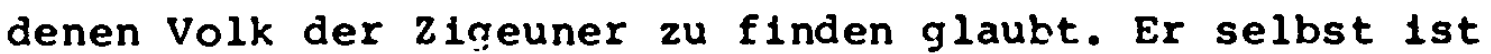
jedoch schon zu sehr zivilisiert und zwängen unterworfen, als $d a \beta$ er die für sich gewollte und in Anspruch genonmene Freiheit auf seine umgebung übertragen konnte. Aleko sprach von den zwăngen der "drückenden Städte" . Ähnlich muß auch Puskin empfunden haben, bevor er 1820 die hauptstadt verlien:

(1) Zu nennen sind hier: "Vospominanie $v$ Carskom Sele" (1814), "Vsevoložskomu" (1819), "N.N." (1819)

(2) Puškin, A.S.: PSS, t. IV, :. 1957: S. 213. Bereits hler weist Puškin auf den zusammenhang stadt - Geld - Unfreiheit hin. . 
Peterburg dušen dlja poeta. Ja žaždu kraev čužich: avos' poludennyj vozduch ozivit moju dusu (1).

/Petersburg 1st fur einen Dichter bedruckend. Ich durste nach fremden Landern: viellelcht belebt die sudliche Luft meine Seele./

Obwohl Moskau und Petersburg im Leben Puškins elne große Rolle gespielt haben, ist sein Engagement fur diese Städe nicht eindeutig zu fixieren.

Unbestreitbar ist fene Nelgung, die elner stadt entgegengebracht wird, ... ein Ergebnis psychologischer, numlich affektiver Prozesse ... Sie lst Ausdruck einer kollektiven, Generationen umspannenden Gestaltungs- und Lebenskraft ... (2).

Diese Nelgung, von der Mitscherlich spricht, kann sich in der Dichtung in der Art und Welse der Darstellung realer Lebensrăme auBern. Hlerbel muB aber Immer berucksichtigt werden, das eine scharfe Trennung zwischen verarbeiteten individuelien Eindrucken und unbewubter Rezeption nicht eingehalten und damit auch in der Interpretation nicht getrennt werden krinnen.

Im "Evgenif Onegin" (1824-1830) spielen Moskau und Petershura wie es schelnt elne für den Fortgana der Handluna unwesentliche Rolle, doch sind belde stadte bel weltem nicht nur staffage. In pittoresken Einzelheiten schildert Puškin das zeltgenussische stadtleben mit allen Merk- und Denkwurdigkeiten.

Nadev šlrokif bollvar,

Onegin edet na bui'var

I tam guljaet na prostore,

.... (3)

/Nachdem er den hreiten Bolivar aufgesetzt hat, geht Onegin auf den Boulevard und flaniert dort ..../

(1) Brief an Vjazemskif vom 21.4. 1820.

(2) ritscherlich, $\Lambda_{0}$ : Anstiftung zum Unfrieden, Frankfurt/v.: S. 31 . 
In diesen zeilen des ersten Kapitels spricht Puskin eine typisch städtische Erscheinungsform an: den Flaneur mit seinem Aktionsrahmen, den großen Poulevard. Die Darstellung von Onegins Tageslauf wird durch gastrononische Einzelheiten eines ahendichen Mahles und durch die Schilderung eines anschließenden Theaterbesuches ergänzt. Durch das nächtliche Petersburg mit seineri Lichtund Schattenspiel fährt Onerin zu einem Ball, mit deri der Tag zu Ende geht.

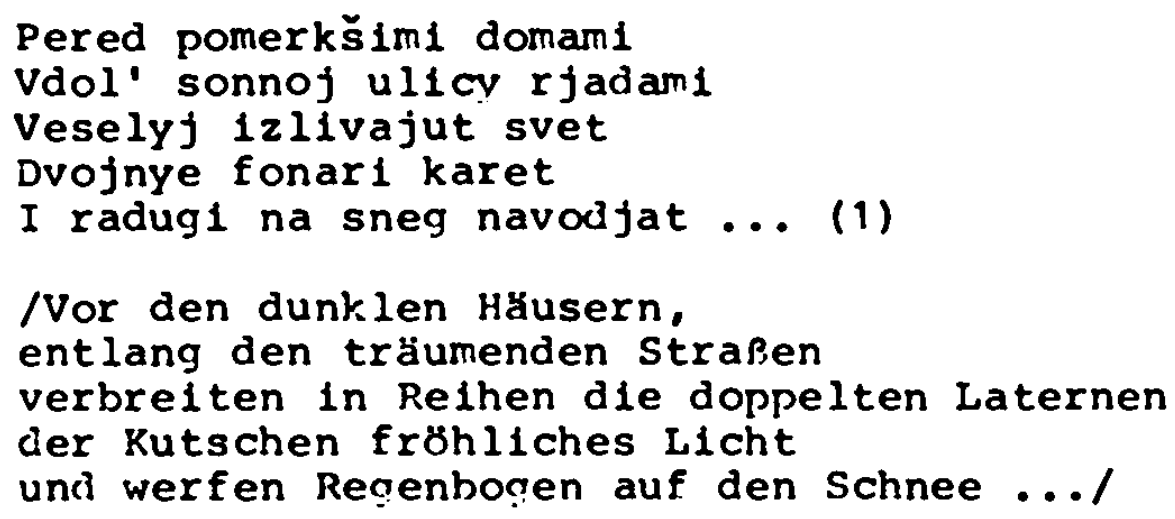

Dieses năchtliche Stadtbild ist nicht allein für Petersburg typisch; allerding̣s erkannte der Leser im Spiel der Andeutungen und geschilderten Verhaltensweisen vor zwar schemenhafter Kulisse den Ort der Handlung. Puškin legt in diesem zusammenhang keinen fiert auf die "Ausgestaltung" der Raumlichkeiten, d.h. das statische Element tritt hinter der. dynamischen v8lig zurück. Der Darstellung des für Onegin typischen gesellschaftlichen Aktionsrahmens und den stilisierten Răumen des Müigganges steht das Eild vom erwachenden Petersburg gegenüber.

A Peterburg neugomonnyj Uz barabanom probuzden. Vstaet kupec, idet raznoscik. Ha birzu tjanetsja izvożik,

(1) Puskin, ג.S.: PSS, t. V; S. 21. 
S kuvainom ochtenka sperit, Pod nej sneg utrennif chrustit. Prosnulsja utra Sum prijatnyj.

Okryty stavn1, ... (1)

/Und das rastlose Petersburg wird berelts von der Trommel aufgeweckt. Der Kaufmann steht auf, der Bote kommt, zur Haltestelle zleht der Kutscher, das Ochtamadchen eilt mit einem Krug, unter ihr knirscht der morgendliche Schnee. Es erwachte das angenehme Rauschen des Morgens, die Fensterlăden sind gerffnet ..../

Das hier geschilderte Milieu unterscheldet sich von den Kreisen, In denen sich Onegin zu bewegen pflegt. Puškin gibt in diesen zeilen einen sozlologischen nuerschnitt en miniature durch das 'tatige' Petersburg.

Die erwachende llauptstadt wird in wirkungsvollem Gegensatz zwischen reich und arm, ... elngefangen.:ein Gegensatz, der hier jedoch keine soziale, keine gesellschaftskritische Funktion hat (2).

Nilsson hat in einem Aufsatz auf den literarischen Hintergrund dieser szene hingewiesen. Fr stellt hierbel eine Xhnlichke1t nit bekannten franzisischen und engl1schen "Sittenschilderungen" von London und Paris fest (3). Seine Schlurfolgerung: diese Art Beschreibungen waren so populăr, das sle bereits Schablone waren. Das gilt auch für das Bild von der "erwachencen Stadt", das Puškin Im "Evgenif Onegin" auf Petersburg ubertragen hat. Die groBe Stadt wird im I. Kapitel zwar in ihrer Komplexitat angedeutet, doch bleiben die verschiedenen Raume unverbunden nebeneinander. Der Held durchmibt sie, ohne threr telihaftig zu werden; er lebt in der stadt, ohne uber sie

(1) Puškin, A.S.: PSS, t. V; S. 25.

(2) Nilsson, N.A.: Das erwachende Petershurg. Eine Bemerkung zu Eugen Onegin;Erster resang, Str. XXXV. In: ScS1. 1954; S. 99.

(3) Nilsson nennt Mercier, Balzac, Di Gkens und 83 gantogs 
zu reflektieren. Vordergrundig und für das sujet bestimmend ist Onegin Antipode des intellektuellen Idealisten Lenskij. In seinem Hahltus ist von Puskin jedoch mehr angelegt. Onegin ist der typische Vertreter stadtischer Melancholie. Als "Dandy", als "Flaneur" baut er "psychische Dämme gegen den aus seiner Jmọebung erwachsenden Pessimismus (1)." Die 'Flucht' auf das Land ist eine notwendige Folae. Daß Puškin die Nktionen onegins nach petersburg verlert, unterstreicht das bestehende Wechselspiel zwischen Stadt - Land - Individuum. Als Typ entspricht Onegin der Tesellschaftlichen Intwicklung der zeit.

In Kapitel VII des Romans ist :oskau Handlungshintergrund. inläßlich der Reise Tatjanas in die alte Hauptstadt heibt es:

Ho vot uz blizko. Pered nimi

Uz belokamennoj hoskvy,

kak zar, krestanil zolotymi

Gorjat starinnye glavy.

Ach, bratcy! Kak ja byl dovolen,

Kogda cerkvej 1 kolokolen.

Sadov, čertogov polukrug

otkryisja predo mnoju varug!

Kak casto $v$ gorestnoj razluke,

$\checkmark$ moej bluždajuščj sud'be,

loskva, ja dumal o tebe!

lloskva... kak mnogo $v$ etori zvuke

Dlja serdca russkogo slilos'! (2)

/Da ist es schon nahe. Vor ihnen brennen schon des weißsteinigen lloskaus

altertumliche Kuppeln mit goldenen Kreuzen wie Feuer.

Ach, Brüder! hie war ich froh, wenn sich vor mir plotzlich das

Halbrund der Kirchen und Glockentürme,

der Gärten und Palaste offnete!

(1) Lepenies, i.: Melancholie und Gesellschaft, Frankfurt/:1. 1972; S. $93 \mathrm{ff}$.

(2) Puškin, A.S.: PSS, V; S. $155 / 56$. Auch hier liegt das bekannte Motiv "pereezd $v$ Moskvu" vor. 
Wie oft in kummervoller Trennung, in meinem unsteten Schicksal, Moskau, dachte 1 ch an dichl Moskau ... was alles verschmolz in diesem wort fur ein russisches Herzl/

Die objektive Beschreibung Moskaus, ausgedrückt auch in der Verwendung herkommilcher Topol (1), ist hier mit persönlichen Empfindungen des Dichters verbunden.

\begin{abstract}
Hier spricht das Ich nicht in seiner Rolle als Erzahler, sondern es ist aus der allgemeinen Fiktion ausgebrochen, es steht neben ihr und spricht Gefuhle einer real existierenden Person, nămlich Puskins selbst aus (2).
\end{abstract}

In elnem Katalog verschledener Sinneseindrlicke wird das individuelle Stadterlebnis Puskins verbalislert. Einzelne iomentaufnahmen verdichten sich zu einem Gesamtbild von Yoskau, dessen lebendige Darstellung auf die Aneinanderreihung verschiedenartiger objekte und subjekte zurückzuführen 1 st.

Pošel! Uže stolny zastavy

belejut: vot po uz Tverskoj

Vozok nesetsja črez uchaby. Mel'kajut mimo budki, baby.

Mal'čski, lavki, fonari,

Dvorcy, sady, monastyri.

Bucharcy, sani, ogorody,

... (3)

/Auf gehts! Schon schimmern die saulen des Schlagbaums; schon holpert der wagen durch die Tverskaja.

(1) Bereits aus Karamzins Moskaubildern sind bekannt: belokamennaja Moskva; zolotye kresty; cerkvy. Ebenfalls an Karamzin erinnert der Eindruck des "arphitheatrischen Moskau-Panoramas". hier durch "polukrug" verbalisiert.

(2) Hielscher, K.: Puškins Versepik. Autoren-Ich und Erzahlstruktur, Mlinchen 1966; S. 130.

(3) Pušk1n, A.S.: PSS, V; S. 156/57. Gudrun Ziegler -9783954793303 
Es huschen vorüber Buden, Weiber,

Knaben, Läden, Laternen,

Palăste, Gärten, Kloster,

Bucharen, Schlitten, Gemüsegärten,

-...l

Der Roman endet dort, wo er begann: in Petersburg, "v bol'కom svete". Onegin kehrt in die stadt zurück, die er vorübergehend zugunsten ländlicher Umgebung verlassen hatte. Seine verinderte Haltung zur stadt entspricht einer gewandelten Einstellung des Dichters. Aus der anfänglich ironischen Schilderung des gesellschaftlichen Lebens in der Hauntstadt ist eine satirische Darstellung geworden. An dieser Verăncerung partizipiert auch onegin.

Tut byl odnako cvet stolicy,

I znat', i mody obrazcy.

Vezde vstrecaemye lica,

Neobchodimye glupcy: (1)

/Hier war nämlich die Blute der Hauptstadt, Muster des Adels und der Mode, Personen, die man uberall trifft, unentbehrliche Dummkopfe:/

:loskau und Petershurg erhalten im "Evgenij Oneoin" ihre lionturen sowohl durch erlebte, detaillierte räumlichgeographisch Beschreibungen, als auch durch die Darstellung ihres zeitgenössischen "byt" (2). Dabei uhernehilen beide Großstădte verschiedene liollen. Petersburg steht für die 'große stadt' schlechthin. Onegin ist ihr typischer Vertreter. Nuf die Kategorie gesellschaftlicher zustände übertragen heiBt dies: die GroBstadt ist der Ort, in dem sich Aktivitäten und Melancholie (chandra) einander bedingen. :loskau hingegen ist

(1) Puگkin, A.S.: PSS, V; S. 176.

(2) Gerade wegen der Darstellung des "byt" nannte Belinskij Puškins Roman "eine Enzyklopădie des russischen Lebens". Neben (iriboedovs "Gore ot uma" ist "Evọenij Onegin" ein typischesGudokighente zeit. 
für Pưkin die stadt mit persönlichem Charakter. Als solche steht sie in direktem Gegensatz zum moderneren Petersburg. Ihre Darstellung Innerhalb des Romans dient aber auBerdem dazu, das Engagement Pǔskins für diese stadt auszudrücken. Damit tritt neben die herkömmlichen 'objektiven' stilisierten stadtbeschreibungen verbalisiertes personnliches Stadterlebnis (1).

In die zeit um 1827, also in die Entstehungszeit des "Evgenij Onegin" fallen die ersten Prosaversuche des Dichters. Sein unvollendet gebliebener Roman "Arap Petra Velikogo " (1827) sollte die Biographie von Puskins Vorfahren Hannibal als Sujet gestalten (2). liachdem die Handlung in Paris begonnen hat, wird im 2. Kapitel das neugegründete Petersburg zum Schauplatz der 'historischen' Ereignisse. Es ist fur Pußkin nicht schwer, aus der sicht des 19. Jahrhunderts ein Bild des 'alten' Petersburg zu vermitteln, kann er doch auf Motive zurückoreifen, die in der Literatur bereits fest verankert sind. $\mathrm{zu}$ nennen ist hier v.a.: die sumpfige, unwirtliche Ungebung und damit verbunden die Vorstellung vom siẹ des menschlichen lilliens uber die Natur. Die Verarbcitung des historischen stoffes zelgt, daß zu Puskins Vorstellung vom frühen petersburg auch das gesellschaftliche Leben gehirrt (3). In der Dynamik solcher szenen gewinnt die Stadt an Gestalt und Intensität, während die statischen Elemente, d.h. die Beschreibung des Raumes

(1) Vor Puskin war auch das Motiv Moskau - Petersburg eindeutig auf eine bildhafte Gegenuberstellung des iuberen der belden städte festgelegt. ilit Puskin beginnt das ästhetische Interesse hinter personliches Erleben und dem Erkennen gesel1schaftilcher zusammenhänge zurückzutreten.

(2) Puškin, A.S.: PSS, VI; S. 9-56.

(3) Für puškin gehört das Leben in der stadt unbedingt zu ihrem 'Hesen'. 
der Konturgebung dienen. Die Komplexität der Stadt zeigt sich erst in der Darstellung inrer Bewohner.

In diesem zusammenhang muB ein Fragment aus dem Jahre 1829 erwähnt werden, das vermutlich den Vorwurf zu einem Gesellschaftsroman bildete. In "Gosti s"ezžalis' na daču" äuBert ein Spanier folgende nnsicht:

Itak, blagodarja vlijaniju.klimata, - skazal on, Peterburg est' obetovannaja zemlja krasoty, ljubeznost1 1 besporočnost1 (1).

/Deshalb, dank des Einflusses des Klimas, - sagte er, - ist Petersburg das gelobte Land der Schonheit, der Liebenswürdigkeit und Makellosigkeit./

Die Antwort eines russischen Gastes ist treffend:

Krasota delo vkusa, - otvečal russkij ...(2)

/Schönheit 1st eine Sache des Geschmacks, antwortete ein Russe .../

Diese zeilen sind ebenso symptomatisch für Puskins Einstellung, wie eine Sentenz, die sich wiederholt in seinen hinterlassenen Schriften findet: "Noskva devið’ja, Peterburg prichožaja."/:loskau ist das Mădchenzimmer, Petershurg das Vorzinmer./ In seinem "Roman v pis'mach" (1829) wird diese Nussage näher uins chrieben.

Otdychaju ot peterburgskoj žizni, kotoraja mne užasno nadoela .... Peterburg prichožaja, Moskva devič'ja, derevnja že naš kabinet. Porjadočnyj čelovek po neobchodimosti prochndit čerez perednjuju $i$ redko zagljadyvaet $v$ devič'ju, a sidit u sebja $v$ svoem kabinete (3).

(1) Puškin, A.S.: PSS, VI; S. 561.

(2) Puskin, A.S.: PSS, VI; S. 561.

(3) Puskin, A.S.: PSS, VI; S. 71. 
IIch erhole mich vom Petersburger Leben, das mich entsetzlich langweilte ... Petersburg ist das Vorzimmer, Hoskau das Mädchenzimmer, das Dorf aber unser Kabinett. Der ordentliche Mensch geht nach Notwendigkeit durch das Vorzimer, schaut selten in das Mädchenzimmer und sitzt in seinem Kabinett./

Diesen zeilen laßst sich eine treffende und zeitnahe Charakteristik der belden stadte entnehmen. Petersburg als das Vorzimmer mit exponierter stellung, wo sich im weitesten Sinne des Wortes das Leben abspielt, ist zwar repräsentativ, aber nicht individuell. Im ubertragenen Sinne bedeutet es: Petersburg ist die Station im Leben der zeitgenossen, die notwendigerweise zu durchlaufen ist, wenn man gesellschaftlich vorankommen will. Das als "Mädchenzimner" bezeichnete Moskau spielt seine Rolle am Rande, etwas vernachläsigt, aber auf seine Art vertraulich. Mit der Gleichsetzung Dorf-Kabinett spricht Puskin die ruhige beschauliche Atmosphare landlicher Umgebung an, deren erholsame und schrpferische Wirkung bereits in seinen frühen werken mehrfach angedeutet wurde.

Puškins iloskaubild kann durch "Grohovščik" (1830) vervollständigt werden (1). Hier wird ein stadtausschnitt geschildert, der als "in der Nahe des Nikitskij Tores liegend" beschrieben wird. Bereits bel Tatjanas Einfahrt in Moskau hatte der Dichter Einzelheiten aneinandergereint, die für die Vorstadt charakteristisch sind. In "Grobovščik" beschränkt er sich auf ein răumliches Minimum. Ort der handlung ist ein Straßenabschnitt, charakterisiert durch einander gegenüberliegende Häuser. Vor diesem nicht naher beschriebenen realen Hintergrund vermischen sich in der Erzählung Traum und wirklichkeit.

(1) Puskin, A.S.: PSS, VI; S. 119-128. 
Mit dem Vorstadtmilieu, den für Hoskau typischen Deutschen, den aus dem Fenster gaffenden Tochtern des Sargmachers und nachbarlichen Einladungen, stellt Puškin erstmals die "Stadt im Kleinen" dar. Das heiBt in diesem Zusamnenhang keine detaillierte Studie, sondern treffend beobachtete Details. Puškins 2 iel ist allerdings nicht eine soziologische Skizze, sondern nach Ciževskij eine literarische Polemik gegen die herkinmilichen phantastischen Erzählungen (1). Hicht ohne Grund wählt der Dichter aber Moskau als llandlungshintergrund. Die stadt selbst erscheint ihm und auch den zeitgenossen als so skurril, daß die Grenze zwischen Traum und rirklichkeit verschwimmt.

Gleichsam als Finleitung zu Puškins "Meànyj vsadnik" können cie Anfangszeilen aus dem rragnent "Ezerskij" (1832) gelten:

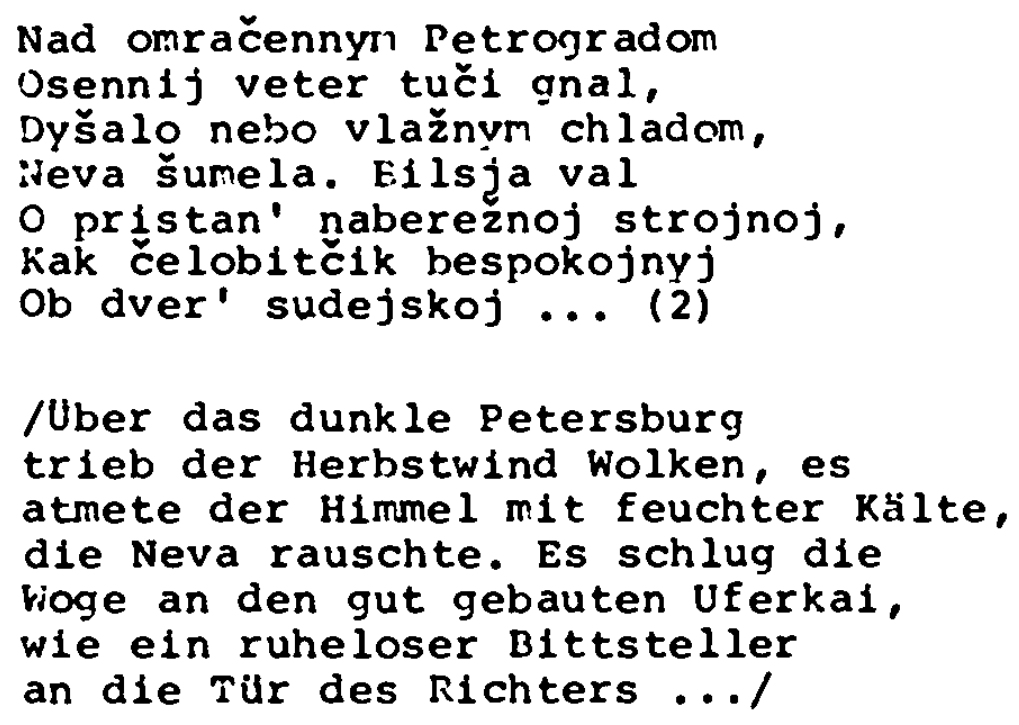

Hier wird die Verhindung der Stact Petersburg mit der Neva angedeutet, von deren Beweçungen eine Bedrohung ausgeht. In diesem zusammenhang verwendet Puškin, neben cer synonymen Behandlung von Fluß und stadt, noch ein weiteres für Petershurg charaliteristisches Motiv, und

(1) Ciževskij, D.: Russ.Literatur des 19.Jahrhunderts, I, München 1964; S. 66. 
zwar: das Wetter.

Im "Mednyj vsadnik" (1833) kommen die Naturgewalten. die in "Ezerskij" noch als gebandigt dargestellt werden, zum Ausbruch. Zwel verschiedene Petersburg-Bilder stehen sich in dieser "Peterburgskaja povest" gegenuber: "gorod pyšnyj" und "gorod bednyj" /glänzende stadt und arme stadt/ (1).

Vor dem realen Hintergrund der Uberschwemmung von 1824 spielen die tragischen Ereignisse um Evgenij. Dieser hatte durch das schreckliche Hochwasser seine Braut verloren. In geistiger Umnachtung erhebt er Protest gegen den Grüder der stadt. Dieser verfolgt Evgenij in Gestalt des lebendig gewordenen Reiterstandbildes und treibt ihn in den Tod (2).

":iednyj vsadnik" beginnt mit einem Panegyrikos auf Peter I. und auf sein Werk, die neue Hauptstadt. Gleichzeitig wird mit einer Beschreibung des Gründungsvorganges die natürliche Lage der stadt skizziert, sowie die politische Notwendigkeit dieser Tat hervorgehoben (3). liach uber hundert Jahren (seit der Grünung) kann Puskin cie "junge Hauptstadt" als "pyకnyj" und "gordelivyj" /glänzend und stolz/ darstellen. Diesen Gesamteindruck vermittelt der Dichter durch eine Beschreibung der arch1tektonischen Elgenart der stadt, sowie stilisierte Details aus dem für Petersburg typischen gesellschaftichen Leben. Der in dieser Darstellung betonte Dualismus von fruher und heute wird von Puskin in der Gegenuberstellung der neuen llauptstadt und des alten Moskau auf eine 'Ideologische' Ebene Ubertragen (4).

(1) Puškin, A.S.: PSS; S. 79.

(2) Das Hochwasser von 1824 wurde vielfach beschrieben. Z.B.: Griboedov: Castnye slučal Peterburgskogo navodnenija; Odoevskij: Nasmeška mertveca; Mickiewicz: Oleszkiewicz.

(3) Puškin betont hier die Idee Peters I. von Petersburg als dem "Fenster nach Europa".

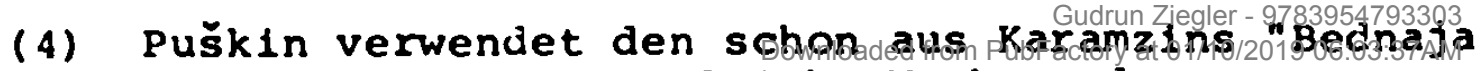
Liza" hekannten Vergleich: Iloskva-vdova. via free access 
In der "Liebeserklärung" an die llauptstadt wird die Faszination angesprochen, die sich aus dem zusammentreffen der architektonischen Konstruktion inmitten der wilden Natur des nordlichen RuBland ergibt.

Ljublju tebja, Petra tvoren'e, Ljublju tvoj strogij, strojnyj vid, Nevy derzannoe tečen'e, Beregovoj ee granit, Troich ograd uzor Eugunnyj. ... (1)

/Ich liebe dich, Werk Peters, Ich liebe delnen strengen, wohlgestalteten Anblick, der Neva mächtigen Lauf, ihrer Ufer Granit, das Muster deiner eisernen Gitter, ...l

Die panegyrische Einleitung wird mit einer beschwrrenden Geste an die stadt und an die rehundig̣ten Naturgewalten beschlossen. Die Geschlossenheit Petersburgs und die reliefartige Schilderung im "Vstuplenie" stehen im vollen Gegensatz zur elgentlichen Erzăhlung. Denn in dieser geht es nicht mehr um die Beschrelbung friedlicher Räume, soncern um Dekomposition und nuseinandersetzunç einzelner Komponenten. Aus dem zusanumenspiel von rind und Flus erwarchst der Stadt eine Becirohung, wollei das Bild cier "an die Tür klopfenden !leva" aus "Ezerskij" hier ungestaltet wird.

lieva rietalas', kak bol'noj

V svoej postele bespokojnoj (2).

/Die lieva wallte sich wie ein unruhioger Kranker in seinem Bett./

(1) Puskin, A.S.: PSS, IV; S. 381 .

(2) Puskin, A.S.: PSS, IV; S. 384 . 
Der hier zundchst angedeutete passive Widerstrelt wird in der Schilderung des ungluckseligen Tages $z u$ einer aktiven Auseinandersetzung. Das AusmaB der Uberschwemmung wird von Puskin in einem eindruckvollen Bild dargestellt: die Stadt Petersburg wurde zu einem Triton, der bis zum Gurtel aus dem Wasser ragt. Innerhalb dieser 'Stadt im Ausnahmezustand' verschmelzen thre einzelnen Raumkomponenten, d.h. es werden die realen topographischen Berelche gegeneinander verschoben. Was von Petersburg selbst noch zu erwahnen 1st, wird zu elnem Negativkatalog: zerborstene Brucken, angeschwemmte Balken und Bretter, aufgewuhlte Friedhofe (1). Inmitten verlorener Perspektiven, inmitten der uferlosen Wasserwliste gestaltet der Dichter einen scharf konturierten Raum: den zufluchtsort Evgenifs vor den steigenden Fluten.

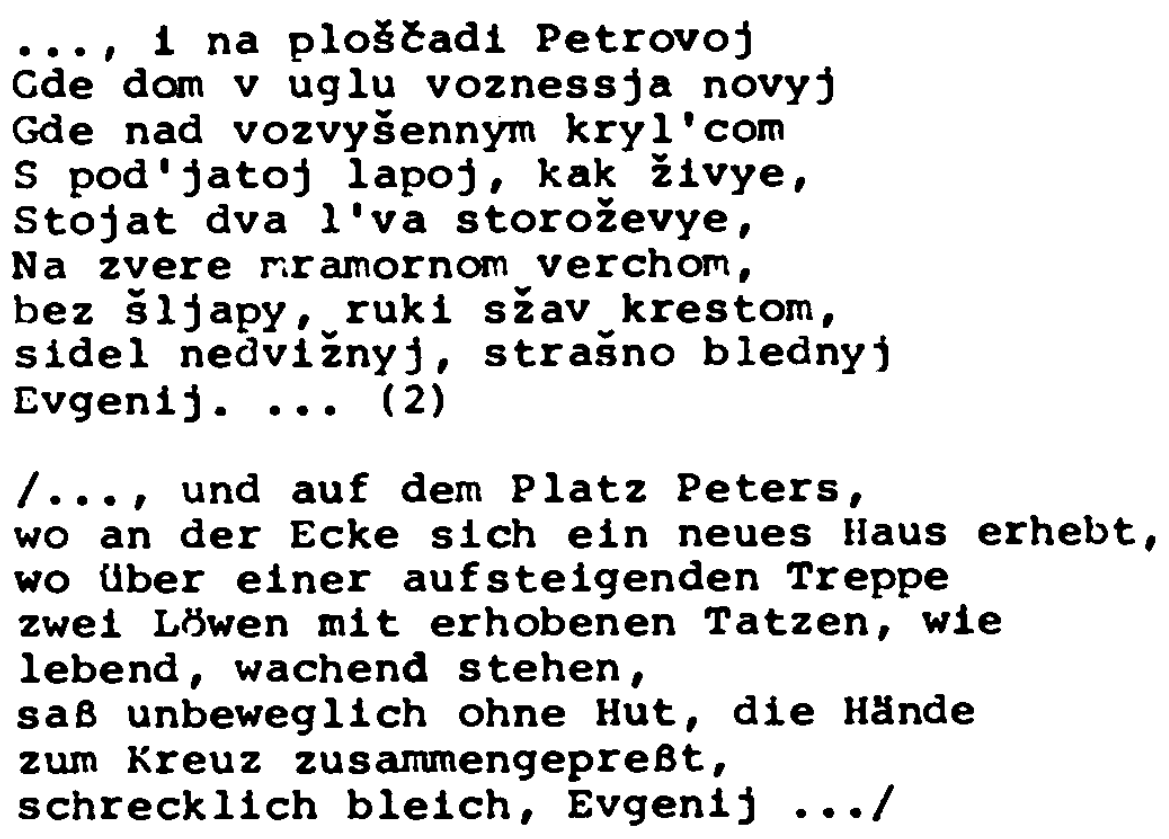

Diesem Ort gegenüber "steht mit erhobener Hand, das Standbild" (3).

(1) Puskin, A.S.: IV; S. 387.

(2) Puskin, A.S.: IV; S. 388.

(3) Puskin, A.S.: IV; S. 389. 
Mit dem Ende des 1. Tells hat sich die Stadt, deren Konturen aus dem bisher Dargesteliten nur andeutungsweise slchtbar wurden, an elnem Punkt verdichtet: dem Standbild Peters I., dem Symbol der Stadt an der Neva. Auf der Suche nach seiner Paraša ellt Evgenif durch die Straßen Petersburgs und durch ihm bekannte Stadtgebiete. Dem Leser werden diese Raume nicht markiert, denn ihre Identifizierung ist nur fur den lielden von Bedeutung. Evgenif mu feststellen, daB seine reale Umgebung nicht mehr mit derjenigen identisch ist, die er in seinem Gedächtnis bewahrt hat.

I vot bežit už on predmest'em,

I vot zaliv, 1 blizok dom ....

Cto $\check{z}$ éto? ...

On ostanovilsja.

Pošel nazad 1 vorotilsjąa.

Gljadit ... Idet ... esce gljadit (1).

/Und schon eilt er in die Vorstadt, ca ist die Bucht, und nahe das Haus ... Doch was ist das? ...

Er hielt inne.

Ging zurück und kehrte um.

Er schaut ... er geht ... schaut noch einmal./

An diesem Punkt, wo die Sinneseindrücke und Vorstellungen nicht mehr ubereinstimmen, ist für den Helden ein normales Raumempfinden nicht mehr mralich, "vse chodit, chodit on krugom" /er geht, und geht im kreise/ (2).

Evgenij, der jede Beziehung zum normalen Lehen, und camit jegliches zeit- und Raunigefuhl verloren hat, irrt durch die Stadt. Puškin verzichtet bein: liinweis auf den Irrweg auf detaillierte Angaben; er verbleibt im Unbestimmten und entspricht somit auch darstellungsmäßig dem augenblicklichen zustand des llelden.
(1) Puskin, A.S.: PSS, IV; S. 391/392.
(2) Puskin, A.S.: PSS, IV; S. 392. 
Ein einziges Mal noch entwirrt sich sein Verstand, was durch das ralumliche Hervortreten des stadtischen H1ntergrundes angedeutet w1rd.

On oxut1lsja pod stolbami Bol'gogo doma. Na kryl'ce s pod'jatoj lapoj, kak zivye. Stojali l'vy storozevye. I prjamo $v$ temnof vysine Nad ograždennoju skaloju Kumir s prostertoju rukoju sidel na bronzovan kone (1).

/Er befand sich plotzlich unter den sarulen eines groben Hauses. Auf der Treppe standen mit erhobenen Tatzen, wie lebend, die wachenden Ioben, und unittelbar in der dunklen Hohe auf dem umzanten Felsen sab das standbild mit ausgestreckter Hand auf seinem bronzenen ROB./

In der Beschreibung der Flucht Evgenifs vor dem lebendig gewordenen Relterstandbild offnen sich die weiten Raume Petersburgs, deren Dimensionen durch das Echo der Pferciehufe noch erweltert werden. Man findet den toten Evgenij schlieblich abselts von der stadt, die ihm zum Verhăngnis wurde.

Puskin hat im "Mednyj vsadnik" bewust auf eine detaillierte Beschrelbung der Hauptstadt verzichtet. Es ging ihm also nicht darum, ein aktuelles stadtbild zu vermitteln. Bereits im "Vstuplenle". In dem er vorwlegend bekannte panegyrische Topol verarbeltete, hatte der Dichter auf das AuBergewöhnliche Petersburgs hlngewlesen. In der geschilderten Ausnahmesituation, wobel die Handlung selbst auf ein Minimum beschrankt blieb, wird vor dem Hintergrund eines realen Erelgnisses der Mythos der Stadt lebendig.

(1). Puskin, A.S.: PSS, IV: S. 394. Diese Zellen entsprechen bis auf geringe Abwe1chungen der Beschrelbung aus dem 1. Kapitel. 
Das Zusammentreffen ungebändigter und gebăndigter Naturkräfte im vom Menschen geformten Raum ist hier eines der handelnden Elemente. Indem sich der Raum von der reinen statik lobsen labt und selbst dynamisch wird, setzt er die Ereignisse in Gang (1). Das Denkmal Peters I.war das Wahrzelchen der stadt und gleichzeitig thr symbol. Es 1st aber nicht nur der wille des stadtgründers, den puš$k$ In im verlebendigten standbild darstellte, sondern sein gewachsenes werk, das zum Angriff auf den Menschen ansetzt. Im "!ednyj vsadnik" wird durch den Gegensatz der panegyrischen Elnleitung und der Grausamkeit der Ereignisse die Fatalitat der stadt Petersburg aufgedeckt.

Fast gleichzeltig mit dem "Ehernen Reiter" entstand eine Erzăhlung, die im weitesten Sinne als "Petershurger Erzăhlung" bezeichnet werden kann. Auch wenn in "Pikovaja dama" (1833) die Stadt selhst kaum hervortritt, ist sie doch lebendig. Sie repräsentiert sich hier vor allem in der Gestalt liermanns, der als Ingenieur Vertreter einer neuen, kuhl denkenden Generation ist. Dies allein spricht natülich noch nicht für die stadt, obwohl die liahl eines Technikers als handelnde Person vor allem in städtischer Ungebung glaubhaft wirkt (2). Dieser Gedanke wird durch die Tatsache bestătigt, daB Puskin Petersburg dann real hervortreten läBt, wenn von Hermann die Rede 1 st. In einer für den Fortgang der Handlung entscheidenden szene wird ein für spätere Petersburgdarstellungen typlsches Bild beschrieben.

(1) D.h.: Elnwirkungen von AuBen verändern den Raum, wobel dessen Umgestaltung neue Aktionen in Gang setzt. Es wăre zu untersuchen, ob und wieweit Puskins Grundeinstellung zum Widerstreit zwischen Kultur (=Petersburg) und Natur von Schellings Naturphilosophie beeinfluBt ist.

(2) M1t Hermann wird ein neuer Personenkreis in die Dichtung des 19. Jahrhunderts aufgenommen. z.B. Vl.odoevskif wählt als Vertreter des rationalen Denkens einen Brigadier und einengletatophalos bkonom fur selne Erzăh lungere. from PubFactory at 01/10/2019 06:03:37AM 
$V$ desfat' Casov večra on uz stojal pered domom grafin1. Pogoda byla uzasnaja; veter vyl, mokryj sneg padal chlop'jami; fonarl svetilis' tusklo; ulicy byli pusty. Izredka tjanulsja Van'ka na toščj kljace svoej, vysmatrivaja zapozdalogo sedoka (1).

/Um zehn Uhr abends stand er bereits vor dem Haus der Grafin. Das Wetter war schauderhaft; der Wind heulte und feuchter Schnee fiel in groben Flocken; die Laternen schimmerten trübe; die straBen waren leer. Selten zog ein Kutscher mit einem mageren Gaul voruber, nach elnem verspäteten Gast Ausschau haltend./

Angedeutet sind hier die vor allem von Gogol' sehr geschätzten dotive: năchtliche Stadt und typisches Petersburger lietter. In diesen zeilen aus "Pikovaja dama" zeigt sich bereits andeutungsweise die Anonymităt städtischer Landschaft. Auf den Handlungsverlauf projiziert heißt das: die stadt ist hermann einerseits schutz fur sein Vorhaben, ir. weiteren Sinne ist sie jedoch fur seine Tat verantwortlich. Der Zusamenhang zwischen der GroBstadt und der llacht des Celdes, die für Hermann verhängnisvoll wurde, wird in der crzahlung noch von der Phantastik überlagert. Puskin hat fedoch diese unhelihringende 'Konstellation', die auf der Konzentration des Kapitals in den stădten beruht, klar erkannt (2).

Die Vorliebe für journalistische stadtbeschreibungen im Sinne der französischen "Feuilletonsde moeurs" hatte zwar auch in den russischen Journalen thren Ausdruck gefuncien, docir war dieses Genre nicht in dem Maße verbreitet wie in cien westlichen Ländern. Im zusammenhang mit Radiščev wurcie schon darauf hingewiesen, daß sich in der russischen Literatur des ersten Viertels des 19. Jahrhunderts das "nravoopisatel'noe opisanie" /sittenbeschreibende Schilcerung/ vor allem in der Reiseliteratur nachweisen läBt.

(1) Puškin, A.S.: PSS, VI; S. 336.

(2) Dieses Motiv ist bel Gogol' und hei Dostoevskif wesentlicher Bestandteil der 'Stadtexzahlungeng' 3303 
Die Vermischung rein beschreibender Passagen mit persönlichen Reflexionen muß hier besonders berücksichtigt werden. Einen in der Art ungewöhnlichen Reisebericht hatte Radiščev in seinem "Putešestvie iz Peterburga $v$ Moskvu" vorgelegt. Ungewöhnlich deshalb, weil die "Reise" nur ein Vorwand für eine Reihung von Episoden und Aufsätzen ist, deren thematischer lintergrund nicht durch das geschilderte Erlebnis durchmessener Raume, sondern durch eine an Rousseau orientierte Moralauffassung gebildet wird. In selnem "Putesestvie 12 Moskvy v Peterburg" (1833/35) tritt Puskin als Antagonist Radiševs auf.

Puskin knüpt in seinem Aufsatz zunächst bewuBt an Radišev an.

... ja načal knigu s poslednej glavy 1 takim obrazom zastavil Radisčeva putešestvovat' so mnoju 12 Moskvy v Peterburg (1).

/... Ich begann das Buch mit dem letzten Kapitel und veranlaßte gewissermaßen Radiščev, mit mir von Moskau nach Petersburg zu reisen./

Sein Bericht uber iroskau beginnt hingegen mit einer deutlichen zeitlichen Distanzierung gegenüber Radišev:

'Mnogo peremenllos' so vremen Radiščeva: nyne pokidaja smirennuju Moskvu 1 gotovjas' uvidet' blestjaščij Peterburg, za zaranee vstrevožen pri mysli peremienit' moj tichif obraz zizni na vichr. 1 šum, ožidajuščij menja ... (2)

(1) Puskin, A.S.: PSS, VII; S. 271. Demerkenswert ist in diesem Zusarumenhang die iatsache, daB sich in den Jahren um 1835 die Themen "Moskau und Petersburg" haufen, wobel die Darstellung der Rivalitat dieser beiden stadte besonders beliebt ist. Vergl. Lermontov und Gogol'.

(2) Puskin, A.S.: PSS, VII; S. 272. 
/Vieles hat sich selt der zeit Radišcevs geăndert: heute, wenn ich das demutige Moskau verlasse und mich anschicke, das glänzende Petersburg zu sehen, gerate $1 \mathrm{ch}$ im voraus bei dem Gedanken, mein stilles Leben gegen den Sturm und Lărm zu vertauschen, der mich erwartet, in Aufregung ..../

"Smirennaja Moskva" und "blestjaščij Peterburg" bedeutet hier in der Gegenüberstellung nicht nur einen auBerlichen Unterschied, sondern auch divergierende Lebensweise. :Moskau 1st gegenwărtig "tichij obraz žizni" /ein stilles B1ld des Lebens/, Petersburg ist "vichr' 1 šum" /Sturm und Larm/. Die zeitliche und raumliche Konfrontation, als zeichen der Evolution oder des Verfalls ist ein einfaches :1ttel, um einer beabsichtigten Darstellung Intensităt zu verleihen. Gerade in dem hier angesprochenen Motivbereich komnit es deshalb haufig zu kontrastierenden Stilislerungen (1). In der nufzahlung der besonderen vorzüge Yoskaus und der gesellschaftlichen resonderheiten gewinnt der Leser den Eindruck von "clonožarnaja Moskva" /:1oskau vor dem. Erand/, als einer 'originellen' Stadt.

Wyne v prismirevక̌j 'loskve ọromnye bojarskile doma stojat nečal'no mezdu šlrokim dvorom, zaroščim travoju, 1 sadom, zapuščennym 1 odičalỹm (2)

/Heute stehen im ruhig gewordenen Moskau riesige Bojarenhäuser traurig zwischen elnem Hof, mit Gras zugewachsen und zwischen einem Garten, vernachlässigt und verwildert./

(1) "Linstrials gab es in Moskau ... (Nekogda v Moskve)", d.h. In der Stadt vor 1812; mit dieser Formel wird die Vergangenheit vergegenwartigt. Nur bedeutet sie hier ar: Ende in Umkehrung des ursprünglichen Sinnes Verfall und nicht wie 1m entsprechenden "gde prežde ... tam nyne" der Petersburger Schilderungen Entwicklung.

Puškin, A.S.: PSS, VII; S. 273. 
Mit dem ăußerlichen Verfall der Hăuser und der städt1schen Landschaft konstatiert Puskin auch gesellschaftliche Veränderungen: aus dem "bel'ètaz" wurde eine Pension. Ehemals "Mittelpunkt russischer Städe" (Lomonosov) gleicht Moskau jetzt eher einer Totenstadt. Die äuBere Verănderung Moskaus ist mit realen politischen Ereignissen verbunden. Der Vergleich mit dem vom Krieg des Jahres 1812 nicht betroffenen Petersburg muB hierbei das Negative an der Moskauer Entwicklung hervorheben. Darüberhinaus deutet Puškin eine allgemeine Entwicklungsrichtung an: die stadt im Umbruch und als Rahmen sozialer Umschichtungsprozesse. Puškin stellt die gesellschaftspolitische Veränderung Moskaus zunächst im Bild der "vereinsamenden" Stadt dar; der Aufstieg Petersburgs und der Verfall :loskaus stehen für ihn in elnem unmittelbaren zusammenhang:

Dve stolicy ne mogut $v$ ravnoj stepeni procvetat' $v$ odnom 1 tom ze gosudarstve, kak dva serdca ne sušcestrujut $v$ tele človećeskom (1)

/Zwel Hauptstädte krinnen in ein und demselben Iand nicht auf gleicher stufe bluhen, wie es keine zivei Herzen in einer. menschlichen korner gibt./

Fưr Radistev lagen die kritischen Punkte der zeitgenössischen Gesellschaft noch in einer aus der Ungleichheit resultierenden Not der Landbevölkerung. DaB auch die grofen Städte soziale Probleme beinhalten, wurde von Puškin an der Verarmung des stäcitischen Adels angedeutet. Aber bereits Ir: Anwachsen der Industrie erkennt er einen wichtigen Faktor, der zu neuen Reichtum der städte fuhren kann. Puskin hat in dieser skizze seine 'kulturpolitische' Stellung eindeutig aufgezeigt. Er hat bereits erkannt, daß die Entwicklung des Reiches nun von den groBen städten ausgeht. In der Bewaltigung ihrer gesellschaftlichen Umgestaltung sieht der Autor die Garantie für den 
Fortbestand der Stadt.

In der Gegenüberstellung des :roskauer und Petersburger Geisteslebens skizziert Puškin das, was Gogol' in seinen "Peterburgskie zapiski 1836 goda" in Katalogform zusammenstellt; so schrelbt Puškin z.B.:

Učenost', ljubov' $k$ iskusstvu 1 talanty neosporimo na storone Moskvy. Moskovskij žurnalizm ub'et žurnalizm. peterburg̣skij (1).

/Gelehrsamkeit, Liebe zur Kunst und Talent sind unbestreitbar auf der Selte :loskaus. Der Moskauer Journalismus schjagt den Jounalismus Petershurgs./

Das im Stil elnes Feuilletons geschriebene Kapitel "Moskva" vermittelt demnach ein diesem Genre gemäBes Bild der alten Yetropole. Verschiedene Bereiche der Stadt werden angesprochen. Sie wirken in der Vielheit und nicht im Deta11. DaB der Dichter auf die beginnende Industrialisierung aufmerksani macht, bedeutet wie schon angedeutet, Einsichtnahrie in eine Funktionsveränderung der Stadt. Ihre Rolle ist nicht mehr, wie am Beispiel Moskaus dargestellt wird, geselliger und gesellschaftlicher Aktionsrahmen, sondern die eines dem gesellschaftlichen viandel unterworfenen Gebildes. In der Gestalt llermanns, des Ingenieurs, hatte Puškin den neuen 'Stadtmenschen' in die Dichtung eingeführt.

Obwohl der Autor in einigen seiner Werke bekannte Moskauund petersburgtopoi verarbeltet und somit an traditionelle Darbletungen des Stoffes anknüpf $t$, welcht seine Grundhaltung den Städten gegenuber von den bisherigen Autoren ab. Sowohl in "Cygany" als auch in der Figur Onegins, als Typ des melancholischen stadters, wird das MiBtrauen gegenüber der GroBstadt angedeutet.

(1) Puskin, A.S.: PSS, VII; S. 276. 
Dabel 1st die Alternative nicht mehr, wie noch bel Griboedov, Flucht aufs Land, sondern versuchte geistiqe Bewältigung durch Auseinandersetzung mit der Umwelt. Diese ist allerdings nur moglich, wenn, wie in "putešestvie", die Realität der kulturpolitischen Entwicklung erkannt wird.

Für die Gestaltung des Stadtstoffes bedeutet dies: Lobsung von einer stilisierten Gesamtschau der Stadt, wobel in der angestrebten Darstellung 'wirksamer' Details durchaus herkimmliche Topoi benutzt werden knnnen. Innerhalb des Textzusammenhanges erhalten diese jedoch neue Funktionen. Vielfach werden sie aber schon bei puskin durch stadtmotive ersctzt, in denen 'abstrahierte' birklichkeit zum Ausdruck kommt, z.B. das typische Petersburger Wetter; die dämonische :1acht des Geldes (vor dem Hintergrund der Stadt); die einsame, nächtliche Großstadt. Obwohl Puskin vorviegend eine lielt schildert, die "schon damals anfing, uninteressant zu werden" (1), ist vor allelı in einigen seiner literarischen lielden das 'urbild' des Städters angelegt: in Oneciln, in Herriann und sogar in Evgenij aus deri "llednyj vsadnik".

(1) Braun, M.: Der Kampf um die birklichkeit in der russischen Iiteratur, Grttingen 1958; S. 27. 
VI. Die dreibiger Jahre. iloskau und Petersburg im Werk der Ze1tgenossen Puškins und Gogol's

Moskva ne bezmolvnaja gromada kamnej cholodnych, sostavlennych $v$ simmetričeskom porjadke .... (1)

Es ist im Rahmen dieser Arbeit nicht miglich, die 11terarische vielfalt der dreisiger Jahre auch nur annahernd darzustellen. Wenn sich die Untersuchung neben Puškin und Gogol' nur noch auf einen Dichter dieser zeit, auf Lermontov, beschränkt, dann aus folgender. Grund: se1ne Darstellung Moskaus und Petersburgs ist symptomatisch fur das sich wandelnde stadtverstandnis der zeit. Schon bei Puškin war zu dem bekannten Fundus verschiedener Stadttopol sowohl elgenes Erleben als auch Einsicht in geselischaftliche Veränderungen getreten. Wahrend 2.b. A. B e s $t u \check{z}$ e $v-M$ a $l i$ n $k i j s$ Vorliebe historischen stoffen und Eeschreibungen des gesellschaftlichen Jebens gilt, sieht vi. o d o e v $k i j$ die große stadt als Bedrohung des Menschen. Zwar 1st gerade dieser vichter stark von den Vorstellungen der Romantik geprägt, doch unahhíng̣ing davon ist folgende passage nusdruck einer allgemeinen rinstellung:

...: zvuk uličnỵch rylej nosilsja po vozduchu: 1 12 vsech ètich raznoobraznych, otdel'nych avižentj. sostavljalos' odno obščee, kotorym dyšalo, žilo eto strannoe čudovišče, skladennoe 12 grudy 1 judej 1 kamnej, kotoroe nazyvajut mnogoljudnym gorodom (2).

(1) Lermontov, M.Ju.: Panorama Moskvy. In: Socinenija, t. VI, M. -L. 1957; S. 369.

(2) Odoevsk1j, V1.: Nasmeska Mertveca. In: Russkie not1. Nachdruck der Ausgabe von 1913. München 1967; S. 118. 
/...; in der Luft hingen die vielen Geräusche der StraBe; und aus all diesen einzelnen und verschledenartigen Bewegungen entstand ein gemeinsames Etwas, in dem ein merkwürdiges Ungetüm atmete und lebte, gebildet aus Menschenmassen und Steinen und das genannt wird: die bevolkerte stadt./

In einer zeit, in der das Interesse an den gesellschaftlichen zusammenhängen wăchst und dies auch verbalisiert wird, vermittelt M.Ju. L e $r$ o $n t \circ v$ (1814-1841) noch einmal ein eindruckvolles Bild panoramatischer Stadtschau (1). Sein "Panorama Moskvy" entstand gleichzeitig mit A.S.Puškins "Putešestvie". Der hier dargestellte Blick uber die stadt dokumentiert nicht nur die persönliche Bezlehung des Dichters zu Moskau, sondern bietet darstellerisch die ideale Möglichkeit, die Stadt im Gesamt zu erfassen. Moskau ist nach Lermontov nur $2 \mathrm{u}$ verstehen, wenn naan einsieht, daB die stadt nicht nur corpus, sondern auch lebendiges Wesen ist.

Moskva ne bezmolvnaja gromada kamnej cholodnych, sostavlennych $v$ simmetričeskom porjadke ... net! U nee est' svoja duša, svoja žizn' (2).

/Moskau ist nicht eine stumme Menge kalter Steine, angeordnet in symmetrischen Linien ... nein!

:loskau hat eine Seele, hat ein eigenes Leben./

lilt dem Blick uber die Stadt (vor. Ivan Velikij aus) verbindet Lermontov das Bild von der stadt als Ozean. Daliei wirc̀ der Elnciruck unmittelbaren Erlebens durch die Plastizität der Gcräuschkulisse vermittelt, welche dem Dichter wie eine "phantastische Ouverture Beethovens" erscheint. Ebenfalls zum bekannten Bildmaterial des Motivs "Blick aus der Vogelschau" gehort der Vergleich der stadt mit einem "Ameisenhaufen" (muravejnik) (3).

(1) liferzu gehoren die Panoramen bei Karamzin, Batjuskov und Griboedov.

(2) Lermontov, :1.Ju.: Sotinenija, VI; S. 369 .

(3) Vergl. Grihoedovs " $Z$ ag̣orodnaja poezdka"ziegler-9783954793303 
Nach einer Abgrenzung des Assoziationsfeldes, das sich in diesem zusammenhang eroffnet hat, nach globalen Eindrucken, sammelt der Betrachter Einzelimpressionen. Die Vorstellung eines sich real in der zeit vollziehenden Rundblicks wird dadurch verstărkt, das Lermontov nacheinander verschiedene Himelsrichtungen optisch erschllebt.

Na sever pered vami, v samom otdalenil na kraju sinego nebosklona, nemnogo pravee Petrovskogo zamka, černeet romaničeskaja Mar'ina rošča, ...

- /Im Norden vor euch, ganz in der Ferne am Rand des blauen Horizonts, ein wenig rechts vom $\mathrm{Pe}-$ trovsker SchloB blinkt schwarz das romanhafte Marienwăldchen, ...l

Somit ist das Blickfeld in seinem aubersten Bereich abgesteckt. Mit dem Vorgang des Naherrückens und dem damit verbundenen stăndigen wechsel der Perspektive, gewinnen die Beobachtungsausschnitte an Kontur und an Details. Bevor in "Petrovskij teatr" der răumlich năchste Punkt erreicht ist, registriert der Betrachter: "bogatye kolonnady, širokie dvory, obnesennye čugunnymi rešetkami (2)." /reiche Săulenreihen, weite Hofe, ungeben mit eisernen Gittern/. Der Rundblick wird im Uhrzeigersinn fortgesetzt, wobei zunächst die räumlich naheliegenden objekte erfaBt werden. "Vasillj Blažennyj" erscheint wie der "Babylonische Turm". Bei der Beschreibung der architektonischen Vielfalt dieses Bauwerkes läbt sich Lermontov von seinen individuellen Eindrucke leiten (3). Er analysiert dieses 'Gesamtkunstwerk' aufgrund von Symetrie und Harmonie.

(1) Lermontov, M.Ju.: Sočinenija, VI;S. 370.

(2) Diese Details bleiben stilisiert. Sie sind nicht typisch für Moskau.

(3) Lermontov vergleicht Vasilij Blažennyj mit "einem geschliffenen Stöpsel, der reich istruanglépacettenos" 
Das unmittelbare Nebeneinander von Beschaulichkeit und Lärm ist für die 'große stadt' charakteristisch. In diesem Zusammenhang schreibt Lermontov:

I čto že? - rjadom s ètim velikolepnym, ugrjumym zdaniem, prjamo protiv ego dverej, kipit grjaznaja tolpa, blešcut rjady lavok, kričat raznosciki, ...(1)

/Und was ist denn das? - neben diesem prächtigen, duisteren Gebăude, seiner Tủr direkt gegenuber, wallt die schmutzige Menge, glänzen Reihen von Lăden, schreien die Ausrufer , .../

Diese dynamische szenerie bleibt der einzige Hinweis auf das verschiedenartige städtische Leben. Der Blick wandert weiter zum Horizont. So wie sich die Moskva in der Ferne verliert, werden auch die Sehenswurdigkeiten unscharf. Der Suden der Stadt wird durch einen historischen Platz bestimmt: durch den Hügel, von dem aus Napoleon das brennende Moskau betrachtete (2). Um das Tableau Moskaus zu vervollständigen, erwăhnt Lermontov noch die westlichen Stadtgebiete. Auch hier streift der Blick wieder den Horizont, wo die Landschaft im Nebel verschwimmt. Mit dem Ende des Rundblicks läBt der Autor auch den Tag zur Neige gehen. Er vergleicht das im abendlichen Glanz erstrahlende Moskau mit einer Schönheit, die nur abends ihren besten Putz anlegt. Mit diesem Bild schliebt die rein topographische Beschreibung der Stadt. Trotz Unmittelbarkeit der Darstellung erscheint Moskau in dieser skizze als Objekt, dessen Details sich im Nahher- und Fernerrulcken er- oder verschließen. "Panorama Moskvy" endet mit einem panegyrischen Finale, in dem die Einmaligkeit und die kulturelle Bedeutung des Kremls hervorgehoben wird.

(1) Lermontov, M.Ju.: Soðinenija, VI; S. 371.

(2) Auf diese historische stelle hat auch Puskin in "Evgenij Onegin" Kap. VII, 37 hingewiesen. 
On /Kreml/ altar' Rossil, na nem dolžny soveršat'sja, 1 uže soveršalis' mnogle žertvy dostojnye otečestva ... Davno 11, kak basnoslovnyj feniks on vozrodilsja iz pyljajuščego svoego pracha ?! (1)

/Er /der Kreml/ ist der Altar RuBlands, auf ihm müssen viele wirdige opfer für das Vaterland geschehen und sind schon geschehen ... Ist es lange her, das er wie ein fabelhafter Phönix aus seiner stäubenden Asche wiedergeboren ist ?!/

Die am Beginn geăuberte Vorstellung eines "beseelten Moskaus" greift Lermontov wieder auf, indem er sie nun auf die "sprechenden Kremlmauern" ubertrăgt. In beiden Bildern will Lermontov nicht das reale Leben in der stadt angesprochen wissen, sondern die historische, 1deologische Bedeutung der stadt und ihres Wahrzeichens. Hierfur spricht auch die Tatsache, daB ausschlieblich historische Baudenkmaler beschrieben werden, wobel schlieblich der Kreml synonym für RuBland, für die Geschichte des Volkes steht.

Im unvollendet gebliebenen Roman "Knjaginja Ligovskaja" (1836) wird der Gedanke von der "Stadt mit Leben" noch einmal aufgegriffen, nur wird er hier in seiner Vordergrünigkeit verstanden. In einem streitgesprăch um die Vorzüge Moskaus und Petersburgs aubert eine der handelnden Personen:

Vsjakij russkij dolžen ljubit' Peterburg: ... Moskva tol'ko velikolepnyj pamjatnik, pyšnaja 1 bezmolvnaja grobnica minuvšego, zdes' žizn', zdes' naši nadeždy ... (2)

/Jeder Russe muB Petersburg lieben: ... Moskau ist nur ein grobartiges Denkmal, ein prächtiges und schweigendes Grabmal des Vergangenen; hier aber ist Leben, hier ist unsere Hoffnung $\ldots$.../

(1) Lermontov, M.Ju.: Soxinenija, VI;S. 373.

(2) Lermontov, M.Ju.: Sołinenija, VI;S. 161. 
Lermontov setzt diese Ansicht $z u$ seiner eigenen Meinung in "Panorama Moskvy" hinzu. Beide Äußerungen treffen sich in der Vorstellung, daB Moskau eine Stadt der Vergangenheit ist (1).

Der Roman "Knjaginja Ligovskaja" beginnt mit detaillierten Zeit-und ortsangaben:

V 1833 godu, dekabrja 21-go dnja v 4 časa popoludni po Voznesenskoj ulice, kak obyknovenno, valila tolpa narodu, 1 meždu pročim šel odin molodoj činovnik: ... (2)

/Im Jahre 1833, am 21. Dezember um 4 Uhr nachmittags strömte wie gewöhnlich über die Voznesenskaja eine Menschenmenge, und unter anderem ging ein junger Beamter: ..../

Lermontov selbst gibt den Grund für die Nennung dieser Fakten an: sie sind Ausgangspunkt für eine Kette von Ereignissen "postigšich vsech moich geroev 1 geroin" /von denen alle meine Heldinnen und Helden erfaBt sind/ (3). Durch die Nennung der Voznesenskaja wird als ort der Handlung Petersburg identifiziert (4). Aktionsrahmen der einleitenden szene ist die große straBe, der Boulevard, die Lebensader der großen städe. Lermontov benutzt hier nicht wie Gogol' das "Straßenmotiv" als Schaubühne, sondern er will den Weg eines Einzelnen in einer Menschenmenge verfolgen und ihn durch sein Verhalten charakterisieren. In der Gegenüberstellung des Individuums zur groBen Masse deutet sich bereits ein großstadttypisches Phänomen an. Der von Lermontov erwähnte 'molodoj činovnik', der im 1. Kapitel noch anonym bleibt, nimmt seinen Weg "mit stoischer Hartnăckigkeit".

(1) Lermontov nennt ausschließlich historische Bauwerke.

(2) Lermontov, M.Ju.: Sotinenija, VI; S. 122.

(3) Lermontov, M.Ju.: Sotinenija, VI; S. 122.

(4) Für Petersburg spricht die wahl eines Beamten als Helden. 
Ein Zwischenfall unterbricht nicht nur die 'Wanderung', sondern wird $z u$ einem sein Leben beeinflussenden Ereignis. Selt er von einem Pferdegespann ungeworfen wurde, hat er den Lenker des Wagens, Pečorin, zu seinem persönlichen Feind erklärt. Entsprechend der Anonymitat des "Beamten" bleibt auch sein weiteres Schicksal zunăchst im Dunkeln. Im folgenden wird der Tagesablauf Pečorins geschildert. Sein 'Fluchtweg' nach dem von $1 \mathrm{hm}$ verursachten Unfall wird mit topographischer Genauigkeit beschrieben.
Meždu tem belyj sultan 1 gnedoj rysak proneslis' vdol' po kanalu, povorotili na Nevskij, s Nevskogo na Karavannuju, ottuda na Simonovskij most, potom napravo po Fontanke - ... (1)
/Inzwischen jagten der weibe sultan und der braune Traber den Kanal entlang, bogen in den Nevskij ein, vom Nevskij gings auf die Karavannaja, von dort uber die Simonov Brücke nach rechts auf die Fon- tanka - ...l

Der geschilderte Weg wird ohne Aufenthalt zurückgelegt. Lermontov will damit weniger ein räumliches Erschlieben des Stadtraumes ausdrlicken, als vielmehr einen zeitfaktor. Mittels einzelner răumlicher Detalls errelcht er eine Annăherung von erzăhlter zeit und Erzahlzeit. Pečrin, der einer anderen sozialen schicht angehort als sein Kontrahent, wird in der inm gemäBen Umgebung geschildert: Im Theater und bel Gesellschaften. Diese Treffpunkte geben dem Dichter die Moglichkeit, uber den zeltgenossischen Petersburger "byt" zu reflektieren (2). In Kapitel IV des Fragments erfahrt der Leser Näheres uber das Petersburger Klima, das als literarisches Motiv bereits bei Puskin Verwendung fand.

(1) Lermontov, M.Ju.: Soðinenija, VI; S. 123.

(2) Als Räume der Geselligkeit nennt Lermontov vor allem das "Aleksandrinskij teatr" und das in den dreibiger

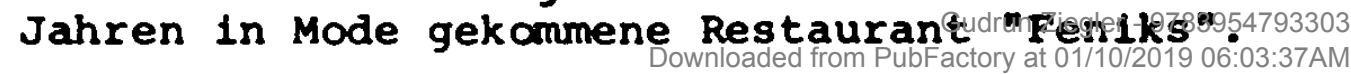


Mnogie žiteli Peterburga, provedšie detstvo v drugom klimate, podverženy strannomu vlijaniju zdešnego neba. Kakoe-to pečal'noe ravnodušie, podobnoe tomu, s kakim naše severnoe solnce otvoračivaetsja ot neblagodarnoj zdešnej zemli, zakradyvaetsja $v$ dušu, privodit $v$ ocepenie vse žiznenye organy. $V$ ètu minutu serdce nesposobno $k$ entuziazmu, um k razmysleniju (1).

/Viele Bewohner Petersburgs, die ihre Kindheit in einem anderen Klima verbacht haben, sind dem sonderbaren EinfluB des hiesigen Himmels unterworfen. Eine Gleichqultigkeit, die der gleich ist, mit der unsere nördliche Sonne sich von der hiesigen undankbaren Erde abwendet, sich in die seele einschleicht, und alle lebenden organe in Erstarrung versetzt. In diesem Augenblick ist das Herz unfahig zum Enthusiasmus und der Verstand unfähig zum Nachdenken./

Man kann diese Negativwirkung des Petersburger Klimas auf die menschliche Psyche synonym für die gesamte Atmosphäre der stadt setzen.

Als starker Kontrast zum "pyšnyj Petersburg"/prachtvolles Petersburg/ um Pečorin muß Lermontovs Schilderung von der 'Nachtseite' der Stadt wirken. Als sich Pečorin im Auftrag des Fursten Ligovskij in ein für ihn selbst ungewöhnliches Milieu begibt, schreibt der Dichter:

Vy probiraetes' snačala čerez uzkij 1 uglovatyj dvor', po glubomomu snegu, ili po židkoj grjazi; vysokie piramidy drov grozjat ežeminutno podavit' vas svoim padeniem, tjaželyj zapach, edkij, otvratitel'nyj, otravljaet vaše dychanie, ... (2)

/Anfangs bahnt man sich durch einen engen eckigen Hof den Weg, durch tiefen Schnee oder flüssigen Schmutz; hohe Pyramiden Holz drohen jede Minute auf einen zu stürzen, schwerer Geruch, scharf und ekelhaft, vergiftet den Atem, .../

Die in der Boulevardszene am Anfang des Romans angedeutete Anonymität der Großstadt setzt sich im Innern der Häuser

(1) Lermontov, M.Ju.: Soxinenija, VI; S. 148.

(2) Lermontov, M.Ju.: Sotinenija, VI; S. 170. 
fort. Auch in dieser Form zeigt sich eines der die menschliche Existenz bedrohenden GroBstadtphänomene. In der vorliegenden fragmentarischen Fassung ist der Handlungshintergrund im zusammenhang mit Pecorin am prăgnantesten ausgearbeitet. Zur Erkenntnis seines Verhaltens und Charakters wird von Lermontov bewust eine intensive Kolorierung vorgenommen. Das Leben Pełorins, der zu den oberen Geselischaftsschichten gehort, spielt sich in den diesen Kreisen of fenen Raumen ab. Diese dienen zwar der menschlichen Kommunikation, bedeuten aber fur das Individuum nur ein zeitliches Lösen aus der Vereinsamung und der eigenen individuelien Problematik. Speziell fur PeCorin werden diese allgemeinen städtischen Răume (Boulevard, Theater, Restaurant) zu Konfliktrăumen (1). Der Beginn des Romans ist nicht nur dadurch bemerkenswert, daBder Dichter in medias res fuhrt. Vielmehr liegt in dieser Szenerie der Versuch wirklichkeitsnahen Erzählens, d.h. nicht nur realistische Schilderung, sondern auch soziologisch-psychologische Motivierung der 'Konfliktsituation'. Ahnlich wie die beiden Hauptkontrahenten auf verschiedenen gesellschaftlichen Ebenen stehen, was durch das jeweiliMilieu unterstrichen wird, kann auch Petersburg als Gesamtheit auf verschiedenen Ebenen identifiziert werden. Einmal ist die stadt in ihrer topographischen Begrenzung verschiedener stadtausschnitte mit ihrer statik erfaBt, wăhrend die von ihr ausgehende wirkung auf die einzelnen Individuen in deren Verhalten untereinander angedeutet ist. Mit dem Versuch, den Vertreter einer niederen Gesellschaftsschicht (die sich speziell fur Petersburg herausgebildet hatte) als tragische Figur in die Literatur zu ubernehmen, beweist Lermontov, daB er die gestalterischen Möglichkeiten des stadtstoffes bereits erkannt hat.

(1) In dieser Ungebung trifft Pecorin wiederholt auf seinen 'Feind'. 
VII. Die erzăhlte Stadt im Werk N.V. Gogol's

Bože moj! stuk, grom, blesk: ... (1)

Am 30. April 1829 schrieb N.V.Gogol' an seine Mutter:

Peterburg vovse ne pochož na pročie stolicy evropejskie 111 na Moskvu. Každaja stolica voobšče charakterizuetsja svoim narodom nabrasyvajuščim na nee pečat' nacional'nosti, na Peterburge že net nikakogo charaktera: inostrancy, kotorye poselilis' sjuda, obžilis' $i$ vovse ne pochoži na inostrancev, a russkie $v$ svoju očered' ob"inostranilis' 1 sdelalis' ni tem 1 drugim (2).

/Petersburg ist anderen europäischen Hauptstädten oder Moskau uberhaupt nicht ähnlich. Jede Hauptstadt wird im allgemeinen durch ihr Volk charakterisiert, das auf sie den stempel der Nationalitat aufdruckt. Aber Petersburg hat überhaupt keinen Charakter: die Ausländer, die sich hier niedergelassen haben, haben sich eingelebt und sind nicht mehr Ausländern ahn11ch, und die Russen ihrerseits werden ausländisch und sind weder das eine noch das andere./

In vielen Briefen Gogol's finden sich solche beschreibenden Passagen über die russische Hauptstadt. Mit Petersburg verbindet ihn, der im Dezember 1828 erstmals in die große stadt kam, eine tiefe persönliche Enttăuschung.

Skažu ešče, čto Peterburg mne pokazalsja vovse ne takim, kak ja dumal, ja ego voobražal gorazdo krasivee, velikolepnee $i$ sluchi, kotorye raspuskali drugie o nem, takže lživy (3).

/Ich sage noch, daB Petersburg sich mit überhaupt nicht so gezeigt hat, wie ich dachte; ich hatte es mir weltaus schöner, grobartiger vorgestellt und die Gerüchte, die andere darüber verbreiten, sind falsch./

(1) Gogol' ' N.V.: Noč' pered roždestvom.

In: Sočinenija, I, M. 1965; S. 131 .

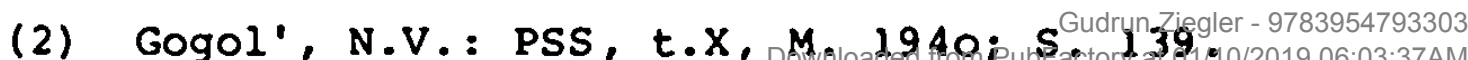

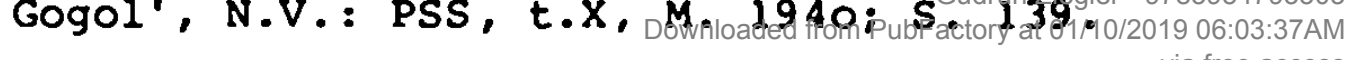


Die Stadt muBte Gogol' so vorkommen, wie dem Schmied Vakula, der in "Noč' pered roždestvom" auf dem Rücken des Teufels geradewegs aus seinem ukrainischen Dorf nach Petersburg kommt.

I vdrug zablestel pered nim Peterburg ves' $v$ ogne. (Togda byla pokakomu-to slučaju 1lljuminacija) (1).

/Und plotzlich erstrahlte unter ihm Petersburg ganz in Feuer. (Es gab das aus irgendeinem Grund eine Festbeleuchtung) ./

Innerhalb des phantastischen Geschehens werden hier Sinneseindrücke tatsächlicher Vorgänge geschildert. Diese wirken auf Vakula allerdings viel phantastischer als seine Reise auf dem Rücken des Teufels (2).

Bože moj! stuk, grom, blesk; po obeim storonam gromozdjatsja četyrech etažnye steny; stuk kopyt konja, zvuk kolesa otzyvalis' gromom 1 otdavalis' s četyrech storon: domy rosli 1 budto podymalis' 1 z zemli na kazdom šagu; mosty drožali, karety letali, 1zvozčiki, forejtory kričali: ... (3)

/Mein Gott! Ein Larm, ein Dröhnen, ein Leuchten; $z u$ beiden Seiten ragten vierstockige Mauern; das Stampfen der Pferdehufe und das Dröhnen der Rader hallte von vier Selten wieder; die Häuser schienen auf Schritt und Tritt aus der Erde $z u$ wachsen; die Brücken zitterten, die Kutschen flogen dahin, Kutscher und Vorreiter schrien: ..../

Für Vakula zeigt sich das Ungeheuerliche städtischer szenerie in einer Verzerrung und Uberdimensionierung realer Vorgänge und Erscheinungen (4).

(1) Gogol', N.V.: SoC., I; S. 131.

(2) vergl. hierzu: Gukovskij, G.A.: Realizm Gogolja, M. - L. 1959 ; S. 56 .

(3) Gogol',N.V.: SoC., I; S. 131.

(4) Auf ahnliche Weise schildert A. Belyj das năchtliche Petersburg. 
... sneg svistel pod tysjač'ju letjaščich so vsech storon sanej; pešechody žalis' 1 tesnilis' pod domami, unizannymi ploškami, i ogromnye teni ich mel'kali po stenam, dosjagaja golovoju trub 1 kryš (1).

/... der schnee knirschte unter tausenden von allen Seiten herbeifliegenden Schlitten; die FuBgänger drängten sich längs der Häuser, die mit lauter Lämpchen besetzt waren, und ihre riesigen Schatten huschten uber die Mauern und erreichten mit den Kopfen die Schornsteine und Dächer./

In dem in den "Arabesken" veröfentlichten Aufsatz "Ob architekture nynesnego vremeni" (1833/34) entwickelte Gogol' auBer einem ästhetischen programm auch allgemeine städtebauliche Ansichten. Nachdem der Autor hier die vielfalt und Harmonie im Panorama orientalischer städte bewundert hatte, schreibt er über die zeitgenössischen Stadtbilder:

Man bemüht sich die Häuser einander immer ähnlicher zu bauen; sie werden dadurch aber Schuppen oder Kasernen ähnlicher, als etwa fröhlichen Behausungen für Menschen (2).

Des weiteren bemängelt er die EbenmäBigkeit und Monotonie, die sich entlang der Straßenzüge verbreitet, wo man nichts anderes bemerkt als "rjad sten 1 bol'కe nicego" /als eine Reihe von wänden und nichts mehr/. Gogol's Vorschlag für eine Gestaltung der Städte: die stadt sollte so gebaut sein, daß die Häusermassen lebende Landschaften darstellen.

Vergleicht man die Thesen Gogol's mit heutigen AuBerungen zum Städtebau, so muB man ihnen Modernität und Einsicht

(1) Gogol', N.V.: Sot., I; S. 131.

(2) Gogol', N.V.: PSS, t. VIII, M. 1952; S. 61. 
in reale Gegebenhelten bescheinigen.

Stadtebau ist gerade auch dort, wo er sich auf Leergehăuse beschränken will, gestaltaktiv. Eine Strabe mit einer langen, stereotypen Reihung gleichartiger Hauser ist keineswegs eine gestaltneutrale strabe, sie ist vielmehr fur das Erleben hochwirksam durch ihre ermudende Monotonie, die als kalt, anonym, abweisend und verwirrend "ortlos" empfunden und abgelehnt wird (1).

Eine solche Eintornigkeit kommt in der Gleichformigkeit der Petersburger stadtanlage zum Ausdruck. Gogol' verarbeitet diese reale Erscheinungsform ebenso als Motiv in seinen "Petersburger Erzăhlungen" wie das mit diesem Komplex verbundene Bild der groben strabe.

Entschieden am interessantesten und schonsten entwickelt sich das Petersburger strabenleben auf der herrlichen New'schen (1) Perspective ... Das Leben auf diesem fashionablen Stück der Perspective um die Mittagszeit kann sich mit dem jeder anderen berühmten straBe der Welt messen und geniebt sich um so angenehmer, da die Decoration $z u$ diesem Schauspiele so auberst prächtig ist (2).

Beschreibungen solcher stadtausschnitte und Schilderungen der sich auf dem Boulevard zur Schau stellenden stadt gehorren zum Bestand zeitgenössischer Stadtbilder (3). Gogol's "Nevskij prospekt" (1834) bildet den Hintergrund fur ein einfaches sujet.

Der Maler Piskarev und der Leutnant Pirogov verfolgen zwel Damen durch das năchtliche Petersburg. Piskarev, der in der einen Passantin das Ideal der Schonheit und des Seelenadels entdeckt zu haben

(1) Lorenzer, A.: Stădtebau: Funktionalismus und Sozialmontage? In: Architektur als Ideologie; Frankfurt/M.1968; S. 7o.

(2) Kohl, J.G.: Petersburg in Bildern und Skizzen, Dresden $u$. Leipzig 1841; S. 62 .

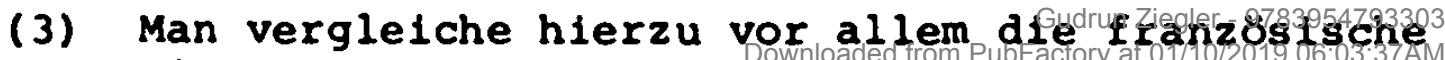
Literatur: V. Hugo, V.J. Jouy, E. Sue, J. Janinass 
glaubt, erlebt eine tiefe Enttäuschung, als er erfahren muB, daB seine Liebe einer Dirne gehört. Aus Verzweiflung gibt er sich dem opium hin und begeht schlieblich Selbstmord. Pirogov hingegen verfolgt eine ehrbare Frau und wird von deren Ehemann verprügelt. Sein Leben ändert sich in keiner Weise.

Die Erzăhlung beginnt mit einer 'Hymne' auf die Lebensader Petersburgs, auf den Nevskij Prospekt.

Net ničego lučše Nevskogo prospekta, po krajnej mere v Peterburge; dlja nego on sostavljaet vse. Cem ne blestit éta ulica - krasavica našej stolicy! Ja znaju, čto ni odin iz blednych $i$ činovnych ee žitelej ne promenjaet na vse blaga Nevskogo prospekta (1).

/Es gibt nichts Schöneres als den Nevskij Prospekt, zumindest in Petersburg nicht; furr Petersburg ist er alles. Welcher Glanz fehlt dieser StraBe - der schönsten unserer Hauptstadt! Ich wei $B$, daB keiner von den blassen und beamteten Bewohnern den Nevskij gegen alle Kostbarkeiten eintauschen würde./

In den zeilen "für Petersburg bedeutet der Nevskij alles" gibt Gogol' zu erkennen, daB der Prospekt nicht nur die große und glänzende straße ist, sondern daB er ein symbol der stadt geworden ist. Die russische Hauptstadt ist schon lange nicht mehr das im Ideologischen verhaftete "Gesamtkunstwerk", sondern eine lebendige stadt, die auch in Details (räumliche Ausschnitte) intensiv wirkt. Der Nevskij Prospekt ist einer der Aktionsrahmen der Petersburger Gesellschaft; er ist eines der Kommunikationszentren der Stadt.

(1) Gogol', N.V.: PSS, t. III; M. 1938; S. 9. 
Nikakoj adres-kalendar' 1 spravočnoe mesto ne dostavjat takogo vernogo izvestija, kak Nevskij prospekt (1).

/Kein AdreBbuch und keine Auskunftsstelle könnte solch zuverlassige Nachrichten geben, wie der Nevskij Prospekt./

Dieser Bemerkung des Dichters folgt eine detaillierte Schilderung der täglichen Szenerle dieser PrachtstraBe. Als Komplex bilden die aneinandergereihten Momentaufnahmen das, was Gogol' zu sagen veranlabt: "Vsemoguscij Nevskij prospekt!" /Allmächtiger Nevskij Prospektl/(2). In dieser Hyperbel ist die aktive Rolle des Nevskij Prospekts angedeutet. Diese wird zwar in "wie viel Veränderungen muB er in vierundzwanzig stunden erleiden" (3) ins Gegenteil verkehrt, doch kann man bereits hier einen Hinweis auf die Duplizität und Widersprüchlichkeit des Nevskij, d.h. der stadt sehen (4).

Wenn Gogol' die StraBe im Wechsel der Tageszeiten beschreibt, benutzt er zwar ein bekanntes Motiv, unterscheidet sich aber von der reinen "nravoopisatel'nost'" durch die Art der Darstellung. Mit Hilfe der verfremdenden Synekdoche zelchnet er ein karnevalistisches Bild der zu bestimmten Tageszeiten auftretenden Bevolkerungsgruppen. Schon Puskin hatte im "Evgenij Onegin" das erwachende Petersburg dargestellt. Wahrend bei ihm die sich entfaltenden Aktivitäten vor allem mit akustischen Eindrücken ver-

(1) Gogol', N.V.: PSS, III; S. 10.

(2) Gogol', N.V.: PSS, III; S. 10.

(3) Gogol', N.V.: PSS, III; S. 10.

(4) Hier liegt ein Vorgang der Entmythologisierung vor. Aus dem allmächtigen Nevskij Prospekt wird ein "leidender". Damit ist auch die Wechselbeziehung StraBe (Stadt) und Individuum angedeutet. Einmal ist die Stadt durch den Menschen geworden, zum anderen wirkt sie auf ihn zuruck. 
bunden waren, offnet sich für Gogol' in der gleichen Situation ein anderes Assoziationsfeld.

Načnem s samogo rannego utra, kogda ves' Peterburạ pachnet gorjacimi tol'ko cto vypečennymi chlebami $i$ napolnen staruchami $v$ izodrannych plat'jach $i$ salopach, soveršajuščimi svoi naezdy na cerkvi 1 na sostradatel'nych prochožich (1).

/Fangen wir mit dem frühen Morgen an, wenn ganz Petersburg nach heiBen frisch gebackenen Broten riecht und von alten Weibern in zerissenen Kleidern und Umhängen wimmelt, die die Kirchen und die mitleidigen Passanten überfallen./

Der frühe Morgen gehört den Arbeitsamen und dem niederen Volk. Das Leben beginnt an der Peripherie der groBen Straße; die Nebenstraßen sind für die Petersburger "bednota" reserviert. Gogol' beschreibt im folgenden den sich 'wandelnden' Nevskij Prospekt. Während er vormittags seiner ursprünglichen Funktion dient, nämlich als Verkehrsweg und städtische Răume durchschneidendes und verbindendes Element, wird er zur Mittagszeit zu einem "pädagogischen Prospekt". Nach zwei Uhr am Nachmittạ wird er vornhemlich durch "verschiedenartige" Bärte beherrscht, an denen man die verschiedene Departementszugehorigkeit ihrer Trăger ablesen kann (2). Je belebter die straße wird, um so weniger treten die einzelnen Individuen durch Details hervor. In der Vielfalt können nur noch die hervorstechendsten und abson-

(1) Gogol', N.V.: PSS, III; S. 10.

(2) Ein ăhnliches Bild entwickelt Heinrich Heine in den "Memoiren des Herren von Schnabelewopski" $(1831 / 34)$ als er den Hamburger Jungfernstieg beschreibt:

"Auf einmal ergriff mich selbst ein närrischer wahnsinn, und als ich die vorüberwandelnden Menschen genauer betrachtete, kam es mir vor, als seien sie selber nichts als zahlen, als arabische Chiffren; und da ging eine krummfüBige zwei ne-

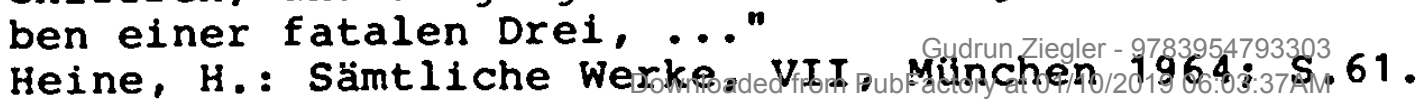


derlichsten Merkmale registriert werden. Sie stehen bei Gogol' wieder synonym für die Menschen. Der Vergleich des Nevskij Prospekt mit einem Ausstellungsraum (vystavka), also statik in zeiten gröBter Dynamik, weist auf die Doppelbobligkeit städischen Wesens hin. In der Ataxie dieser belden Krafte, Statik und Dynamik, hat Gogol' eines der wesentlichen städtischen Elemente erkannt. Mit dem Hereinbrechen der Dämmerung verăndert sich die stadt. Sie gestaltet sich in einem phantastischen spiel aus Licht und Schatten, in dem sich die Dimensionen verzerren (1). Auf dem nächtlichen Prospekt beginnt, unmittelbar aus der physiologischen Beschreibung heraus, die Handlung um Pirogov und Piskarev. In den Augen des Malers Piskarev nimmt, unterstutzt vom trügerischen $\mathrm{Zwielicht}$ der stadt, die von ihm verfolgte Dame "auberiridische" Züge an. Gogol' charakterisiert den Maler als Vertreter eines Standes, der für Petersburg zwar typisch aber ebenso ungewöhnlich ist.

Étot molodoj čelovek prinadležal k tomu klassu, kotoryj şostavljaet u nas dovol'no strannoe javlenie... Eto isključitel'noe soslovie očen' neobyknovenno $v$ tom gorode, gde 111 činovniki, 111 kupcy, 111 masterovye nemcy (2).

/Dieser junge Mann gehörte zu der Klasse, die bel uns eine ziemlich seltsame Erscheinung bildet ... Dieser exklusive stand ist sehr ungewöhnlich in der stadt, wo fast alle entweder Beamte, Kaufleute oder deutsche Handwerker sind./

Gogol's ironische Bemerkung, daB ein Künstler im "Land des Schnees" eine ungewöhnliche Erscheinung sei, läbt den kommenden Konflikt Piskarevs mit seiner Umgebung

(1) Vergl, auch "Noč' pered roždestvom".

(2) Gogol', N.V.: PSS, III; S. 16. In diesen zeilen ist die "merkantil'nost'" der Hauptstadt angedeutet. 
ahnen. Was der Dichter uber die Petersburger Künstler zu sagen weiB, ist typisch für die 'MittelmäBigen'. Es fehlt dem Petersburger Maler an inspirierender Umgebung; seine Bilder haben graues, trübes Kolorit, "neizgladimaja pečat' severa" /den unauslöschlichen Stempel des Nordens/ (1).

Es ist die Stadt, die so deprimierend auf den Menschen wirkt. Erst im Schein der Laterne, bei künstlichem Licht, sieht dieser seine Phantasie beflügelt. Das nächtliche Petersburg, durch das Piskarev der Unbekannten folgt, zeigt sich als phantastisches Eigenwesen. Wie durch Facetten wird das reale Bild der stadt gebrochen.

Trotuar nessja pod nim, karety so skačuščimi lošad'mi kazalis' nedvižimy, most rastjagivalsja $i$ lomalsja na svoej arke, dom stojal kryšeju vniz, budka valilas' $k$ nemu navstreču ... (2)

/Das Trottoir eilte unter ihm dahin, die Equipagen mit den galoppierenden Pferden schienen unbeweglich, die Brücke zog sich in die Länge und brach in inrer Wölbung, das Haus stand auf dem Dache, das Schilderhäuschen fiel ihm entgegen .../

In der Desorganisation des Raumes, den der Held durchschreitet, der aber nur in seinen Augen als gestört erscheint, deutet sich die Bedrohung seines Ichs an. Für Piskarev, der immer mehr dem Opium verfiel, begann die Auflösung von zeit und Raum. Indem er die städtische Gesellschaft flieht und zuflucht in der Droge sucht, will er die Diskrepanz zwischen Traum und wirklichkeit auf seine Weise losen. In der desillusionierenden Grobstadt mub er sich künstliche Träume schaffen, in

(1) Gogol', N.V.: PSS, III; S. 17.

(2) Gogol', N.V.: PSS, III; S. 19. 
denen seine Vorstellungen vom Reinen, Schönen und Guten noch intakt ist.

Piskarevs Scheltern basiert nicht auf sozialen Unzulanglichkeiten. Seine Einsamkeit ist selbstgesucht. Sie bildet gleichsam den "Mantel" für seine Trăume. Selbst die Erkenntnis realer Vorgänge, d.h. das zeltweilige Erwachen aus dem Rausch, verstärkt nur noch seine Sensibilităt. Der Nevskij Prospekt, die Lebensader der groBen stadt, wird für den künstler Piskarev zum Schicksal. Ihm, der durch seinen Beruf von vornherein eine Sonderstellung in dieser stadt einnimmt, werden seine uberwachen sinne zum Verhängnis. Er kann der Tăuschung uber die schöne fremde Dame nur deshalb erliegen, weil die nachtliche stadt "alles in einem falschen Licht erscheinen läbt" (1). Plskarev sieht den Effekt und nicht die Ursache. Sein Tod schlieblich bleibt genauso folgenlos und unbemerkt wie sein Leben.

Mit den Erelgnissen um den Maler laufen die Erlebnisse des Leutnant Pirogov parallel. Auch er verfolgt eine thm unbekannte Dame. Um Nachfolgendes zu erklären, gibt auch hier Gogol' eine Charakteristik des Helden und der Gesellschaft, in der er sich zu bewegen pflegt. Sein Leben gestaltet sich genau so szenisch, wie der geschilderte Tageslauf auf dem Nevskij. Piskarevs Gang durch Petersburg hatte zu Reflexionen uber sein ungewohnliches Verhalten Anlab gegeben. Für Pirogov 1st der ăhnliche Vorgang nicht ungewohnlich, deshalb wird sein Weg knapp und prăzise beschrieben.

On1 vošl1 temnym1 Razansk1mi vorotami v Meščanskuju ulicu, ulicu tabaçnych 1 meločnych lavok, nemcev-remeslennikov 1 čuchonskich nimf. Blondinka

(1) Gogol', N.V.: PSS, III; S. 46.

Der Autor weist hier auf die mit dem Wachsen der Grobstädte verbundene Bedeutung der Prostitution hin. 
bežala skoree 1 vporchnula v vorota odnogo dovol'no zapačkannogo doma (1).

/Sie gelangten durch das finstere Kazaner Tor in die Mešanskaja, die Straße der Tabak- und Kramläden, der deutschen Handwerker und der finnischen Nymphen. Die Blondine ging schneller und hüpfte durch das Tor eines ziemlich schmierigen Hauses./

Gogol' beschreibt das Milieu deutscher Handwerker (2), in das der Leutnant geraten ist, als Groteske (Hyperbel). Selbst nach der 'Ehrenkränkung' durch den Ehemann der Blondine hat sich das Leben Pirogovs nicht geändert. Für ihn war die Episode mit der Fremden schon in dem Moment erledigt, als er in die eigene Umgebung wieder zurückkehrt. Die Erlebnisse des Leutnant heben sich vom Schicksal des Malers als platt und oberflächlich ab. Der Nevskij Prospekt ist für Pirogov eine Realität, die er zu nutzen weik, d.h. an die er sich angepast hat, mit der er lebt.

Am SchluB der Erzăhlung greift Gogol' noch einmal das Thema des "allmächtigen" Prospektes auf. Für beide Erzählstrănge war er real räumlicher Ausgangspunkt; in seiner Wirkung entspricht er aber der Bedeutung eines Symbols für Petersburg. Diese Identifikation wurde meist in dem von Gogol' dargestellten soziologischen Querschnitt der auf dem Nevskij Prospekt Flanierenden gesehen. Die Erklärung liegt aber tiefer, denn nicht ohne Grund 'degradiert' der Autor die verschiedensten Passanten zu statussymbolen ohne Leben und Individualität.

(1) Gogol', N.V.: PSS, III; S. 36.

(2) In der Schilderung des Milieus deutscher Handwerker greift Gogol' das auf, was auch schon Puskin dargestellt hat: die nicht zu übersehende Rolle der Bewohner der Vorstädte, die sowohl in Moskau als auch in Petersburg die Ausländer, vor allem Deutsche, spielten. 
Sie täuschen über das wahre sein hinweg.

No strannee vsego proisšestvija, slučajuščiesja na Nevskom prospekte. 0 , ne ver'te étomu Nevskomu prospektu! ... Vse obman, vse mečta, vse ne to, cem kažetsja! ... Kak ni razvevajsja vdali plašč krasavicy, ja ni za čto ne pojdu za neju ljubopytstvovat'. Dalee, radi boga, dalee ot fonarja! 1 skoree skol'ko možno skoree, prochodite mimo (1).

/Am seltsamsten sind die Vorgänge auf dem Nevskij Prospekt. O glaubt ihm nicht, diesem Nevskij Prospekt! ... Alles Lug und Einbildung, alles ist nicht das, als was es erscheint! ... Wie anziehend auch aus der Ferne der Mantel einer Schonen weht, ich werde thr niemals aus Neuglerde folgen. Man gehe, um Gottes willen, möglichst weit von der Laterne weg! Man gehe so schnell wie moglich an ihr voruber.

In diesen Zeilen fast Gogol' das zusammen, was seiner Meinung nach das Dämonische an der stadt ausmacht: sie lst eine einzige Lüge für alle diejenigen, die sich der Realităt verschließen (2). Die grobe stadt

vernichtet den, der seine Augen nicht offenhalt. Der Maler Piskarev, der einem Wahnbild nachjagt, und schlieblich in den Selbstmord getrieben wird, ist nicht ein Opfer sozialer Misstunde, sondern er ist existentiell ein schwerpunktloses Geschöpf (3).

(1) Gogol', N.V.: PSS, III; S. $45 / 46$.

(2) Man vergleiche hierzu die zellen Rilkes aus dem "Stundenbuch" (1905):

Die groben städte sind nicht wahr; sie täuschen den Tag, die Nacht, die Tiere und das kind; ihr Schwelgen lugt, sie luggen mit Geräuschen und mit den Dingen, welche willig sind.

Rilke, R.M.: Das Stundenbuch, Frankfurt/M. 1962; S. 97 .

(3) Holthusen, Joh.: Gogol' und die Grobstadt.

In: RuBland in Vers und Prosa. München 1973; S. 49. 
In der Verschiebung der realen stadtelemente ins Uberdimensionale und Extreme weist der Dichter auf die 'Wesenheit' der großen stadt "as half-inferno, as halfmadhouse" (1). Hinter optischen Verfremanungseffekten versteckt sich ebenso wie hinter den Hyperbeln ("miriady karet vljatsja s mostov"/Myriaden von Kutschen ergossen sich von den Brücken/) (2) die Grobstadt als ort der Vermassung und Isolation. Dieses Problem wird von Gogol' immer wieder in seinen "Petersburger Erzăhlungen" variiert.

Die "Zapiski sumasłedకego" (1834), deren einfaches sujet von einer unerfullten Liebe handelt, benutzt als Motiv den ZusammenstoB eines 'outsiders' mit der Wirklichkeit. Gogol's Intention führt aber über eine Darstellung dieses Konfliktes hinaus. Die Wenigen Straßenszenen der Erzählung stehen am Beginn. Als realen Hintergrund für die Ereignisse wählt der Dichter das für Petersburg typische Wetter.

Ja nadel staruju šinel' i vzjal zontik, potomu čto šel prolivoj doždik. Na ulicach ne bylo nikogo: odni tol'ko baby, nakryvšis' polami, da russkie kupcy pod zontikami, da kučera popadalis' mne na glaza. Iz blagorodnych tol'ko naš brat činovnik plelsja (3).

/Ich nahm meinen alten Mantel und den Schirm, denn es regnete in Strömen. Auf den Straßen war niemand; einzig die Weiber, die sich mit den Rockzipfeln bedeckt hatten, einige russische Kaufleute unter Schirmen und Kutscher kamen mir unter die Augen. Von den Wohlgeborenen schleppte sich nur unsereiner, ein Beamter vorbei./

Der Weg Popristins, des Schreibers der "zapiski", führt

(1) Erlich, V.: Gogol, New Haven and London 1969; S. 82 .

(2) Gogol', N.V.: PSS, III; S. 46.

(3) Gogol', N.V.: PSS, III; S. 194. 
zum Zverkovschen Haus.

Perešl1 v Gorochovuju, povorotili v Meščanskuju, ottuda $v$ stoljarnuju, nakonec $k$ Rokuškinu mostu 1 ostanovilis' pered bol'sim domom. Etot dom ja znaju, skazal ja sam $v$ sebe. Eto dom zverkova. Éka mašina! Kakogo $v$ nem naroda ne živet: skol'ko kucharok, skol'ko poljakov! A našej brat'i, činovnikov, kak sobak, odin na drugom sidit. Tam est' 1 u menja odin prijatel', kotoryj chorošo igraet na trube (1).

/Wir durchquerten die Gorochovaja, bogen in die Mescanskaja ein, von dort in die Stoljarnaja, schlieblich kamen wir zur Rokuskin Brücke und blieben vor einem groBen Haus stehen. Diese Haus kenne 1ch, sagte $1 \mathrm{ch} z \mathrm{z}$ mir selbst. Das ist das Zverkovsche Haus. Was fur eine Maschine! Was für Leute leben nicht darin: wieviele Kochinnen, wieviele Polen! Von unsereinem, den Beamten, sitzt einer auf den anderen, wie die Hunde. Dort habe ich auch einen Freund, der gut Trompete blast./

Gogol' beschreibt hier wohl eines der ersten gröberen Mietshäuser in Petersburg (2). Fur dieses Sinnbild grobstädtischer Bauformen, das Menschen verschiedenster Schichten beherbergt, hat Popriscin die treffende Bezelchnung: "Ekka małsina!"(3) In den Aufzelchnungen vom 12. November hălt er die Atmosphare der Mešanskaja fest, "wo der Geruch nach Rohl aus allen Läden dringt." (4)

(1) Gogol', N.V.: PSS, III; S. 195/196. .

(2) 1817 wurde in Petersburg das erste Fünf-Etagenhaus erbaut.

(3) Popristin spricht hier das aus, was man heute als "versteinerte Klassenstruktur" bezeichnet.

Man erinnert sich hier ebenso an die Beschreibung der Wohnung Makar Devuskins in Dostoevskijs "Bednye ljudi".

(4) Gogol', N.V.: PSS, III; S. 200. 
Die Stadt Petersburg wirkt auf den Helden der Erzählung im wesentlichen durch ihre Sozialstruktur. Seine anspruchslose Tätigkeit im Departement bringt ihm nur in seinen Augen Vorteile, setzt inn aber vor den Mitmenschen herab. Popriscins fixe Idee, er sei der König von spanien, entwickelt sich aus der Uberlagerung von wirklichkeit und Phantasie. Seine Tragik liegt vordergrünig in seiner unerfullten Liebe zur Tochter seines Vorgesetzten. Obwohl er einsieht, daB die standesgrenzen nicht zu überwinden sind, zieht er keine Konsequenzen. Es liegt nahe, den geistigen Defekt des Helden auf eine defekte Umgebung zurückzuführen.

Als Vergleich kann hier Gogol's "Portret" (1834/35) herangezogen werden.

Die Erzählung gliedert sich in zwei Teile, wobei als eine Grundidee die Beziehung zwischen Künstler und Gesellschaft dargestellt wird. Im ersten Teil wird die Geschichte des Malers Cartkov erzählt, sowie sein mit einem Gemälde zusammenhängender Aufstieg und Untergang verfolgt.

Der zweite Teil berichtet von der Entstehung des dämonischen Bildes und von seiner verhängnisvollen Wirkung auf den Schöpfer des Kunstwerkes.

Gogol' beginnt mit einer detaillierten Beschreibung des Schauplatzes. Die vor dem Bilderladen des Sčukinschen Kaufhauses versammelten Gaffer bilden in ihrer soziologischen Zusammensetzung ein ebensolches Gemisch wie die verschiedenartigen ausgestellten Bilder (1). Es sind hier mehr die kleinen Leute, die Dienstboten und Bewohner der Vorstädte, die sich an den mittelmäBigen Kunstwerken ergötzen. Der Künstler Cartkov, der zufällig vor dem Laden stehen geblieben war, erwirbt ebenso zufällig

(1) Man kann diese Passage mit der Beschreibung des Gedränges vor der Theaterkasse in den "Peterburgskie zapiski 1836 goda" vergleichen. 
das Portrăt "mit den ausdrucksvollen Augen". Gogol' beschreibt den Weg, den Cartkov mit dem Bild unter dem Arm zu seiner Wohnung nimmt. Das abendliche Petersburg wird hier mit den Augen eines Malers geschildert, obgleich Cartkov selbst an seiner Umgebung keinen Anteil nimmt.

I počt1 mašinal'no šel skorymi šagami, polnyj besčuvstvija ko vsemu. Krasnyj svet večernoj zari ostavalsja ešč na polovine nebe; ešče domy obraščennye $k$ toj storone, Cut' ozarjalis' ee teplym svetom; a meždu-tem uže cholodnoe sinevatoe sijan'e mesjaca stanovilos' sil'nee. Poluprozračnye legkie ten 1 chvostami padali na zemlju, otbrasyvaemye domami 1 nogami pešechodcev (1).

/Er eilte fast mechanisch mit schnellen Schritten, gleichgultig gegen alles. Der halbe Himmel war noch mit rotem Licht des Abenrots bedeckt; die nach jener Selte schauenden Hauser waren noch schwach mit seinem warmen Licht ubergossen; aber dazwischen wurde schon das kalte blaulichweiBe Licht des Mondes stärker. Halb durchsichtige leichte Schatten, von den Hausern und Menschenbeinen zurulckgeworfen, legten sich als Schweife uber die Erde./

Das Heim Cartkovs befindet sich auf der Vasil'evskij Insel.

Ustalyj 1 ves' $v$ potu, dotaščilsja on $k$ sebe $v$ pjatnadcatuju Iiniju na Vasil'evskoj Ostrov. S trudom 1 s otdyškoj vzobralsja on po lestnice, oblitoj pomojami i ukrašennoj sledami košek 1 sobak (2).

/Mude und schweibbedeckt erreichte er seine Behausung in der fünfzehnten Linie auf der Vasil'evski Insel. Mit Muhe und schwer atmend stieg er die Treppe hinauf, die mit Spülwasser übergossen war und durch Spuren von Hunden und Katzen verschönt war.

(1) Gogol', N.V.: PSS, III; S. 83.

(2) Gogol', N.V.: PSS, III; S. 83. 
Diese Umgebung, dazu gehört auch sein kahles Atelier, vertauscht Cartkov mit dem modischen Petersburg, nachdem er auf wunderbare Weise zu Geld gekommen ist. Er unterwirft sich ganz dem Geschmack der zeit, d.h. er past sich an. Mit der Veränderung seiner Umgebung verändert Cartkov auch seinen künstlerischen Stil, bis inn schlieblich die Erkenntnis, sein Talent zugunsten materieller Werte vergeudet $z$ u haben, zur Selbstaufgabe zwingt. Wenn Gogol' die Ereignisse um den Maler Cartkov vor den Hintergrund der russischen Hauptstadt stellt, dann ist die stadt nicht nur in ihrer räumlichen Funktion wesentlich. Sie ist in diesem zusammenhang Symbol und symptom für bestimmte Verhaltensmuster der zeitgenossen. Der zweite Teil der Erzählung beginnt mit der Schilderung einer Auktion, die Gaffer und Käufer verschiedenster Schichten zusammenbringt (1). Der Bericht des Malers B., der die Vorgeschichte des auf der Auktion aufgetauchten dämonischen Gemäldes wiedergibt, beginnt mit einer eindrucksvollen Beschreibung des Petersburger Stadt'eils Kolomna (2).

Tut vse ne nepochože na drugie časti Peterburga; tut ne stolica $i$ ne provincija; ... Sjuda ne zachodit buduščee, zdes' vse tíšina $i$ ostavka, ...(3)

/Hier ist alles ganz anders als in den anderen Teilen Petersburgs; hier ist weder Hauptstadt noch Provinz; ... Hierher kommt nicht die zukunft, hier ist alles still und auBer Dienst, .../

(1) Vergl, hierzu die Szene vor dem Schaufenster.

(2) Kolomna wurde seit 1736 besiedelt. Es war ursprünglich das Wohngebiet der am Bau der Hauptstadt beteiligten Arbeitskräfte aus der russischen Stadt Kolomna.

(3) Gogol', N.V.: PSS, III; S. 119. 
Verabschiedete Beamte, Köchinnen, Witwen und mittellose Menschen gehören hierbel in Kolomna noch zur oberen Gesellschaftsschicht, wobel die Witwen die "Aristokratie" bilden. Die niederste Menschengruppe beschreibt Gogol' als "graue Menschen, deren Kleidung, Gesicht, Haare und Augen eine trube, aschgraue Farbe haben" (1). Diese leidenschaftslosen und vegetierenden Bewohner Kolomnas werden von Gogol' zwar als Gruppe bzw. als Individuen beschrieben, sie sind aber fir thn mehr von 'psychologischem Wert'. Eine Begründung threr sozialen Not oder etwa sozialkritische Ansätze werden vom Autor nicht gegeben. In der Beschreibung der verschiedensten Typen, die den Stadttell Kolomna bevölkern, steht diese Passage den sogenannten "fizlologiCeskie ocerki"/physiologische Skizzen/ nahe (2). Entscheidet man sich für die Interpretation, daB die Gier nach Geld und die Macht des Geldes eine den Menschen verderbende Kraft darstellt, dann bedeutet diese Erzählung eine elndringliche Darstellung der sich verändernden zeltgenössischen Gesellschaft (3). Da Gogol' seine Absicht nie direkt bekanntgibt, sondern eine Ubertragung gesellschaftlicher Probleme auf eine Metaebene vorzieht, muB man in diesem Fall die Darstellung vom Eindringen des Bösen und Teuflischen in die Welt der Kunst dechiffrieren. Die obige Deutung ist dabei ein mögliches Ergebnis.

Vor der ungewöhnlichen Hauptstadt, deren Mythos auch noch zur zeit Gogol's lebendig ist, spielen sich unge-

(1) Gogol', N.V.: PSS, III; S. 119.

(2) Die "fiziologiCeskie oterki" zeichnen sich durch sujetloses Aneinanderreihen räumlicher und sozialer Details aus.

(3) Mit wachsender Industrialisierung auch der russ1schen Städte wird der Weg zur kapitalistischen Gesellschaftsordnung geebnet. Gogol' deutet hier auf einer höheren Ebene die "merkantil'nost" "der Hauptstadt an. 
wöhnliche Ereignisse ab. Die stadt ist prädestiniert für auBerordentliche Vorfälle. Von diesen sagt Gogol' in seiner Erzählung "Nos" (1836):

Kto čto ni govori, podobnye proisšestvija byvajut na svete; redko, no byvajut (1).

/Man kann sagen was man will, solche Ereignisse kommen vor in der Welt; sie sind selten, aber sie kormen vor./

In "Nos" wird die Stadt Petersburg nicht nur als realer Hintergrund greifbar, sondern sie trägt selbst in dieser Funktion zu einer Verwischung von Fiktion und wirklichkeit bei.

Der Kollegienassessor Kovalev erwacht eines Morgens ohne Nase. Sein Barbier findet diese gleichzeitig in einem Brotlaib. Verschreckt uber ein mögliches berufliches Versagen wirft er die Nase in die Neva. Kovalev, als Mensch 'ohne Gesicht', ausgestoBen von der Gesellschaft, trifft seine Nase, die auf dem Nevskij Prospekt spazieren făhrt. Sie steht im Rang iber ihm. Polizei und zeitung versagen bei der Suche nach ihr, bis sle wegen Paßvergehens festgenommen wird. Die Nase will zunächst im Gesicht Kovalevs nicht mehr haften, bis dieser eines Tages erwacht und die Nase an ihrem alten Platz vorfindet.

Petersburg zeigt sich in der Erzählung als Labyrinth, das zwei wirklichkeitsebenen gleichzeitig zuläBt; ein normales städtisches Leben und höchst ungewöhnliche surreale Ereignisse. So erregt die Nase, die auf dem Nevskij Prospekt spazieren geht, zwar Aufsehen, aber keine Verwunderung. Die grotesken Situationen der Erzählung ereignen sich jeweils an den typischsten Plätzen der Hauptstadt.

(1) Gogol', N.V.: PSS, III; S. 75. 
So endet z.B. die Episode um Ivan Jakovlevič, dem Barbier auf der Issaksbrücke, bevor die weiteren Ereignisse um ihn "in einem geheimnisvollen Nebel" verschwinden (1). Kovalev trifft auf seine verschwundene Nase auf der Hauptstrabe Petersburgs und beobachtet diese, wie sie die Kazaner Kathedrale betritt (2). Gogol' hat diese typischen Plätze mit Bedacht gewăhlt, um das zusammentreffen zwischen der realen und der surrealen Ebene effektvoll darstellen zu können. So wie der Nevskij Prospekt in einem anderen licht erscheint und als Lügner entlarvt wird, bedeutet das in "Nos" geschilderte Nebeneinander für die Stadt ein sehr zweifelhaftes und widersprüchliches Element. Ihre wahre Physiognomie zeigt sich auf dem Höhepunkt der Groteske, als die Nase Kovalevs zur allgemeinen Sehenswirdigke1t der Stadt 'avanciert'. Dabei trifft Gogol' in der hier angedeuteten Kommerzialisierung des $\mathrm{Ab}-$ sonderlichen reale gesellschaftliche Erscheinungsformen (3). Die phantastischen Vorgänge um die verlorene Nase entsprechen dem Wesen der Stadt Petersburg, die von Gogol' immer wieder als widersprüchlich und nicht auf einen Blick erfaBbar geschildert wird. Die russische Metropole ist für den Autor eine Herausforderung, " a baffling labyrinth, an intricate social organism replete with opportunities and pitfalls, a maze of contradictions." (4) Daruber hinaus ist Kovalev der Typ des veranwortungslosen und angepabten Menschen, dessen einziger Stolz sein Titel ist und dessen einziges Interesse dem eigenen Ich gehört.

(1) Gogol', N.V.: PSS, III; S. 52.

(2) In einer anderen Fassung betritt die Nase ein Kaufhaus.

(3) In der detaillierten Schilderung eines zeitungsbüros und dem Hinweis auf die geistlosen Interessen einiger Gesellschaftskreise wird diese Deutung unterstüzt.

(4) Erlich, V.: Gogol, New Haven/London $1969 ;$ S. 75/76. 
In die Entstehungszeit der "Petersburger Erzählungen" fallen Gogol's "Peterburgskie zapiski 1836 goda". Diese ursprünglich als Reisebriefe geplanten Aufzeichnungen gliedern sich in zwei Teile: in einen Vergleich zwischen Petersburg und Moskau und in einen Bericht uber das zeitgenössische Petersburger Theaterleben (Peterburgskaja scena). Die "zapiski" gehören zum Genre der kritischen journalistischen Literatur.

Mit der Gründung der Stadt Petersburg und vor allem mit der Verlegung der Residenz in die neue stadt hatte sich zwischen den beiden größten Städten des russischen Reiches eine natürliche Rivalität entwickelt. Einer der Gründe dafür, daB sich gerade um 1835 ein gesteigertes Interesse an vergleichenden Darstellungen der beiden Städte herausbildete, lag in der Konzentration zweier bedeutender ideologischer Strömungen in Moskau und Petersburg. Die alte Hauptstadt war zum Zentrum der Slavophilen geworden, während ihre Gegner, die westler, sich in Petersburg etablierten. Einer der Programmunkte der Slavophilen basierte auf der kritischen Einstellung zum Werk Peters I., die etwa auf folgenden Uberlegungen beruht:

St.Peterburg war ein vollendeter Ausdruck und die natürliche Erbin seines (d.i.Peter I.) Werkes. Diese Stadt war eine Quintessenz von Rationalismus, Formalismus, Materialismus, Juristerei und Zwang, sie war aus dem Nichts erbaut worden, ohne geistige weihe oder geschichtliche Rechtfertigung, sogar der Boden auf dem sie stand, war eher finnisch als russisch (1).

Obgleich Gogol's Einstellung zu Petersburg durchaus nicht positiv war, fehlt seinen Darstellungen eine etwa ähnliche ideologische 'Begeisterung'. Petersburg ist für ihn tatsächlich die große Stadt, zu deren Verständnis und

(1) Riasanovsky, N.v.: Russland und der Westen, München $1954 ;$ S. 77 . 
und Entdeckung die "Peterburgskie zapiski" beitragen sollten. In der Gegenuberstellung mit Moskau und durch den lakonischen journalistischen stil wirkt allerdings manches uberspitzt und auf die zeitgenossen als Herausforderung. So auberte sich A. Grigor'ev zu den "Zapiski": "... strannaja, mraxnaja kartina" /ein merkwilirdiges, dunkles Bild/ (1). Bereits in seinen "Mysli o geografil" (1833) hatte Gogol' gefordert, das bel elner Darstellung von Stadten von der Lage auszugehen sei. Entsprechend beginnen seine "Zapiski" mit einer Betrachtung uber die extreme geographische Lage der Hauptstadt.

V samom dele, kuda zabrosilo russkuju stolicu - na kraj sveta! Strannyj narod russkij: byla stolica $v$ Rieve - zdes' sliskom teplo, malo cholodu: pereechala russkaja stolica $v$ Moskvu - net, 1 tut malo choloda: podavaj bog Peterburg! (2)

/In der Tat, wohin hat es die russische Hauptstadt verschlagen - ans Ende der Welt! Merkwürdig ist das russische Volk: es hatte eine Hauptstadt in Kiev hier war es zu warm und wenig kälte; die russische Hauptstadt ubersiedelte nach Moskau - nein, auch hier war es zu wenig kalt: Gott reiche uns Petersburg!/

Trotz dieser 1ronischen Einfuhrung enthält diese Aussage eine wesentliche Information, die nicht nur bel Gogol' literarisch verarbeitet wurde: die besonderen klimatischen Verhaltnisse in Petersburg. 2wischen Moskau und Petersburg liegen Welten. Neben dem altertülichen Moskau, wobel Gogol' die gerade in den dreibiger Jahren vollzogene bauliche Verănderung in Moskau nicht berilcksichtigt, fältt die neue Pracht Petersburgs besonders auf (3).

(1) Grigor'ev, A., zitiert nach: Gillel'son, M.I.: Gogol' v Peterburge, L. 1961; S. 195.

(2) Gogol', N.V.: PSS, VIII; S. 177.

(3) Nach dem Brand Moskaus (1812) wurde die Stadtanlage um den Kreml neu geplant und neue Stelinbauten $e^{-}$ richtet. 
Gogol' zählt $2 u$ den wesentlichsten Unterschieden belder Stadte die verschiedenen Bezlehungen $z u$ ihren Bewohnern. Er konstatiert für Petersburg eine dem Neuen aufgeschlossene Bevollkerung, Geschätstüchtigkeit und Akkuratesse. Moskau haftet am Alten. Die divergierende Entwicklung zeigt sich auch in den unterschiedilchen geistigen Interessen, die an den verschiedenen in belden städten erscheinenden Journalen abzulesen sind. So beschaftigt man sich in Moskau "mit Kant und Schelling" (1), in Petersburg mehr mit "bffentlichen Angelegenheiten" (2). Des weiteren:

V Moskve literatory proživajutsja, v Peterburge naživajutsja (3).

/In Moskau schlagen sich die Schriftsteller durch, in Petersburg werden sie relch./

Wegen ihrer apodiktischen Art sind die Aussagen Gogol's zwar vielfach einzuschränken, doch trifft er die wesentlichen Tendenzen gesellschaftlicher Entwicklung. Der zweite Teil der "Peterburgskie zapiski" beschreibt das Repertoire der Petersburger Theater, wobe1 Gogol' eigene Ansichten uber die Aufgaben der Komödie entwickelt. Nachdem er zunächst auf die Vielfaltigkeit des Publikums hingewiesen hat, begründet er die vorliebe der Petersburger fur Balett und Opern und gibt schlieblich eine detaillierte Skizze des Gedränges vor dem Alexander-Theater (4).

(1) Damit spricht Gogol' die Gruppe der "ljubomudry" an, des Kreises um Odoevskij, Anfang der zwanziger Jahre.

(2) Die Rolle Petersburgs als Verwaltungs-und Handelsstadt ist damit angedeutet.

(3) Gogol', N.V.: PSS, VII; S. 178. Dies entspricht der Tatsache, daB sich der Erfolg eines Werkes vor allem nach der Aufnahme durch die Petersburger Gesellschaft richtete.

(4) Zentrum des russischen Theaterlebens war in den dreibiger Jahren das Petersburger Alexander-The-

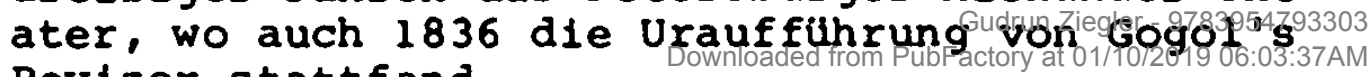
Revizor stattfand. 
Gogol' beschliebt seine "Petersburger Aufzeichnungen" mit einer allgemeinen Beschreibung der Vergnügungen der stădtischen Bevblkerung. Er skizziert damit das im Wechsel der Jahreszeiten sich verăndernde Flair der Stadt. Zusammenfassend ist zu sagen: die "Peterburgskie zapiski" sind eine Sammlung stadtischer Details. Sie schildern das zeitgenossische Petersburg, das in den "Petersburger Erzăhlungen" auf einer anderen Ebene dargestellt wird. Auch hier halten sich positive und negative Eindrucke die waage.

In die Entstehungszeit der "zapiski" făllt die Urauffulhrung des "Revizor". Obwohl als ort der Handlung eine Gouvernementsstadt gewählt wurde, ist die russische Hauptstadt stăndig gegenwărtig. Chlestakov, der fălschlich für den Beamten aus Petersburg gehalten wurde und auch sein Diener Osip reflektieren beide, jeder auf seine Weise, lber das Leben in der Residenz. Vordergrundig ist für die Bewohner der Kleinstadt der Name Petersburg mit der Quelle allen Ubels verbunden, denn aus ihr wird das Unhell in der Gestalt des Revizors erwartet. Wie der weitere Verlauf aber zeigt, steht die Residenz immer im Hintergrund, wenn es gilt "sich einzurichten". Der 2.Akt beginnt mit einer Hymne des Dieners Osip auf den Abwechslungsreichtum der Hauptstadt:

Vtoroj mesjac pošel, kak uže Pitera! ... konečno, esli pojdet na pravdu, tak zit'e $v$ Pitere lučše vsego. Den'gi by tol'ko byli, a žizn'tonkaja 1 političnaja: keatry (1), sobaki tebe tancujut, a vse, čto chočeš' (2).

/Der zweite Monat ist vergangen, seit wir aus Petersburg fort sind! ... natürlich, wenn man es genau betrachtet, ist das Leben in Piter besser als alles.

(1) Gogol', N.V.: PSS, III; S. 190.

(2) Gogol', N.V.: PSS, IV; S. 26. vergl. hierzu die Erzăhlung Kopejkins aus "Mertvye dusi". 
Wenn man nur Geld hatte, das Leben ist so fein und politisch: Theater, die Hunde tanzen groBartig, und alles was man will./

Osip schildert die Vergnügungen eines Menschen, dessen 'Ansprïche' durch das Leben in der Grobstadt gereizt sind. Damit ist gewissermaBen das vorspiel zu Chlestakovs groBem Auftritt im 3. Akt gegeben. Indem dieser die Hauptstadt in den kühnsten Farben beschreibt, setzt er sich gleichzeitig selbst ins rechte Licht.

Ėch! Peterburg! Cto za žizn', pravo! (1)

/Ach Petersburg! Was für ein Leben, in der Tat!/

Chlestakov ist kein Betrüger; sein phantasievoller Bericht von petersburg zeugt davon, daB auch er vom stadtischen Leben völlig 'infiziert' ist. Die Hyperbeln in seiner Schilderung haben den Effekt, daß seine zuhörer noch mehr in Verwirrung geraten. Der falsche Revizor erbaut vor den Kleinstadtern ein Megalopolis. Er berichtet von "Melonen, von denen eine siebenhundert Rubel kostet", von Menschenmengen, die sich in seinem Vorzimmer drängen und von "fünfunddreibigtausend Kurieren", die durch die Petersburger StraBen eilen (2). Diesen Hyperbeln liegt als realer Hintergrund das Motiv vom festlichen und vergnugungssüchtigen, verwalteten und verdorbenen Petersburg zugrunde (3). Der kleinen verlotterten Provinzstadt, die im Grunde genommen ein Petersburg en miniature ist, wird die Fiktion der Residenz vorgegaukelt (4).

(1) Gogol', N.V.: PSS, IV; S. 48.

(2) Gogol', N.V.: PSS, IV; S. 50.

(3) Gogol' hatte in den "Peterburgskie zapiski" als eine der Hauptforderungen an die Komödie den "vernyj spisok obšestvo" / wahres Bild der Gesellschaft/geaubert.

(4) Gukovskij weist auf den Effekt des Stückes bei der Uraufführung hin, den er mit Griboedovs "Gore ot uma"

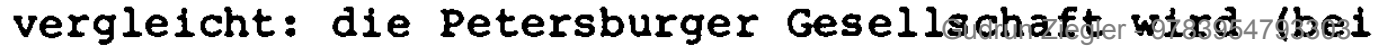

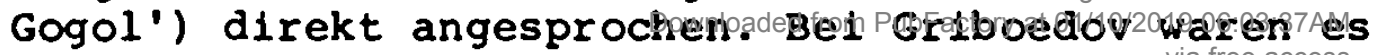
dio Mnakallor. 
Gogol' verlieb bald nach der Urauffuhrung des "Revizor" Petersburg, um im Ausland zu leben. Selne Erzahlung "Sinel'" wurde 1841 in Rom fertiggestellt.

\begin{abstract}
Akakij Akakıevič Bašmačkin, ein niederer Beamter ohne Personlichkelt, braucht einen neuen Mantel. Er fast den Entschlus, elnige Entbehrungen auf sich zu nehmen und die notigen finanzielien Mittel zu beschaffen. Dieses ziel, fur das er nun zu leben beginnt, verändert sein ganzes Dasein. Als er im Besitz des neuen Mantels ist, laden ihn Kollegen aus dem Departement $z u$ einer Feier ein. Auf dem Heimweg durch das nachtliche Petersburg wird ihm sein neuer Mantel geraubt. Als seine Bemuhungen um den Wledergewinn seines Mantels und der Einsatz seiner letzten Krafte vergeblich ist, geht Akakij Akakievič zugrunde. Nach seinem Tode erscheint er als Măntel stehlendes Gespenst in der Hauptstadt.
\end{abstract}

Gogol' wählte in Akakij einen Vertreter der niederen Rangstufen zum Helden der Erzahlung, dessen Dienst im Departement aus dem Kopieren von Schriftstücken besteht. Diese mechanische Arbeit ist sein einziger Lebensinhalt, bevor er sich notwendigerweise mit der Anschaffung eines Mantels befassen muB. Akakij Akakievič ist ein Mensch. für den "nichts anderes existierte"(1). Aus der volligen Identifikation des Helden mit seiner sinnlosen-mechanischen Arbeit resultiert ein Tun ohne Intention und Variation; die Beziehungen Akakijs zu seiner Umwelt, zu Petersburg sind auf ein Minimum beschrankt. Er lebt unter Vernachlässigung jeglicher sozlaler Bezüge und Verantwortung. Zwischen Offentlichkeit und Privatheit kennt er keinen Unterschied. Obwohl Bašmačkin in der perfekten Isolation lebt, wird sie von ihm nicht als solche empfunden, denn durch sie kann er erst existieren. Der Angriff auf diese geschlossene Welt des armen Beamten erfolgt von auBen, und zwar in der Gestalt des typischen Petersburger Wetters.

(1) Gogol', N.V.: PSS, III; S. 145. 
Est' v Peterburge sil'ny̧ch vrag vsech, polučajuščich četyresta rublej v god zalovan'ja, ili okolo togo. Vrag etot ne kto drugoj, kak nas severnyj moroz...

/In Petersburg haben alle diejenigen, die an die vierhundert Rubel Jahresgehalt bekommen, einen grimmigen Feind. Dieser Feind ist kein anderer als unser nördlicher Frost ..../

Akakij kann sich der ständigen Bedrohung durch die Naturgewalten nicht entziehen; sein EntschluB, den alten Mantel zum Schneider Petrovič zu tragen, ist das Ergebnis eines einmaligen Ringens. Man kann aber trotzdem nicht von einer Uberwindung des eigenen Ichs sprechen. Die für Akakij ungewöhnliche Handlungsweise resultiert aus einem psychologischen ProzeB (2), dex aus dem einmaligen Gedanken an einen neuen Mantel entstanden ist. Aus Sparsamkeitsgründen nähert sich die Lebensweise Basmackins einerseits dem Existenzminimum, doch wird andererseits sein Leben durch die Gedanken an den neuen Mantel "reicher und inhaltsvollex" (3). Diese Veränderung hin zu einem neuen Leben ist nur scheinbar, denn er vermag nicht endgültig aus seiner Isolation auszubrechen (4). Auf dem Heimweg von der Abendgesellschaft läßt sich Akakij dazu hinreiBen, einer Dame $\mathrm{zu}$ folgen. Schlieblich gelangte er aus den belebten Gassen der stadt in eine Gegend, in der die Trostlosigkeit alle natürlichen Dimensionen $z u$ verzerren scheint; endlose Bretterzäune, kleine Häuschen geben diesen Eindruck wieder.

(1) Gogol', N.V.: PSS, III; S. 147.

(2) Man könnte diesen Vorgang als Autosuggestion bezeichnen.

(3) Gogol', N.V.: PSS, III; S. 154.

(4) Gogol' stellt dies durch das zwanghafte Verhalten des Beamten auf der abendlichen Einladung dar.

Gogol', N.V.: PSS, III; S. 160. 
On približilsja $k$ tomu mestu, gde perežyvalas' ulica beskonečnoju ploščad'ju s edva vidnymi na drugoj storone ee domami .... (1)

/Er naherte sich der stelle, wo die strabe auf einen ungeheuer weiten Platz mundete, auf dessen anderer Selte man kaum die Häuser erkennen konnte ..../

Akakij empfindet die Weite des Taumes als personliche Bedrohung, vor der er die Augen verschliebt. Das Gefuhl, an die Ungebung ausgeliefert zu sein, wird zur Realitat, als man ihm seinen neuen Mantel raubt. Mach miBgluckten Versuchen, den Mantel wieder zu erlangen, wird das typische Petersburger Wetter fur ihn zum zweiten Mal zum Schicksal.

Kak. on sošel s lestnicy, kak vyšel na ulicu, ničego uz étogo ne pomnil Akakij Akakievič ... on šel po v'juge, svistevšej v ulicach, razinuv rot, sbivajas' s trotuarov: veter, po peterburgskomu obyčaju, dul na nego so vsech četyrech storon, iz vsech pereulkov (2).

/Wie er die Treppe herunter kam und wie er auf die StraBe gelangte, das konnte Akakij Akakievic nicht begreifen .... er ging durch das Schneegesthber durch die StraBen, mit offenem Mund, kam vom Trottoir ab; der Wind blies nach Petersburger Gewohnheit von allen vier Seiten gleichzeitig, aus allen NebenstraBen./

Vordergrundig ist Akakij ein Opfer der Witterung geworden, sein Untergang bedeutet jedoch mehr. Der Versuch des armen Beamten, sich aus der Isolation zu losen, miBlingt, als er seines Schutzes beraubt wird. So wie Piskarev an der zwiespältigkeit der stadt zugrunde geht, unterliegt auch Akakij den 'Einflüssen' der Umgebung.

(1) Gogol', N.V.: PSS, III; S. 161.

(2) Gogol', N.V.: PSS, III; S. 167. 
Als Widergänger behrrscht er die Räume der Stadt und verunsichert die Personen, von denen e $r$ zu Lebzeiten beherrscht wurde. Gogol' benutzt in den phantastischen Szenen reale topographische Angaben, um die Vorgänge glaubhafter zu machen. Bei der Schilderung der tatsächlichen Ereignisse war hingegen der Raum indifferent geblieben (1). Die natürliche Erklärung für Akakijs Untergang, daß sich dank des Petersburger Klimas die Krankheit schneller entwickelte, bedeutet zunächst ein physiologisches Alibi für die wahren Hintergründe.

I Peterburg ostalsja bez Akakija Akakieviča kak budto by $v$ nem ego i nikogda ne bylo (2).

/Und Petersburg blieb ohne Akakij Akakievič, als ob er niemals dort gelebt hätte./

Diese Anmerkung deckt beängstigende soziale Hintergründe auf. Diese sind hier nicht einfach aus den gesellschaftlichen Unterschieden, die besonders im Komplex GroBstadt überaus krass hervortreten, abzuleiten. Vielmehr weisen sie auf ein tiefer liegendes Problem des Menschen in dieser Umgebung hin. Akakij ist ein Mensch ohne Eigenleben, ein anonymus inmitten einer anonymen Gesellschaft.. Seine Versuche, aus der Isolation auszubrechen, sind zu schwach. Sie sind deshalb erfolglos, da von Außen, von den Mitmenschen, nur geringes oder kein Interesse an dem armen Beamten besteht.

Die gleichzeitig mit "Sinel"" entstandene "Povest' 0 kapitane Kopejkine", die in das 10. Kapitel der "Mertvye dusi" (t.I) eingefügt wurde, beinhaltet eine Beschreibung Petersburgs, die an Osips Bericht im "Revi-

(1) Diese Darstellungsart konnte auch in "Nos" und "Zapiski susmašedక̌ego" beobachtet werden.

(2) Gogol', N.V.: PSS, III; S. 169. 
zor" erinnert. Die Hauptstadt erscheint hier als Marchen aus 1001 Nacht, wo die Hăuser solch glänzende Turklinken haben, "daB man sich am besten ein stuck seife kauft und zwel stunden lang die hände wäscht", bevor man den Griff anzufassen wagt (1).

Auch diese Ubertreibungen basieren auf realen Eindrücken. Sie gehorren zum Motiv von Petersburg als dem "nordlichen Palmyra" (2). Das Bild von der Hauptstadt ist in den Vorstellungen der Zeitgenossen und vor allem der Provinzbewohner so sehr verdichtet, das man gern bereit ist, alle Ungeheuerlichkeiten zu glauben. So kann zum Beispiel der Sohn Manilovs in "Mertvye dusi" auf die Frage nach der schonsten Stadt nur blitzartig antworten: "Peterburg".

Anfang der vierziger Jahre entstand Gogol's Fragment "Rim", in dem auf einer anderen Ebene das bestatigt wird. was in den "Petersburger Erzăhlungen" im Detall zum Ausdruck kam. Geschildert wird der Lebensweg elnes jungen 1talienischen Fürsten, der, nach unzulänglicher Ausbildung im Heimatland, nach Paris reisen darf. Paris tut sich vor ihm als "ewig wallender Rrater" auf (3). In diesen Worten deutet sich bereits eine neue Art an, die Grobstadt (allgemein) zu begreifen: die große stadt als ständig brodelnde und an sich selbst entzundende Masse. Gogol' erfast hier das Wesen der Stadt Paris. Es ist eine lebendige Stadt, die das hat, was Petersburg erst erwerben muB: Paris ist eine stadt mit Geschichte, die aus sich heraus leben kann. Darin liegt auch der Grund, daB

(1) Gogol', N.V.: PSS, VI; S. 200.

(2) Der Topos vom "nordlichen Palmyra" wurde für Petersburg seit der Mitte des 18. Jahrhunderts gebraucht. Palmyra war eine reiche und eindrucksvolle stadt in der syrischen Steppe, deren Blutezeit um $300 \mathrm{n}$. Chr. lag.

(3) Gogol', N.V.: PSS, III; S. 222.

1850 schreibt V.Hugo: "Paris ist die einzige stadt der heutigen Welt, dieosbahd fimpliueraustandb:cines

Vulkans befindet." zitiert nach Minder, parisess.s.301. 
der Autor in seinen Petersburger Erzăhlungen die russische Hauptstadt immer nur in ihren Typen und dem Typischen darstellt. In Rom, dem zeugen einer sterbenden Kultur, wird die wahrhaft "ewige" stadt dargestellt, eine stadt, die nicht so sehr in ihren Denkmälern, als in ihren Bewohnern lebt. Ein Vergleich mit Moskau bietet sich an.

Obwohl Petersburg im Leben und Werk Gogol's von groBer Bedeutung ist, läBt sich die stellung des Autors zu dieser stadt nicht auf eine einfache Formel bringen, wie es v. Sklovskij versucht hat:

Peterburg Gogolja - lož 1 razočarovanie. Ėto gorod moroza, syrosti i fonarej, oblivajuščich ljudej vorvan'ju (1)

/Das Petersburg Gogol's - das ist Lüge und Enttäuschung. Es ist die Stadt des Frostes, der Feuchtigkeit und der Laternen, die die Menschen mit Tran übergießen./

Damit sind allenfalls einige Motive der Petersburg-Dichtungen Gogol's getroffen. Chrapcenko năhert sich dem Stadtverständnis bei Gogol' von der anderen Seite. Er bezeichnet Petersburg als "soziales Milieu, in dem Menschen leben und handeln" (2). Damit wird in einem Teil die Intention des Dichters getroffen. Seine Beziehung zu Petersburg ist auf jeden Fall von persönlichen Erlebnissen geprägt, die hier im einzelnen nicht berücksichtigt werden konnten. Vordergründig spiegelt sich dieses in der Motivwahl wieder: Wetter, Beamte, Flaneure, Einsamkeit u.a.m.

(1) Sklovskij, V.: Povesti o proze, M. 1966; S. 66.

(2) Chrapčenko, M.B.: Peterburgskie povesti Gogolja. In: IANSSSR, otd. lit.1 jaz., 1952; XI,1; S. 5 . 
Als weiterer wesentlicher Bestandteil des Gesamtbildes kommt die Entdeckung der stadt als Erlebnishintergrund in Frage; dies bedeutet auch gleichzeitig eine Anerkennung der Stadt als zivilisationsphänomen. Vor allem die Dichter des 18. Jahrhunderts und des beginnenden 19. Jahrhunderts hatten versucht, die stadt in ihrem äuBeren Ganzen zu erfassen, als Monument und architektonisches Gebilde. Wo die Dynamik der stadt geschildert wurde, handelte es sich um stilisierte Beschreibungen. Mit Puskin war ein Wandel in der Darstellung des Petersburgstoffes eingetreten. In Evgenij begehrt erstmals der Mensch gegen den Mythos auf und in Hermann hatte der Autor erstmals einen Helden gestaltet, dessen Ideen und Leidenschaften ganz dem 19. Jahrhundert angehorten. Lermontovs činovnik aus "Knjaginja Ligovskaja" lebt aus seiner Auseinandersetzung mit einem gesellschaftlich uber ihn stehenden Kontrahenten. Sowohl bel Puskin als auch bel Lermontov werden zwar typische stadtbewohner geschildert, aber sie waren threr Anlage nach durchaus fahig, ihr Eigenleben $\mathrm{zu}$ führen und eine "Idee" $\mathrm{zu}$ vertreten. Diese Fahigkeit haben die Gogol'schen Helden bereits verloren. Sie sind die Opfer eines Entwicklungsprozesses, der mit dem realen wachstum der großen städte einhergeht, d.h. eine Vertiefung menschlicher und sozialer Gegensătze, die Begünstigung der Vereinsamung des Einzelnen bis zum Verlust der Existenz. Die Entlarvung der dänonischen Kräfte der Stadt, die sich hinter einer glänzenden Fassade verbergen, trifft eine Problematik, die weitreichender ist als die 'vordergrundige' zerstörung eines ästhetischen Ideals.

Die Fremdheit, die Undurchsichtigkeit schafft Angst und Abenteuer. All diese Affekte gehen darauf zurück, daB die GroBstadt, eben wie Babylon, die grobe Hure ist (1). 
Das "nördliche Palmyra" hat in der Dichtung Gogol's eine endgültige Entmythologisierung erfahren. Aus einer persönlichen Enttăuschung entstanden, bietet sich das Gesamtbild Petersburgs dem Leser in zertrummerter Form dar. Alltăgliche Vorgănge und Ereignisse werden so dargestelit, als handele es sich um Ausnahmesituaticnen. Damit kann Gogol' sein eigenes Engagement zunächst verschleiern, kann aber nicht darüber hinweg täuschen, dab er Petersburg als ort der dämonischen Becirohung des Menschen erkannt hat. Nur in der Darstellung der Extreme kann sich die stadt als urbanes Gefüge offenbaren, kann die Dialektik der wirkenden Krafte erkannt werden. 
VIII. Uberblick uber die vierziger Jahre

Mokryj granit pod nogami, po bokam doma vysokie, cernye, zakoptelye ....(1)

Die Entwicklung zur urbanen Gesellschaft, die in Westeuropa bereits Mitte des 18. Jahrhunderts in den Metropolen Paris und London Ihren Anfang nahm, setzt in RuBland erst voll im 19. Jahrhundert ein. Von den russischen Städten konnten nur Moskau und Petersburg als GroBstädte bezeichnet werden. Im Vergleich mit Paris, das bereits 1836 etwa 900 ooo Einwohner zählte, nahmen sich diese belden städte eher wie kleinstădte aus. Innerhalb des russischen Relches waren sie jedoch beredter Ausdruck fur die Bevölkerungsexplosion am Beginn des Industriezeitalters. Vergleichende $\mathrm{zahlen}$ deuten auf ein etwa adăguates Wachstum von Moskau und Petersburg.

\begin{tabular}{|c|c|c|c|c|}
\hline Moskau: & $\begin{array}{l}1784 \\
1812 \\
1830\end{array}$ & $\begin{array}{l}\text { ca. } \\
\text { ca. } \\
\text { ca. }\end{array}$ & $\begin{array}{l}217 \\
251 \\
305\end{array}$ & $\begin{array}{l}000 \\
000 \\
000\end{array}$ \\
\hline Petersburg: & $\begin{array}{r}1725 \\
1825 \\
1835\end{array}$ & $\begin{array}{l}\text { ca. } \\
\text { ca. } \\
\text { ca. }\end{array}$ & $\begin{array}{r}75 \\
425 \\
515\end{array}$ & $\begin{array}{l}000 \\
000 \\
000\end{array}$ \\
\hline
\end{tabular}

Moskau blieb die heimliche Hauptstadt des Landes. Als Gegenstand der Iiteratur war es aber seit Puskin immer mehr von Petersburg verdrăngt worden. In den vierziger Jahren äuBert sich die literarische Konzentration auf die Hauptstadt in verschiedenen Skizzen, die versuchen, die zeitgenössische stadt zu erfassen.

(1) Dostoevskij, F.M.: Bednye ljudi. In: PSS, t.I, S. 85 . 
Die Schilderung bekannter sphären, die auch als "domašnost'" zu bezeichnen sind, ist eines der in diesen Skizzen angestrebten ziele. Versuche, diese Schriften und ihre genrebestimmenden Kriterien $z u$ erfassen, heben meist die informatorische Absicht hervor. Des weiteren könnte man die "očerki" /Skizzen/ auf grund der Darstellungsart leicht in die Nahe des Feuilletons einreihen. Berücksichtigt man die dargestellten Themen und den verarbeiteten stoff, wäre eine weitere Modifizierung dieses weitverbreiteten Genres möglich. Vor allem die sogenannten "fiziologičeskie očerki" beschreiben verschiedene Menschentypen in ihrer vorwiegende städtischen Umgebung. Sie können in erweiterter Form zu Milieustudien werden, deren wesentliche Bedingung hierbei der "natural'nyj protokolizm" /natürlicher Protokollismus/ ist (1). Das bedeutet auch, daB der Erzähler bzw. Autor gar nicht oder nur am Rande hervortritt.

Für die Entwicklung der Grobstadtliteratur in der 2. Hälfte des 19. Jahrhunderts waren die "Physiologien" von nicht geringer Bedeutung. In "reiner Form" waren sie zwar recht kurzlebig, lassen aber gleichzeitig Ansatzpunkte für die grobseren Erzăhlformen, wie etwa den Roman erkennen (2). Die Vorliebe dieser skizzen für die "Schattenseiten" der städte, die mit deren wachstum immer sichtbarer wurden, weist auf einen gesellschaftlichen ErkenntnisprozeB, der schon bei Gogol' sichtbar wurde. Das Ergebnis ist die Verarbeitung und Reflexion realer Prozesse.

Da zu diesen "očerki" aus dem Petersburger Leben die umfangreiche Untersuchung cejtlins vorliegt und die neuere Arbeit von Peters wertvolle Ergänzungen bringt,

(1) Vinogradov, V.: Gogol' 1 natural'naja škola, L. 1925; S. 68 .

(2) In Frankreich entstand mit Hugos "Notre Dame de Paris" (1831) einer der ersten Großstadtromane. 
sollen hier einige Bemerkungen genügen (1). Die "Fiziologija Peterburga" erschien 1845 in zwei Bănden. Die Redaktion hatte N.V. $N$ e $k$ a s o v (1821-1877) ubernommen, der selbst auch mit zwel Beitrăgen - "Peterbugskie ugly" und "Cinounik" - inhaltlich betelligt war. In seiner eigenen Rezension zum ersten Tell der Sammlung schrieb Nekrasov:

...das Buch, das die "Physiologie Petersburgs" genannt wird hat das ziel, alle Geheimnisse unseres gesellschaftlichen Lebens aufzudecken, alles Triebfedern der freudigen und traurigen Szenen unseres häuslichen Milieus, alles Quellen unserer Erscheinungen auf den Straben; .... (2)

Und weiter präzisiert Nekrasov seine Vorstellungen von den Leistungen des Genres:

.... dafur bist du eine Physiologie, eine Geschichte unseres inneren Lebens, das tief und dunkel ist, mit Flitter bedeckt, mit prächtigen Fassaden maskiert ... (3)

Nekrasov hat in diesen Zeilen seine zielvorstellungen und Erwartungen zusammengefast. Die Aufdeckung der hinter der glänzenden Fassade verborgenen Kräfte weist auf Gogol'. In der Einfuhrung zu "Fiziologija Peterburga" verweist V.G. $B$ e 1 i $\mathrm{s} k i j$ (1811-1848) auf die Notwendigkeit, mit "allen vielfaltigen Seiten des russischen Seins, der russischen Gesellschaft bekannt zu werden" (4).

(1) Cejtlin, A.G.: Stanovlenie realizma v russkoj literature. Russkij fizlologiCeskij oterk, M. 1965. Peters, J.U.: Turgenevs "Zapiski ochotnika" innerhalb der oxerk Tradition der 40-er Jahre, Berlin 1972.

(2) Nekrasov, N.A.: Sobr. soC., t. VII, M.1967; S. 96.

(3) Nekrasov, N.A.: Sobr. soX., t. VII; S. 97.

(4) Belinskij, V.G.: Sobr. sot., t. II, M. 1948; S. 753 . 
Belinskij hebt in diesem zusammenhang die Fähigkeit der Franzosen hervor, sich selbst $z u$ belachen und $z u$ beobachten. Darin sieht er einen der Gründe für den großen Erfolg franzbsischer Literatur. Seiner Meinung nach kennen selbst die russischen Leser jeden winkel von Paris. Mit dem Sammelband Nekrasovs soll nun endilich eine Charakteristik Petersburgs erscheinen. Cejtlin hat in seiner Untersuchung darauf hingewiesen, daB zwischen 1839 und 1848 in RuBland nicht weniger als siebenhundert "fiziologičeskie očerki" erschienen sind. Daß aber diese zahl im Vergleich zu französischen Veroffentlichungen dieses Genres gering ist, wird von Peters betont (1). Damit erklärt er auch die apodiktische Behauptung Belinskijs, nach dessen Ansicht es in RuBland uberhaupt an Beispielen dieser Gattung fehle.

"Fiziologija Peterburga" stellt sich, wie aus den Worten Belinskijs ersichtlich ist, mit einem Programm vor. Trgtzdem unterscheiden sich die in beide Bände aufgenommenen Skizzen nicht nur durch die Art der Darstellung und Thematik, sondern auch durch ein stellenweise recht individuelles Verständnis von der Gattung.

Belinskij ist mit drei feuilletonistischen Beiträgen an beiden Bänden beteiligt, Seine "Peterburg 1 Moskva" (I) und "Aleksandrinskij teatr" (II) und "Peterburgskaja literatura" (II) heben sich von den Skizzen Nekrasovs, Grigorovits und der anderen Schriftsteller ab.

In "Peterburg $i$ Moskva" polemisiert Belinskij gegen die Slavophilen, nach deren Ansicht Petersburg eine "zufällige" Erscheinung ist. Um dem zu begegnen legt Belinskij die historische Bedeutung Petersburgs dar und entwickelt die

(1) Belinskij, V.G.: Sobr. sot., t.II; S. 754. Der Autor betont, daB vor allem Basuckijs 1834 erschienenes "Panorama Peterburga" nicht nachgeahmt werden solle. Basuckij hatte vor allem statistisches Material von Petersburg gesammelt. 
Idee, daB zwischen Moskau und Petersburg eine direkte Abhängigkeit bestehe. Mit dem Wachstum Petersburgs verändere sich das Bild Moskaus (1).

Die Ursache dafur sieht Belinskij in der aligemeinen Europäisierung des Landes (2). Für ihn ist die Existenz zweier Hauptstädte kein politisches Problem, sondern eine notwendige Folge aus der historischen Entwicklung RuBlands. Beide Hauptstädte seien als Verkorperung einer Idee unentbehrlich. Auf den Vorwurf slavophiler Rreise, Petersburg besitze weder Geschichte noch Tradition, antwortet Belinskij mit dem Hinweis auf die enge Verbundenheit der stadt mit ihrem Grunder. Bereits in seiner 140-jahrigen Geschichte sei Petersburg ein "velikij istoriCeskij pamjatnik" /ein grobes historisches Denkmal/ geworden (3). Trotzdem könne man Petersburg nicht mit dem historischen Metropolen Paris und Rom vergleichen. Eine Ahnlichkeit bestehe eher mit den groBen städten Nordamerikas. Nach Belinskij liegt die Bedeutung Petersburgs fur RuBland darin, daB es im Gegensatz zum konservativen Moskau Repräsentant des Neuen (novizna) uberhaupt ist. Neben diesem ideologischen Gerust enthălt "Peterburg 1 Moskva" Schilderungen der Moskauer und Petersburger Architektur, eine Beschreibung der Bevolkerung beider städte und ihrer Interessen. Zwar werden in den ocerki vielfach der groBen Welt die einfachen Leute gegenubergestellt, eine reflektierende sozialkritische Darstellung der bereits um 1840 stark ausgeprägten städtischen schichten ist nicht beabsichtigt. Dennoch weist die Vorliebe für das trübe und graue Petersburger Kolorit mit seinen Schlupfwinkeln und Mietshäusern auf ein Erkennen realer Zustände. Zum anderen stellt diese den Realismus vorbereitende Richtung (natural'naja skola) auch eine Art Romantik dar, die in der

(1) Diesen Gedanken hatte bereits Puskin in "Putesestvie iz Moskvy v Peterburg" geăuBert.

(2) Dies zeigte sich zumindest rein auberlich in der auch in Moskau eingeführten europăischen Bauweise.

(3) Belinskij, V.G.: Sobr.soc. I I 
Exotik der Nachtseiten groBer Städte liegt (1).

Für diese Ansicht spricht Nekrasovs Beitrag "Peterburgskie ugly". Diese Skizze ist seinem unvollendeten Roman "žizn' $i$ pochoždenija Tichona Trostnikova" entnommen. Das von Nekrasov konzipierte Romansujet verarbeitet das bekannte Motiv von "pereezd Peterburga".

Ein junger Provinzler kommt in die russische Hauptstadt, wo er in der Auseinandersetzung mit den sozialen Widersprüchen der stadt auch den Kampf um seine eigene Existenz aufnehmen muB.

Die "Petersburger Winkel" beginnen mit einer pittoresken Beschreibung eines Petersburger Mietshauses, wie es typisch für die vorstadt ist (2).

/Das Haus, dessen Hof ich betrat, war auBerordentlich groB, alt und verkommen; ein unertrăglicher Geruch schlug mir entgegen und ich wurde von verschiedenartigen Schreien und Pochen ganz betäubt: das Haus war voll von Handwerkern, die bei offenem Fenster arbeiteten und sangen (3)./

Uber die Bewohner des Hauses geben kuriose Schilder und zeichnerische Erklärungen erste Informationen. Vor Trostnikov öffnen sich die verschiedenen Hinterhöfe; sein Eindringen gleicht einem Abstieg in den bas fond (4). Trostnikov findet in einem Kellerraum Unterkunft. Die Art der Beschreibung dieses Gewölbes ist vielfach als "dagerrotipnost" " bezeichnet worden. Die Ahnlichkeit mit photographischen Aufnahmen ist insofern gegeben, als Nekrasov eine Beschreibung des Raumes ohne jegliche Metaphorik gibt.

(1) Diese Entwicklung war in den Romanen Balzacs und Sues vorgegeben.

(2) MMan erinnere sich an die Beschreibungen bei Gogol' in "Zapiski sumasšedšego" (dom Zverkova) und in "Portret" (Cartkovs Wohnung auf der Vasilij-Insel).

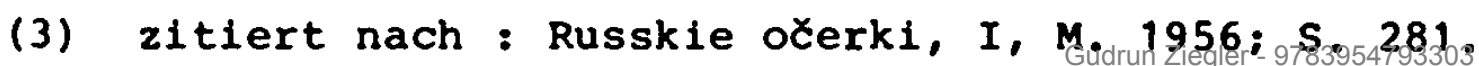

(4) Hierzu: Hugo "Notre Dame de Paris una ${ }^{0}$ Sue via sterès des Paris". 
In diesem "Winkel" macht Trostnikov die Bekanntschaft verschiedener Personen, die von Nekrasov mit unterschiedilcher Intensitat beschrieben werden. Weder Belinskijs Aufsatz "Peterburg 1 Moskva" noch Nekrasovs "Peterburgskie ugly" erfullen als Ganzes die Bedingungen, die fur das physiologische Genre typisch sind (1). Sie treffen sich mit den ubrigen Beitrăgen lediglich im Prinzip der Lokalisierung, d.h. der brtlichen Festlegung auf Petersburg (2).

Mit Puskin hatte andeutungsweise ein Prozeb der Losl8sung vom stadtstoff als zu erfassendem Ganzen begonnen. Damit verbunden war auch ein Abrücken von der Vorstellung einer für Petersburg geltenden Schopfer-Werk Identifizierung. Damit lauft eine Evolution der Darstellungsmöglichkeiten parallel, die immer mehr an den tatsăchlichen Gegebenheiten der stadte orientiert ist. Eine Beschreibung der negativen seiten der Grobstadt bedeutet aber auch bei Nekrasov noch keine sozialkritische und anklagende Auseinandersetzung mit der Wirklichkeit. Erst mit Dostoevskij kann diese neue Entwicklung beginnen.

(1) Hierzu sehr ausfürlich: Peters, J.-U.: Turgenevs 'Zapiski ochotnika' innerhalb der ocerk Tradition .... Berlin 1972; S. 5 ff.

(2) "Fiziologija Peterburga" enthălt auBerdem: Dal': Peterburgskij dvornik; Grebenka: Peterburgskaja storona; Grigorovic: Loterejnyj bal; und Peterburgskie Sarmanšiki; Kulsılckij: Omnibus. 
IX. Zus ammenfassender Uberblick

Zwischen den in dieser Arbelt untersuchten literarischen Werken, zwischen Feofan Prokopovičs panegyrischer Rede und den Physlologien der vierziger Jahre liegen uber elnhundert Jahre. Die Darstellung des Stadtstoffes bestätigt die allgemeine Entwicklung der russischen Literatur hin zur Prosa. Die vorgelegten Interpretationen, sind keineswegs erschbpfend, sondern als beisplelhaft fur den jewelligen Stand der literarischen Entwicklung zu werten. Sie sollen daruber hinaus die These bestatigen, dab die wahl und Gestaltung eines auberpoetischen stoffes das Verständnis des Autors von realen Gegebenheiten spiegelt. Die individuelle Brechung der Realitatserfahrung des einzelnen Dichters labt allerdings Ausnahmen $2 u$, die aber den angefuhrten Thesen nicht prinzipiell widersprechen. Diese Verschiedenheit der Realitätserfahrung, die noch für die ersten Jahrzehnte des 19. Jahrhunderts gilt,ermoglicht andererselts Aussagen uher den Grad der Emanz1pation des Autors. Moskau und Petersburg waren einle1tend als literarischer stoff definiert worden. Die Untersuchung hat ergeben, daB sich das Bewubtsein, hier ein zur Darstellung geeignetes Material zu besitzen, erst bilden muste.

Die Oden-Dichter des 18. Jahrhunderts gestalteten nicht nur mit Hilfe biblischer und antiker Topol ein klischeehaftes stadtbild von Petersburg, sondern zeigten durch die Gleichsetzung der stadt mit ihrem Grunder ihre Unterwerfung unter ldeologische 2 wange. Stellenwelse hatte $\mathrm{sich}$ diese Beschrănkung gelockert. Trediakovskij erwelterte z.B. den zeltlichen Rahmen und stellte Petersburg als Stadt mit zukunft dar, wahrend Lomonosov bere1ts ein abstrahierendes Bild von der lebendigen stadt erarbeltet. In den Satiren der 2. Halfte des 18. Jahrhunderts 18sen sich die Autoren von dem Versuch, die Stadt als Ganzes, das tellweise bis zum Begriff reduziert war, zu erfassen. 
Gerade hler zelgt sich wiederum die Verknupfung von Stoff und Genre, Indem in der Darstellung Modeersche1-

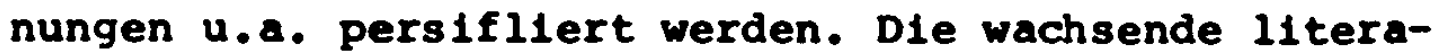
rische Bearbeltung des Stadtstoffes weist auf die groBer werdende Bedeutung der Stadtkultur im russischen Reich hin. Whyrend bel Karamzin erstmals die stadt Moskau als st1lislerte Landschaft erscheint und die stadt als Raum zur Charakterisierung der Helden herangezogen wird, 188t sie sich andeutungsweise von festgefugten Vorstellungen. Das in den Satiren zwar schon angesprochene Stadt-Land Motiv erhalt bel Karamzin wertende Bedeutung. In der Folgezelt wird die stadt zum Symbol der zivilisation. Das Engagement der Dichter fur Moskau oder Petersburg. auf Grund Individuelien Erlebens, zeigt sich in der Vorliebe fur Detalls. Ihrer Darstellung liegt eine umfassende abgeschlossene Vorstellung von beiden stădten zu Grunde. In der Abwendung von der "glänzenden Stadt" hin zur "armen Stadt" , In der Darstellung stadtischer Nachtselten zelgt sich die personliche Befreiung der Autoren vom asthetischen Optimismus. Mit beginnender Reflexion uber grobstadtische Unzulänglichkeiten zelgt sich in der stoffgestaltung die Annaherung an den realen historischen ProzeB. Diesen Entwicklungszustand findet Dostoevskij vor. In se1nen Erzahlungen und Romanen wird die stadt selbst zum Handelnden, d.h. es luberlagern sich literarischer stoff und realer Entw1cklungsprozeB. Die Unterschiede zwischen Moskau und Petersburg spielen keine Rolle mehr. 
L $i$ t e r a t u r e r z e i c h n is

Werkausgaben:

Batjuskov, K.N.: Sołinenija, red. Blagogo, M.-L.1934.

Belinskij, V.G.: Sobranie soxinenij v 3-ch tomach, M. 1948 .

Bestuzev - Marlinskij, A.A.: Soxinenija v 2-ch tomach, M. 1958 .

Derzavin, G.R.: Stichotvorenija, L. 1957.

Dostoevskij, F.M.: Polnoe sobranie sotinenij

v 30-i tomach, I. 1972 ff.

Glinka, F.N.: Izbrannye proizvedenija, M. 1957.

Gogol', N.V.: Polnoe sobranie soxinenij, t. 1-14, M. 1937-1952.

Gogol', N.V.: Socinenija v dvuch tomach, M. 1965.

Griboedov, A.S.: Solinenija v dvuch tomach, M. 1971.

Kantemir, A.: Sobranie stichotvorenij, L. 1956.

Karamzin, M.: Izbrannye socinenija $v$ dvuch tomach, M. -L. 1964 .

Krylov, I.A.: Polnoe sobranie solinenij, pod.red. v. Kallasa, t. 1-4, Pb. 1904-1905.

Lermontov, M.Ju.: Socinenija v 6-i tomach, M. -I. 1954-1957.

Lomonosov, M.V.: Polnoe sobranie socinenij, t. 1-10, M. -L. 1950-1957.

Nekrasov, N.A.: Sobranie solinenij v 8-i tomach, M. $1965-1967$.

Odoevskij, Vl.: Russkie noti. Nachdruck der Ausgabe von 1913, München 1967. (Slavische Propyläen.24.)

Prokopovid, F.: Solinenija, pod red. Eremina, M.-L.1961.

Puskin, A.S.: Polnoe sobranie solinenij v 10-i tomach, 2.1zd., M. 1956-1958.

Radišev, A.N.: Putełestvie iz Peterburga v Moskvu, L. 1969. 
Ryleev, K.F.: Polnoe sobranie socinenij, pod red. Cejtlina, M.-L. 1934, repr. The Hague 1967. (Academia reprint.4.)

Sumarokov, A.P.: Izbrannye proizvedenija, 2.izd., L. 1957 .

Trediakovskij, V.K.: Izbrannye proizvedenija, 2.izd., M. -L. 1963.

Vjazemskij, P.A.: Stichotvorenija, L. 1958.

Sammelbănde:

N.I. Novikov 1 ego sovremenniki. Izbrannye soxinenija, M. 1961 .

Oxerki moskovskoj žizni, M. 1962.

Russkie ocerki, t. I, M. 1956.

Russkie povest 1 XIX veka 40 - 5o-ch godov, 2 tt., M. 1952.

Sekundärliteratur:

Allgemeine stadtgeographie, hrsgg. von P. Scholler, Darmstadt 1969 .

Anciferov, N.P.: Moskva 1 Peterburg v ¿izni i tvorCestve Gogolja. In: Gogol' v skole, M. 1954; S. 653-704.

Anger, A.: Literarisches Rokoko, Stuttgart 1962.

Architekturnyj putevoditel' po Leningradu, L. 1971.

Asukin, N.S.: Moskva v žizni i tvorČestve A.S. Puškina, M. 1949 .

Bachelard, G.: Poetik des Raumes, München 1960.

Bahrdt, H.P.: Die moderne GroBstadt, Reinbeck 1961.

Benjamin, W.: Paris - die Hauptstadt des 19. Jahrhunderts. In: Schriften I., Frankfurt/M. 1955; S. 406-422.

Berkov, P.N.: Istorija russkoj žurnalistiki XVIII veka, M. - L. 1952 .

Blagoj, D.D.: Iiteratura i dejstvitel'nost', M. 1959. 
Blagoj, D.D.: Istorija russkoj literatury XVIII veka, 1zd. 4-oe, M. 1960.

Böschenstein, R.: Idylle, stuttgart 1967.

Bollnow, O.F.: Mensch und Raum, Stuttgart 1963.

Bourdieu, P.: Sozlologie der symbolischen Formen, Frankfurt/M. 1970.

Braun, 1.: Der Kampf un die rirklichke1t in der russischen Iiteratur, Gsttingen 1958.

Brinkmann, H.: Peter I. in der russischen Literatur, phil.Diss. Giessen 1963.

Bunin, A.lY: Geschichte des russischen Städtebaus bis zum 19. Jahrhundert, Berlin 1961.

Cejtlin, A.G.: Stanovlenie reallzma v russkoj literature. Russkij fizlologiceskij ocerk, H. 1965.

ChrapCenko, M.B.: Peterburgskie povesti Gogolja. In: Izvestija NN SSSR, otd. 11t.1 jaz.. 1952; $X I, 1 ; S .3-30$.

Chrapčenko, 11.B.: Tvor Cestvo Gogolja, M. 1956.

Ciževsk1j, D.: Slavische Barockliteratur, itunchen 1970. (Forum Slavicum.23.)

Ciževskij, D.: Russische Literaturqeschichte, I. Die Romantik, München 1964. (Forum Slavicum.1.)

Curtius, F.R.: Euronalsche Literatur und lateinisches i1telalter, 6.Aufl., Munchen 1967.

Éjchenbaum, B.: Lermontov. Nachdruck der Leningrader Iusgahe von 1924, München 1967. (Slavische Propyläen.35.)

Epocha prosvešenija. Iz istoril meždunarodnych russkoj literatury, L. 1967.

Erlich, V.: Gogol, New Haven and London 1969. (Yale Russian and East Furopean Studies.8.)

Fanger, D.: Dostoevsky and nomantic Realism. A Study of Dostoevsky in relation to Balzac, Dickens and Gogol, Chicago-London 1967.

Frenzel, E.: Stoff-, ilot1v- und Symbolforschung, Stuttgart 1963 . 
Frenzel, E.: Stoff- und Motivgeschichte, Berlin 1966.

Fridman, N.V.: Proza Batjuškova, M. 1965.

Fridman, N.V : "Progulka po Moskve" K.N. Batjuskova. (Batjuskov 1 Griboedov). In: Izv. AN SSSR, otd. 11t. 1 Jaz., 1962; XXI,6; S. 510-522.

Georg1, J.G.: Versuch einer Beschreibung der RuBlsch Kayserlichen Residenzstadt St.Petersburg und der Merkwürdigkeiten der Gegend, St. Petersburg 1790.

Gersenzon, M.: Griboedovskaja Moskva, H. 1914.

Geseriann, U.: Die Entdeckung der unteren Volksschichten durch die russische Literatur, Wiesbaden 1972.

Giedion, S.: Raum, Zeit und Architektur, Ravensburg 1965. $\frac{\text { G1llel'son, M.I.; V.A.Manujlov; A.N. Stepanov: }}{\text { Gogol' V Peterburge, L. 1963. }}$

(iogol'v škole. Sbornik statej, M. 1954.

Gordin, A.: Krylov v Peterburge, L. 1969.

Grasshoff, H.: Zur llenschenbildproblematik der russischen Aufklärung. In: ZS1, 1970; XV,6; S. 812-836.

Jukovsk1j, G.X..: Real1z7: Gogolja, 1.-L. 1959.

liarimol, P.: Unsere Zukunft: die Stadt, Frankfurt/M. 1972.

lyauser, $\lambda .:$ Sozialreschichte cer Kunst und Ilteratur, ? Iünchen 1367.

Heine, H.: Aus den Memolren des Herren von Schnabelewopsk1. In: Simtliche lierke, VII, :tünchen 1964.

ỉlelscher, K.: A.S. Puškıns Versepılk. Autoren-Ich und Erzăhlstruktur, München 1966. (Slavistische Be1träge.22.)

Hingley, $R_{.}:$Von Puschkin bis Tolstoj, eine Iiteratursozlologie, München 1967.

l.olthusen, Joh.: zur literarischen Typologie und zum "lotivbestand der "Petersburger Erzahlungen", Insbesondere bei Puskin und Gogol'. In: HSi, 1959; IV , 2; S. 148-168. 
Holthusen, Joh.: Russland in Vers und Prosa. Vortrăge zur russischen Literatur des 19. und 20. Jahrhunderts, Munchen 1973. (Slavistische Beitrăge.69.)

Istorija russkogo iskusstvo, VI, i1. 1961.

Ivanova, R.A.: lioskva v ̌̌iznl 1 tvorčestve :1.Ju. Lermontova, 1827-1832, M. 1950 .

JauB, H.R.: Literaturgeschichte als Provokation, Frankfurt/M. 1970.

Klotz, V.: Die erzahlte Stadt. Eln Motiv als Herausforderung des Romans von Lesag̣e bis DKblin, München 1969.

Kohl, J.G.: Petersburg in Blldern und Skizzen, Dresden und Leipzị 1841.

Kosik, K.: Die Dialektik des Konkreten. Elne Studile zur Problematik des ienschen in der Welt, Frankfurt/:1. 1967.

Lausberg, H.: Eleniente der literarischen Rhetorik, !lünchen 1967.

Lefèbvre, H.: Die Revolution der Stadte, :iünchen 1972.

Lepentes, $\because$. : ilelancholie unci Gesellschaft, Frankfurt/ii. 1969.

Literaturnye panjatnye mesta Leningrada, L. 1968.

Lo Gatto, E.: Il inito di Pietroburgo, Milano 1960.

Lorenzer, A.: Städtebau: Funktionalismus und Sozialmontage? zur sozialpsychologischen runktion der Architektur. In: Architektur als Ideologie, rrankfurt/:i. 1968; S. 71-104.

Lukács, G.: Russische Literatur - Russische levolution, Auscerăilte Schriften III, Reinbek 1969.

Lunch, K.: Das Bild der Stact. Seschichte und fusblick, Köln 1963.

inder, R.: Paris in der französischen Literatur $11760-$ 1960). In: Dichter in cer Gesellschaft, Darmstadt 0.J.; S. 287-340.

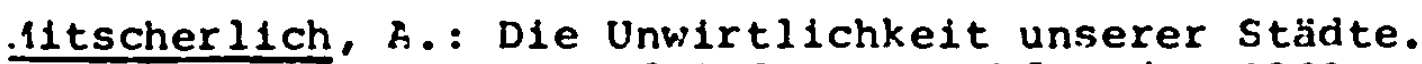
I.nstiftung zum Unfrieden, Frankfurt/!!. 1969.

11tscherlich, A.: Thesen zur stadt der Zukunft, Frankfurt/l1. 1971. 
Mumford, F.: Die Stadt. Geschichte und Ausblick, $\bar{K} 8 \ln 1963$.

Nilsson, N.:i.: Das erwachende Petershurg. Elne Bemerkung zu Eugen Onegin, erster Gesang, strophe XXXV. In: ScS1, 1954; I; S. 98-102.

Pahl, J.: Die Stadt im Aufbruch der perspektivischen ivelt, Berlin-FRankfurt 1963.

Peters, J.U.: Turgenevs "Zapiski ochotnika" innerhalb der očerk Tradition der 40-er Jahre. Zur Entwicklung des realistischen Erzählens in Russland, Berlin 1972. (Veroffentlichungen der Abteilung für Slavische Sprachen und Iiteraturen des Osteuropa Instituts an der FU Berlin.40.)

Poznanskij, V.V.: oxerki istoril russkoj kul'tury pervoj poloviny XIX veka, M. 1970.

Probleny tipologi1 russkogo realizma, M. 1969.

Riasanovsky, N.V.: Russland und der Westen, Müchen 1954.

R1ha, R.: Die Beschreibung der "Großen Stadt", zur Entstehung des Großstadtmotivs in der deutschen Literatur (ca.1750-1850), Bad liomburg v.d.ll. 1970.

[11ke, R..:1.: Das Stundenbuch, Frankfurt/:1. 1962.

iothe, H.: iv.i. Karamzins europäische Reise. Der Eeginn cies russischen formans, Bad llomburg v.d.ll. 1968.

Russkie pisateli v iloskve, ". 1973.

Busskaja proza, pod red. B. r.jchenbaurna 1 i?u. Tynjanova, The liague 1965. (slavistic printings and reprintings. XLVIII.)

Saruchanjan, E.: Dostoevskij v Peterburge, I. 1970.

Schlegel, $\lambda$. li.: Die Kunstlehre. In: Kritische Schriften und Eriefe II, stuttgart 1963.

Schlegel, F.: Gespräch über die Poesie (1800). In: ithenäum II, Reinbek 1969; S. 153-202.

Schr:idt-3elenberg, w.: Soziologle und stădtebau. Versuch einer systematischen Grundlegung. Stuttọart-Bern 1968. 
Sengle, F.: Wunschbild Land und Schreckbild Stadt. In: Studium generale, 1963; XVI,10; S. 619-630.

Seybold, E.: Das Genrebild in der deutschen Literatur. vom Sturm und Drang bis zum Realismus, Stuttgart 1967 .

Sklovskij, V.: Povesti o proze, M. 1966.

Sklovsk1j, $V_{j}:$ zametki o proze russkich klassikov, M. 1953 .

Sokolov, A.N.: Orerki po istoril russkoj poèmy XVIII 1 pervoj poloviny XIX veka, it. 1955.

Die Stadt. Bild - Gestalt - Vision. Europäische Stadtbilaer im 19. und 20. Jahrhundert. Katalog der Ausstellung in der Kunsthalle Bremen, 16.11.197320.1.1974.

Städtke, K.: Die Entwicklung der russischen Frzählung (1800-1825), Berlin 1971. (Verbffentlichungen des Instituts für Slawistik.57.)

Stök 1, G.: Russische Geschichte, Stuttgart 1962.

Talbot-Rice, T.: Die Kunst Pusslands, ziirich 1965.

Todorov, T.: Poetik der Prosa, Frantfurt/il. 1972.

Toniaševskij, B.: Puškin 1 Peterturg. In: Puškin, issledovanija 1 materialy, III, 'i. - L. 1960; S. 37-45.

I'oriaševskij, E.: 'jeorija literatury. Poetika, 4.1zu., H.-L. 1928; repr. New York 1967.

Vinogradov, V.. : Gogol' i natural'naja skola, L. 1925.

l.ytrzens, G.: Pjotr Andreevič Vjazenskij. Studie zur russischen Literatur- und Kulturgeschichte des neunzehnten Jahrhunderts, Wien 1961. 



\section{SLAVISTISCHE BEITR ̈̈GE}

Verzeichnis der bisher erschienenen Bände

1. Maurer,J.: Das Plusquamperfektum im Polnischen. 1960, 64 S. - 2 . Kadach,D.: Die Anfänge der Literaturtheorie bei den Serben. 1960, V, 182 S. - 3. Moskalik,M.: Janka Kupala, der Sänger des weiBruthenischen Volkstums. 1961, $241 \mathrm{~S}$. - 4. Pleyer,V.: Das russische Altgläubigentum. $1961,194 \mathrm{~S}$. - 5. Mihailovic, M.: Tempus und Aspekt im serbokroatischen Präsens. 1962, VIII, 64 S. - 6. Rösel,H.: Aus Vatroslav Jagićs Briefwechsel. 1962, $75 \mathrm{~S}$. - 7. Schmidt,A.: Valerij Brjusovs Beitrag zur Literaturtheorie. 1963, 159 S. - 8. Minde, R.: Ivo Andrić. 1962, 198 S. - 9. Panzer,B.: Die Funktion des Verbalaspekts im Praesens historicum des Russischen. 1963, 106 S. - 10. Mrosik,J.: Das polnische Bauerntum im Werk Eliza Orzeszkowas. 1963, 211 S. - 11. Felber,R.: Vojislav Ilić. 1965, 271 S. - 12. Augustaitis,D.: Das litauische Phonationssystem. 1964, 155 S. - 12a. Auras,C.: Sergej Esenin. 1965, $211 \mathrm{~S}$. - 13. Koschmieder-Schmid,K.: Vergleichende griechisch-slavische Aspektstudien. 1967, 196 S. - 14. Klum,E.: Natur, Kunst und Liebe in der Philosophie Vladimir Solov'evs. 1965, $333 \mathrm{~s}$. - 15. Albrecht,E.: Das Türkenbild in der ragusanisch-dalmatinischen Literatur des XVI. Jahrhunderts. 1965, 256 S. - 16. Gesemann,W.: Die Romankunst IVan Vazovs. 1966, $131 \mathrm{~S}$. 17. Perí̌ic,D.: Goethe bei den Serben. 1968, 304 S. - 18. Mares,F.V.: Die Entstehung des slavischen phonologischen Systems und seine Entwicklung bis zum Ende der Periode der slavischen Spracheinheit. 1965, $87 \mathrm{~S}$. - 19. Holzheid,S.: Die Nominalkomposita in der Iliasübersetzung von $N$. I. Gnedic. 1969, 92 S. - 20. Chmielewski,H.: Aleksandr Bestužev-Marlinskij. 1966, $134 \mathrm{~S}$. - 21. Schaller,H.W.: Die Wortstellung im Russischen. 1966, 389 S. - 22. Hielscher,K.: A. S. Puskins Versepik. 1966, 169 S. - 23. Küppers,B.: Die Theorie vom Typischen in der Literatur. 1966,354 S. - 24. Hahl-Koch,J.: Marianne Werefkin und der russische Symbolismus. 1967, 126 S. - 25. Gardner,J.: Das Problem des altrussischen demestischen Kirchengesanges und seiner linienlosen Notation. 1967, IX,270 S. - 26. Baldauf,L.: Der Gebrauch der Pronominalform des Adjektivs im Litauischen. 1967, 104 S. - 27. Kluge,R.-D.: Westeuropa und RuBland im Weltbild Aleksandr Bloks. 1967, $393 \mathrm{~S}$. - 28. Kunert,I.: J. U. Niemcewicz: Spiewy historyczne. 1968, II, $132 \mathrm{~S}$. - 29. Steinke, K.: Studien über den Verfall der bulgarischen Deklination. 1968, X, $133 \mathrm{~s}$. 30 . Tschöpl,C.: Vjaceslav Ivanov. 1968, 235 S. - 31. Rehder,P.: Beiträge zur Erforschung der serbokroatischen Prosodie. 1968, $247 \mathrm{~S}$. - 32. Kulman,D.: Das Bild des bulgarischen Mittelalters in der neubulgarischen Erzählliteratur. 1968, $276 \mathrm{~S}$. - 33. Burkhart,D.: Untersuchungen zur Stratigraphie und Chronologie der südslavischen Volksepik. 1968, III, 549 S. - 34. Günther, H.: Das Groteske bei N. V. Gogol'. 1968, 289 S. - 35. Kazoknieks,M.: Studien zur Rezeption der Antike bei russischen Dichtern zu Beginn des 19. Jahrhunderts. 1968, 269 S. - 36. Schmidt, H.: Hus und Hussitismus in der tschechischen Literatur des 19. und 20. Jahrhunderts. 1969, 296. S. - 37. Schneider,S.: Studien zur Romantechnik Miroslav Krlezas. 1969, 285 S. - 38. Stephan,B.: Studien zur russischen Castuska und ihrer Entwicklung. 1969, 358 S. - 39. Girke,W.: Studien zur Sprache N. S. Leskovs. 1969 , VIII, 220 S. - 40. Mares, F. V.: Diachronische Phonologie des Ur- und Frühslavischen. 1969, $126 \mathrm{~S}$. - 41. Wosien,M.-G.: The Russian Folk-Tale. 1969, 237 S. - 42. Schulz, R.K.: The Portrayal of the German in Russian Novels. 1969, V, $213 \mathrm{~S}$. - 43. Baudisch,G.: Das patriarchalische Dorf im Erzählwerk von Janko 
M. Veselinovíc. 1969, 225 S. - 44. Stölting,W.: Beitrăge zur Geschichte des Artikels im Bulgarischen. 1970, VII, 296 S. - 45. Hucke,G.:Jurij Fedorovit Samarin. 1970, $183 \mathrm{~S}$. - 46. Höcherl,A.: Zur Ubersetzungstechnik des altrussischen "Jüdischen Krieges" des Josephus Flavius. 1970, 183 S. - 47. Sappok,C.: Die Bedeutung des Raumes für die Struktur des Erzählwerks. 1970, 154 S. - 48. Guski,A.: M. Ju. Lermontovs Konzeption des literarischen Helden. 1970, 225 S. - 49. Lettmann,R.: Die abstracta 'um' und 'razum' bei Belinskij. 1971, $167 \mathrm{~S}$. - 50.Lettmann-Sadony,B.: Karolina Karlovna Pavlova. 1971, 181 S. - 51. Brümmer, C.: Beiträge zur Entwicklungsgeschichte der frühen Romane L. M. Leonovs, 1971, $231 \mathrm{~S}$. - 52. Schmidt,C.: Bedeutung und Funktion dex Gestalten der europäisch östlichen Welt im Werk Thomas Manns. 1971, $366 \mathrm{~S}$. - 53. Eschker,W.: Untersuchungen zur Improvisation und Tradierung der Sevdalinka an Hand der sprachlichen Figuren. 1971, 275 S. - 54. Schmidt, О.: Нензвестный поэт П.Д.Бутурлин. Анализ творчвства. 1971, 229 S. 55. Mönke,H.: Das Futurum der polnischen Verba. 1971, 184 S. - 56.Raekke,J.: Untersuchungen zur Entwicklung der Nominalkomposition im Russischen seit 1917. - 57. Müller-Landau,C.: Studien zum Stil der Sava-Vita Teodosijes. 1972, 183 S. - 58. Dippe,G.: August Senoas historische Romane. 1972, $177 \mathrm{~S}$. - 59. Hetzer,A.: Vjaceslav Ivanovs Tragödie "Tantal". 1972, 202 S. - 60. Andreesen,W.: Untersuchungen zux Translation von Substantiven zu Adjektiven im Altrussischen. 1972, 151 S. - 61. Neureiter, F.: Kaschubische Anthologie. 1973, VIII, 281 S. - 62. Gavrin,M.: Kroatische Ubersetzungen und Nachdichtungen deutscher Gedichte zur zeit des Illyrismus. 1973, 226 S. - 63. Grahor,0.: France in the Work and Ideas of Antun Gustav Matos. 1973, 247 S. - 64. Döring,J.R.: Die Lyrik Pasternaks in den Jahren 1928-1934. 1973, XXVI, 390 S. - 65. Högemann-Ledwohn, E.: Studien zur Geschichte der russischen Verserzählung in der zweiten Hälfte des 19. Jahrhunderts. 1973, $428 \mathrm{~s}$. - 66. Gonschior, H.: Die geneigten Vokale als Reflexe altpolnischer Längen im Wörterbuch von Jan Mączynski. 1973, 391 S. - 67. Talev, I.: Some Problems of the Second South Slavic Influence in Russia. 1973, XIV, 430 S. - 68. Auerbach, I.: Nomina abstracta im Russischen des 16. Jahrhunderts. 1973, VI, $368 \mathrm{~S}$. - 69. Holthusen,J.: RuBland in Vers und Prosa. 1973, 212 S. - 70. Guski,H.: Die satirischen Komödien V.I.Lukins (1737-1794). 1973, 250 S. 71. Sternkopf,J.: Sergej und Vladimir Solov'ev. 1973, XXXI, $667 \mathrm{~S}$. 72. Wenzel,F.: SPLIT. Ein Verfahren zur maschinellen morphologischen Segmentierung russischer Wörter. 1973, IX, 203 S. - 73. Bachmann, E.: Ivo Kozarcanin - Leben und Werk. 1974, 250 S. - 74. Schmidt,B.: Stilelemente der mündichen Literatur in der vorrealistischen Novellistik der Serben und Kroaten. 1974, 309 S. - 75. Jakoby,W.: Untersuchungen zur Phonologie und Prosodie einer kajkavischen Mundart (Gornja Stubica). 1974, X, 256 S. - 76. Schultze,B.: Der Dialog in F. M. Dostoevskijs Idio $1974,314 \mathrm{~S}$. - 77. Hilf,E.A.: Homonyme und ihre formale Auflösbarkeit im System Sprache, dargestellt an altrussischen Berufsbezeichnungen. 1974, 129 S. - 78. Wiehl,I.: Untersuchungen zum Wortschatz der Freisinger Denk mälex. Christliche Terminologie. 1974, $169 \mathrm{~s}$. - 79. Pribic, R.: Bonaventu ra's Nachtwachen and Dostoevsky's Notes from the Underground. A Comparison in Nihilism. 1974, $155 \mathrm{~S}$.

\section{In VoRBEREITUNG FÜR ENDE 1974:}

80. Ziegler,G.: Moskau und Petersburg in der russischen Literatur (ca 1700-1850). Zur Gestaltung eines literarischen Stoffes. VI, $198 \mathrm{~S}$. - 81. Wörn,D.: Aleksandr Bloks Drama Pesnja sud'by, übersetzt, kommentiert und interpretiert. $X, 545$ S. - 82. Timberlake,A.: The Nominative Object in Slavic, Baltic, and West Fjnمic 265-Sag Gudrun Ziegler -9783954793303 